\title{
Untersuchung Rezeptor-vermittelter Interaktionen zwischen Defensinen und Zellen des Immunsystems
}

\author{
Dissertation \\ zur Erlangung des Doktorgrades \\ der Mathematisch-Naturwissenschaftlichen Fakultäten \\ der Georg-August-Universität zu Göttingen
}

vorgelegt von

Jasmin Grigat

aus Walsrode

Göttingen 2007 
D 7

Referentin: Frau Prof. Dr. Hoyer-Fender

Koreferent: Herr Prof. Dr. Hardeland

Tag der mündlichen Prüfung: 7.11.2007 


\section{Inhaltsverzeichnis}

Abkürzungsverzeichnis .8

1 EINLEITUNG. .10

1.1 Das angeborenen und das adaptive Immunsystem. 10

1.2 Chemokine 12

1.3 Antimikrobielle Peptide. 13

1.3.1 Defensine. 13

1.3.1.1 $\alpha$-Defensine 17

1.3.1.2 $\beta$-Defensine.

1.4 Allgemeine Prinzipien der Rezeptor-vermittelten Signaltransduktion. 21

1.6 Zellmigration 25

1.7 Ziel der Arbeit 29

2 MATERIAL UND METHODEN. 30

2.1 Materialien 30

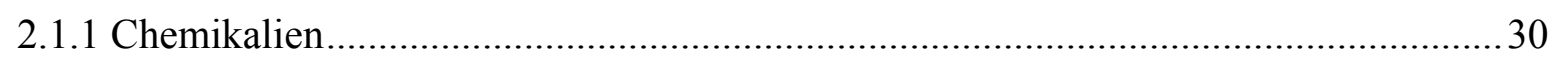

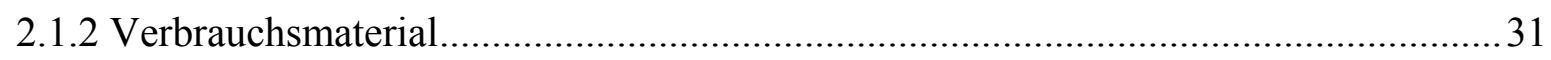

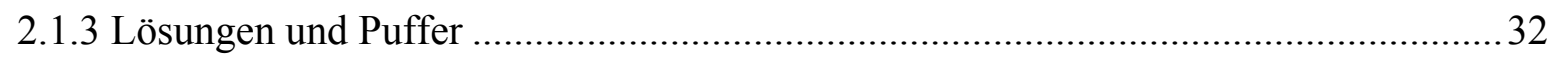

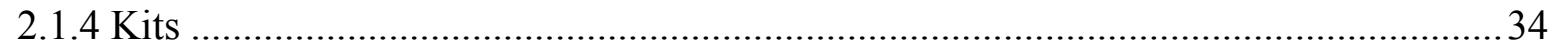

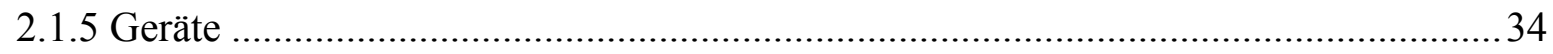

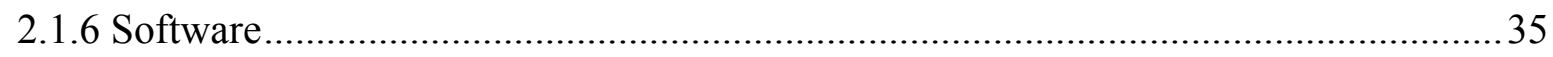

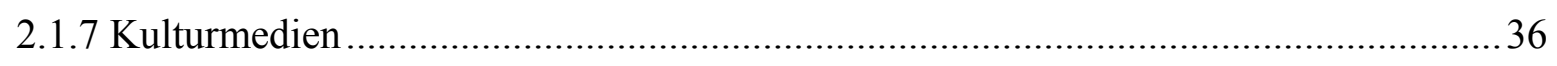

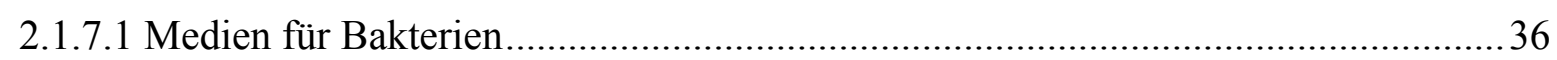

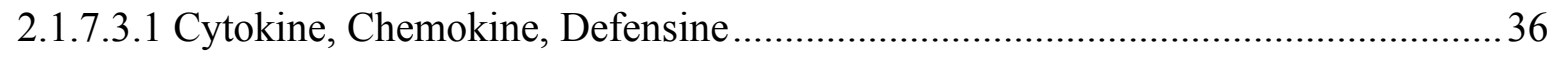

2.2 Zellbiologische Methoden ...........................................................................................38

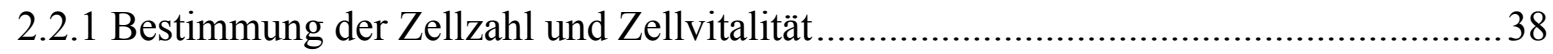




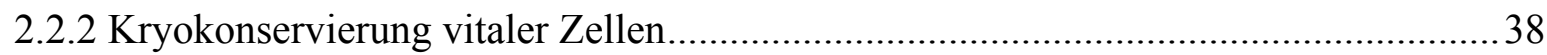

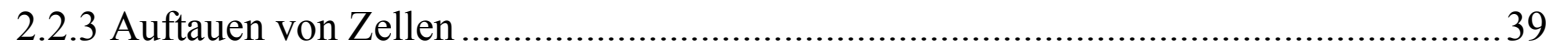

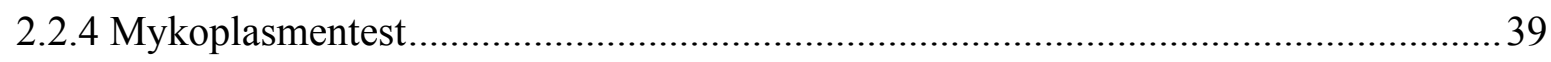

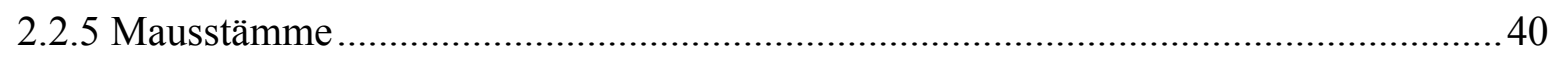

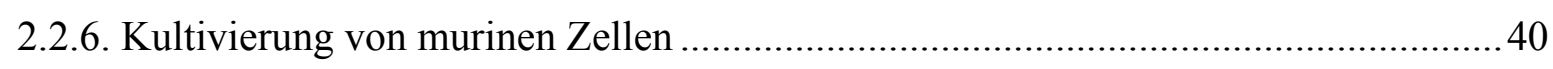

2.2.6.1 Gewinnung von murinen hämatopoetischen Stammzellen aus Knochenmark ........40

2.2.6.1.1 Generierung und Kultivierung von murinen Monocyten ................................... 41

2.2.6.1.2 Generierung und Kultivierung von murinen Mastzellen....................................... 41

2.2.6.2 Gewinnung von murinen Lymphocyten aus der Milz......................................... 42

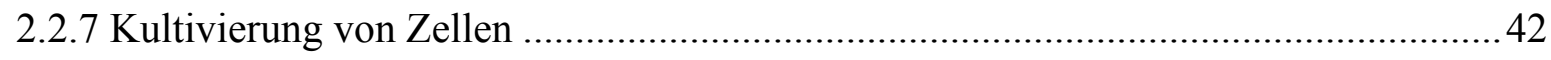

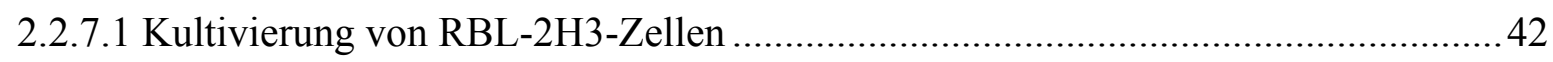

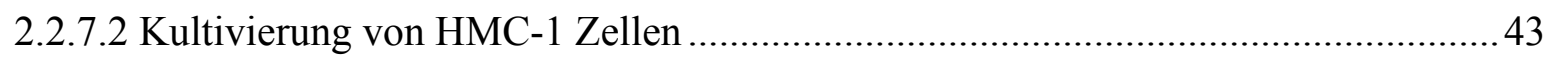

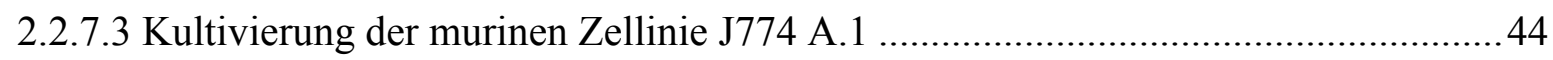

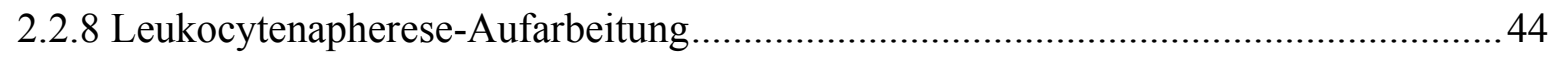

2.2.8.1 Gewinnung und Kultivierung von Monocyten und Makrophagen aus PBMNL .....46

2.2.8.2 Gewinnung und Kultivierung von Granulocyten aus Vollblut................................47

2.2.9 Zellaufreinigung mittels Magnetischer Zell-Sortierung $\left(\mathrm{MACS}^{\circledR}\right)$...........................47

2.2.9.1 Aufreinigung von humanen T-Lymphocyten-Fraktionen aus PBMNL ..................47

2.2.9.2 Aufreinigung muriner T-Lymphocyten-Fraktionen ........................................... 49

2.2.10 Funktionelle Untersuchungen von Zellen mittels Durchflußcytometrie (FACS) .....49

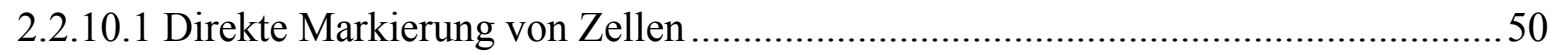

2.2.11 Fluoreszenzphotometrische Messung der intrazellulären Calciumionen-Freisetzung .52

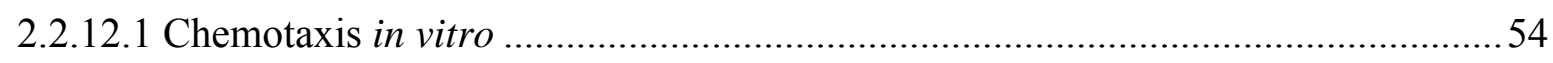

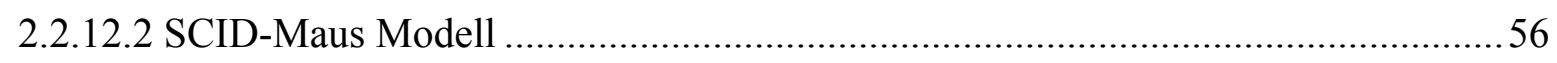

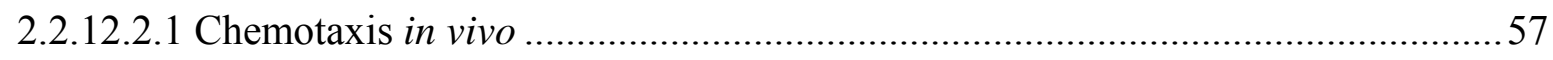

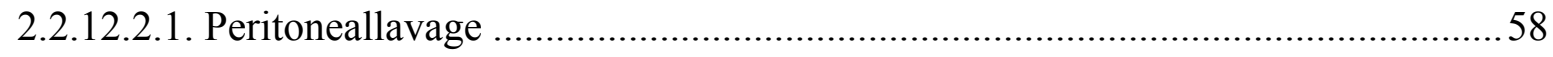

2.3. Molekularbiologische Methoden ..................................................................5

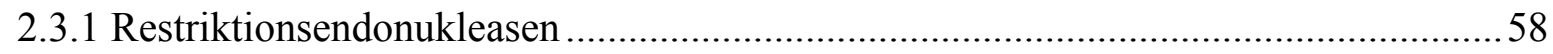

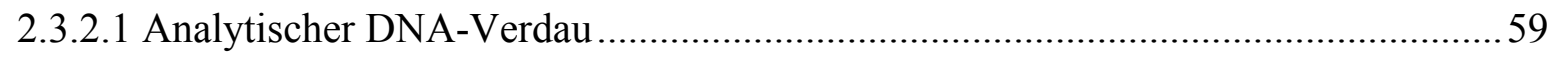

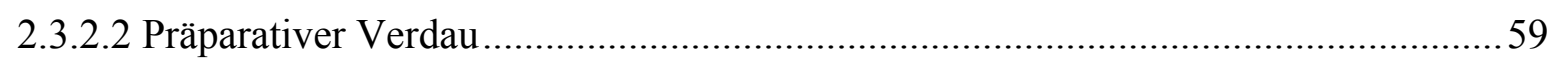

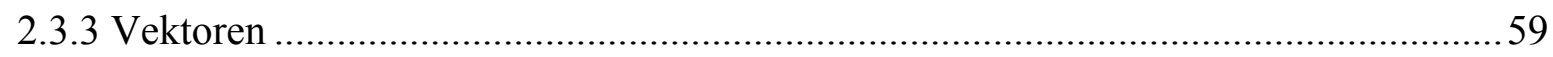

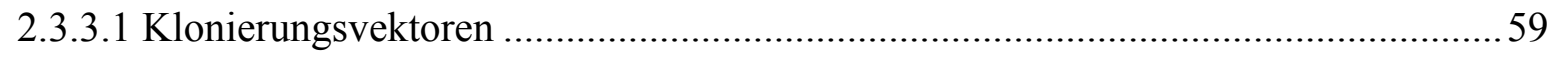

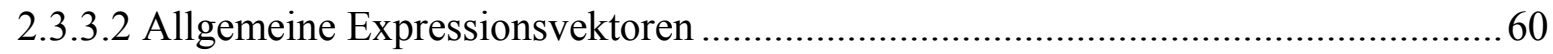




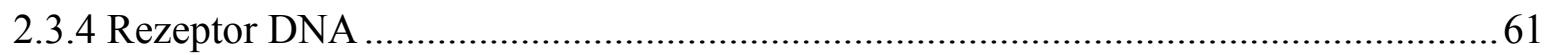

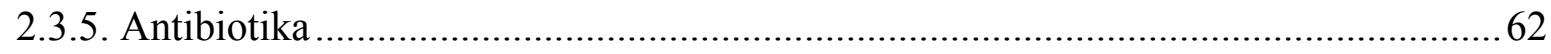

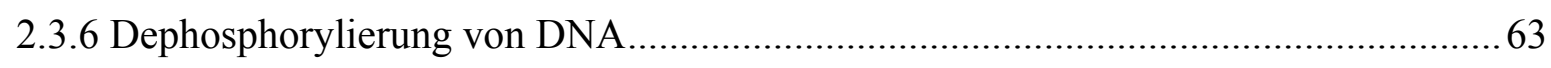

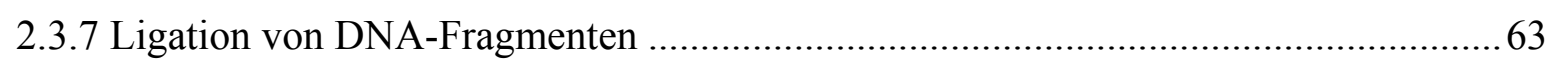

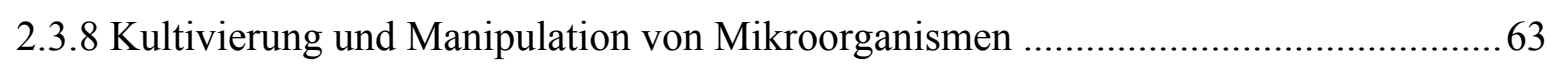

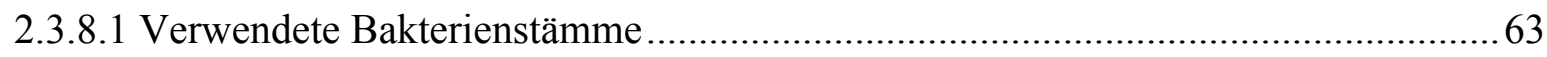

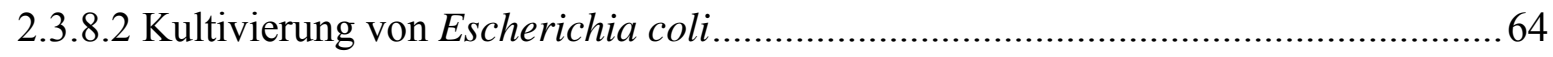

2.3.8.3 Präparation von chemisch kompetenten E. coli- Zellen ........................................64

2.3.8.4 Transformation von chemisch kompetenten E. coli- Zellen...................................64

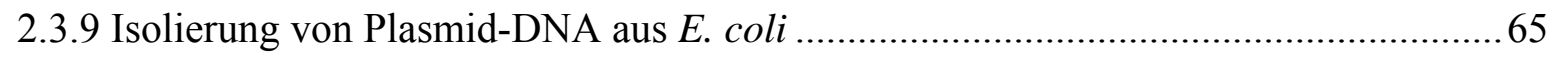

2.3.9.1 Isolierung von Plasmid-DNA aus $3 \mathrm{ml}$ Kulturen (STET Methode)........................65

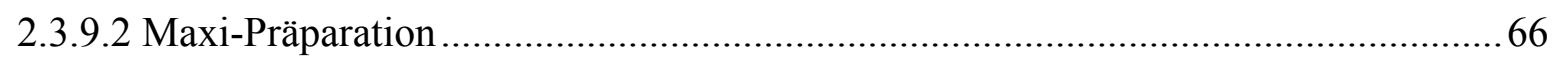

2.3.10 Reinigung von DNA durch Phenol-Chloroform-Extraktion ...................................66

2.3.11 Konzentrations- und Reinheitsbestimmung von DNA .......................................... 67

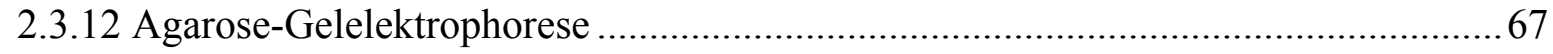

2.3.13 Isolierung von DNA-Fragmenten aus Agarosegelen............................................68

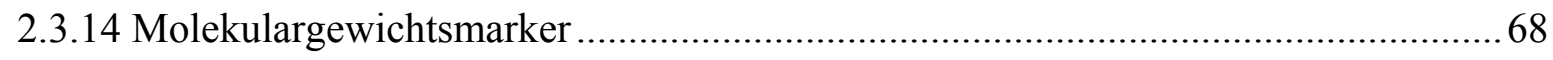

2.3.15 Stabile Transfektion von Plasmid-DNA in RBL-2H3-Zellen ..................................68

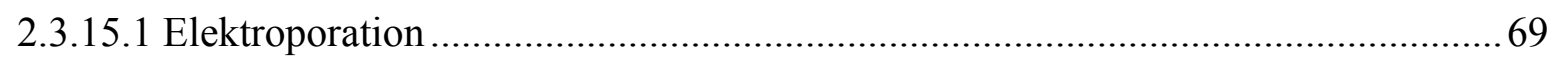

2.3.15.2 Identifizierung und Subklonierung von Transfektanten .....................................69

2.4 Schließend- und beschreibend-statistische Auswertung .......................................... 70

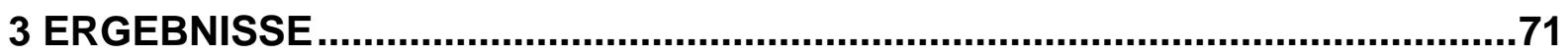

3.1 Herstellung des FPRL-2-Rezeptors ................................................................71

3.1.1 Funktionelle Analyse der RBL-2H3-FPRL-2-Transfektante ................................ 72

3.2 Untersuchung der in vitro Migration von Granulocyten ..................................74

3.3 Untersuchung der in vitro Migration unbehandelter Monocyten.......................76

3.4 Untersuchung der in vitro Migration humaner Makrophagen ........................... 76

3.5 Untersuchung der in vivo Chemotaxis humaner Makrophagen ......................... 78

3.6 Untersuchung der Migration humaner dendritischer Zellen .................................81 
3.8 Untersuchung der Migration humaner T-Lymphocyten 85

3.8.1 Untersuchung der Migration von $\mathrm{CD}^{+} / \mathrm{CD} 45 \mathrm{R}^{+}{ }^{+} \mathrm{T}$-Lymphocyten.............................. 86

3.8.2 Untersuchung der Migration von $\mathrm{CD}^{+} / \mathrm{CD} 45 \mathrm{RA}^{+} \mathrm{T}$-Lymphocyten. 88

3.9 Untersuchung der Migration muriner T-Lymphocyten .90

3.10 Untersuchung der Migration muriner Mastzellen. .91

3.11 Untersuchung der Migration der Mastzelllinie HMC-1 94

3.12 Untersuchung der intrazellulären Calciumfreisetzung in HMC-1 Zellen......95

3.13 Herstellung von RBL-2H3-CCR6-Transfektanten..........................................98

3.13.1 Funktionelle Analyse der RBL-2H3-CCR6-Transfektante 99

3.14 Untersuchung der Defensin-induzierten Signaltransduktion 101

3.14.1 Untersuchung der Rolle der MAPK bei der Chemotaxis humaner Makrophagen .. 101

3.14.2 Untersuchung der Rolle der MAPK bei murinen Mastzellen.................................. 103

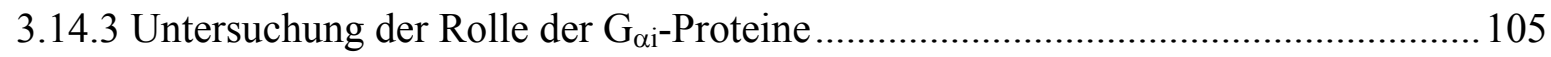

3.15 Untersuchungen zur Rolle der PKC bei der Rezeptor-Desensibilisierung .. 106

3.15.1 Untersuchung der homologen Rezeptor-Desensibilisierung 106

3.15.2 Untersuchung der heterologen Rezeptor-Desensibilisierung . 108

4 DISKUSSION .113

4.1 Wirkung der Defensine auf die Migration der Granulocyten. 113

4.2 Wirkung der Defensine auf die Migration unbehandelter humaner

Monocyten 114

4.3 Wirkung der Defensine auf die Migration humaner und muriner Makrophagen. .114

4.4 Wirkung der Defensine auf die Migration der DC 116 
4.5 Wirkung der Defensine auf die Migration humaner und muriner T-Lymphocyten 117

4.6 Wirkung der Defensine auf die Migration humaner und muriner Mastzellen

4.7 Wirkung der Defensine auf die intrazelluläre Calciumfreisetzung in HMC-1-Zellen 120

4.8 Wirkung der Defensine auf die Migration der RBL-2H3-CCR6-Transfektante 121

4.9 Rolle der MAP-Kinasen bei der Defensin-inuzierten Migration 122

4.10 Rolle der $G_{\alpha i}$-Proteine bei der Defensin-induzierten Migration 123

4.11 Homologe und heterologe Desensibilisierung der Defensine. 124

4.12 Homogenität der Defensine trotz hoher Sequenzvariabilität. 126

4.13 Ausblick 129

5 ZUSAMMENFASSUNG .131 


\section{Abkürzungsverzeichnis}

Abb.

Abbildung

AS

Aminosäure

CCR6

CC-Rezeptor 6

DC

Dendritische Zellen

DNA

Desoxyribonukleinsäure

E. coli

Eschericha coli

ERK

extrazelluär regulierte Kinase

FACS

Fluoreszenz-aktivierte Zellsortierung

FCS

fetales Kälberserum

FITC

Fluoreszeinisothiocyanat

FPRL-2

Formyl Peptid ähnlicher Rezeptor

F2L

FPRL-2 Ligand

GM-CSF

Granulocyten/Monocyten-Kolonie stimulierender Faktor

GPCR

G-Protein gekoppelter Rezeptor

GR

Granulocyten

$\mathrm{h}$

Stunde

HBD

Humanes $\beta$-Defensin

HD

Humanes Defensin

HLA-DR

Humanes Leukocyten Antigen-Isotyp HLA Klasse II

HMC-1

Humane Mastzelllinie 1

HNP

Humanes neutrophiles Peptid

$\mathrm{IgE}$

Immunglobulin $\mathrm{E}$

IL-3

Interleukin 3

IL-4

Interleukin 4

JNK

cJun N-terminale Kinase

J774A.1

murine Makrophagen-Zelllinie

$\mathrm{kb}$

kilo Basen

$\mathrm{MACS}^{\circledR}$

magnetisch aktivierte Zellsortierung

MAPK

Mitogen-aktivierte Phospho-Kinase

$\mathrm{mBD}$

murines $\beta$-Defensin

M-CSF

Makrophagen-Kolonie stimulierender Faktor

MHC

Haupthistokompatibilitätskomplex 
PBMNL

PBS

PE

$\mathrm{pH}$

$\mathrm{PKC}$

PMA

RBL-2H3

SCF

SCID

SEM mononukleäre Zellen des peripheren Blutes

Phosphat-gepufferte Kochsalzlösung

Phycoerythrin

Negativ dekadischer Logarithmus der Protonenkonzentration

Protein Kinase C

Phorbol 12-Myristat 13-Acetat

Ratten basophile Leukämie Zelllinie

Stammzellfaktor

Severe combined immunodefiance

Standard Error of mean 


\section{Einleitung}

\subsection{Das angeborenen und das adaptive Immunsystem}

Im Verlauf der Evolution haben sich zwei miteinander kooperierende Systeme von Abwehrmechanismen entwickelt. Dabei handelt es sich zum Einen um das angeborene Immunsystem, welches bereits $\mathrm{zu}$ einem sehr frühen Zeitpunkt innerhalb der Individualentwicklung eines Organismus vorhanden ist und eine geringe Spezifität aufweist. Es umfasst unter anderem Entzündungs- und Gerinnungsprozesse, antimikrobielle Peptide, phagocytotisch aktive Zellen sowie Einkapselungsvorgänge.

Zum Anderen ist es das adaptive Immunsystem, das bei den Vertebraten zusätzlich neben dem angeborenen Immunsystem auftritt. Dieser Teil des Immunsystems beruht auf der spezifischen Erkennung von Antigenen putativer Pathogene und der Bildung spezifischer Antikörper. Es wird auch als erworbenes Immunsystem bezeichnet, da es sich im Verlauf des Lebens als eine Anpassung an eine Infektion mit einem spezifischen Krankheitserreger entwickelt. Weiterhin führt es letztlich zur Bildung des so genannten ,immunologischen Gedächtnisses“, denn die adaptive Immunantwort gewährleistet in vielen Fällen eine lebenslange Immunität gegen eine erneute Infektion mit einem dem Immunsystem bereits „bekannten“ Pathogen. Dabei kann auf diesen wiederholten Kontakt mit dem Krankheitserreger deutlich schneller und effektiver reagiert werden.

Die immunologischen Prozesse des angeborenen und des adaptiven Immunsystems werden in humorale und zelluläre Mechanismen unterteilt. $\mathrm{Zu}$ den Elementen des humoralen angeborenen Abwehrsystems zählen die Faktoren des Komplementsystems, Cytokine, Chemokine, antimikrobielle Peptide (Defensine, Cathelicidine) sowie reaktive Intermediate von Sauerstoff und Stickstoff. Die humorale Immunität im adaptiven Immunsystem wird durch die Antikörperproduktion der B-Lymphocyten gewährleistet und kann im Gegensatz zur zellulären Immunität durch Transfusion des Antikörper-enthaltenden Serums an einen Empfänger übertragen werden (Janeway, et al., 2002).

Die Funktionen der zellulären angeborenen Immunantwort werden von den Phagocyten übernommen. Sie gewährleisten die Phagocytose sowie die Einkapselung von Endoparasiten. Hierbei spielt die Erkennung und Opsonierung der Pathogene eine übergeordnete Rolle, sowie die Aktivierung anderer Zellen mittels löslicher Mediatoren. Die zelluläre adaptive Immunantwort bezieht sich auf die Gesamtheit der erwobenen Immunität. Dazu zählen 
sowohl die Antigen-präsentierenden Zellen (Dendritische Zellen, Makrophagen und B-Lymphocyten) als auch die Effektorzellen (T-Lymphocyten).

Das Immunsystem beruht generell auf der Unterscheidung von fremden und eigenen Strukturen, wobei das angeborene Immunsystem der Vertebraten von Keimbahn kodierten Rezeptoren abhängig ist, welche sich wiederholende Muster von molekularen Strukturen auf der Oberfläche von Mikroorganismen erkennen können. Diese so genannten Pathogen-assoziierten molekularen Muster (PAMPs) kommen in den eukaryotischen Zellen nicht vor (z. B. LPS der Gram-negativen Bakterien, $\beta-1,3-G l u c a n$ der Pilze oder Peptidoglucan). Wird nun ein solches Muster mit Hilfe von Mustererkennungsrezeptoren (PRRs) erkannt, kommt es als Folge verschiedener Signaltransduktionswege zur Induktion von Genen, welche für antimikrobielle Peptide kodieren, die in der Lage sind die Zellmembran bzw. die Zellwand der Pathogene zu zerstören (Hultmark, 2003). Die Promotoren der Gene, welche für die antimikrobiellen Peptide kodieren, enthalten SequenzMotive, die den NF-кB-response-Elementen ähneln. Es wird angenommen, dass die Aktivierung von NF- $\kappa \mathrm{B}$ der ursprüngliche und zentrale Signalweg für die Aktivierung des angeborenen Immunsystems ist. So gibt die Genomanalyse Hinweise darauf, dass es einen hoch entwickelten Mechanismus der Immunabwehr bereits zu der Zeit gab, als sich in der Evolution die Vorfahren von Tieren und Pflanzen voneinander trennten. Bei diesem Mechanismus, den sowohl Tiere als auch Pflanzen besitzen, handelt es sich um den TollSignalweg für die Aktivierung von Genfunktionen durch NF-kB (Janeway et al., 2002).

Ein Beispiel für die Erkennung solcher Muster ist die Aktivierung der Makrophagen durch die Wechselwirkung zwischen LPS und Mustererkennungsrezeptoren von Gewebszellen an einem Infektionsherd. Die Makrophagen dienen dabei nicht nur der möglichen Entfernung des Pathogens durch Phagocytose. Die Aktivierung dieser Zellen löst vornehmlich die Freisetzung von Cytokinen und anderen Mediatoren aus, welche im Gewebe eine Entzündung hervorrufen und neutrophile Zellen sowie Plasmaproteine an den Ort der Infektion rekrutieren. 


\subsection{Chemokine}

Die wichtigste Funktion der Inflammation ist die der Leukocyten-Infiltration in das betroffene Gewebe. Für die Aufrechterhaltung der Leukocyten-Rekrutierung ist vor allem die interzelluläre Kommunikation zwischen den infiltrierenden Leukocyten und dem Endothelium, den Stroma- sowie den parenchymalen Zellen essenziell. Dies wird durch die Generierung von Cytokinen wie etwa IL-1 und TNF, der Expression von ZelloberflächenAdhäsionsmolekülen sowie der Produktion von chemotaktisch wirkenden Molekülen, wie den Chemokinen, vermittelt (Keane et al., 2000).

Chemokine (Chemotaxis, Cytokine) sind eine Klasse von Cytokinen mit der Eigenschaft von Chemoattraktoren, welche eine Chemotaxis, das heißt eine gerichtete Migration der Leukocyten mit dem entsprechenden Rezeptor vermitteln können. Bei der Entdeckung dieser Moleküle durch einen Cytokintest wurden sie zunächst als Interleukine bezeichnet. Die Chemokine sind kleine Proteine mit vier konservierten Cysteinen, welche zwei essenzielle Disulfidbrücken bilden. Anhand dieser Disulfidbrücken werden $\mathrm{CX}_{3} \mathrm{C}-, \mathrm{CXC}-, \mathrm{CC}-$ und $\mathrm{C}$-Chemokine unterschieden. Während es nur jeweils ein $\mathrm{CX}_{3} \mathrm{C}$ - (Fraktalkin) und ein C-Chemokin (Lymphotaktin) im humanen System gibt, sind bis heute etwa 50 CXC-und CC-Chemokine bekannt (Charo und Ransohoff, 2006). Bei den CC-Chemokinen liegen die Cysteine direkt nebeneinander, während die Cysteine im Falle der CXC-Chemokine durch eine Aminosäure getrennt sind. Die CC-Chemokine vermitteln die Migration von Monocyten, basophilen und eosinophilen Zellen, T-Lymphocyten, Dendritische Zellen (DC) sowie Natürlichen Killer-Zellen (NK-Zellen). Dahingegen wirken die CXC-Chemokine auf mononukleäre Leukocyten des peripheren Blutes (PBMNL) und Lymphocyten.

Alle Chemokine besitzen eine ähnliche Aminosäuresequenz und wirken über die unter 1.5 beschriebenen heptahelikalen G-Protein-gekoppelten Proteine (GPCR). Dabei lösen sie vornehmlich die Chemotaxis von Leukocyten aus und leiten diese Zellen somit zum Ort der Infektion oder Inflammation. Dabei ist der beeindruckendste Effekt der Chemokine die von ihnen innerhalb weniger Sekunden bewirkte Formveränderung der betreffenden Zellen. Die Polymerisierung und der Zusammenbruch des Aktinnetzwerkes führt letztlich zur Bildung von Lamellipodien, welche die Migration der Zellen ermöglichen. Zudem führt die Stimulierung der Zellen durch Chemokine zur verstärkten Expression und zur Aktivierung von Integrinen, welche die Leukocyten befähigen, sich an die endothelialen Zellen der Blutgefäße zu adhärieren, bevor sie in das infizierte Gewebe einwandern (Baggiolini, 1998; s. auch 1.6). 
Produziert werden die Chemokine von nahezu allen somatischen Zellen, einschließlich den Monocyten, den Makrophagen, den Mastzellen, den T- und B-Lymphocyten sowie den neutrophilen Zellen. Diese Zellen können die Chemokine als Antwort auf eine Vielzahl von Faktoren wie Viren, bakterielle Produkte, Interleukin-1 (IL-1), Tumor-Nekrose-Faktoren (TNF) oder C5a synthetisieren (Keane und Strieter, 2000). Da die Chemokine sowohl von den Zellen des Immunsystems als auch von Gewebszellen produziert werden können, ist die Rolle der Chemokine bei Entzündungen und Infektionen nicht zu unterschätzen.

\subsection{Antimikrobielle Peptide}

Die antimikrobiellen Peptide bilden eine heterogene Gruppe kleiner Proteine, deren gemeinsames Charakteristikum ihre antimikrobielle Aktivität ist. Wenngleich ihre Existenz bereits jahrzehntelang bekannt war, so wurde ihre Bedeutung für das Immunsystem der Mammalia erst in jüngster Zeit erkannt (Gallo et al., 2002).

Auf Grund struktureller und funktioneller Unterschiede werden die antimikrobiellen Peptide in zwei große Familien eingeteilt: die Defensine und die Cathelicidine.

Sowohl im humanen als auch im murinen System ist bisher lediglich je ein Vertreter der Cathelicidine identifiziert worden: LL-37 (Sorensen et al., 2001) bzw. CRAMP (Gallo et al., 1997). LL-37 (37 Aminosäuren lang) besitzt eine breite antimikrobielle Aktivität gegenüber Gram-positiven sowie -negativen Bakterien (Turner et al., 1998), welche durch Synergismus mit der antimikrobiellen Aktivität der Defensine gekennzeichnet ist (Nagaoka et al., 2000). Des Weiteren ist LL-37 durch seine spezifische Bindung an den FPRL-1-Rezeptor in der Lage Neutrophile, Monocyten und T-Lymphocyten chemotaktisch anzulocken (Yang et al., 2000).

\subsubsection{Defensine}

Die humanen Defensine sind kurze, kationische Peptide mit $\beta$-Faltblatt Struktur. Ihre molekulare Größe liegt zwischen 3 bis $5 \mathrm{kDa}$ bei einer Länge von 18 bis 42 Aminosäuren. Anhand der Position und Verknüpfung von 6 konservierten Cystein Resten, also der Lage der intramolekularen Disulfidbrücken, werden die Defensine in drei Familien eingeteilt: $\alpha-, \beta-$ und $\theta$-Defensine (Lehrer et al., 1999; Yang et al., 2002). Diese drei Disulfidbrücken stabilisieren die für die Defensine typischen drei antiparallelen $\beta$-Faltblatt-Strukturen. Die 
$\theta$-Defensine sind zirkuläre Peptide und wurden bisher ausschließlich in Phagocyten von Primaten entdeckt (Tang et al., 1999). Sie werden in dieser Arbeit nicht berücksichtigt.

Trotz einer beträchtlichen Variation der Aminosäuresequenz innerhalb der Mitglieder der Defensin-Familie (lediglich 5 der 6 Cysteine können als konservierte Aminosäuren betrachtet werden) weisen sowohl die $\alpha$ - als auch die $\beta$-Defensine eine beeindruckende Ähnlichkeit in ihrer Sekundär- und Tertiärstruktur auf (Hill et al., 1991; Bauer et al., 2001; Szyk et al., 2006). Dies wird durch die folgende Abbildung verdeutlicht.

A

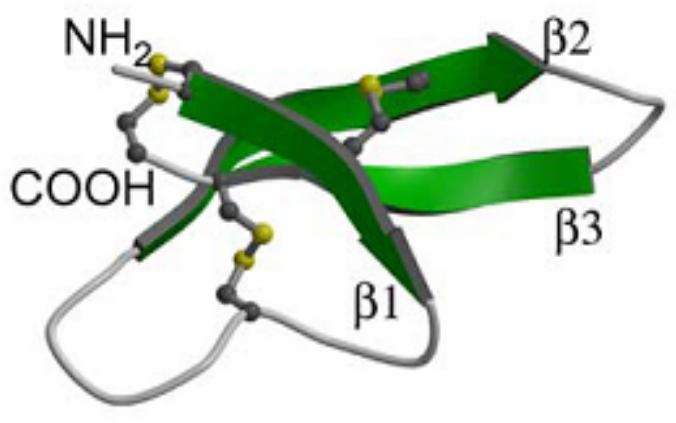

B

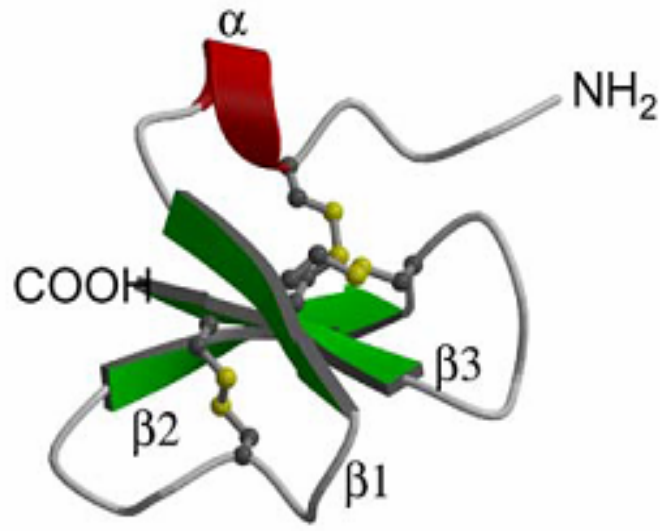

Abb. 1: Schematische Darstellung der Sekundärstruktur des $\alpha$-Defensins HNP-3 (A) sowie des $\beta$-Defensins HBD-1 (B). Wie alle Defensine zeigen sowohl $\alpha$ - als auch $\beta$-Defensine drei antiparallele $\beta$-Faltblattstrukturen (grüne Pfeile) sowie drei konservierte Disulfidbrücken zwischen den hier gelb dargestellten Cysteinen. Im Unterschied zu den $\alpha$-Defensinen besitzen die $\beta$-Defensine zusätzlich eine kleine aminoterminale $\alpha$-Helix-Struktur. Die Abbildungen sind der Veröffentlichung der Gruppe um Schneider (Schneider et al., 2005) entnommen und wurden mit den Programmen Molscript und Raster 3D erstellt (Protein Daten Bank Access Numbers: 1DFN für HNP-3 und 1E4S für HBD-1).

Die Defensine haben ein breites antimikrobielles Spektrum: Gram-negative und Grampositive Bakterien, Pilze sowie Viren. Dabei wird der Mechanismus der Tötung bzw. Inaktivierung von Mikroorgansimen durch Defensine noch nicht gänzlich verstanden. Es wird aber davon ausgegangen, dass beides eine Konsequenz der Zerstörung der Integrität der Zellmembranen ist. Die antimikrobiellen Peptide machen sich hierbei einen fundamentalen Unterschied im Aufbau der Membranen von Mikroben und multizellulären Lebewesen zu Nutze. Die Membranen der Bakterien sind so organisiert, dass die äußere Seite der Lipiddoppelschicht eine große Anzahl an Lipiden mit negativ geladenen PhospholipidKöpfen besitzt. Im Gegensatz dazu besteht die äußere Seite der Zellmembranen von Eukaryoten hauptsächlich aus Lipiden ohne Netto-Ladung. Hier sind die meisten negativ geladenen Komponenten an die cytoplasmatische Seite der Membran verlagert. 
So scheinen die kationischen Defensine ihre Wirksamkeit zu entfalten, indem sie die Integrität der negativ geladenen phospholipidreichen Zellmembranen von Mikroorganismen zerstören (Gallo et al., 2002). Die polare Topologie der Defensine mit räumlich getrennten, geladenen und hydrophoben Regionen ermöglicht ihnen, sich in die Phospholipidmembranen zu integrieren, so dass die hydrophoben Regionen in der Phospholipidmembran liegen und die kationisch geladenen Regionen mit den anionischen Phospholipid-Köpfchen interagieren (Yang et al., 2002). Die Defensine binden dabei an Lipopolysaccharide der Gram-negativen Bakterien, an Polysaccharide und Teichonsäuren der Gram-positiven Bakterien sowie an Phosphatidylglycerol Gram-negativer und Gram-positiver Bakterien. Alle diese Membranstrukturen unterscheiden sich von den Phosphatidylcholin-reichen eukaryotischen cytoplasmatischen Membranen, wodurch die Selektivität dieser Peptide zum Teil begründet werden kann (Schneider et al., 2005). Kommt es zur Aggregation mehrerer Defensine, können sie Kanal-ähnliche Poren bilden. Dies führt letztlich zur Veränderung des Membranpotentiales auf Grund der steigenden Permeabilität für Wasser und Ionen und hat somit die Lyse des Mikroorganismus zur Folge.

Neben diesem direkten Effekt der antimikrobiellen Immunität sind die Defensine zudem Regulatoren des angeborenen Immunsystems. So bewirken beispielsweise humane $\beta$-Defensine die Aktivierung und Degranulierung von Mastzellen, was die Freisetzung von Histamin und Prostaglandin $\mathrm{D}_{2}$ zur Folge hat (Niyonsaba et al., 2001). Im Fokus der derzeitigen Forschung steht die Funktion der Defensine als Effektoren des adaptiven Immunsystems. Die ersten Hinweise hierfür lieferten die Ergebnisse der Gruppe um Yang, die zeigen konnten, dass die $\alpha$-Defensine HNP-1 und -2 die Migration von humanen Monocyten und T-Lymphocyten vermitteln konnten (Territo et al., 1989; Chertov et al., 1996).

Es wird angenommen, dass sich $\alpha$ - und $\beta$-Defensine aus einem $\beta$-Defensin Vorläufer-Gen entwickelt haben (Semple et al., 2006). Liu et al. (1997) zeigten, dass das HBD-1-Gen in 100$150 \mathrm{~kb}$ des $\alpha$-Defensin-Genclusters auf dem kurzen Arm des Chromosoms 8 lokalisiert ist und leiten daraus den direkten Beweis ab, dass es einen gemeinsamen evolutionären Ursprung der zwei Defensin-Familien gibt. Die Organisation der Defensin-Gene auf dem Chromosom 8 ist im Folgenden dargestellt. 


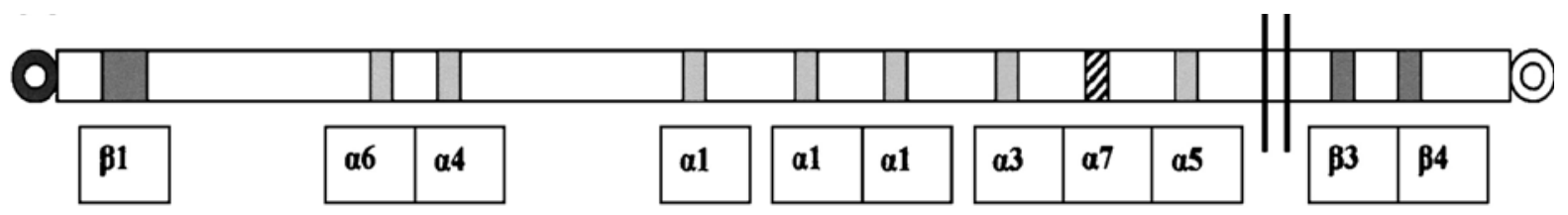

Abb. 2: Abfolge der Defensin-Gene auf dem Chromosom 8p22-p23. Die beiden vertikalen Linien repräsentieren die Sequenzlücke in der DNA zwischen dem $\alpha$ - und dem $\beta$-Defensin Gencluster. Die $\beta$-DefensinGene sind dunkelgrau, die $\alpha$-Defensin-Gene hellgrau hinterlegt. Die $\alpha$-Defensin-kodierenden Gene sind mit $\alpha 1$ bis $\alpha 6$, die $\beta$-Defensin-Gene mit $\beta 1, \beta 3$ und $\beta 4$ beschriftet. Das $\alpha$-Defensin Pseudo-Gen DEFA7P (GenBank Accession Nr. AY746432, A98570, and A98571) ist schraffiert dargestellt. Der offene bzw. der schwarze Ring zeigt die Richtung des Telomers bzw. des Centromers an. Die Abbildung ist der Veröffentlichung von Linzmeier und Ganz (2005) entnommen.

\begin{tabular}{|c|c|c|c|}
\hline Bezeichnung & Gen & Peptide & Syntheseort \\
\hline$\alpha 1$ & DEFA1 & HNP-1, HNP-2 & Neutrophile Zellen \\
\hline$\alpha 3$ & DEFA3 & HNP-3 (HNP-2) & Neutrophile Zellen \\
\hline$\alpha 4$ & DEFA4 & HNP-4 & Neutrophile Zellen \\
\hline$\alpha 5$ & DEFA5 & HD-5 & Paneth-Zellen \\
\hline$\alpha 6$ & DEFA6 & HD-6 & Paneth-Zellen \\
\hline$\beta 1$ & DEFB1 & HBD-1 & Epithel-Zellen \\
\hline$\beta 3$ & DEFB103A & HBD-3 & Epithel-Zellen \\
\hline$\beta 4$ & DEFB4 & HBD-2 & Epithel-Zellen \\
\hline
\end{tabular}

Tabelle 1: Übersicht über $\alpha$ - und $\beta$-Defensin-Gene, die von Ihnen kodierten Peptide sowie Syntheseorte. Für das $\alpha$-Defensin HNP-2 ist nicht klar, ob es ausschließlich vom DEFA1 Gen kodiert wird oder zusätzlich auch vom DEFA3 Gen.

Die Tabelle 1 zeigt die Gene, welche für $\alpha$ - und $\beta$-Defensine kodieren. Die $\alpha$-Defensine entstehen aus Genen mit drei Exons, während die $\beta$-Defensin-Gene zwei Exons enthalten (Lehrer und Ganz, 2002). Alle humanen $\alpha$ - und $\beta$-Defensine werden aus Vorläuferproteinen (sogenannten Prodefensinen) durch proteolytische Spaltung prozessiert. Die $\alpha$-DefensinVorläuferproteine bestehen aus einem Signalpeptid ( 19 AS), einer anionischen vorgelagerten Domäne (37-51 AS) sowie der aktiven bzw. reifen carboxyterminalen Defensin-Domäne (2934 AS). So wird vermutlich auch das HNP-2 Peptid aus den Propeptiden HNP-1 und HNP-3 posttranslational generiert (Linzmeier und Ganz, 2005; Ganz, 2003).

Das DEFA1 Gen liegt zudem in zwei bis fünf Kopien vor. Dieser Gen-AnzahlPolymorphismus wurde ebenfalls für die $\beta$-Defensin-Gene DEFB4 sowie DEFB103A mit einer Anzahl von 2 bis 6 Kopien beschrieben (Linzmeier und Ganz, 2005). Während die $\alpha$-Defensin-Gene für HNP-1 bis -3 konstitutiv und proportional zur Anzahl der Genkopien in neutrophilen Zellen exprimiert werden, zeigte sich, dass die Expression von HBD-2 durch Cytokine, vor allem durch IL-1, reguliert wird (Liu et al., 2002). 
Die $\alpha$-Defensine HD-5 und -6 werden in sekretorischen Vesikeln als Propeptide gespeichert und daraufhin durch Trypsin, welches als Prodefensin Konvertase agiert, sowie durch die Metalloproteinase Matrilysin gespalten (Ghosh et al., 2002; Salzman et al., 2003; Wilson et al., 1999).

Die humanen $\beta$-Defensin-Vorläuferproteine bestehen ebenfalls aus einem Signalpeptid, einem kurzen Propeptid (dies kann auch komplett fehlen) sowie dem reifen Defensin-Peptid am C-Terminus. HBD-2 wird von epidermalen Keratinocyten in lipidreichen Vesikeln sekretiert. Die Lagerung sowie die Freisetzungswege der anderen $\beta$-Defensine sind derzeit noch nicht genau aufgeklärt (Ganz, 2003).

\subsubsection{1 $\alpha$-Defensine}

Die $\alpha$-Defensine werden primär von Neutrophilen synthetisiert, weshalb ihnen der Name humane Neutrophile Peptide (HNP) gegeben wurde. Die $\alpha$-Defensine unterscheiden sich vornehmlich von den $\beta$-Defensinen durch die Verknüpfung der Cysteinreste. Während bei den $\beta$-Defensinen die Cysteine 1 und 5, 2 und 4 sowie 3 und 6 miteinander verbunden sind, weisen die $\alpha$-Defensine Disulfidbrücken zwischen Cystein 1 und 6, 2 und 4 sowie 3 und 5 auf. Von den 6 bekannten humanen $\alpha$-Defensinen werden vier (HNP-1 bis HNP-4) hauptsächlich in neutrophilen Granulocyten gefunden (Harwig et al., 1994). In diesen Zellen sind 5 bis $7 \%$ des gesamten Proteingehalts $\alpha$-Defensine (Schneider et al., 2005). Zudem sind auch aktivierte Lymphocyten, NK- Zellen sowie Monocyten als Produzenten dieser Defensine identifiziert worden (Agerbert, et al., 2000). Dahingegen werden die humanen $\alpha$-Defensine HD-5 und HD-6 ausschließlich von den Paneth-Zellen des Dünndarms und in Epithelzellen des weiblichen Urogenitaltraktes synthetisiert (Selsted et al., 1992; Quale et al., 1998).

Die antimikrobielle Aktivität der $\alpha$-Defensine richtet sich vornehmlich gegen Escherichia coli, Listeria monocytogenes, Salmonella typhimorium sowie Candida albicans (Schröder, 1999).

Während die Aminosäurensequenzen der aus den neutrophilen Granulocyten stammenden $\alpha$-Defensine HNP-1 bis -3 lediglich in einer Aminosäure variieren, weisen HNP-4 sowie die Defensine der Paneth-Zellen gegenüber den neutrophilen Defensinen eine Sequenzübereinstimmung von weniger als $50 \%$ auf. Die folgende Abbildung zeigt die Aminosäurensequenzen der verschiedenen $\alpha$-Defensine sowie die charakteristischen Disulfidbrücken zwischen den 6 Cysteinen. 


\section{Humane neutrophile $\alpha$-Defensine}

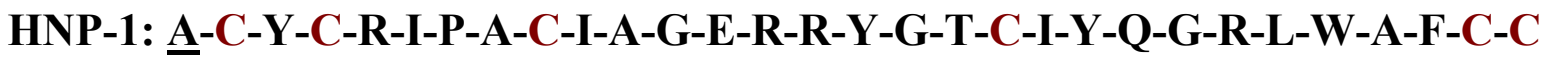

HNP-2: _ C-Y-C-R-I-P-A-C-I-A-G-E-R-R-Y-G-T-C-I-Y-Q-G-R-L-W-A-F-C-C

HNP-3: D-C-Y-C-R-I-P-A-C-I-A-G-E-R-R-Y-G-T-C-I-Y-Q-G-R-L-W-A-F-C-C

HNP-4: V-C-S-C-R-L-V-F-C-R-R-T-E-L-R-V-G-N-C-L-I-G-G-V-S-F-T-Y-C-C

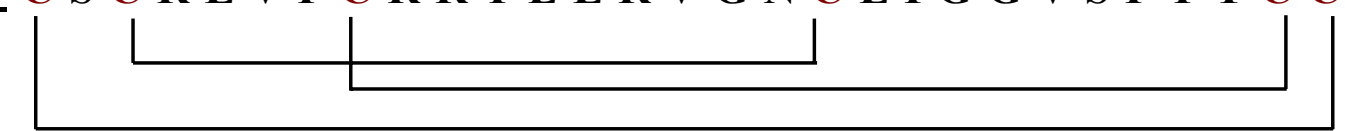

\section{Humane intestinale $\alpha$-Defensine}

HD-5: A-T-C-Y-C-R-T-G-R-C-A-T-R-E-S-L-S-G-V-C-E-I-S-G-R-L-Y-R-L-C-C-R

HD-6: A-F-T-C-H-C-R-R-S----C-Y-S-T-E-Y-S-Y-G-T-C-T-V-M-G-I-N-H-R-F-C-C-L

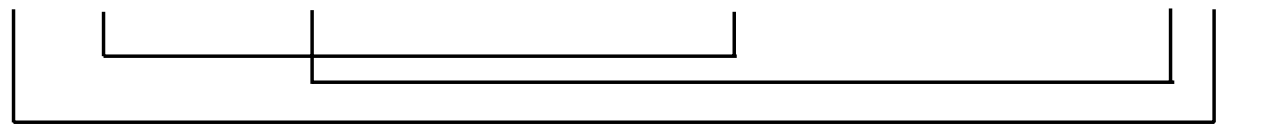

Abb. 3: Aminosäuresequenzen der humanen $\alpha$-Defensine der neutrophilen Zellen (HNP) sowie der Paneth-Zellen des Interstitiums (HD). In den Sequenzen der neutrophilen Defensine ist die einzige variierende Aminosäure unterstrichen dargestellt. Die konservierten Cysteine sind rot und die für $\alpha$-Defensine charakteristischen Disulfidbrücken (Cystein1+6; Cystein2+4; Cystein3+5) durch Linien verbunden dargestellt. Die Sequenzen sind aus der Arbeit von Raj und Dentino entnommen (Raj und Dentino, 2002).

Es wird vermutet, dass die $\alpha$-Defensine eine wichtige Rolle bei der Erhaltung von intakten mukosalen Barrieren spielen, da sowohl HD-5 als auch HD-6 bei der Pathogenese der entzündlichen Morbus Crohn-Erkrankung eine Rolle spielen (Wehkamp et al., 2005a). So konnte ein Zusammenhang zwischen der deutlich verminderten Expression von HD-5 und HD-6 in den Paneth-Zellen und der Morbus Crohn-Erkrankung des Dünndarms festgestellt werden (Wehkamp et al., 2005b). Des Weiteren kam es zu einer Abnahme der Expression von HD-5 bei der mit HIV verbundenen Cryptosporidose, einer Form der Gastroenteritis (Kelly et al., 2004). Im Gegensatz dazu steigen die Konzentrationen von HD-5 und HD-6 bei akuten Koliken (Frye et al., 2000). Eine Veröffentlichung der Arbeitsgruppe um Guo zeigt zudem, dass die Neutrophilen-Defensine in der Lage sind, die Replikation des HIV in Monocyten und in aus Monocyten generierten Makrophagen zu unterdrücken (Guo et al., 2004). 
Neben ihrer direkten antimikrobiellen Wirkungen können $\alpha$-Defensine sowohl die angeborene als auch die adaptive Immunität beeinflussen (Yang et al., 2002). Es konnte gezeigt werden, dass sie die Proliferation und die Cytokin-Produktion muriner Milzzellen in vitro induzieren können. Zudem verstärken die $\alpha$-Defensine die Immunglobulinproduktion auch gegen Tumorantigene in vivo und können damit die Überlebenszeiten Tumor-tragender Versuchstiere verlängern (Lillard et al., 1999; Tani et al., 2000; Brogden et al., 2003). In Übereinstimmung mit diesen Untersuchungen konnte für HNP-1 und -2 eine chemotaktische Mobilisierung von $\mathrm{CD}^{+} / \mathrm{CD} 4 \mathrm{RA}^{+}$naiven sowie $\mathrm{CD}^{+}$T-Lymphocyten in vitro bei Konzentrationen nachgewiesen werden, welche 10 bis 100 mal niedriger waren als die antimikrobiell wirksamen. Ferner lockten HNP-1 und -2 Dendritische Zellen an, die aus Monocyten bzw. CD34 ${ }^{+}$Vorläuferzellen hergestellt worden waren (Yang et al., 2000). Humane $\alpha$-Defensine bewirkten in Monocyten eine Verstärkung der Produktion von TNF- $\alpha$ und IL-1 $\beta$ nach Vorstimulation mit Staphylococcus aureus oder PMA (Chaly et al., 2000).

Kontroverse Ergebnisse über die HNP-1/-2 induzierte Migration von Monocyten verdeutlichen die unklare Einordnung und den bis dato geringen Wissensstand über diese Defensine, abgesehen von der Rolle dieser Peptide bei der Pathogenabwehr (Bowdish et al., 2006).

Hinweise auf den oder die noch unbekannten Rezeptor/en für die $\alpha$-Defensine liegen in der Literatur bisher ebenfalls noch nicht vor.

\subsubsection{2 $\beta$-Defensine}

Zur Gruppe der $\beta$-Defensine werden im humanen System bisher vier verschiedene Peptide (HBD-1 bis -4) gezählt, welche alle eine konservierte Disulfidverbindung zwischen folgenden Cysteinen aufweisen: Cys1-Cys-5, Cys2-Cys4 und Cys3-Cys6. Die Gene weiterer, bisher unbekannter, $\beta$-Defensine wurden bereits beschrieben (Schutt et al., 2002). $\beta$-Defensine werden primär von epithelialen Zellen der Haut, Niere, Lunge, des Gastrointestinal- sowie des Urogenitaltraktes exprimiert. Sie können konstitutiv sezerniert werden, ihre Expression kann aber auch durch Exposition gegenüber Bakterien und inflammatorischen Stimuli wie Cytokinen induziert werden (Diamond et al., 1996; Stolzenberg et al., 1997; Harder et al., 1997; Ganz, 2003).

HBD-1 wird vor allem in den Henle-Schleifen der Niere konstitutiv exprimiert. Die HBD-2 Expression ist hingegen durch LPS und Cytokine wie TNF- $\alpha$ und IL-1 $\beta$ induzierbar. Sowohl 
HBD-2 als auch HBD-3 wurden anfänglich aus der Haut von Psoriasis-Patienten aufgereinigt. Beide Defensine werden zudem in den Epithelien der Atemwege sowie in den Mandeln exprimiert. Das $\beta$-Defensin HBD-4 wird im Magen, in den Testis, im Uterus, in der Schilddrüse, in der Lunge und in der Niere exprimiert und weist somit die weiteste Verbreitung im menschlichen Körper auf (Semple et al., 2006). Die antimikrobielle Wirkung der $\beta$-Defensine richtet sich vor allem gegen Escherichia coli, Pseudomonas aeruginosa, Staphylococcus aureus sowie Candida albicans (Schröder, 1999).

Im Vergleich $\mathrm{zu}$ den $\alpha$-Defensinen weisen die $\beta$-Defensine eine deutlich größere Sequenzvariabilität auf. So stimmt die Aminosäuresquenz von HBD-4 nur zu etwa $25 \%$ mit der von HBD-1, -2 und -3 überein (Lehrer und Ganz, 2002). Dennoch scheinen die konservierten Disulfidbrücken sowohl der humanen als auch der murinen Defensine die Bildung der charakteristischen Tertiärstruktur dieser Peptide zu ermöglichen. Abbildung 4 zeigt einen Vergleich der Aminosäuresequenzen der humanen $\beta$-Defensine HBD-1 bis HBD-4 sowie der murinen $\beta$-Defensine mBD-2 und mBD-8.

\section{$\underline{\text { Humane } \beta \text {-Defensine }}$}

HBD-1： C-V-S-S-G-G-Q-C-L-Y-S-A-C-P-I-F-T-K-I-Q-G-T-C-Y-R-G-K-A-K-C-C-K

HBD-2: C-L-K-S-G-A-I-C-H-P-V-F-C-P-R-R-Y-K-Q-I-G-T-C-G-L-P-G-T-K-C-C-K

HBD-3: C-R-V-R-G-G-R-C-A-V-L-S-C-L-P-K-E-E-Q-I-G-K-C-S-T-R-G-R-K-C-C-K

HBD-4: C-G-Y-G-T-A-R-C-R-K---K-C-R-S-Q-E-Y-R-I-G-R-C-P-N-T-Y-A---C-C-K

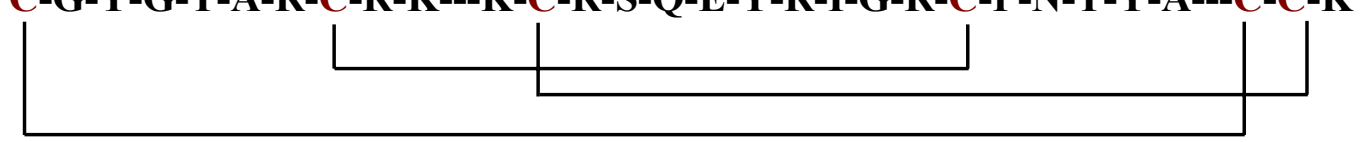

\section{$\underline{\text { Murine } \beta \text {-Defensine }}$}

mBD-2: C-H-T-N-G-G-Y-C-V-R-A-I-C-P-P-S-A-R-R-P-G-S-C-F-P-E-K-N-P-C-C-K

mBD-8: C-I-R-N-G-G-I-C-Q-Y---R-C-I-G-L-R-H-K-I-G-T-C---G-S-P-F-K-C-C-K

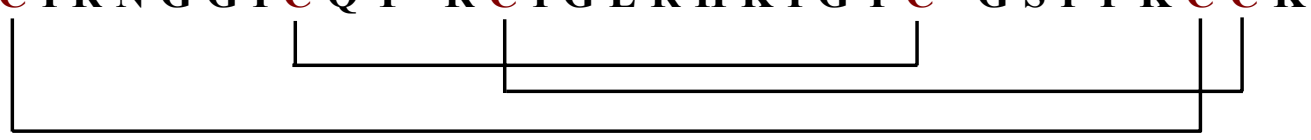

Abb. 4: Aminosäuresequenzen der humanen $\beta$-Defensine 1 bis 4 (HBD) sowie zweier muriner $\beta$-Defensine (mBD). Die konservierten Cysteine sind rot markiert dargestellt. Die für $\beta$-Defensine charakteristischen Verknüpfungen der Cysteine (Cystein1+5; Cystein2+4; Cystein3+6) über Disulfidbrücken ist mittels verbindender Linien dargestellt. Die Sequenzen wurden aus der Veröffentlichung von Bauer und Mitarbeitern entnommen (Bauer et al., 2001). 
Das $\beta$-Defensin HBD-2 scheint eine besondere Funktion in der Immunabwehr zu übernehmen, da es zunehmend mit diversen Haut- sowie intestinalen Krankheiten in Verbindung gebracht wird. Im Falle der Neurodermitis, welche oft mit einer Infektion durch Staphylococcus aureus einhergeht, konnte eine verminderte HBD-2-Expression nachgewiesen werden (Ong et al., 2002). In der Lunge wurde ebenfalls eine Herunterregulierung von HBD-2 bei verschiedenen Infektionen sowie entzündlichen Erkrankungen einschließlich der Cystischen Fibrose festgestellt (Chen et al., 2004). $\mathrm{Zu}$ einem Anstieg des HBD-2Proteinspiegels kommt es hingegen bei Psoriasis, einer Krankheit, bei der die Patienten zumeist äußerst resistent gegenüber bakteriellen Infektionen sind (Chung und Dale, 2004) sowie bei entzündlichen Erkrankungen des gastrointestinalen Traktes wie etwa Morbus Crohn oder der von Helicobacter pylori ausgelösten Gastritis (Wehkamp et al., 2003).

Es zeigte sich weiterhin, dass auch die $\beta$-Defensine eine wichtige Rolle bei der angeborenen sowie der adaptiven Immunität spielen. Die $\beta$-Defensine modulieren die Cytokinantwort von mononuklearen Blutzellen (Boniotto et al., 2006) und fördern die systemische Antigen- oder Tumor-spezifische Immunantwort (Biragyn et al., 2001; Brogden et al, 2003; Ma et al., 2006). HBD-1 bis -3 sowie die murinen $\beta$-Defensine mBD-2, -3 und -29 induzierten selektiv die Migration von Gedächtnis-T-Lymphocyten und unreifen DCs. Sowohl für HBD-2 als auch für mBD-2 und -3 konnte gezeigt werden, dass sie mit dem CCR6-Rezeptor interagieren (Yang et al., 1999; Biragyn et al., 2001), dessen eigentlicher Chemokinligand CCL20 ist (Power et al., 1997). Über die Bindung an CCR6 sollen diese Defensine die Fähigkeit erlangen, aus CD34 ${ }^{+}$ Vorläuferzellen abgeleitete DC sowie Gedächtnis-T-Lymphocyten zu rekrutieren (Yang et al., 1999).

Da einige $\beta$-Defensine zusätzlich auch die Chemotaxis von Monocyten und Mastzellen induzieren konnten, welche den CCR6-Rezeptor nicht exprimieren, wurde die Existenz weiterer Rezeptoren für $\beta$-Defensine postuliert (Yang et al., 2002).

\subsection{Allgemeine Prinzipien der Rezeptor-vermittelten Signaltransduktion}

Ein generelles Problem aller Zellen, die auf Reize reagieren, besteht darin, dass sie den Reiz zunächst als solchen wahrnehmen und ihn schließlich in die Zelle weiterleiten müssen. Dem Erkennen eines Reizes dienen die Rezeptorproteine auf der Zelloberfläche, an die extrazelluläre Liganden binden können. Die auf diese Weise aktivierten Rezeptoren 
induzieren daraufhin intrazelluläre Signalwege. Es findet also eine Umwandlung des Signals statt, welche als Signaltransduktion bezeichnet wird (Janeway et al., 2002).

Alle Rezeptoren an der Zelloberfläche, die eine Signalfunktion besitzen, sind entweder selbst Transmembranproteine oder gehören zu Proteinkomplexen, welche das Zellinnere mit der äußeren Umgebung verbinden. Viele Rezeptoren verändern ihre Konformation, wenn es zur Bindung des Liganden kommt. Bei einigen Rezeptoren öffnen sich durch diese Konformationsänderung Ionenkanäle, bei anderen beeinflusst die Änderung den cytoplasmatischen Teil des Rezeptors, wodurch dieser sich mit intrazellulären Signalproteinen und Enzymen zusammenlagern und diese aktivieren kann.

Die meisten Rezeptoren lösen in der Zelle Signale durch die Aktivierung von Proteintyrosinkinasen aus. Einmal aktiviert, können diese Tyrosinkinasen wiederum andere cytoplasmatische Signalmoleküle phosphorylieren und aktivieren. Ein Beispiel hierfür sind die Rezeptoren von Wachstumsfaktoren. Diese besitzen eine cytoplasmatische Domäne mit einer eigenen Tyrosinkinaseaktivität und sind in der Regel inaktiv. Sobald sie aber durch Aggregation von mehreren Rezeptoren miteinander in Kontakt kommen, können sie sich gegenseitig durch Transphosphorylierung aktivieren.

Aber nicht nur die Aktivierung und Deaktivierung von Enzymen ist eine Folge der Phosphorylierung, sondern auch die Bereitstellung von Bindungsstellen für andere Proteine. Cytosolische Proteine, die sich an phosphorylierte Stellen an der Membran heften, werden so um die Kinase herum konzentriert und können nun ihrerseits phosphoryliert und aktiviert werden. Die phosphorylierten Proteine werden aber ebenso schnell durch Proteinphosphatasen wieder inaktiviert, so dass eine erneute Aktivierung erfolgen kann und das Signal zeitlich begrenzt auftritt.

Weiterer wichtiger Bestandteil der Signaltransduktionswege sind die Adaptorproteine. Sie enthalten zwei oder mehr Domänen wie beispielsweise die SH2- und SH3-Domänen, welche Protein-Protein-Wechselwirkungen vermitteln. Ein solches Protein (z. B. Src) kann über seine SH2-Domäne an einen Phosphotyrosinrest eines Rezeptors und über seine SH3-Domäne an andere Proteine binden. Diese Proteine werden so in die Nähe der Zellmembran gebracht, wo sie durch Rezeptor-ständige Tyrosinkinasen phosphoryliert werden können.

$\mathrm{Zu}$ einer bedeutenden Proteinfamilie, die von Adaptoren gebunden wird, gehören die Guaninnucleotid-Austauschfaktoren (GEFs: guanine-nucleotide exchange factors). Die GEFs übertragen das Signal auf G-Proteine wie zum Beispiel Ras oder Rho. G-Proteine 
können in zwei Zuständen vorliegen: in aktiver Form, wenn sie GTP gebunden haben, und in inaktiver Form, wenn sie GDP gebunden haben. Die inaktive Form kann durch die intrinsische GTPase Aktivität regeneriert werden (s. auch 1.5). Aktiviert werden die G-Proteine, wie bereits erwähnt, durch die GEFs, die GDP gegen GTP austauschen. Sind die G-Proteine aktiviert worden, setzen sie unter anderem die Kaskade der mitogenaktivierten Proteinkinasen (MAPK) in Gang (Widmann et al., 1999).

Der MAPK Signalweg spielt bei den Vertebraten eine bedeutende Rolle bei der Rekrutierung von Leukocyten zu Infektionsherden und ist zudem von Saccharomyces cervisiae bis zum Homo sapiens hochkonserviert. Derzeit sind drei Hauptsignalwege der MAP-Kinasen im humanen System bekannt. Dabei wird die MAP-Kinase ERK (extrazellulär regulierte Protein Kinase) vor allem mit den Signaltransduktionswegen der Zellproliferation, der Zelltransformation sowie der Zelldifferenzierung assoziiert, während JNK (c-Jun $\mathrm{NH}_{2}$ terminale Kinase)- und p38-vermittelte Signalwege vornehmlich in den Bereichen Apoptose, Stress Antworten sowie Entzündungen von Bedeutung sind (Widmann et al., 1999).

Eine Gemeinsamkeit aller MAP-Kinasen ist die Fähigkeit Threonin- und Tyrosin-Reste zu phosphorylieren. Einmal aktiviert können die MAP-Kinasen weitere Kinasen oder auch Transkriptionsfaktoren (z. B. $\mathrm{NF}_{\mathrm{K}} \mathrm{B}$ durch p38) im Cytoplasma oder im Zellkern phosphorylieren und somit aktivieren (Keane et al., 2000). Dies führt letztendlich zu einer Expressionssteigerung oder-abnahme der jeweiligen Zielgene.

Mittlerweile gibt es eine ständig wachsende Liste von Proteinen, die Teil des Signalweges der von Chemokinen und Defensinen ausgelösten Chemotaxis sind. Wenngleich die Forschung hier noch am Beginn steht, so ist doch die Beteilung der G-Protein gekoppelten Rezeptoren (GPCRs) an dieser Signaltransduktion unbestritten. Diese Rezeptoren werden im Folgenden Abschnitt 1.5 beschrieben.

\subsection{G-Protein-gekoppelte Rezeptoren}

Das Wirkungsspektrum der G-Protein-gekoppelten Rezeptoren ist äußerst komplex. So sind sie zum Einen in die Verarbeitung von visuellen, gustatorischen und olfaktorischen Reizen involviert, spielen zum Anderen aber auch eine wichtige Rolle bei Entzündungsprozessen, der Chemotaxis, der Endo- und Exocytose sowie beim Zellwachstum und bei der Zelldifferenzierung. Weiterhin wirken auch Hormone wie Adrenalin oder Glucagon sowie 
Neurotransmitter wie Serotonin und Acetylcholin über G-Protein-gekoppelte Rezeptoren. Ein Ligand ist dabei in der Lage, mehrere Rezeptoren einer Familie zu aktivieren. So kann Adrenalin beispielsweise an neun verschiedene GPCR binden und Serotonin aktiviert 15 dieser Rezeptoren (Alberts et al., 2001). Bekanntester Vertreter der Viren, welche an einen G-Protein gekoppelten Rezeptor binden und in die Zelle eindringen, ist das HI-Virus (humanes Immundefizienz Virus). Das HIV dringt mit Hilfe eines Komplexes aus zwei nichtkovalent gebundenen Glykoproteinen in der Virushülle (gp120, gp41) in die Zelle ein. Dabei bindet gp120 an das Zelloberflächenmolekül CD4 und kann sich somit an die CD4 exprimierenden Zellen (T-Lymphocyten, Makrophagen und DCs) anlagern. Für das Eindringen des Rezeptors nutzt das Virus die G-Protein gekoppelten Chemokinrezeptoren (vor allem CCR5 und CXCR4) als Corezeptoren. Nach der Bindung des Corezeptors verursacht gp41 dann die Fusion der Virushülle mit der Plasmamembran der Zelle (Janeway et al., 2002).

Die an G-Proteine gekoppelten Rezeptoren sind als integrale Membranproteine an der Übertragung von Signalen über die Cytoplasmamembran in das Cytosol hinein beteiligt. Die Bindung des extrazellulären Liganden an seinen Rezeptor bewirkt eine Interaktion zwischen dem Rezeptor und einem heterotrimeren G-Protein auf der intrazellulären Seite der Membran und die damit verbundene Aktivierung des G-Proteins löst eine intrazelluläre Kette von Signalen aus.

G-Protein-gekoppelte Rezeptoren zählen zu der Superfamilie der heptahelikalen Transmembranproteine. Sie besitzen eine extrazelluläre oder transmembranäre Bindungsdomäne, an die der Ligand binden kann. Das G-Protein hingegen bindet an Aminosäuren der zweiten und dritten intrazellulären Schleife des Rezeptors. Als Rezeptor mit einer extrazellulären Liganden-Bindungsdomäne besitzt auch der GPCR lange N-terminale Aminosäuresequenzen sowie einen relativ kurzen intrazellulären C-terminalen Anteil.

Die Kopplung der heptahelikalen Rezeptoren an G-Proteine erlaubt eine Amplifikation des Signals, da ein Ligand-gebundener Rezeptor in kurzer Zeit viele G-Proteine aktivieren kann (Hille, 1992). Diese G-Proteine sind Teil einer GTPase-Superfamilie und aus drei Polypeptiden aufgebaut: einer $\alpha$-Untereinheit, welche GTP bindet und hydrolysiert, einer $\beta$-Untereinheit sowie einer $\gamma$-Untereinheit. Die $\beta$-und die $\gamma$-Untereinheit bilden ein Dimer, das nur unter denaturierenden Bedingungen dissoziiert und somit ein funktionelles Monomer darstellt. Die Aktivierung des G-Proteins wird durch seine Interaktion mit spezifischen cytoplasmatischen Segmenten des Ligand-aktivierten heptahelikalen Rezeptors ausgelöst 
(Gudermann et al., 1995) und führt zum Austausch des an die $\alpha$-Untereinheit gebundenen GDP gegen GTP. Durch die intrinsische GTPase-Aktivität der $\mathrm{G}_{\alpha}$-Untereinheit wird das GTP hydrolysiert und somit in den inaktiven Zustand gebracht. Im Anschluss an die GTPHydrolyse dissoziiert die inaktive $\mathrm{G}_{\alpha}$-Untereinheit von dem Effektor und reassoziiert mit dem $\mathrm{G}_{\beta \gamma}$-Komplex. Sowohl die aktivierte $\mathrm{G}_{\alpha}$-Untereinheit als auch der $\mathrm{G}_{\beta \gamma}$-Komplex sind in der Lage, Effektorproteine zu modulieren. So aktivieren die G-Proteine second messenger (z. B. cAMP), welche die Aktivierung von Serin/Threonin-Kinasen wie Proteinkinase A oder die durch Diacylglycerol (DAG) und Calcium aktivierte Proteinkinase C bewirken. Diese Proteinkinasen phosphorylieren die GPCR und führen über diesen negativen RückkopplungsMechanismus zur Unterbrechung der Signaltransduktion.

Als Folge der Phosphorylierung des Rezeptors erfolgt eine Konformationsänderung des Rezeptors durch die mit der stark negativen Ladung des Phosphatrestes einhergehende Veränderung der elektrostatischen Wechselwirkungen. Die Konformationsänderung schwächt die Affinität des Rezeptors zum G-Protein, so dass es auf Grund der verminderten Interaktion zwischen Rezeptor und G-Protein zu einer von einer Desensibilisierung des Rezeptorsignals kommt. Weiterhin führt die Bindung des Rezeptor-Arrestin-Komplexes an Clathrin zur Entfernung des phosphorylierten Rezeptors von der Zelloberfläche in das Zellinnere in Form von sogenannten „Clathrin-coated pits“ (Membranvesikel). Diese fusionieren mit Endosomen, in denen die Rezeptoren intrazellulär abgebaut werden. Anschließend werden die Rezeptoren über Transportvesikel wieder an die Zelloberfläche zurückgeführt (Alberts et al., 2001). In der Zeit dieser Internalisierung des Rezeptors ist der Rezeptor wiederum inaktiv (ca. 30 bis 60 min). Sowohl die Desensibilisierung als auch die Internalisierung der GPCR führen dazu, dass bei steigender Ligandenkonzentration, nach Erreichen des stärksten Rezeptorsignals bei der optimalen Konzentration des Liganden, ein Abfall des Signals erfolgt. Die Rezeptoren sind dabei zum Teil durch Liganden bereits blockiert und daher nicht mehr aktivierbar oder sie befinden sich in der Internalisierungsphase. Beides führt zur typischen Glockenform der Dosis-Wirkungskurven dieser GPCR-Ligand-Interaktion.

\subsection{Zellmigration}

Die Mobilisierung von Zellen des Immunsystems zu den Orten einer Infektion ist eine der wichtigsten Funktionen des angeborenen und des adaptiven Immunsystems. Dabei ist die Rekrutierung der Zellen Teil der Entzündungsreaktion und wird von Zelladhäsionsmolekülen 
vermittelt, deren Expression an der Oberfläche des lokalen Blutgefäßendothels induziert wird. Die Zellmigration in ein Gewebe hinein bedarf multipler chemotaktischer Signale. Dabei wächst die Anzahl der Leukocyten-Attraktoren mit der Charakterisierung der extensiven Chemokinfamilie ständig weiter. Die Chemokine induzieren die Chemotaxis der Leukocyten und regulieren zudem die adhäsiven Fähigkeiten der Leukocyten-Integrine (Oppenheim et al., 1991; Baggiolini, 1998). Vor der eigentlichen Migration unterlaufen die Zellen eine Polarisierung mit der Bildung eines Lamellipodiums am Leitsaum sowie eines Uropodiums an der hinteren Seite. Diese Zellform erlaubt den Zellen, die Kräfte des Cytoskelettes in das Voranschreiten des Zellkörpers umzuwandeln. Diese morphologischen Veränderungen des Cytoskelettes, die Bildung von Integrin-vermittelten fokalen Adhäsionspunkten sowie die koordinierte Bindung und Ablösung der Zelle von den Endothelzellen, welche die gerichtete Migration bewirkt, sind beeindruckende Effekte der Chemokine (Sanchez-Madrid und Pozo, 1999).

Eines der ersten Ereignisse bei der Polarisierung der Leukocyten, welches durch Chemoattraktoren ausgelöst wird, ist die Veränderung der Verteilung des filamentösen F-Aktins von einer radialen Symmetrie über die gesamte Zelle zur Akkumulation an dem späteren Leitsaum der Zelle, woraus die typische, Amöben-ähnliche, polarisierte Form resultiert. Die Migration und die Polarisierung der Zelle benötigt des Weiteren eine drastische Rekonfiguration des Tubulin. Eine weitere Konsequenz der Polarisierung ist die nur am Leitsaum der Zelle stattfindende Extension einschließlich der Bildung von Lamellipodien und Filopodien. Die Lamellipodien sind breite, flache Strukturen mit vernetzten Aktinfilamenten, während die Filopodien eher dünne und zylindrische Formen haben, und die Aktinfilamente in seilartigen Bündeln gruppiert sind. Bei der Extension von Lamellipodien und Filopodien als Antwort auf einen chemotaktischen Stimulus kommt es zur lokalen AktinPolymerisierung. Dabei erfolgt zunächst ein Anstieg der Aktin-Polymerisierungstellen. Hierauf folgt eine Addition von monomerem G-Aktin (globuläres Aktin) an diese F-AktinWachstumsstellen in der Nähe der Zellmembran sowie ein Abbau des Aktinnetzes am Uropodium.

Während der Migration ist das Aktinnetzwerk stabil mit den Oberflächenrezeptoren verbunden, welche ihrerseits mit dem Substrat interagieren. Für die Adhäsion an das Substrat sowie für die Extension von Filopodien und Lamellipodien werden eine Gruppe von Cytoskelett-assoziierten Proteinen von Phosphoproteinen wie der Fokal-Adhäsions-Kinase (FAK), Paxillin oder Tensin an Tyrosinen phosphoryliert. Auf Aktin und Myosin basierende Kontraktionen in Fibrillenbündeln (so genannte „stress fibers“) vermitteln die 
Vorwärtsbewegung der Zelle. Dabei ist die kontinuierliche Bewegung der Zelle in eine Richtung durch die ununterbrochene Regeneration des Netzwerkes durch die AktinPolymerisierung am Leitsaum und der Depolymerisierung an der Hinterseite der Zelle (Lauffenburger und Horwitz, 1996). Die Migrationsgeschwindigkeit der Leukocyten beträgt dabei ca. $5 \mu \mathrm{m}$ pro Minute. Nur wenig Erkenntnisse gibt es bis dato in Bezug auf die Membran-Cytoskelett-Interaktionen, welche zur Konzentrierung von chemosensorischen Rezeptoren am Leitsaum führen. Die Abbildung 5 stellt die Abläufe der Migration von Zellen schematisch dar.

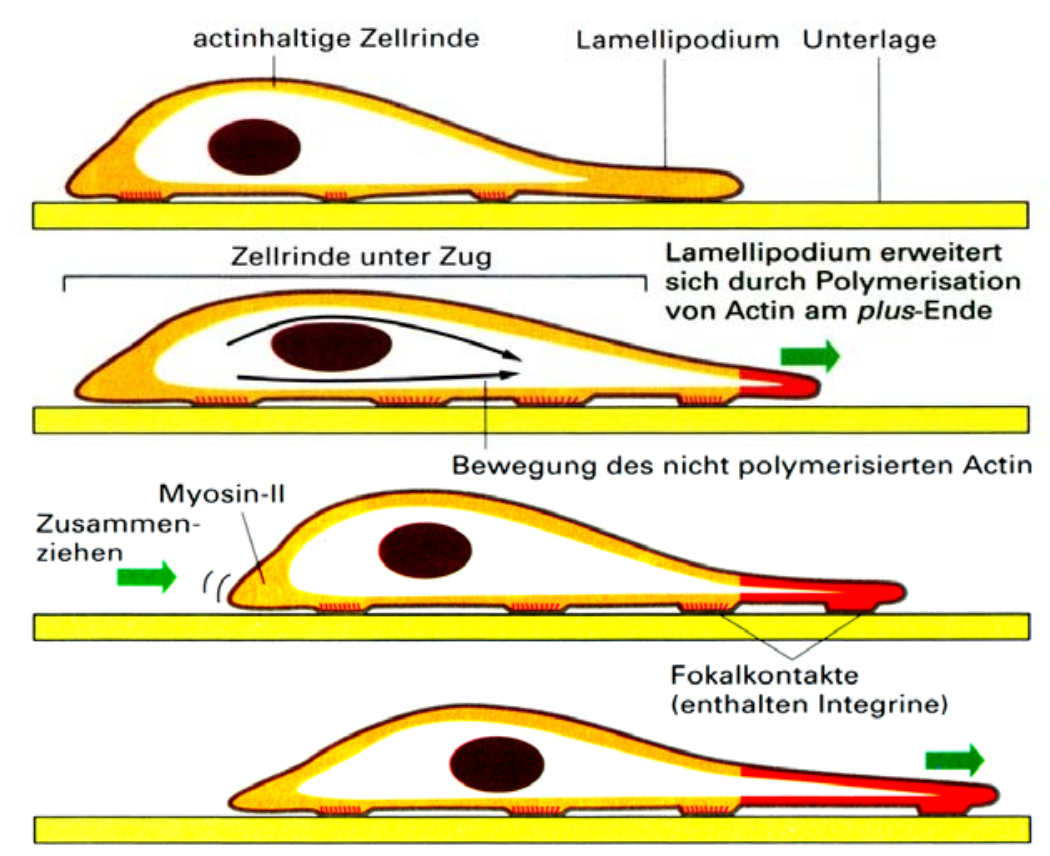

Abb. 5: Modell zur Migration einer Zelle. Dabei bewegt sich die Zelle durch die Aktin-Polymerisierung sowie durch die Verknüpfung von fokalen Adhäsionskontakten am Leitsaum vorwärts . Die Kontraktion der Zelle an der Rückseite mit Hilfe des Myosin II vermindert die Zugkraft, welche durch die Aktin-Polymerisierung entstanden ist. Durch den Wechsel von Polymerisierung und Depolymerisierung sowie durch den Auf- und Abbau der Fokalkontake kommt es zur Zellmigration. Das neu polymerisierte Aktin der Zellrinde ist rot dargestellt. Diese Abbildung wurde einem Lehrbuch von Alberts und Mitarbeitern (Alberts et al., 2004) entnommen.

Für die Mobilisierung von Leukocyten sind drei Familien von Zelladhäsionsmolekülen essenziell: die Selektine, welche zu Beginn der Leukocyten-Endothel-Wechselwirkung eine große Rolle spielen. Bei den Selektinen handelt es sich um membranständige Glykoproteine, welche an spezifische Kohlenhydratgruppen binden. Die Wechselwirkungen zwischen den Leukocyten und dem Endothel werden durch die Bindung der Selektine an fucosylierte 
Oligosaccharidliganden auf den vorüberziehenden Leukocyten ausgelöst. Die Bindung zwischen Selektinen und Leukocyten ist nicht stark genug, um den Scherkräften des Blutstromes Stand zu halten. Dadurch rollen die Zellen durch den ständigen Wechsel zwischen Bindung und Ablösung am Endothel entlang.

Die rollende Adhäsion ermöglicht allerdings eine festere Bindung der Leukocyten durch interzelluläre Adhäsionsmoleküle (ICAMs) des Endothels. Diese ICAMs verbinden sich mit den heterodimeren Integrinen der Leukocyten nach Aktivierung durch das Chemokin IL-8 Diese stabile Bindung beendet die Rollbewegung und es kann zur Extravasion, der Wanderung der Leukocyten aus den Blutgefäßen durch die Endothelzellen, kommen.

Für diesen Vorgang ebenso wie für die Migration entlang eines Chemokingradienten, sind adhäsive Wechselwirkungen zwischen Integrinen und dem immunglobulinähnlichen Adhäsionsmolekül CD31, welches sowohl auf den Leukocyten als auch an den Verbindungen zwischen den Endothelzellen exprimiert wird, nötig. Durch diese Interaktion gelangen die Zellen durch die Endothelschicht und durchqueren die Basalmembran mit Hilfe proteolytischer Enzyme, welche die Membran zerstören. Diese Wanderung durch die Gefäßwand wird auch als Diapedese bezeichnet. Anschließend wandern die Leukocyten entlang der Konzentrationsgradienten der von den Zellen am Infektionsherd ausgeschütteten Chemokine.

Die einzelne Schritte, die zur Extravasion der Leukocyten durch die Endothelzellen der Blutgefäße hin zu den Orten der Entzündung führen, werden in der folgenden Abbildung 6 gezeigt. 


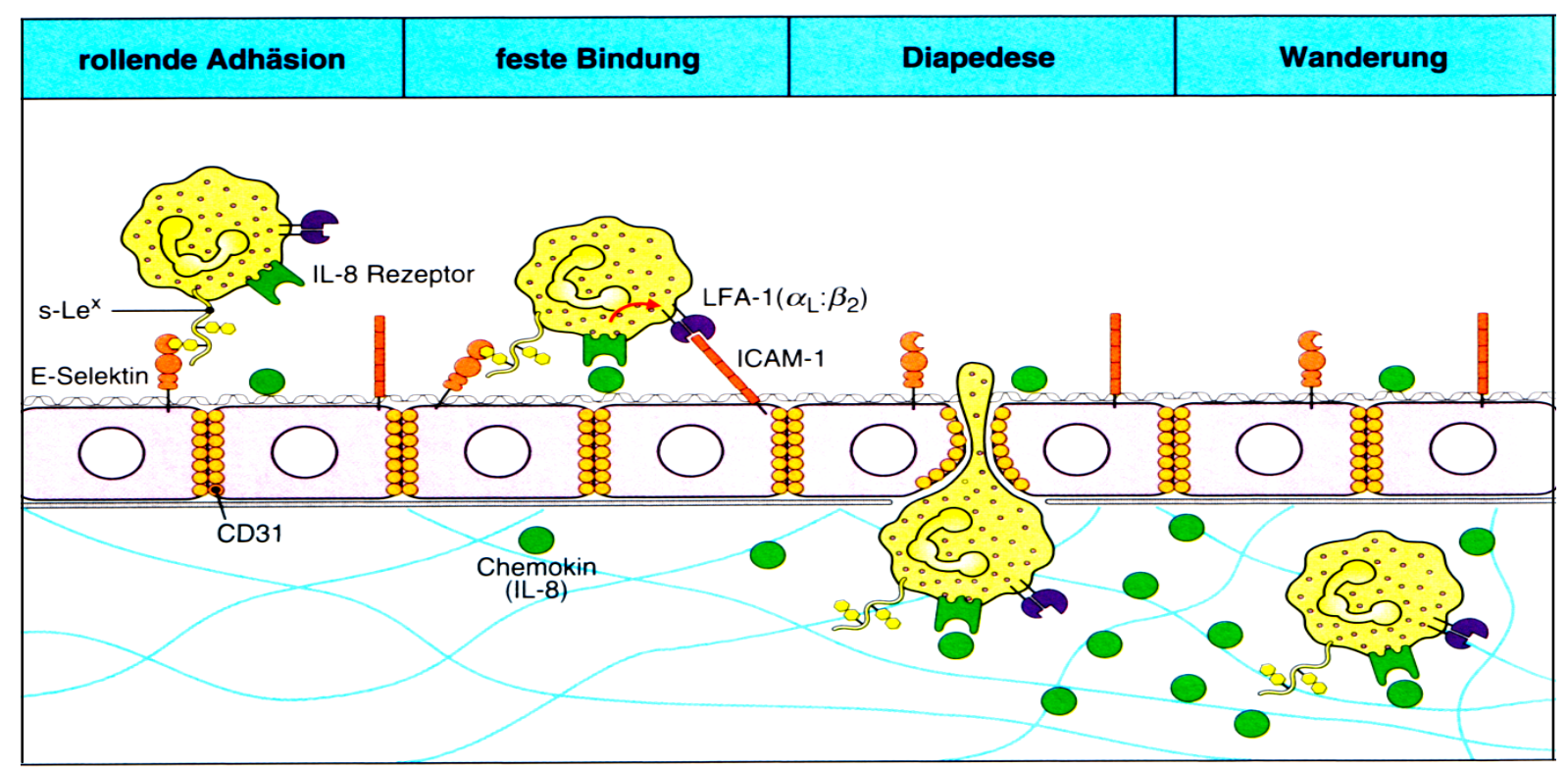

Abb. 6: Chemokin-vermittelte Migration von Leukocyten aus den Blutgefäßen durch Endothelzellen zum infizierten Gewebe. Rollende Adhäsion: durch schwache Bindung von s-Le ${ }^{x}$ (Sialyl-Lewis ${ }^{x}$-Rest) der Leukocyten an E-Selektine der Endothelzellen. Feste Bindung: die Verlangsamung der im Blutstrom fließenden Leukocyten ermöglicht stärkere Wechselwirkungen zwischen Endothel und Leukocyten durch die von IL-8 induzierte Aktivierung des ICAM-1 Rezeptors LFA (funktionelle Leukocytenantigene, Integrine) auf den Leukocyten. Diapedese: CD31-vermittelte Migration der Leukocyten durch die Endothelzellen sowie die Basalmembran. Wanderung: Migration der Leukocyten entlang eines Chemoingradienten zum Infekionsherd. Die Abbildung wurde von Janeway und Mitarbeitern entwickelt (Janeway et al., 2002).

\subsection{Ziel der Arbeit}

Die Erkenntnisse über die immunmodulatorischen Wirkungsweisen der Defensine sind, ungeachtet der anerkannten Bedeutung dieser Peptide für die Wirtsabwehr durch das angeborene Immunsystem, noch in ihren Anfängen. Widersprüchliche Ergebnisse in der Literatur bezüglich der chemotaktischen Wirkung von $\alpha$ - und $\beta$-Defensinen auf Monocyten und Makrophagen (Territo et al., 1989; Chertov et al., 1996; Yang et al., 2000), fehlende Kenntnisse über den oder die Rezeptoren, welche die Defensin-induzierte Chemotaxis auf den Zellen des Immunsystems vermitteln sowie erste Hinweise auf die Bedeutung der Defensine bei diversen Erkrankungen des gastrointestinalen Traktes und der Haut verdeutlichten die Notwendigkeit von detaillierten Untersuchungen des Defensin-Systems.

Das Ziel der vorliegenden Arbeit war es, den Einfluss der $\alpha$ - und $\beta$-Defensine auf Zellen des angeborenen und des erworbenen Immunsystems zu untersuchen. Es sollten 1. die primären Zielzellen der Defensin-vermittelten Immunmodulation identifiziert werden, 2. die Anzahl unterschiedlicher Defensin-Rezeptoren auf Immunzellen bestimmt werden und 3. die gegenseitigen Wechselwirkungen der Rezeptoren einschließlich der beteiligten Signaltrandsduktionswege aufgedeckt werden. 


\section{Material und Methoden}

\subsection{Materialien}

\subsubsection{Chemikalien}

Im Einzelnen wurden folgende Chemikalien von den angegebenen Quellen bezogen:

Agar

Agarose

Alkalische Phosphatase (CIP; 1Unit/ $\mu$ )

Ampicillin

Bactopepton

Blocking-Reagenz

Borsäure

Bradford-Reagenz (Roti Quant)

Bromphenolblau

Chloroform

Desoxynucleotidtriphosphate (dNTPs)

Dimethylsulfoxid (DMSO)

DNA-Längenstandard Ladder High Range

Ethanol

Ethidiumbromid-Stammlösung $(10 \mathrm{mg} / \mathrm{ml})$

Ethylendiamintetraessigsäure (EDTA)

Fötales Kälberserum (FCS)

G-418 Sulfat (Geneticin ${ }^{\circledR}$ )

L-Glutamin (100 x)

Glycerol

Indo-1

Iscove's Modified Dulbecco's Medium (IMDM)

Isoamylalkohol

Isopropanol
Difco (Detroit, USA)

Sigma (Deisenhofen, D)

Roche (Mannheim, D)

Sigma (Deisenhofen, D)

Invitrogen $\mathrm{GmbH}$ (Karlsruhe, D)

$\gamma$-Globulin, human, Cohn-

Fraktion II, III, Sigma

Roth (Karlsruhe, D)

Roth (Karlsruhe, D)

Sigma (Deisenhofen, D)

Roth (Karlsruhe, D)

Sigma (Deisenhofen, D)

Sigma (Deisenhofen, D)

MBI FERMENTAS GmbH

(St.-Leon-Rot, D)

Roth (Karlsruhe, D)

Roth (Karlsruhe, D)

Sigma (Deisenhofen, D)

Greiner (Frickenhausen, D)

Calbiochem (Bad Soden, D)

Invitrogen $\mathrm{GmbH}$ (Karlsruhe, D)

Sigma (Deisenhofen, D)

Invitrogen GmbH (Karlsruhe, D)

Cambrex (Taufkirchen, D)

Roth (Karlsruhe, D)

Roth (Karlsruhe, D) 
Kaliumdihydrogenphosphat

Kaliumchlorid

Lymphoprep $^{\mathrm{TM}}$

Natriumacetat

Natriumchlorid

Natriumdihydrogenphosphat

Natriumhydroxid

Penicillin-Streptomycin (10000 Units/ml)

Phenol

Pluronic F127

Propidiumjodid-Stammlösung $(1 \mathrm{mg} / \mathrm{ml})$

Rinderserumalbumin (BSA)

RPMI-1640

Saccharose

Salzsäure

T4-DNA-Ligase (400 Units/ $\mu$ l)

T4-DNA-Polymerase (3 Units/ $\mu 1$ )

Tris-Base

Trichostatin A

Trypanblau

Tween 20

Xylencyanol

Hefe Extrakt
Roth (Karlsruhe, D)

Roth (Karlsruhe, D)

Nycomed Pharmas (Oslo, N)

Roth (Karlsruhe, D)

Roth (Karlsruhe, D)

Riedel de Haen (Seelze, D)

Roth (Karlsruhe, D)

Invitrogen GmbH (Karlsruhe, D)

Roth (Karlsruhe, D)

Invitrogen, Karlsruhe

Sigma (Deisenhofen, D)

Biolabs (Frankfurt a.M., D)

Cambrex (Taufkirchen, D)

Roth (Karlsruhe, D)

Roth (Karlsruhe, D)

Invitrogen $\mathrm{GmbH}$ (Karlsruhe, D)

Invitrogen $\mathrm{GmbH}$ (Karlsruhe, D)

Roth (Karlsruhe, D)

Sigma (Deisenhoen, D)

Merck, Darmstadt

Sigma (Deisenhofen, D)

Sigma (Disenhofen, D)

Invitrogen (Karlsruhe, D)

\subsubsection{Verbrauchsmaterial}

Die verwendeten Verbrauchsmaterialien wurden im Einzelnen von den angegebenen Quellen bezogen:

Einmalküvetten für Bradford-Assay

Elektroporationsküvetten $(0,4 \mathrm{~cm})$ Gene Pulser ${ }^{\circledR}$ Cuvette

Eppendorf-Reaktionsgefäße (1,5 ml und $2 \mathrm{ml}$ Safe-Lock)

Falconröhrchen (steril, $15 \mathrm{ml}$ und $50 \mathrm{ml}$ )
Braun (Melsungen, D)

BIO RAD (München, D)

Eppendorf (Hamburg, D)

Sarstedt (Frickenhausen, D) 
FACS-Platten

FACS-Röhrchen $(5 \mathrm{ml}, 75$ x $12 \mathrm{~mm})$

Glaswolle

Glasgeräte

Glaspipetten

HTS Transwell ${ }^{\circledR}-24$ System (5, 8 und $12 \mu \mathrm{m}$ Poren);

Corning

Einmal-Injektionskanülen $(0,4$ x $20 \mathrm{~mm})$

MACS $^{\circledR}$ Separation Columns MS

Multi-Adapter

Neubauer-Zählkammer

Pasteurpipetten

PCR-Reaktionsgefäße (0,2 ml Safe-Lock)

Petrischalen (steril, $82 \mathrm{~mm}$ )

Einmal-Spritzen (steril, $10 \mathrm{ml}$ und $50 \mathrm{ml}$ )

Einmal-Sterilfilter $(0,2 \mu \mathrm{m} ; 0,45 \mu \mathrm{m})$

Zellkulturbedarf (96-well, 24-well Platten,

3, 5, 6 und 9cm Kulturschalen,

Einmal-Pipetten, Einfrierröhrchen, Spitzen etc.)
96 Rundbodenwells, Greiner,

(Nürtingen, D)

BD, (Erembodegem, B)

Merck (Darmstadt, D)

Schütt (Göttingen, D)

Schütt (Göttingen, D)

Beyer-Laborbed. (Düsseldorf, D)

Braun (Melsungen, D)

Miltenyi Biotec (Gladbach, D)

Sarstedt (Frickenhausen, D)

Braun (Melsungen, D)

Roth (Karlsruhe, D)

Eppendorf (Hamburg, D)

Greiner (Frickenhausen, D)

Braun (Melsungen, D)

Sarstedt (Frickenhausen, D)

Greiner (Frickenhausen, D)

\subsubsection{Lösungen und Puffer}

Ampicillinlösung

EDTA

FACS-Puffer

FACS-Fixierung
$500 \mathrm{mg}$ Ampicillin (Natriumsalz) in $10 \mathrm{ml}$ Aqua destillata gelöst, steril filtriert, aliquotiert, Lagerung bei $-20^{\circ} \mathrm{C}$.

0,5 M (14,6 g) EDTA, ad $100 \mathrm{ml}$ Aqua destillata, pH 8,0 mit $\mathrm{NaOH}$ eingestellt, autoklaviert.

$490 \mathrm{ml} \mathrm{PBS} ; 2,5 \mathrm{ml} 20 \% \mathrm{NaN}_{3}$ (Natriumacid); 7,5 ml FCS

PBS mit $1 \%$ Formalin 
G-418-Lösung

Krebs-Ringer-Lösung

Natriumacetat (3M)

PBS

Probenpuffer

Puromycinlösung

$10 \times$ TBE-Puffer

$10 \times \mathrm{TBS}$

TBS-Tween

1 M Tris-Base

Trypsin/EDTA

TE
$1 \mathrm{~g} \mathrm{G}-418$ in $10 \mathrm{ml}$ Aqua destillata gelöst, steril filtriert, aliquotiert, Lagerung bei $-20^{\circ} \mathrm{C}$.

$140 \mathrm{mM} \mathrm{NaCl}, 4 \mathrm{mM} \mathrm{KCl}, 1 \mathrm{mM} \mathrm{MgCl}_{2}, 10 \mathrm{mM}$ D-Glucose, $10 \mathrm{mM}$ HEPES (pH 7,0; Vermeidung des Ausfallens von $\mathrm{Ca}^{2+}$ ), $1 \mathrm{mM} \mathrm{CaCl}$, ad 11 Aqua destillata.

24,61 g Nartiumacetat, ad $100 \mathrm{ml}$ Aqua destillata , $\mathrm{pH} 4,8$ mit $\mathrm{HCl}$ einstellen.

$8 \mathrm{~g} \mathrm{NaCl}, 0,2 \mathrm{~g} \mathrm{KCl}, 1,44 \mathrm{~g} \mathrm{NaHPO}_{4}, 0,24 \mathrm{~g} \mathrm{~K} \mathrm{HPO}_{4}$, ad 11 Aqua destillata, $\mathrm{pH} 7,4$ mit $\mathrm{HCl}$ eingestellt, autoklaviert.

0,25\% Bromphenolblau, 0,25 \% Xylencyanol, $15 \%$ Glycerol, (Blaumarker) ad 10ml Aqua destillata.

$25 \mathrm{mg}$ Puromycin in $10 \mathrm{ml}$ Aqua destillata gelöst, steril filtriert, aliquotiert, Lagerung bei $-20^{\circ} \mathrm{C}$.

$108 \mathrm{~g}$ Tris-Base, $55 \mathrm{~g}$ Borsäure, $40 \mathrm{ml} \mathrm{0,5} \mathrm{M}$ EDTA $(\mathrm{pH} \mathrm{8,0)}$, ad 11 Aqua destillata, $\mathrm{pH} 8,0$ mit $\mathrm{HCl}$ eingestellt, autoklaviert

$24 \mathrm{~g}$ Tris, $80 \mathrm{~g} \mathrm{NaCl}$ ad 11 Aqua destillata, $\mathrm{pH}$ 7,6

$100 \mathrm{ml} 10 \mathrm{x}$ TBS, $1 \mathrm{ml}$ Tween 20 ad 11 Aqua destillata

121,1 g Tris-Base, ad 11 Aqua destillata, $\mathrm{pH} 8,6$

0,2 mM EDTA in PBS (autoklaviert), $0.025 \%$ Trypsin

10mM Tris/HCl pH 8,0, autoklaviert 


\subsubsection{Kits}

Es wurden folgende kommerziell erhältlichen Produkte verwendet:

$\mathrm{MACS}^{\circledR}$ murine $\mathrm{CD} 4^{+} \mathrm{T}$-cell isolation kit

$\mathrm{MACS}^{\circledR}$ human memory $\mathrm{CD} 4^{+} \mathrm{T}$-cell isolation kit

$\mathrm{MACS}^{\circledR}$ human naive $\mathrm{CD} 4^{+} \mathrm{T}$-cell isolation kit

Plasmid Midi und Maxi Kit

Qiaex II Gel Extraction Kit

Nucleo Bond ${ }^{\circledR}$ PC500 Kit AX
Miltenyi Biotec (Gladbach, D)

Miltenyi Biotec (Gladbach, D)

Miltenyi Biotec (Gladbach, D)

Qiagen (Hilden, D)

Qiagen (Hilden, D)

Machery \& Nagel (Düren, D)

\subsubsection{Geräte}

Autoklav

Bakterienschüttler Certomat BS-T, B.

Biophotometer

Brutschrank T6060

$\mathrm{CO}_{2}$-Inkubator

Durchflusscytometer

Durchflusscytometer zur $\mathrm{Ca}^{2+}$-Messung

Elektrophorese-Kammer Agagel Maxi

Elektroporator Gene Pulser II

Feinwaagen

Gefrierschrank $\left(-20^{\circ} \mathrm{C}\right)$

Gene Amp PCR-System 9600

Invertmikroskop

Kühlschrank

Laborschüttler UNIMAX 2010

Laborzentrifuge $400 \mathrm{R}$

Luminometer TD-20/20

Mastercycler-Gradient

Megafuge 1.0R

Lichtmikroskop
KSG GmbH (Olching, D)

Braun Biotech (Melsungen, D)

Eppendorf (Hamburg, D)

Heraeus (Hanau, D)

Heraeus (Hanau, D)

FACS Calibur BD (Heidelberg, D)

LSR BD (Heidelberg, D)

Biometra (Göttingen, D)

Bio Rad (München, D)

Sartorius (Göttingen, D)

Liebherr (, D)

Perkin Elmer (Boston, USA)

Axiovert 35, Zeiss (Jena, D)

Liebherr (, D)

Heidolph (Kehlheim, D)

Heraeus (Hanau, D)

Turner Designs (CA, USA)

Eppendorf (Hamburg, D)

Heraeus (Hanau, D)

Zeiss (Jena, D) 
Millipore H2O-Anlage Milli-Q plus

Mini Macs ${ }^{\circledR}$ Magnet \& Stand

Netzgerät Consort E844 Power Supply

Personal-Computer

pH-Meter PHM 63 Digital

Pipetman Pipetus-akku

Sterilbank Hera Safe

Stickstofftank Air Liquide

Thermoblock Dri-Block DB-3A

Tischzentrifuge Eppendorf 5415 D

Typ UNO 96

Ultratiefgefrierer $\left(-80^{\circ} \mathrm{C}\right)$

Ultrazentrifuge Sorvall Superspeed RC2-B

UV-Transluminator undVideosystem

Variofuge 3.0R

Vortex Genie $2^{\mathrm{TM}}$

Wasserbad
Millipore GmbH (Eschborn, D)

Miltenyi Biotec (Gladbach, D)

Braun (Melsungen, D)

LG

Radiometer (Kopenhagen, DK)

Hirschmann Laborgeräte (Eberstadt, D)

Heraeus (Hanau, D)

Kryotechnik GmbH (Düsseldorf, D)

Techne (Cambridge, GB)

Eppendorf (Hamburg, D)

Biometra (Göttingen, D)

Snijders (Tilburg, NL)

DuPont (Bad Homburg, D)

LTF Labortechnik (Wasserburg, D)

Heraeus (Hanau, D)

Bender \& Hobein AG (Zürich, CH)

Grant Science Services (München, D)

\subsubsection{Software}

Folgende Software wurde zumeist zur Verarbeitung der Daten verwendet:

Cellquest Pro (FACS-Analyse)

Flow Jo (Calcium-Messungen)

WinMDI (FACS-Auswertung)

Excel (Statistik, Diagramme)

Word (Textverarbeitung)
BD Heidelberg

BD Heidelberg

Microsoft Windows

Microsoft Windows

Microsoft Windows 


\subsubsection{Kulturmedien}

\subsubsection{Medien für Bakterien}

Die verwendeten Medien wurden mit destilliertem Wasser angesetzt und anschließend 20 Minuten bei $121^{\circ} \mathrm{C}$ autoklaviert. Die angegebenen Mengen gelten (wenn nicht anders angegeben) für einen Liter Medium.

LB (Luria-Bertani)-Medium $10 \mathrm{~g}$ Bactotrypton $(1 \%), 5 \mathrm{~g}$ Hefeextrakt $(0,5 \%) 10 \mathrm{~g}$ $\mathrm{NaCl}(1 \%)$, ad 1 Liter mit Aqua destillata, $\mathrm{pH} 7,0$.

Für das Gießen von Agar-Platten wurden dem Medium $15 \mathrm{~g}$ (1,5 \%ig) Agar zugegeben. Im Anschluss an das Autoklavieren wurden eventuell zuzusetzende Antibiotika (100 $\mu \mathrm{g} / \mathrm{ml})$ nach Abkühlung des Mediums auf etwa $50^{\circ} \mathrm{C}$ hinzugefügt.

SOB-Medium

5 g Trypton (2 \%ig), 1,25 g Hefeextrakt (0,5\%ig), $146 \mathrm{mg} \mathrm{NaCl}(10 \mathrm{mM}) 47 \mathrm{mg} \mathrm{KCl},(2,5 \mathrm{mM}) 508 \mathrm{mg}$ $\mathrm{MgCl}_{2}$ × $6 \mathrm{H}_{2} \mathrm{O}$, (10 mM) $516 \mathrm{mg} \mathrm{MgSO}_{4} \times 7 \mathrm{H}_{2} \mathrm{O}$ (10 mM), ad 0,25 1 Aqua destillata, $\mathrm{pH}$ 7,0, autoklaviert.

\subsection{Cytokine, Chemokine, Defensine}

rhuC5a

rhuC3a

rhuGM-CSF

huCCL-3; muCCL-3 (MIP1 $\alpha$ )

huCCL19; muCCL19 (MIP3ß)

huCCL20; muCCL20 (MIP3 $\alpha$ )

rhuIL-4

rmuGM-CSF

rmuM-CSF

rmuIL-3

rmuIL-4
Abt. für Immunologie, Universität Göttingen

Abt. für Immunologie, Universität Göttingen

Immunotools

Pepro Tech Inc Tebu, USA

Pepro Tech Inc Tebu, USA

Pepro Tech Inc Tebu, USA

Immunotools

Pepro Tech Inc Tebu, USA

Pepro Tech Inc Tebu, USA

Pepro Tech Inc Tebu, USA

Pepro Tech Inc Tebu, USA 
GM-CSF (Granulocyten/Makrophagen-Kolonie stimulierender Faktor) ist ein Protein, welches von Makrophagen, T-Lymphocyten, Mastzellen, Endothelzellen und Fibroblasten sekretiert wird. Dieses Cytokin dient als Wachstumsfaktor für Leukocyten und stimuliert hämatopoetische Stammzellen zur Proliferation zu Granulocyten (Neutrophile, Eosinophile, Basophile) und Monocyten. Die Monocyten verlassen das Kreislaufsystem und wandern in das Gewebe ein. Dort reifen sie schließlich zu Makrophagen heran.

M-CSF (Makrophagen-Kolonie stimulierender Faktor) wird von Makrophagen und dendritischen Zellen synthetisiert und bewirkt die Proliferation und Differenzierung von hämatopoetischen Zellen zu Makrophagen.

IL-3 (Interleukin-3) ist ein Cytokin, welches die Proliferation von pluripotenten hämatopoetischen Vorläuferzellen stimulieren kann. Es wird von aktivierten T-Lymphocyten sekretiert, um das Wachstum sowie die Differenzierung von T-Zellen im Knochenmark anzuregen. Durch gemeinsame Wirkung von IL-3 und SCF wird zudem die Entwicklung der myeloischen Stammzellen zu Mastzellen erreicht.

SCF (Stammzellfaktor) wird von Fibroblasten, Hepatocyten, Keratinocyten, Endothelzellen, Langerhans-Zellen, Thymus-Stromazellen, Knochenmark-Stromazellen, und Mastzellen produziert. Nur wenige Zellen, in der Haut nur Mastzellen und Melanocyten, besitzen einen Rezeptor für SCF, der dem c-Kit, einem Produkt eines Protoonkogens entspricht. Die Funktionen des SCF beinhalten u. a. das Wachstum sowie das Überleben der einzelnen Zielzellen durch eine Inhibierung der Apoptose. In vivo wird außerdem durch eine PräInkubation mit SCF eine erhöhte IgE-vermittelte Histamin- und Serotoninfreisetzung beobachtet. Bei Melanocyten kommt es zu vermehrter Melaninsynthese.

\section{Verwendete Defensine:}

HBD-1 bis -4

HBD-2

mBD-8

HNP-1; HNP-3; HD-5

HNP-1
Pepro Tech Inc Tebu, USA

zusätzlich Bachem, D; Pepta Nova, D

Pepro Tech Inc Tebu, USA

Pepta Nova, D

zusätzlich Bachem, D; Pepro Tech, USA 


\subsection{Zellbiologische Methoden}

\subsubsection{Bestimmung der Zellzahl und Zellvitalität}

Die Zellzahlbestimmung erfolgt in einer Neubauer-Zählkammer. Dazu werden $10 \mu \mathrm{l}$ der Zellsuspension zur Zellvitalitätsbestimmung mit gleichem Volumen Trypanblau versetzt und unter dem Phasenkontrastmikroskop ausgezählt.

Der Azofarbstoff Trypanblau wird verwendet, um den Anteil vitaler Zellen nach einer Aufreinigung, Ernte oder einer ähnlich traumatisierenden Prozedur zu bestimmen. Tote Zellen weisen eine veränderte Membrandurchlässigkeit auf. Trypanblau kann deshalb ungehindert eindringen und färbt tote Zellen umgehend blau. Diese sind dadurch im lichtmikroskopischen Bild von den hell erscheinenden, vitalen Zellen sehr gut zu unterscheiden. Die Zählung sollte innerhalb von 2 bis 3 Minuten nach Anfärbung erfolgen, da auch lebende Zellen nach einiger Zeit den Farbstoff aufnehmen.

\subsubsection{Kryokonservierung vitaler Zellen}

Die meisten Zellarten können unter weitgehender Erhaltung ihrer Vitalität kryokonserviert werden. Als Einfriermedium dient hierzu FCS mit einem Anteil von 10 \% DMSO. Das DMSO verringert die Bildung von Eiskristallen, welche zur Membranperforation der Zellen führen würden. Auf Grund des cytotoxischen Effektes des DMSO muss zügig mit vorgekühlten Reagenzien auf Eis gearbeitet werden.

Generell sollten maximal $1 \times 10^{7}$ Zellen pro ml Einfriermedium eingefroren werden. Nach erfolgter Zellzahlbestimmung erfolgt eine Zentrifugation der Zellen bei $300 \mathrm{x}$ g für 8 min in der Kühlzentrifuge. Anschließend wird der Überstand abgesaugt, das Pellet in der benötigten Menge Einfriermedium gelöst und in Kryoröhrchen aliquotiert. Die Kryoröhrchen werden zunächst in Styroporbehältern (dies gewährleistet eine Einfrierkinetik von ca. $1^{\circ} \mathrm{C}$ pro min) bei $-80^{\circ} \mathrm{C}$ eingefroren und später in flüssigen Stickstoff $\left(-196^{\circ} \mathrm{C}\right)$ überführt. Hier lassen sich die Zellen über mehrere Jahre unter geringem Vitalitätsverlust lagern. 


\subsubsection{Auftauen von Zellen}

Zunächst wurden die Zellen im Wasserbad bei $37^{\circ} \mathrm{C}$ zügig aufgetaut. Der Inhalt der Kryoröhrchen wurde dann über 5 min mit einer Pasteurpipette langsam in $10 \mathrm{ml}$ Medium (jeweils das Kultivierungsmedium des Zelltyps) getropft, da die Vitalität der Zellen bei langsamer Verdünnung des DMSO deutlich höher ist. Im Anschluss erfolgte eine Zentrifugation bei $300 \mathrm{~g}$ und $20^{\circ} \mathrm{C}$ für $8 \mathrm{~min}$. Nach Absaugen des Überstandes wurde das Zellpellet in $10 \mathrm{ml}$ Medium resuspendiert und auf eine Kulturschale gegeben.

\subsubsection{Mykoplasmentest}

Alle Zelllinien wurden in regelmäßigen Abständen auf Mykoplasmen untersucht, um eine Beeinflussung der Versuchsergebnisse ausschließen zu können. Mykoplasmen sind die kleinsten selbstständig vermehrungsfähigen Prokaryonten und leben auf eukaryotischen Zellen als Membranparasiten. Hierdurch können sowohl die Proliferation als auch das Sekretions- und Wanderungsverhalten der Zellen stark beeinträchtigt werden.

Der Nachweis der Parasiten erfolgte durch die Färbung der Mykoplasmen-DNA in den infizierten Zellen mit Hilfe des spezifischen Fluoreszenzfarbstoffes DAPI (4-Diamino-2Phenylindol-di-hydrochlorid). Hierzu wurden die zu untersuchenden Zellen in ObjektträgerKulturkammern (Flexiperm) ausgesät. Nach Absaugen des Mediums wurden die Zellen einmal mit PBS gewaschen. Anschließend erfolgte eine Inkubation der Zellen mit $200 \mu 1$ DAPI-Gebrauchslösung (1 mg DAPI in 10ml PBS entspricht der Stammlösung; Gebrauchslösung= Stammlösung 1:100 mit Methanol verdünnt) bei RT für 15 min. Die Objektträger wurden daraufhin unter fließendem Wasser gespült und unter dem Fluoreszenzmikroskop analysiert. Bei einer Infektion ließ sich eine starke grüne Fluoreszenz am Zellkern erkennen. Die Mykoplasmen waren als einzelne kleine Punkte bzw. Linien am Cytoplasmasaum zu erkennen. 


\subsubsection{Mausstämme}

Balb/C: Knochenmarkaufreinigung zur Generierung von murinen Mastzellen, Makrophagen und dendritischen Zellen (DC) sowie in vivo Wanderungsversuche mit PKH-26 gefärbten Balb/C Zellen

SCID (CB-17 beider Geschlechter; Gewicht: 19-24 g; Charles River (Sulzfeld, D): in vivo Wanderungsversuche

Narkose: Hostaket, Intervet Rompun, Bayer, Leverkusen

\subsubsection{Kultivierung von murinen Zellen}

\subsubsection{Gewinnung von murinen hämatopoetischen Stammzellen aus Knochenmark}

Balb/C Mäuse wurden durch den Einsatz von $\mathrm{CO}_{2}$ getötet, und die Oberschenkel- und Schienbeinknochen der Hinterläufe unter sterilen Bedingungen frei präpariert, von Muskeln und Sehnen befreit und in PBS überführt. Die Knochenenden wurden angeschnitten, das Knochenmark mittels PBS-gefüllter Spritze in eine Petrischale ausgespült und die Suspension auf ein Sieb gegeben, um die restlichen Knochenstückchen und Gewebereste zu entfernen. Die gefilterte, mit Knochenmarkszellen angereicherte PBS-Lösung wurde resuspendiert, in ein Röhrchen überführt und für 10 min bei 300 x g ohne Bremse zentrifugiert. Nach dem Verwerfen des Überstandes wurde das Pellet in $5 \mathrm{ml}$ Erythrocyten-Lysepuffer aufgenommen und 5 min bei $37^{\circ} \mathrm{C}$ inkubiert. Im Anschluss an die Erythroctenlyse wurde das Röhrchen mit PBS aufgefüllt, zentrifugiert, der Überstand abgesaugt, in $10 \mathrm{ml}$ Medium resuspendiert und auf eine 10-ml-TC-Schale überführt.

Nun erfolgte eine Inkubation von $2 \mathrm{~h}$ im Brutschrank, in der sich die adhärenten Zellen am Boden der TC-Schale anheften konnten. Danach wurde der Überstand mit den Suspensionszellen abgenommen, in ein neues Falconröhrchen überführt, die Schale einmal vorsichtig mit PBS gespült und ebenfalls in das Falconröhrchen überführt. Der Überstand enthielt die nicht adhärenten Zellen, zu denen auch die hämatopoetischen Stammzellen gehören. Nach der Ermittlung der Zellzahl und dem Zentrifugieren der Suspension, wurden

$5 \times 10^{5}$ Zellen in $1 \mathrm{ml}$ Medium aufgenommen. Diese Zellen konnten nun, wie folgend 
beschrieben, mittels unterschiedlicher Cytokinzusätze zu Makrophagen, dendritischen Zellen (DC) oder Mastzellen differenziert werden.

\subsection{Generierung und Kultivierung von murinen Monocyten}

Die aus dem Knochenmark gewonnenen Zellen werden in entsprechendem Medium aufgenommen und nun jeweils zu einem Milliliter pro Napf auf 24well-Platten ausplattiert. Für die Generierung von DCs wurden $100 \mathrm{U} / \mathrm{ml}$ muGM CSF sowie $100 \mathrm{U} / \mathrm{ml}$ muIL-4 zugefügt.

Die Entwicklung zu Makrophagen wurde durch Zugabe von 100 U/ml muM-CSF erreicht. Nach zwei Tagen wurden aus jedem Napf vorsichtig $500 \mu 1$ Medium entnommen, verworfen und durch neues Medium inklusive Cytokinen ersetzt. Nach weiteren drei Tagen erfolgte die Ernte der nicht adhärenten Zellen der muGM-CSF haltigen Kulturen durch Poolen und Spülen der 24well-Platten mit PBS. Nach der Zellzahlbestimmung wurde 5 min bei $300 \mathrm{x}$ g ohne Bremse zentrifugiert, der Überstand abgesaugt, die Zellen mit Medium auf $5 \times 10^{5}$ pro ml eingestellt und die Suspension zu je $3 \mathrm{ml}$ pro well auf 6well-Platten ausplattiert. Nach weiteren zwei Tagen wurden die Zellen durch Abnahme der Überstände und vorsichtiges Spülen der Näpfe gewonnen. Bei muM CSF-haltigen Kulturen wurden am dritten und fünften Tag pro well $500 \mu 1$ verworfen und durch frisches Medium mit Cytokinen ersetzt. Die Ernte erfolgte am siebten Tag, indem die Kulturen $30 \mathrm{~min}$ auf Eis gestellt und anschließend mit PBS abgespült wurden.

\subsection{Generierung und Kultivierung von murinen Mastzellen}

Zur Gewinnung von murinen Mastzellen wurden die Knochenmarkszellen auf eine 6wellPlatte ausplattiert und dem Medium jeweils $200 \mathrm{U} / \mathrm{ml}$ mIl-3 und muSCF zugegeben. Nach einer Woche wurde die Zellzahl bestimmt und bei starker Proliferation eine Umsetzung auf eine größere Platten-Anzahl vorgenommen. Durch das regelmäßige Umsetzen konnten die adhärenten Makrophagen entfernt werden. Je nach Bedarf wurde 1-2 mal pro Woche frisches Medium mit Cytokinen zugefügt. Die vollständige Ausreifung der Mastzellen ist nach etwa 4 Wochen erreicht. $\mathrm{Zu}$ diesem Zeitpunkt sind über $95 \%$ der Zellen zu Mastzellen 
differenziert, was sowohl morphologisch als auch durch die Expression von CD117 (Mastzell-Marker) festgestellt werden konnte.

\subsubsection{Gewinnung von murinen Lymphocyten aus der Milz}

Im Thymus werden Prä-T-Lymphocyten in T-Lymphocyten umgewandelt. Nach der Ausbildung eines umfangreichen Reservoirs an gegen spezifische Antigene gerichteten T-Lymphocyten ist der Thymus somit als primäres lymphatisches Organ nicht mehr notwendig, denn die Vermehrung der einzelnen T-Lymphozyten-Klone erfolgt, falls entsprechende Antigene in den Körper gelangen, in den T-Lymphocyten-Regionen der sekundären lymphatischen Organe. Zu diesen sekundären lymphatischen Organen zählt neben den Lymphknoten auch die Milz. Daher wurden für die Aufreinigung von murinen T-Lymphocyten Milzzellsuspensionen verwendet.

Die Maus wurde hierzu mit $\mathrm{CO}_{2}$ getötet. Nach der Durchtrennung der Haut sowie Eröffnung des linken Brustkorbbereichs unter sterilen Bedingungen wurde die rote Milz freipräpariert und in eine mit PBS gefüllte Petrischale überführt. Im Anschluss wurde ein Schnitt in die bindegewebige Kapsel der Milz gesetzt und an dieser Stelle eine PBS-gefüllte Spritze eingestochen. Die Milz wurde gespült, bis sie hell wurde. Anschließend wurde die Zellsuspension bei 600 x g für 10 min zentrifugiert. Die in der Milzzellsuspension enthaltenen Erythrocyten wurden, wie bereits in 2.2.6.1 beschrieben, lysiert und abzentrifugiert.

Nun konnte die Aufreinigung der vornehmlich aus B- und T-Lymphocyten bestehenden Milzzellen erfolgen (s. 2.2.9.2)

\subsubsection{Kultivierung von Zellen}

\subsubsection{Kultivierung von RBL-2H3-Zellen}

Die adhärenten, Fibroblasten-ähnlichen RBL-2H3 (Ratten basophile Leukämie) -Zellen wurden in 10\%-igem FCS-RPMI 1640 Medium mit $1000 \mathrm{U} / \mathrm{ml}$ Penicillin-Streptomycin kultiviert. Für die Kultivierung stabiler Einzelzellklone der Zelllinie wurde dem Medium nach der Transfektion $600 \mu \mathrm{g} / \mathrm{ml}$ G418 zugegeben. Die generierten Klone wurden während der ganzen Zeit ihres Gebrauchs in G418-haltigem Selektionsmedium gehalten. 
Zum Trypsinieren und Ernten der Zellen wurde das Medium zunächst von den Kulturschalen abgesaugt und diese dann zweimal mit PBS gewaschen. Es folgte die Überschichtung mit Trypsin/EDTA und eine Inkubation der Zellen bei $37^{\circ} \mathrm{C}$ für $5 \mathrm{~min}$ im Zellinkubator. Nach Ablösung der Zellen wurden diese in Kulturmedium aufgenommen und in dem jeweils gewünschten Verhältnis neu ausplattiert. Sollte die Zellzahl genau ermittelt werden, so wurden die Zellen in der Neubauer-Kammer ausgezählt und die Zellzahl mit folgender Formel berechnet:

Zellzahl x $10^{4}$ x Verdünnungsfaktor $=$ Zellzahl $/ \mathrm{ml}$ Medium

Die RBL-2H3-Zelllinie wurde für die stabile Transfektion des humanen CCR6-Rezeptors sowie des humanen FPRL-2-Rezeptors eingesetzt. Beide Transfektanten wurden für die in vitro Chemotaxis sowie zur Analyse der intrazellulären Calciumionen-Freisetzung eingesetzt.

\subsubsection{Kultivierung von HMC-1 Zellen}

Die HMC-1 Zelllinie stammt von einem Patienten mit Mastzell-Leukämie. Nachweislich verfügt diese Zelllinie ebenso wie die humanen Mastzellen in ihren Granula über Histamin, Tryptase und Chloracetatesterase, lässt sich mit Toluidinblau schwach färben, besitzt aber keinen funktionellen, hochaffinen IgE-Rezeptor (Butterfield et al. 1988, Hamann et al., 1994; Nilsson et al., 1994a). Zwei Punktmutationen im c-kit proto-Onkogen bewirken dessen konstitutive Phosphorylierung und eine damit verbundene Autoaktivierung. Aufgrund dessen proliferieren HMC-1 Zellen in Kultur ohne rhSCF-Zusatz (Furitsu et al., 1993). Obwohl HMC-1 Zellen nicht alle typischen Mastzellcharakteristika aufweisen, besitzen sie dennoch eine große Ähnlichkeit zu humanen Mastzellen und sind ein hervorragendes Modell für die Mastzellforschung (Agis et al., 1996).

Die humane Mastzelllinie HMC-1 wurde in 10 \%igem FCS-IMDM Medium mit 1000 U/ml Penicillin-Streptomycin in Gewebekulturflaschen .kultiviert. Da diese Zelllinie zur Bildung von Zellaggregaten neigt, war es nötig, die Zellen vor der experimentellen Verwendung sorgfältig zu resuspendieren. HMC-1 Zellen wurden in dieser Arbeit für in vitro ChemotaxisVersuche (s. 2.2.12.1) sowie für die Messung intrazellulärer Calciumionen Freisetzung (s. 2.2.11) verwendet. 


\subsubsection{Kultivierung der murinen Zellinie J774 A.1}

J774 A.1 ist eine aus einem Tumor der Balb/C-Maus isolierte Makrophagen-Zelllinie. Die adhärenten Zellen wurden in 10 \%igem FCS-RPMI 1640 Medium mit 1000 U/ml PenicillinStreptomycin kultiviert und für die in vitro Chemotaxis eingesetzt.

\subsubsection{Leukocytenapherese-Aufarbeitung}

Die Leukocytenapherese ist eine Methode zur Gewinnung eines Leukocytenkonzentrates aus Spenderblut. Andere Blutbestandteile, wie Plasma und Erythrocyten, werden dem Spender bei der Blutabgabe größtenteils wieder zugeführt. Die Aufarbeitung der Leukocytenapherese mittels einer Dichtegradientenzentrifugation über Lymphoprep $^{\mathrm{TM}}$, einem ficollhaltigen Präparat $(5,6 \% \mathrm{w} / \mathrm{v})$, erlaubt die Gewinnung von humanen mononukleären Leukocyten des peripheren Blutes (PBMNL). Die PBMNL enthalten 60-80 \% T-Lymphocyten, bestehend aus $\mathrm{CD}^{+}{ }^{+}$T-Helfer- sowie $\mathrm{CD}^{+}$cytotoxischen T-Zellen, 8-15 \% B-Lymphocyten, 10-20\% Monocyten (mononukleäre Phagocyten) und 5-12 \% NK-Zellen. Ferner enthält das Blut noch einen geringen Anteil Erythrocyten, Granulocyten und DCs.

Das verwendete Ficoll ist eine kolloidale Lösung aus Methylcellulose. Diese gewährleistet die Aggregation der noch enthaltenen Erythrocyten. Die Oberflächen der Erythrocyten sind stark negativ geladen und stoßen sich gegenseitig ab. Diese physiologisch notwendigen Abstoßungskräfte werden von Ficoll abgeschwächt. Somit wird die Sedimentation der Erythrozyten erleichtert. In Lymphoprep ${ }^{\mathrm{TM}}$ befindet sich außer Ficoll auch Natriummetrizoat $(9,6 \% \mathrm{w} / \mathrm{v})$. Diese Verbindung mit hoher Dichte gestattet die Auftrennung der einzelnen Zellarten in Abhängigkeit ihrer jeweiligen spezifischen Dichte.

In der Dichtegradientenzentrifugation sedimentieren die Zellen größerer Dichte (Erythrocyten und Granulocyten) im Schwerefeld der Zentrifuge, während die Zellen geringerer Dichte (Lymphocyten und Monocyten) in der Interphase zwischen Blut und Trennmedium verbleiben. Die Interphase enthält also die mononukleären Zellen sowie einige Thrombocyten, welche in diversen Waschschritten entfernt werden.

Die nach der Dichtegradientenzentrifugation erhaltenen Phasen sind in Abbildung 7 graphisch dargestellt. 


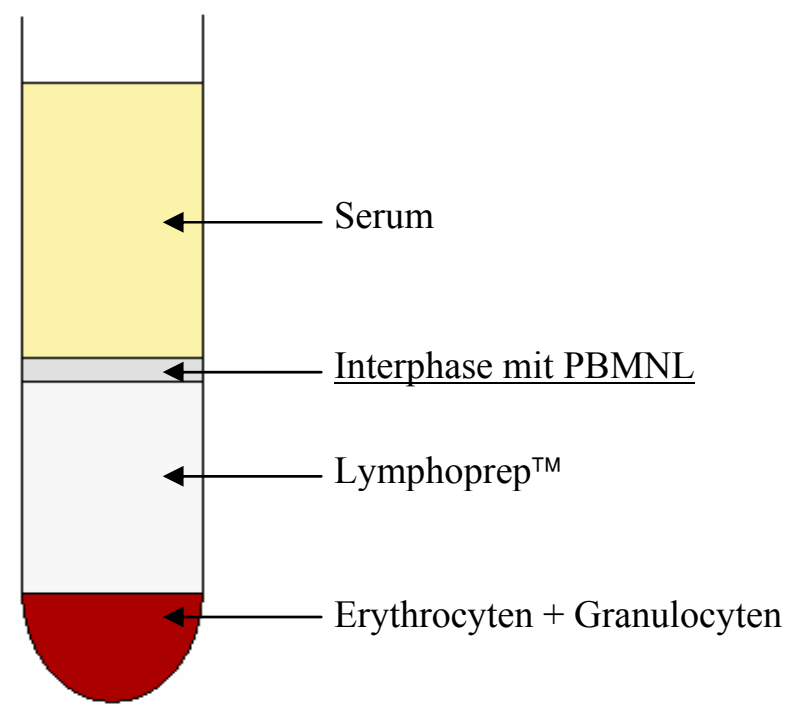

Abb. 7: Auftrennung des humanen Blutes nach Dichtegradientenzentrifugation. $\mathrm{PBMNL}=$ monomukleäre Leukocyten des peripheren Blutes.

Das Leukocytenkonzentrat wurde in eine sterile Flasche überführt und im Verhältnis 1:1 mit PBS (RT) vermischt. Jeweils $15 \mathrm{ml}$ Lymphoprep ${ }^{\mathrm{TM}}$ wurden in mehrere 50 ml-Röhrchen vorgelegt und anschließend je $25 \mathrm{ml}$ des verdünnten Blutes vorsichtig aufgeschichtet. Nach der Zentrifugation (20 min bei RT und $1000 \mathrm{~g}$ ohne Bremse) wurde der gelbliche Überstand abgesaugt und die daran angrenzende trüb-weiße Interphase (sie enthält die PBMNL) abgenommen und in auf Eis vorgekühlte 50ml-Röhrchen überführt. Diese wurden mit vorgekühltem PBS bis auf $50 \mathrm{ml}$ aufgefüllt und bei $4^{\circ} \mathrm{C}$ und $1000 \mathrm{x}$ g ohne Bremse für $10 \mathrm{~min}$ zentrifugiert. Im Anschluss wurden die Überstände abgesaugt, die Zellpellets in 5 bis $10 \mathrm{ml}$ kaltem PBS resuspendiert, die Röhrchen aufgefüllt und anschließend bei $400 \mathrm{x} g$ und $4^{\circ} \mathrm{C}$ für 5 min mit Bremse zentrifugiert. Dieser Waschschritt wurde solange wiederholt, bis die Überstände makroskopisch klar waren und bei der mikroskopischen Untersuchung keine Thrombocyten $\mathrm{zu}$ erkennen waren. Nach Beendigung des Waschvorganges wurde die Gesamtzellzahl in einer Zählkammer nach Neubauer bestimmt.

Zur Gewinnung von autologem Serum für die anschließende Kultivierung der Zellen wurden die der Leukocytenapherese beigegebenen Serummonovetten bei $1700 \mathrm{x} g$ und RT für $10 \mathrm{~min}$ ohne Bremse zentrifugiert. Die Überstände (Serum) wurden in ein Spitzröhrchen überführt und die Serummonovetten mit dem verbleibenden Blutkuchen verworfen. 


\subsubsection{Gewinnung und Kultivierung von Monocyten und Makrophagen aus PBMNL}

Die Adhärenz von Monocyten ist auf speziellen Kunststoffoberflächen möglich und kann auf diesem Wege für die Gewinnung dieser Zellen ausgenutzt werden. Die Fähigkeit zur Adhärenz verlieren die Monocyten während der Kultivierung relativ schnell, wenn sie durch Zugabe von GM-CSF und IL-4 zu DC ausdifferenzieren. Dieser Verlust der Adhärenzfähigkeit ist demzufolge reifungsabhängig (Bjerke, Gaudernack, 1985). Lediglich die Makrophagen, welche ausschließlich mit GM-CSF behandelt wurden, bleiben adhärent. Die durch die Leukocytenapherese-Aufarbeitung gewonnenen Zellen wurden in Abhängigkeit der nachfolgenden Versuche auf verschiedenen Zellkulturschalen und in unterschiedlicher Zahl ausplattiert:

TC-Schale $1 \mathrm{ml}: \quad 1,0 \times 10^{7}$ Zellen

TC-Schale $5 \mathrm{ml}: \quad 2,5 \times 10^{7}$ Zellen

TC-Schale $10 \mathrm{ml}: \quad 5,0 \times 10^{7}$ Zellen

TC-Schale $15 \mathrm{ml}: \quad 1,0 \times 10^{8}$ Zellen

Die gewünschte Zellzahl der gewonnenen PBMNL wurde in Adhärenzmedium (RPMI 1640; $5 \%$ autologes Serum; $100 \mathrm{IU} / \mathrm{ml}$ Penicillin; $100 \mu \mathrm{g} / \mathrm{ml}$ Streptomycin) suspendiert und auf TC-Schalen verteilt. Anschließend inkubierten die Kulturen eine Stunde im Brutschrank $\left(37^{\circ} \mathrm{C}, 5 \% \mathrm{CO}_{2}\right)$, um die Monocyten adhärieren zu lassen.

Für die Gewinnung von MoDC wurden die Überstände, welche die nicht adhärenten Lymphocyten enthielten, hiernach abgesaugt und die TC-Schalen wenige Male vorsichtig mit warmem PBS abgespült, um die restlichen Lymphocyten zu entfernen. Im Anschluss erfolgte die Zugabe von $37^{\circ} \mathrm{C}$ warmem Kulturmedium sowie der Cytokine GM-CSF (100 U/ml) und IL-4 (300 U/ml). In Abhängigkeit der Ansätze und der Dauer der Kultivierung wurde den Zellen am dritten und fünften Tag neues Medium zugeführt. Hierfür wurde die Hälfte des Mediums entnommen, zentrifugiert, der Überstand abgesaugt und durch neues Kulturmedium und entsprechende Cytokinmengen ersetzt. Nach einer Woche exprimierten die Zellen die für DC charakteristischen Marker HLA-DR, jedoch kein CD14. Die moderate Expression von CD86 sowie eine geringe CD83 Expression sprach dafür, dass es sich hierbei um unreife DC handelte (Soruri et al., 2003).

Um Makrophagen aus den PBMNL zu generieren, wurden die nicht adhärenten Lymphocyten nach der Adhärenz durch vorsichtiges Spülen der TC-Schalen mit warmem PBS entfernt. Die Zellen wurden mit GM-CSF-haltigem Medium (100 U/ml) zwei bis drei Tage kultiviert und 
zeigten dann die typische hohe Expression des Makrophagenmarkers CD14 ${ }^{+}$sowie moderate bzw. geringe Expression von HLA-DR.

\subsubsection{Gewinnung und Kultivierung von Granulocyten aus Vollblut}

Für die Gewinnung von Granulocyten wurden $100 \mathrm{ml}$ Vollblut ohne vorherige Leukocytenapherese 1:1 mit PBS verdünnt und wie unter 2.2.8 für die PBMNL-Aufreinigung beschrieben auf $15 \mathrm{ml}$ Lymphoprep $^{\mathrm{TM}}$ aufgeschichtet. Nach erfolgter Dichtegradientenzentrifugation wurden nun das Plasma, die Interphase sowie das Trennmedium bis auf die sedimentierten Erythrocyten und Granulocyten abgesaugt. Das Pellet wurde zur Erythroctenlyse in $5 \mathrm{ml}$ Erythrocytenlysispuffer aufgenommen und $5 \mathrm{~min}$ bei $37^{\circ} \mathrm{C}$ inkubiert. Im Anschluss erfolgten mehrere Waschschritte (1200 rpm, RT) mit PBS, um die Erythrocytenreste möglicht komplett $\mathrm{zu}$ entfernen. Anschließend wurde die Zellzahl bestimmt und die Reinheit der Granulocyten mittels FACS analysiert. Hierzu wurden die Zellen mit anti-P12/1-FITC sowie anti-HLA-DR-PE gefärbt. Der C5aR-Antikörper P12/1 diente dabei als Positivkontrolle, wohingegen der MHC-Klasse-II-Antikörper HLA-DR-PE als negative Kontrolle diente, da Granulocyten nur MHC-Klasse-I exprimieren.

\subsubsection{Zellaufreinigung mittels Magnetischer Zell-Sortierung $\left(\mathrm{MACS}^{\circledR}\right)$}

\subsubsection{Aufreinigung von humanen T-Lymphocyten-Fraktionen aus PBMNL}

Zur Isolierung von humanen T-Lymphocyten aus PBMNL wurden zunächst Blutzellen aus einer Leukocytenapherese mittels Ficoll-Dichtegradienten soweit aufgereinigt, dass ausschließlich die mononukleären Zellen erhalten blieben (s. 2.2.8 LeukocytenaphareseAufreinigung). Im Anschluss wurden die Gedächtnis bzw. naiven T-Lymphocyten mit Hilfe des jeweiligen Aufreinigungskits der Firma Miltenyi Biotec durch negative Selektion aus der heterogenen Zellsuspension separiert. Die negative Selektion erfolgte durch einen Cocktail aus Biotin-konjugierten monoklonalen Antikörpern, welche die unerwünschten Zellpopulationen markieren. Durch die darauffolgende Inkubation mit Anti-BiotinMicroBeads konnten nun die so markierten Zellen im Magnetfeld zurückgehalten werden, während die nicht markierten, aufzureinigenden Zellen das Magnetfeld passierten. 
Alle Arbeitsschritte sind zügig durchzuführen und die Zellen sowie verwendete Lösungen sollten kühl gelagert sein. Hierdurch können unspezifische Zellmarkierungen vermieden werden.

\section{Magnetische Markierung}

1. Bestimmung der Zellzahl

2. Zentrifugation der Zellsuspension (PBMNL) bei $300 \mathrm{x}$ g für $10 \mathrm{~min}$. Verwerfen des Überstandes.

3. Zellpellet in $40 \mu 1$ Puffer pro $10^{7}$ Zellen resuspendieren.

4. $10 \mu \mathrm{l}$ des Biotin-Antikörper-Cocktails zu den Zellen geben

5. Gut mischen und $30-40$ min bei $4-8^{\circ} \mathrm{C}$ und unter vorsichtigem Schwenken inkubieren

6. $30 \mu 1$ Puffer pro $10^{7}$ Zellen zugeben

7. Zugabe von $20 \mu \mathrm{l}$ anti-Biotin-MicroBeads und weitere $15 \mathrm{~min}$ bei $4-8^{\circ} \mathrm{C}$ inkubieren.

8. Zellen mit 1-2 ml Puffer pro $10^{7}$ Zellen bei $300 \mathrm{x}$ g für $10 \mathrm{~min}$ waschen und den Überstand verwerfen.

9. Resuspendieren von bis zu $10^{8}$ Zellen in $500 \mu$ Puffer.

\section{Magnetische Separation}

Es wurden MACS MS Separation Columns der Firma Miltenyi Biotec verwendet. Der eingesetzte Puffer wird mitgeliefert und setzt sich wie folgt zusammen: PBS ( $\mathrm{pH} 7,2$ ), $0,5 \%$ BSA und 2 mM EDTA.

- Die Säule wird in das magnetische Feld eingebracht und zunächst mit $500 \mu 1$ Puffer gespült.

- Die vorbereitete Zellsuspension wird ohne Luftblasen und in einem Fluss auf die Säule gegeben und der Durchfluss in einem Röhrchen aufgefangen (da in diesem Falle eine negative Selektion der gewünschten Zellfraktion erfolgt ist, handelt es sich hierbei bereits um die angereicherten Gedächtnis- bzw. naiven T-Lymphocyten). 


\section{Evaluierung der Reinheit der T-Lymphocyten-Fraktion}

Die Reinheit der erhaltenen Fraktion wurde mittels Durchflusscytometrie ermittelt. Hierfür wurden die Zellen mit den Antikörpern CD4-PE/CD45RO-FITC für Gedächtnis T-Lymphocyten sowie CD4-PE/CD45RA-FITC für naive T-Lymphocyten markiert (s. 2.2.10 FACS) und mittels Durchflusscytometer analysiert. Für die in dieser Arbeit verwendeten Abbildungen wurden nur Experimente gewählt, bei denen eine Reinheit von über $95 \%$ erzielt wurde.

Des Weiteren wurden die Zellen für in vitro Chemotaxis-Versuche direkt verwendet, um eine putative vorherige Aktivierung der Zellen ausschließen bzw. reduzieren zu können.

\subsubsection{Aufreinigung muriner T-Lymphocyten-Fraktionen}

Die, wie unter 2.2.6.2 dargestellt, aus der murinen Milz gewonnenen Lymphocyten wurden zunächst mit Hilfe des murinen $\mathrm{CD}^{+} \mathrm{T}$-cell Isolationskits aufgereinigt. Wie bereits zuvor für die humanen T-Lymphocyten beschrieben, wurde eine Isolation der murinen $\mathrm{CD}^{+}$Zellen ebenfalls mit Hilfe der negativen Selektion erreicht. Zur Gewinnung der naiven T-Lymphocyten wurde daraufhin das Eluat mit $10 \mu \mathrm{CD} 62 \mathrm{~L}$ MicroBeads pro $1 \times 10^{7}$ Zellen für 15 min auf Eis inkubiert. Nach einem Waschschritt bei $300 \mathrm{x}$ g für 10 min erfolgte dann, wie zuvor dargestellt, die magnetische Separation der Zellen.

Die Zellen des Eluats stellten nun die $\mathrm{CD}^{+} / \mathrm{CD}_{2} \mathrm{~L}^{-}$Gedächtnis T-Lymphocyten dar, während die $\mathrm{CD}^{+} / \mathrm{CD} 2 \mathrm{~L}^{+}$naiven T-Lymphocyten in der Säule zurückgehalten wurden. Diese wurden nun mit Hilfe von $500 \mu$ Puffer außerhalb des magnetischen Feldes durch den passenden Stempel aus der Säule gepresst. Auch hier erfolgte die Evaluierung der Reinheit der Zellfraktionen durch die im Folgenden beschriebene FACS-Analyse.

\subsubsection{Funktionelle Untersuchungen von Zellen mittels Durchflußcytometrie (FACS)}

Die Durchflusscytometrie (FACS-Analyse: fluorescence activated cell sorting) Fluoreszenzmarkierter Zellen ermöglicht die gleichzeitige Erfassung von Größe (Vorwärtsstreulicht), Granularität (Seitwärtsstreulicht) und Expression Fluoreszenz-markierter Antigene auf einzelnen Zellen. Die verwendete Laser-Wellenlänge von $488 \mathrm{~nm}$ entspricht der Anregungswellenlänge sowohl des grün-fluoreszierenden Fluoreszeinisothiocyanat (FITC) 
mit einer Emissionswellenlänge von $530 \mathrm{~nm}$ als auch der des rot-fluoreszierenden Phycoerythrins (PE), das ein Emissionsmaximum bei $585 \mathrm{~nm}$ besitzt. Die Stärke der Expression von definierten Antigenen kann anhand des Mittelwertes der Fluoreszenzintensität MnX beurteilt werden.

Diese Methode bietet die Möglichkeit, einzelne Zellen quantitativ, schnell und exakt zu charakterisieren und deren Antigenstruktur zu erfassen (Scheffold \& Kern, 2000). Das Durchflusscytometer saugt die Antikörper-markierte Zellsuspension durch eine feine Stahlkapillare ins Innere des Geräts, wo die Zellen durch hydrodynamische Fokussierung einzeln in einer Kapillare von einem Laserstrahl erfasst werden. Dazu wird die Zellprobe aus der Kapillare in das Zentrum eines mit Flüssigkeit (sheath fluid) durchflossenen Raumes gespritzt. Durch die konische Form dieses Teilstücks wird der Durchmesser verkleinert und durch die konstante Strömung die Zellen im Zentrum einzeln aufgereiht. Auf diese Weise passieren die Zellen alle einzeln den Laserstrahl.

Durch die Streusignale lassen sich Größe und Granularität der Zellen bestimmen. Die Größe der Zellen kann anhand ihrer Vorwärtsstreuung (Forward Scatter, FS) und die Granularität anhand ihrer Seitwärtsstreuung (Side Scatter, SS) ermittelt werden. Die Fluoreszenzsignale werden vom Gerät an dichromatischen Filtern registriert und die Information an Photodioden weitergeleitet. Die Lichtsignale finden sich in drei Fluoreszenzkanälen wieder, deren Filter unterschiedliche Wellenlängen detektieren können und somit auch in der Lage sind, Zellen mit drei unterschiedlich markierten Antigenen gleichzeitig zu erfassen.

Die Abbildungen der FACS-Analysen in dieser Arbeit zeigen die Fluoreszenzintensität der Zellen im Verhältnis zur Anzahl der Zellen als statistische Verteilung in Form eines Histogramms. Dabei wird jede einzelne Zelle, die den Laser passiert, einem Kanal entsprechend ihrer Emissionsintensität zugeordnet und ist somit das Maß für die an einer Zelle gebundenen FITC- oder PE-Antikörper.

\subsubsection{Direkte Markierung von Zellen}

Für eine direkte Färbung wurden pro Messansatz 2 bis $10 \times 10^{5}$ Zellen in eine RundbodenMikrotiterplatte überführt und für $1 \mathrm{~min}$ bei $1400 \mathrm{rpm}$ bei RT abzentrifugiert. Anschließend wurden die Zellen in $100 \mu$ FACS-Puffer (1,5\% FCS, 0,1\% $\mathrm{NaN}_{3}$ in PBS) aufgenommen und 15 min mit Hitze-aggregiertem humanem $\operatorname{IgG}(20 \mu \mathrm{g} / 100 \mu \mathrm{l}$; Sigma-Aldrich) inkubiert, um 
unspezifische Bindungsstellen zu blockieren. Danach wurden die Zellen mit FITC- bzw. PEmarkierten monoklonalen Antikörpern in einer Endkonzentration von $10 \mu \mathrm{g} / \mathrm{ml}$ für $45 \mathrm{~min}$ im Dunkeln auf Eis inkubiert und die Platte im Anschluss zweimal mit je $150 \mu$ FACS-Puffer gewaschen. Hierauf wurde das Zellpellet in $400 \mu \mathrm{l}$ FACS-Fixierung resuspendiert und in FACS-Röhrchen überführt und mittels Durchflusscytometer analysiert.

Bei einer indirekten Färbung erfolgte nach der Inkubation des in diesem Falle unmarkierten Primärantikörpers eine weitere 45 minütige Inkubation mit einem direkt markierten, gegen den Primärantikörper gerichteten Sekundärantikörper.

Verwendete Antikörper:

\begin{tabular}{|ccccc|}
\hline Spezifität & Isotyp & Zellklon & Markierung & Hersteller \\
\hline Isotyp Kontrolle & Maus IgG1 & DAK-G01 FI & FITC & Dako \\
& Maus IgG2a & DAK-G01 PE & PE & Dako \\
F(ab')2 & Maus IgG & & & Dianova \\
Fragment & (H+L) & polyklonal & FITC & R\&D \\
huCCR6 & Maus IgG2b & 53.103 .111 & FITC & Miltenyi \\
huCD45RO & Maus IgG2a & 5 K239 & FITC & Miltenyi \\
huCD45RA & Maus IgG1 & R494 & FITC & Miltenyi \\
huCD4 & Maus IgG2a & CLA-1.37 & PE & Biovision \\
HA-tag & Ratte IgG1 & $3 F 10$ & FITC & Deinco Technologies Inc. \\
huHLA-DR & Maus IgG2a & L243 & PE & Dako \\
huCD14 & Maus IgG2a & TÜK4 & FITC & Diaclone Sas \\
huCD86 & Maus IgG1 & B-T7 & FITC & Miltenyi \\
muCD4 & Ratte IgG2b & GK1.5 & PE & Miltenyi \\
muCD62L & Ratte IgG2a & MEL-14-H2.10 & FITC & Miltenyi \\
muCD117 & Ratte IgG2b & & PE & Miltenyi \\
muCD11c & Ratte IgG2a & RS-D9 & FITC & Abteilung Immunologie \\
& & & & Universität Göttingen \\
muC5aR & Ratte IgG2a & $20-70-30-1$ & keine & Abteilung Immunologie \\
& & & & Universität Göttingen \\
\hline muC3aR & Ratte IgG1 & 15G2F12E12 & keine &
\end{tabular}




\subsubsection{Fluoreszenzphotometrische Messung der intrazellulären Calciumionen- Freisetzung}

Das Calciumion ist ein sehr wichtiger intrazellulärer messenger, welcher für die Aktivierung und Deaktivierung zahlreicher biologischer Vorgänge in Zellen verantwortlich ist. Die Stimulation eines über G-Protein gekoppelten Rezeptors aktiviert über die $\beta \gamma$-Einheit des G-Proteins die membrangebundene Phospholipase C, welche Phosphatidylinositol-4,5bisphosphat in Inositol-1,4,5-triphosphat $\left(\mathrm{IP}_{3}\right)$ und 1,2-Diacylglycerin (DAG) spaltet (Berridge et al., 1987). $\mathrm{IP}_{3}$ wiederum katalysiert die Freisetzung von Calciumionen aus intrazellulären Speichern, wie etwa dem endoplasmatischem Reticulum (Berridge und Irvine, 1984), die eine um den Faktor $10^{3}$ bis $10^{4}$ erhöhte Calcium-Konzentration im Vergleich zum Cytoplasma besitzen. In der Membran des endoplasmatischen Reticulums (ER) befindet sich eine $\mathrm{Ca}^{2+}$-ATPase, welche die Calciumionen aus dem Cytosol in das ER pumpt und somit den Konzentrationsgradienten aufrechterhält.

\section{Wirkprinzip der Fluoreszenzindikatoren}

Für die Messung der intrazellulären Calciumkonzentration stehen verschiedene Methoden zur Verfügung. Es bieten sich u.a. die ratiometrischen Fluoreszenzfarbstoffe Fura-2 oder Indo-1 an. In dieser Arbeit wurde das Indo-1 Acetyloxymethylester-Derivat (AM) verwendet, da es eine größere Calcium-Sensitivität aufweist als das Fura-2, welches durch eine geringere Calcium-Dissoziationskonstante gekennzeichnet ist $\left(\mathrm{K}_{\mathrm{d}}\right.$ Indo- $1=0,23 ; \mathrm{K}_{\mathrm{d}}$ Fura-2=0,27). Die Dissoziationskonstante ist der Wert, bei dem 50\% des Indikatorfarbstoffes an das Zielion, in diesem Fall Calcium, gebunden sind. Je kleiner der $\mathrm{K}_{\mathrm{d}}$-Wert, desto stärker ist die Affinität des Farbstoffes für das Zielion. Indo-1 AM wird bei $351 \mathrm{~nm}$ angeregt und hat seine Emissionsmaxima bei $405 \mathrm{~nm}$ in der $\mathrm{Ca}^{2+}$-gebundenen Form und $485 \mathrm{~nm}$ in der $\mathrm{Ca}^{2+}$-freien Form. Die Veränderung der $\left[\mathrm{Ca}^{2+}\right]$ i wird als Verhältnis (Ratio) zwischen den beiden Fluoreszenzintensitäten gemessen. Durch die Messung mit ratiometrischen Farbstoffen können eine ungleichmäßige Farbstoffverteilung innerhalb der Zelle, die variierenden Zellgrößen, das Ausbleichen des Farbstoffes und die unterschiedliche Verteilung des Farbstoffes in den einzelnen Zellen ausgeglichen werden. Die Messung der intrazellulären Calciumkonzentration ist unabhängig von der absoluten Konzentration an Farbstoff in der Zelle, Faktoren wie Zelldicke und -größe spielen keine Rolle, Fehlermöglichkeiten aufgrund eines möglichen Austrittes von Farbstoff aus der Zelle oder Ausbleichen werden reduziert. Da 
die genannten Punkte bei beiden Wellenlängen die gleiche Auswirkung haben, fallen sie durch die Bildung der Ratio entweder ganz weg, oder werden minimiert.

Der Fluoreszenzfarbstoff Indo-1 ist ein Komplexbildner für zweiwertige Kationen, der an ein Chromophor gekoppelt ist. Indo-1 selbst ist als organische Säure sehr gut wasserlöslich und kann aus diesem Grunde die Zellmembran nicht permeieren. Das Indo-1 AM, welches durch die Veresterung der Carboxylfunktionen lipophile Eigenschaften besitzt, kann hingegen die Zellmembran passieren. Zur Detektion des freigesetzten Calciums werden die Zellen mit dem Chelat-bildenden Indo-1 AM inkubiert. Der Fluoreszenzfarbstoff wird von der Zelle aufgenommen und von den ausschließlich im Cytosol vorkommenden unspezifischen Esterasen an der Estergruppe hydrolysiert, sodass sich der Fluoreszenzfarbstoff als freie Säure in der Zelle anreichert und aufgrund der negativen Ladung die Zellen nicht mehr durch die Membran verlassen kann. In dieser Form kann Indo-1 nun freies Calcium komplexieren. Die darauffolgende Fluoreszenzveränderung dient der Bestimmung des im Cytosol befindlichen Calciums.

Im Fokus dieser Arbeit steht die Veränderung der intrazellulären Calciumkonzentration verschiedener Zelltypen nach Stimulation mit verschiedenen Chemokinen und Defensinen, welche zumeist über G-Protein gekoppelte Rezeptoren agieren. Hierfür wurden 1 x $10^{6}$ Zellen in $500 \mu 1$ RPMI Medium mit 5 \% FCS aufgenommen. Die Färbelösung (200 $\mu 1$ Medium 5 \% FCS + 1 mM Indo-1 AM + 0,02 \% Pluronic F127 (Molecular Probes, Invitrogen, Karlsruhe, D) wurde zu den Zellen gegeben und $25 \mathrm{~min}$ bei $30^{\circ} \mathrm{C}$ und $300 \mathrm{rpm}$ im Dunkeln inkubiert. Das anionische Detergens Pluronic F127 diente der besseren Lösbarkeit des Indo-1 AM Esters in wässrigen Lösungen, wie dem Medium, und somit der einfacheren Aufnahme durch die Zellen. Im Anschluss wurde die Farbstoffaufnahme durch Zugabe von $700 \mu 1$ Medium mit $10 \%$ FCS abgestoppt und die Zellen 10 min bei $37^{\circ} \mathrm{C}$ inkubiert. Durch zwei Waschschritte für $5 \mathrm{~min}$ bei $1800 \mathrm{rpm}$ mit Krebs-Ringer-Lösung $\left(+1 \mathrm{mM} \mathrm{CaCl}_{2}\right)$ wurde das überschüssige Indo-1 AM entfernt. Anschließend wurden die Zellen in $900 \mu 1$ dieses Puffers aufgenommen und bis zur Messung bei Raumtemperatur lichtgeschützt aufbewahrt. Die Freisetzung der Ionen nach Rezeptorstimulation kann dann im Fluoreszenzspektralphotometer verfolgt und mit Hilfe des Analyseprogrammes Flow Jo (Beckton Dickenson) ausgewertet werden. Um eine Relation der erzielten intrazellulären Calciumfreisetzung zur Verfügung zu haben, wurde abschließend eine Stimulation der Zellen mit $100 \mathrm{nM}$ des Calcium-Ionophors Ionomycin durchgeführt. 
Ionomycin ist ein Calcium-Ionophor, das Calciumionen im Komplex 1:1 bindet. Die

Steigerung des $\mathrm{Ca}^{2+}$-Influx durch Ionomycin wird hierbei durch die direkte Stimulation des Kationenkanals der Calciumspeicher (endoplasmatisches bzw. sarkoplasmatisches Retikulum) erreicht und nicht durch eine direkte Wirkung an der Plasmamembran (Liu und Hermann, 1978; Morgan und Jacob, 1994). Isoliert wurde dieses Antibiotikum aus Streptomyces conglobatus. Es wird in der Forschung vornehmlich verwendet, um die intrazelluläre $\mathrm{Ca}^{2+}$ Konzentration zu erhöhen.

\subsubsection{Chemotaxis in vitro}

Als Chemotaxis wird die gerichtete Wanderung von Zellen in Richtung auf einen Stimulus hin oder von einem Stimulus weg bezeichnet. Sie ist abhängig von der Exprimierung der jeweiligen Chemokinrezeptoren und kann als Beweis für die Funktionalität eines Rezeptors dienen. Chemokinese hingegen bezeichnet die generell erhöhte Motilität von Zellen aufgrund eines Stimulus, welche aber keine Migration in Richtung des Stimulus beinhaltet, weshalb hierbei von ungerichteter Migration gesprochen wird.

Um sicher zu stellen, dass in den vorliegenden Experimenten Chemotaxis und keine Chemokinese gemessen wurde, erfolgte eine so genannte Schachbrett-Analyse. Dabei wurde CCL19 10-8 M sowohl in das untere als auch gemeinsam mit den Testzellen in das obere Kompartiment der Kammer eingesetzt. Die Menge der unter diesen Bedingungen gewanderten Zellen wurde wie unten beschrieben ermittelt und mit der Positivkontrolle CCL19 10-8 M nur im unteren Kompartiment - verglichen.

Es wurden 1 x $10^{6}$ Zellen pro $\mathrm{ml}$ in Chemotaxismedium $(0,1 \mathrm{~g}$ BSA (1\%) in $10 \mathrm{ml}$ RPMI1640/PenStrep) aufgenommen. Anschließend wurden die Einsätze mit der gewünschten Porengröße in einer 24well Platte platziert und jeweils $600 \mu \mathrm{l}$ der $\mathrm{zu}$ testenden Chemokinlösungen (ebenfalls in Chemotaxismedium gelöst) luftblasenfrei in den unteren Teil der Kammern pipettiert. Als Negativkontrolle diente das Chemotaxismedium ohne Chemokinzusatz. $100 \mu \mathrm{l}$ der Zellsuspension wurden in die Einsätze pipettiert und die 24well Platte im Brutschrank bei $37^{\circ} \mathrm{C}$ und $5 \% \mathrm{CO}_{2}$ inkubiert. Im Falle chemotaktisch stimulierter Migration wanderten die Zellen vom oberen Kompartiment durch die Poren des Filters in den unteren Teil der Kammer.

Der Aufbau des in vitro Chemotaxissystems wird in der folgenden Abbildung dargestellt. 


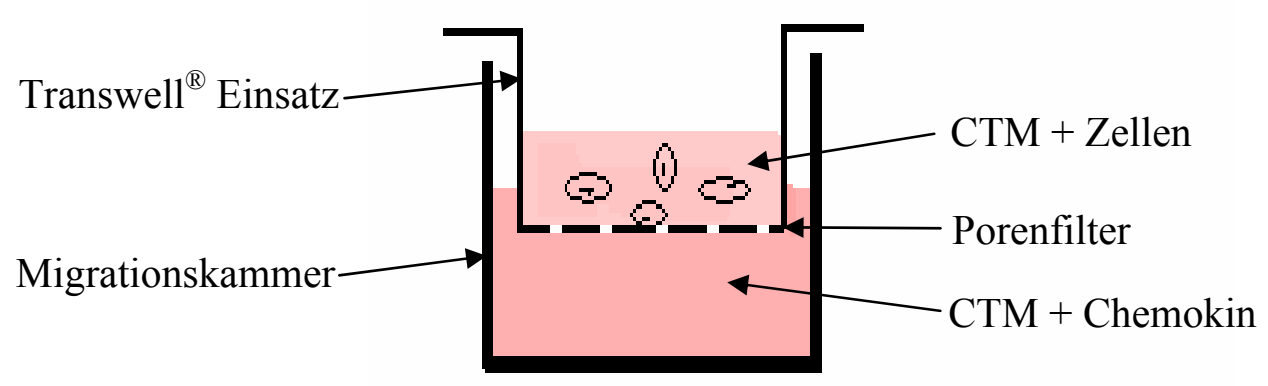

Abb. 8: Aufbau des Transwell ${ }^{\circledR}$ Filtersystems zur Analyse der Chemotaxis in vitro. $\mathrm{CTM}=$ Chemotaxis Medium.

Im Anschluss an die Inkubation wurden die Einsätze entnommen und die Unterseite mit Medium gespült, um die sich hier befindlichen Zellen abzulösen. Bei adhärenten Zellen war es zudem notwendig, die 24well Platte für 30 min auf Eis zu stellen, um die Zellen vom Boden ablösen zu können. Hierauf wurde jeder Napf separat geerntet und gespült, die Zellsuspension herunterzentrifugiert, das eventuell vorhandene Pellet in $500 \mu \mathrm{PBS}$ resuspendiert und die Zellzahl ermittelt.

Für humane und murine Makrophagen und DC (dendritische Zellen), HMC-1 (human mast cell line-1) sowie die RBL-2H3 Transfektante wurden Einsätze mit $8 \mu \mathrm{m}$ Porengröße verwendet. Murine Mastzellen, Granulocyten sowie humane naive sowie Gedächtnis T-Lymphocyten benötigten einen Einsatz mit $5 \mu \mathrm{m}$ Porengröße. Die Inkubationszeiten lagen für die humanen und murinen Makrophagen und DC, sowie für Granulocyten und die RBL-2H3 Transfektanten bei 90 min, für HMC-1 bei $3 \mathrm{~h}$ und für die Lymphocyten bei $4 \mathrm{~h}$.

Um die Rolle der Protein-Kinase C (PKC) bei der Rezeptordesensibilisierung zu untersuchen, wurden 1 x $10^{6}$ Zellen pro ml Medium mit $4 \mu \mathrm{M}$ PKC-Inhibitor GF109 bzw. Gö6976 bei $37^{\circ} \mathrm{C}$ für 30 min präinkubiert und nach Zentrifugation für die Chemotaxis verwendet. Für Desensibilisierungstudien wurde die gleiche Anzahl Zellen ebenfalls für 30 min bei $37^{\circ} \mathrm{C}$ mit dem jeweiligen Chemokin (200 ng/ml) oder PMA (2 $\mu \mathrm{g})$ präinkubiert.

Ebenso wurde untersucht, ob MAP-Kinasen bei der Signaltransduktion der Chemotaxis intervenieren. Hierfür wurden die Zellen bei $37^{\circ} \mathrm{C}$ für 30 min mit $20 \mu \mathrm{M}$ der folgenden MAPK-Inhibitoren inkubiert: PD098059 (ERK-Inhibitor), SB203580 (p38-Inhibitor), SP600125 (JNK-Inhibitor). 
Die Funktion von $\mathrm{G}_{\alpha \mathrm{i}}$ Proteinen bei der Signaltransduktion wurde mit Hilfe einer über NachtInkubation von $100 \mathrm{ng} / \mathrm{ml}$ Pertussis-Toxin vor dem jeweiligen Experiment analysiert. Pertussis Toxin ist das Haupt-Endotoxin, welches von virulenten Stämmen des Bakteriums Bordetella pertussis synthetisiert wird. Es katalysiert die ADP-Ribosylierung der $\alpha$-Untereinheit der heterotrimeren Guanin-Nucleotid-bindenden regulatorischen Proteine $\mathrm{G}_{\mathrm{i}}$, $\mathrm{G}_{\mathrm{o}}$, und $\mathrm{G}_{\mathrm{t}}$ (Kaslow, 1992; Gierschik, 1992). Dies hindert die G-Proteine an der Interaktion mit Zellmembran-Rezeptoren und stört somit die intrazelluläre Signaltransduktion. Da die Ga-Untereinheiten in dem GDP-gebundenen, inaktiven Zustand bleiben, können sie weder die Adenylat-Cyclase inaktivieren, noch Natriumkanäle öffnen. Daher dient Pertussis Toxin vornehmlich der Untersuchung der Adenylate-Cyclase-Regulation sowie der Rolle von $\mathrm{G}_{\mathrm{i}}$-Proteinen bei der Signaltranduktion.

GF109 (Bisindolylmaleimide I) ist ein hoch-selektiver, Zell-permeabler und reversibler Protein-Kinase C (PKC) Inhibitor, welcher als kompetitiver Inhibitor der ATP-Bindungsstelle der PKC agiert. GF109 weist eine starke Selektivität für $\mathrm{PKC}_{\alpha^{-}}, \beta \mathrm{I}^{-}, \beta \mathrm{II}^{-}, \gamma^{-}, \delta^{-}$, and $\varepsilon_{\varepsilon}$-Isozyme auf (Hers et al., 1999; Gekeler et al., 1996).

Gö6976 (12-(2-Cyanoethyl)-6,7,12,13-tetrahydro-13-methyl-5-oxo-5H-indolo (2,3-a) pyrolo $(3,4-c)$-carbazol) ist ein Zell-permeabler Inhibitor der PKC und inhibiert selektiv $\mathrm{Ca}^{2+}$ abhängige $\mathrm{PKC}_{\alpha}$-Isozyme sowie $\mathrm{PKC}_{\beta \mathrm{I}}$. Im Gegensatz hierzu hat dieser Inhibitor keinen Effekt auf die Kinase-Aktivität der $\mathrm{Ca}^{2+}$-unabhängigen $\mathrm{PKC}_{\delta^{-}}, \varepsilon^{-}$, und $\zeta_{-}$-Isozyme, auch nicht im mikromolaren Bereich (Gschwendt et al., 1996; Qatsha et al., 1993).

\subsubsection{SCID-Maus Modell}

Die SCID (severe combined immuno deficiency)-Maus, die infolge eines genetischen Defektes kein funktionsfähiges Immunsystem besitzt, wird bei Experimenten verwendet, bei denen eine Immunreaktion des Wirtsorganismus umgangen werden muss.

Da die hier eingesetzten SCID-CB17 Mäuse weder eigene T- noch B-Lymphozyten besitzen, haben sie eine Immuntoleranz gegenüber humanen immunkompetenten Zellen und können somit für in vivo Migrationsversuche mit humanen Zellen verwendet werden. 
Haltungsbedingungen:

Die Tiere wurden unter pathogenfreien Bedingungen in Typ 3 Makrolonkäfigen mit Edelstahldeckel gehalten. Als Einstreu wurde entstaubte Weichholzfaser verwendet. Die Mäuse wurden mit Alleinfutter für Mäuse RM 204 gefüttert und das Trinkwasser wurde durch zweifache Ozonierung und Ansäuerung ( $\mathrm{pH}$ 4-5) keimfrei gemacht und in MakrolonTränkflaschen mit Edelstahlkappe gegeben. Futter und Wasser standen den Mäusen ad libidum zur Verfügung. Die Temperatur im Tierstall betrug $20 \pm 2^{\circ} \mathrm{C}$, die relative Luftfeuchte $60 \pm 10 \%$. Der Hell/Dunkel-Rhythmus wurde auf $12 \mathrm{~h}: 12 \mathrm{~h}$ eingestellt.

\subsection{Chemotaxis in vivo}

Alle Tierversuche wurden in Übereinstimmung mit den Richtlinien des Tierschutzes durchgeführt und waren vom Land Niedersachsen genehmigt.

Für Migrationsversuche mit humanen Zellen wurden die zu untersuchenden Zellen zunächst geerntet und 1 x $10^{7}$ Zellen in $200 \mu$ PBS sowie das $\mathrm{zu}$ untersuchende Chemokin/Anaphylatoxin in $200 \mu \mathrm{PBS}$ aufgenommen und in eine $1 \mathrm{ml}$ Spritze überführt. Die SCID-Mäuse wurden durch die intraperitoneale Injektion von $100 \mu \mathrm{l}$ des Narkosecocktails (Hostaket/Rompun/PBS $=1 / 1 / 8$ ) sediert. Die Wirkung der Narkose setzte ca. 5 bis 10 Minuten nach der Injektion ein. Während dieser Zeit sollten die Mäuse ruhig und abgedunkelt stehen. Anschließend wurde die jeweilige Chemokin-/Anaphylatoxinlösung ebenfalls intraperitoneal appliziert. Daraufhin wurde die Zellsuspension in eine der vier Schwanzvenen injiziert. In Abhängigkeit des verwendeten Chemokins/Anaphylatoxins sollten die Zellen 4 h, 24 h bzw. 48 h in den Peritonealraum einwandern. Die gewanderten Zellen wurden mit Hilfe der im Folgenden beschriebenen Peritoneallavage geerntet.

Bei Experimenten mit murinen Zellen wurden diese vor Injektion mit dem rot fluoreszierenden Farbstoff PKH-26 (Sigma-Aldrich, Deisenhofen, D) nach Angaben des Herstellers für eine spätere Detektion markiert. Alle weiteren Schritte wurden wie für humane Zellen dargestellt durchgeführt. 


\subsection{Peritoneallavage}

Nach Ablauf der Inkubationszeit wurden die Mäuse mittels einer Überdosis $\mathrm{CO}_{2}$ getötet, die Haut des Abdomens und das Peritoneum durch einen kleinen Schnitt perforiert und mit einer Pasteurpipette kaltes PBS in die Bauchhöhle pipettiert, resuspendiert und in ein gesondertes Spitzröhrchen überführt. Der Pipettiervorgang wurde so oft wiederholt, bis $7 \mathrm{ml}$ PBS verbraucht waren. Die so gewonnenen Zellen wurden mit Trypanblau gefärbt, gezählt und auf $2 \times 10^{6}$ Zellen pro ml in FACS-Puffer eingestellt. Anschließend wurden die humanen Zellen sofort mit anti-HLA-DR-PE in Kombination mit anti-CD14-FITC oder anti-CD86-FITC gefärbt, um die migrierten humanen Makrophagen beziehungsweise DCs mit Hilfe der FACSAnalyse (s. 2.2.10) identifizieren zu können. Die absolute Anzahl der gewanderten Zellen wurde durch den durchflusscytometrisch ermittelten prozentualen Anteil der gefärbten Zellen auf die gezählte Gesamtzellzahl der Peritoneallavage berechnet.

Für Desensibilisierungsexperimente wurden $1 \times 10^{7}$ fluoreszenzmarkierte Zellen in $1 \mathrm{ml}$ PBS bei $37^{\circ} \mathrm{C}$ für $1 \mathrm{~h}$ mit $2 \mu \mathrm{g}$ des jeweiligen Chemokins präinkubiert. Nach zweimaligem Waschen der Zellen mit PBS wurden die Zellen in $200 \mu 1$ PBS resuspendiert und für die Injektion verwendet.

\subsection{Molekularbiologische Methoden}

\subsubsection{Restriktionsendonukleasen}

Alle verwendeten Restriktionsendonukleasen stammen von der Fermentas GmbH (St. LeonRot, D). Im Folgenden werden die Schnittstellen der eingesetzten Restriktionsenzyme gezeigt.

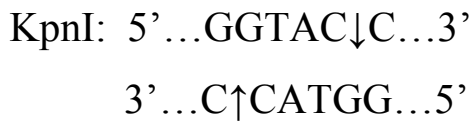

XhoI: 5'...C $\downarrow$ TCGAG...3'

3'...GAGCT $\uparrow$ C...5'

PvuI: 5'...CGAT $\downarrow$ CG...3'

3'...GC $\uparrow \mathrm{TAGC} \ldots .5$ ' 


\subsubsection{Analytischer DNA-Verdau}

Für analytische Restriktionsreaktionen wurden ca. $10 \quad \mu \mathrm{g}$ DNA mit 1-2 Units Restriktionsenzym in einem Reaktionsvolumen von $20 \mu \mathrm{l}$ für $2-3 \mathrm{~h}$ bei $37^{\circ} \mathrm{C}$ inkubiert.

\subsubsection{Präparativer Verdau}

Für die Restriktion präparativer Mengen DNA wurden entsprechend größere Volumina eingesetzt. Die verwendeten Restriktionsendonukleasen wurden hierbei meist in einem Reaktionsvolumen von $50 \mu$ eingesetzt. Wurde mit zwei oder mehr Enzymen gearbeitet, so wurde entweder ein Reaktionspuffer gewählt, in dem alle Enzyme effizient schneiden konnten, oder die Reaktion wurde sequenziell durchgeführt. Hierfür wurde die DNA nach dem ersten Verdau gefällt, im Reaktionspuffer für das zweite Enzym aufgenommen und erneut verdaut.

Sowohl beim analytischen als auch beim präparativen Verdau von DNA wurden die vom Hersteller empfohlenen Reaktionsbedingungen unter Einsatz der jeweiligen Puffer eingehalten.

\subsubsection{Vektoren}

\subsubsection{Klonierungsvektoren}

Sowohl die FPRL-2 (formyl peptide receptor-like 2)- als auch die humane CCR6-cDNA wurden in dem pcDNA3.1+ Klonierungsvektor (5,43 kb; s. Abb. 9) vom UMR cDNA Resource Center (USA) bezogen. Da für FPRL-2 keine kommerziellen Antikörper erhältlich waren, wurde für eine einfache Detektion eine cDNA mit 3x HA-tags am N-Terminus gewählt. Diese konnte nun mit Hilfe eines FITC-markierten HA-tag-Antikörpers bei der Durchflusscytometrie sichtbar gemacht werden. 

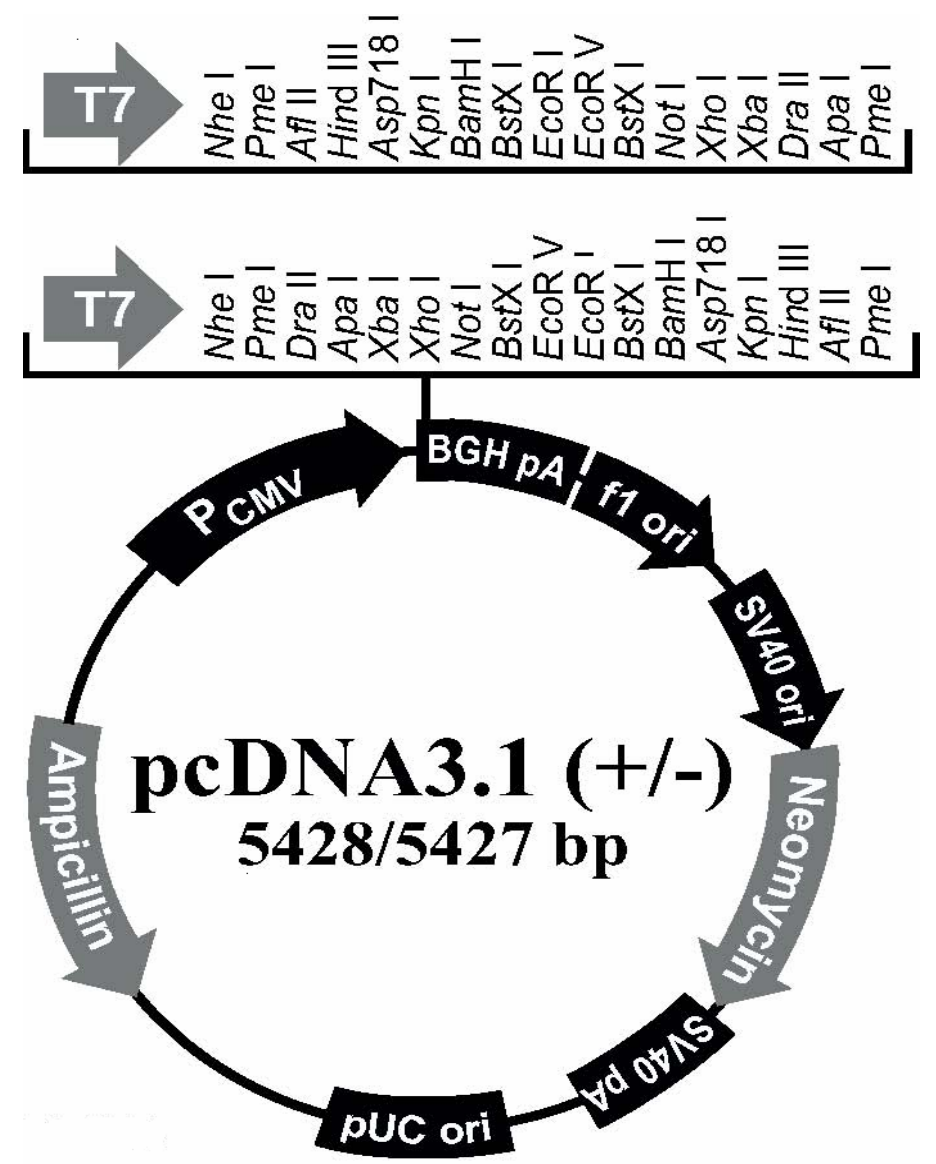

Abb. 9: Restriktionskarte des Klonierungsvektors pcDNA3.1+

\subsubsection{Allgemeine Expressionsvektoren}

Der Expressionsvektor pEF1/Myc-HIS-A (6,2 kb) der Invitrogen GmbH wurde zur stabilen Expression aller Rezeptorkonstrukte genutzt. pEF1/Myc-HIS-A setzt sich aus dem pUCPlasmidfragment und der EF-1 $\alpha$ Expressionskassette zusammen. Als Selektionsmarker diente Ampicillin in Prokaryoten und Geneticin in Eukaryoten.

Sowohl die FPRL-2- als auch die CCR6-cDNA wurden mit den Restriktionsenzymen Kpn I und Xho I aus dem Klonierungsvektor p pcDNA3.1+ herausgeschnitten und in den ebenfalls Kpn I sowie Xho I verdauten Expressionsvektor pEF1/Myc-HIS-A kloniert.

Die folgende Abbildung zeigt die Restriktionskarte des Expressionsvektors. 


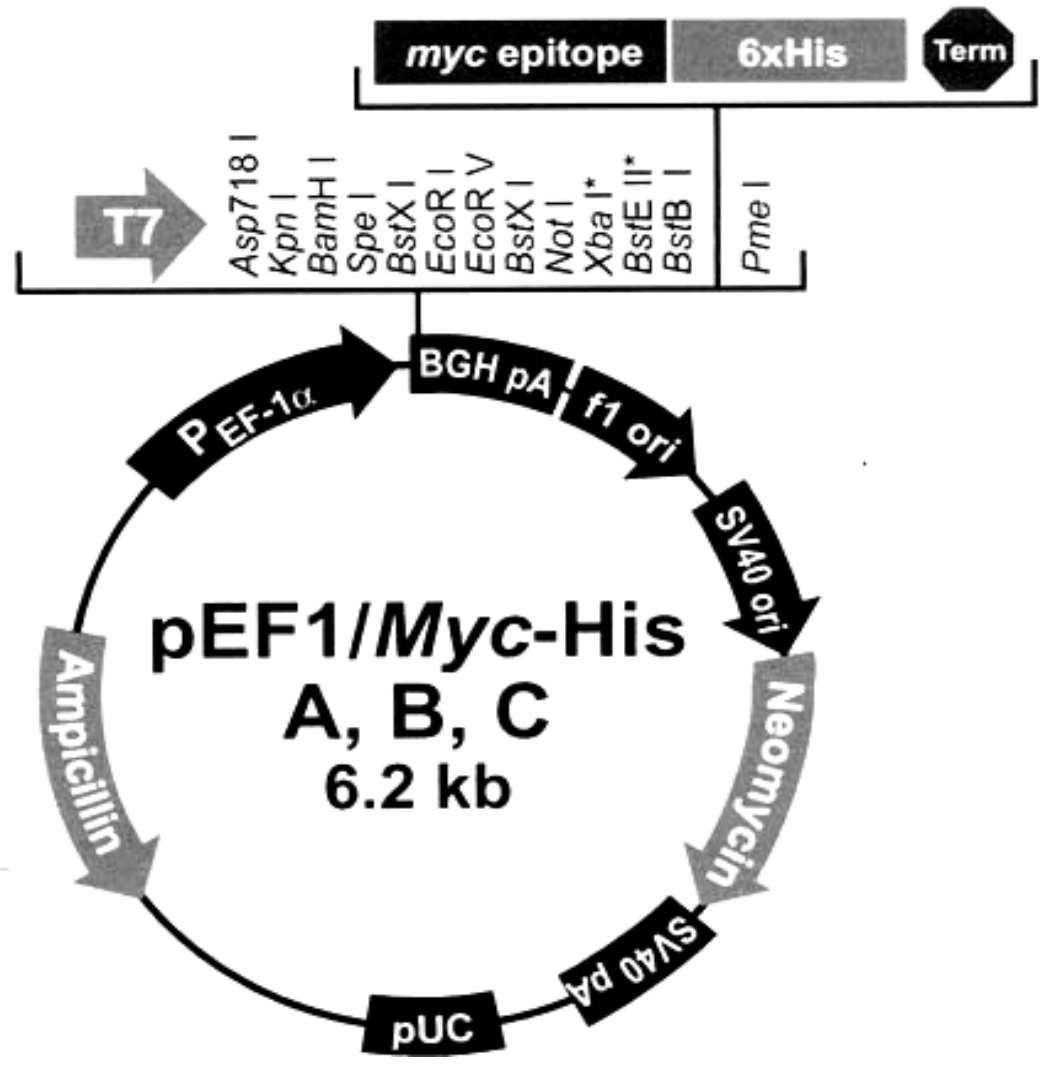

Abb. 10: Restriktionskarte des Expressionsvektors pEF1-MycHIS-A

Für stabile Transfektionen in RBL-2H3-Zellen wurde das Vektor-Insert-Konstrukt mit PvuI, dessen Schnittstelle im Ampicillin-Resistenzgen liegt, linearisiert.

\subsubsection{Rezeptor DNA}

FPRL-2 (3xHA):1,15 kb; clone ID: FPRL20TN00; HA-tag Sequenz: TAC CCA TAC GAC GTC CCA GAC TAC GCC

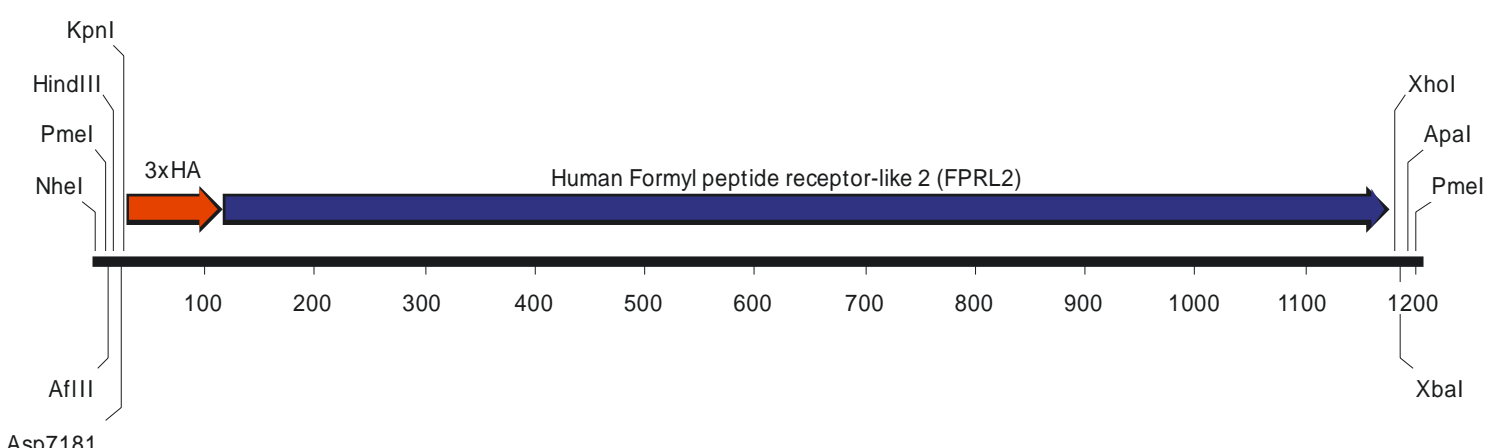

Abb. 11: Schematische Darstellung der FPRL-2 (3xHA)-DNA-Sequenz einschließlich Restriktionsstellen. 
CCR6: 1,13 kb; clone ID: CCR0600000

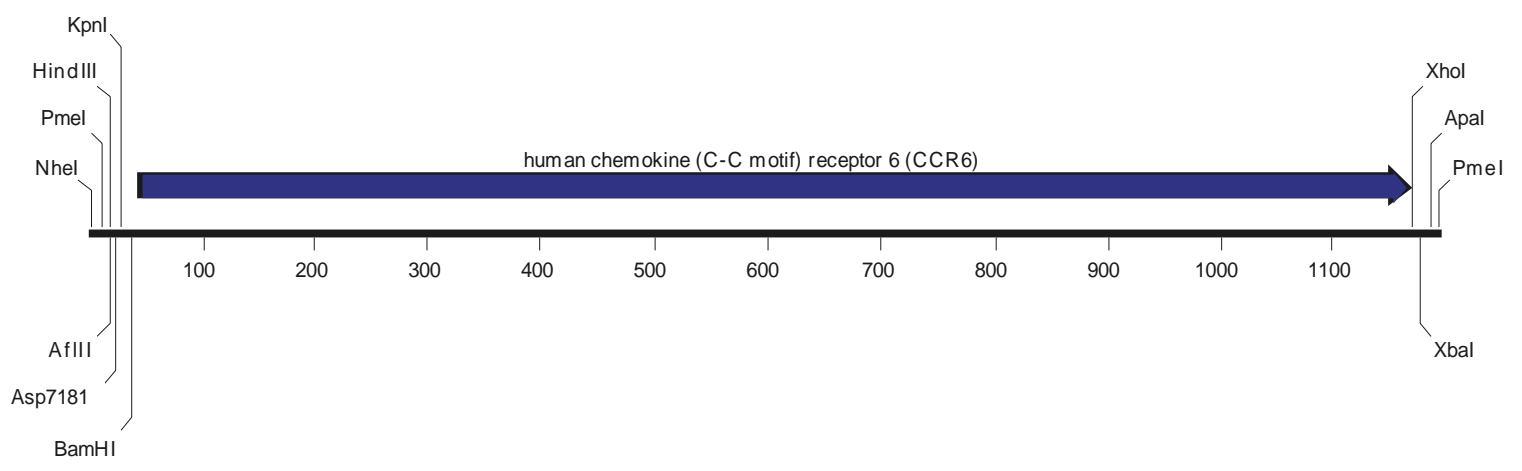

Abb. 12: Schematische Darstellung der verwendeten CCR6-DNA-Sequenz einschließlich der Restriktionsstellen. Ebenso wie Abbildung 11 dem Datenblatt der Firma Invitrogen entnommen.

\subsubsection{Antibiotika}

Ampicillin:

Ampicillin wirkt gegen die meisten Gram-negativen Bakterien, indem es die Bildung der bakteriellen Mureinschichten unterbindet.

\section{G418 Sulfat $\left(\right.$ Geneticin $\left.^{\circledR}\right)$ :}

Es handelt sich um ein pro- und eukaryotisches Zelltoxin, welches die Protein-Biosynthese zum Erliegen bringt, indem es an die 30S- bzw. 40S-Untereinheit bindet. Durch die Expression der Aminoglycosid-3'-Phosphotransferase wird die Bindung an die ribosomale Untereinheit verhindert und damit G418 unwirksam. Die Aminoglycosid-3'Phosphotransferase hebt ebenfalls die Wirkung von Kanamycin und Neomycin auf.

Ampicillin wurde in einer Konzentration von $50 \mathrm{mg} / \mathrm{ml}$ in sterilem Aqua destillata gelöst. Anschließend wurde die Lösung durch einen 0,22 $\mu \mathrm{m}$-Filter sterilfiltriert, aliquotiert und bei $-20^{\circ} \mathrm{C}$ eingefroren. G418 Sulfat $(50 \mathrm{mg} / \mathrm{ml})$ wurde in $100 \mathrm{mM}$ HEPES, pH 7,3 gelöst, durch einen $0,22 \mu \mathrm{m}$-Filter sterilfiltriert, aliquotiert und ebenfalls bei $-20^{\circ} \mathrm{C}$ eingefroren. 


\subsubsection{Dephosphorylierung von DNA}

Um bei einer Ligation einer Religation der beiden Vektorenden vorzubeugen, wurde die linearisierte Vektor-DNA einer Dephosphorylierung durch CIAP (Calf Intestine Alcaline Phosphatase) unterzogen. Hierzu wurde der Restriktionsansatz durch Hitzeinaktivierung für $15 \mathrm{~min}$ bei $65^{\circ} \mathrm{C}$ abgestoppt und dann nach Zugabe von $1 \mu \mathrm{CIAP}$ für $1 \mathrm{~h}$ bei $37^{\circ} \mathrm{C}$ inkubiert. Mit Hilfe der alkalischen Phosphatase wurden somit die terminalen 5'-Phosphatgruppen der Vektor-DNA entfernt und die Religation des Plasmids ohne Integration der Insert-DNA konnte vermindert werden.

\subsubsection{Ligation von DNA-Fragmenten}

In dieser Arbeit wurden lineare DNA-Fragmente mit kohäsiven Enden mit der T4-DNALigase ligiert. DNA-Ligasen katalysieren die Bildung von Phosphodiesterbindungen zwischen einer freien $5^{6}$-Phosphatgruppe und einer 3'-Hydroxylgruppe von zwei miteinander kompatiblen DNA-Enden.

Hierzu wurden die zu ligierenden DNA-Fragmente in einem Gesamtvolumen von $20 \mu$ unter Verwendung von $2 \mu \mathrm{l}$ des mitgelieferten Reaktionspuffers mit 5 Units T4 DNA-Ligase für 2 bis $3 \mathrm{~h}$ bei RT inkubiert. Die DNA-Konzentration betrug zwischen 1 und $10 \mu \mathrm{g} / \mathrm{ml}$, das molare Verhältnis Vektor/Insert-DNA lag zwischen 1:3 und 1:9. Im Anschluss wurde die Ligationsreaktion für 10 min bei $65^{\circ} \mathrm{C}$ abgestoppt und die DNA ohne weitere Reinigung zur Transformation eingesetzt.

\subsubsection{Kultivierung und Manipulation von Mikroorganismen}

\subsubsection{Verwendete Bakterienstämme}

Für die Transformation von Plasmid-DNA und Ligationsansätzen wurden ausschließlich Escherichia coli K 12 Derivatstämme verwendet:

XL1-blue (recA endA1 gyrA96 thi-1 hsdR17 supE44 relA1 lac[F' proAB lacl ${ }^{\mathrm{q}} \Delta \mathrm{M} 15$ tn10 $\left(\right.$ Tet $\left.\left.^{\mathrm{r}}\right)\right]$ ) 


\subsubsection{Kultivierung von Escherichia coli}

Die Zellen wurden in Luria-Bertani (LB)-Vollmedium (s. 2.1.7.1) bei $37^{\circ} \mathrm{C}$ kultiviert. Zur Selektion transformierter Zellen wurde dem Medium Ampicilin zugesetzt.

\subsubsection{Präparation von chemisch kompetenten $E$. coli- Zellen}

Zur Anzucht der Zellen wurde zunächst eine Kolonie E. coli- Zellen in 15 ml LB-Medium angeimpft und für 6 bis $8 \mathrm{~h}$ bei $37^{\circ} \mathrm{C}$ inkubiert. Aus dieser Vorkultur wurden dann durch Überimpfen von 5, 3 bzw. $1 \mathrm{ml} 3$ Hauptkulturen zu je $100 \mathrm{ml}$ LB angeimpft, die über Nacht bei 18 bis $22^{\circ} \mathrm{C}$ mit $200 \mathrm{U} / \mathrm{min}$ bis zu einer $\mathrm{OD}_{600 \mathrm{~nm}}$ von 0,55 inkubiert wurden.

Für die Ernte wurden die Zellen für 10 min auf Eis inkubiert und bei $2500 \mathrm{x}$ g für $10 \mathrm{~min}$ bei $4^{\circ} \mathrm{C}$ abzentrifugiert. Das Sediment wurde in $100 \mathrm{ml}$ Inoue-Puffer (10 mM PIPES, $15 \mathrm{mM}$ $\mathrm{CaCl}_{2} \times 2 \mathrm{H}_{2} \mathrm{O}, 250 \mathrm{mM} \mathrm{KCl}, 55 \mathrm{mM} \mathrm{MnCl} 2$ × $4 \mathrm{H}_{2} \mathrm{O}$; $\mathrm{pH}$ 6,7) durch vorsichtiges Schwenken resuspendiert, für $10 \mathrm{~min}$ auf Eis gestellt und erneut abzentrifugiert. Daraufhin wurden die Zellen in $10 \mathrm{ml}$ Inoue-Puffer aufgenommen und vorsichtig mit 0,75 ml DMSO vermischt. Der Ansatz wurde anschließend erneut 10min auf Eis inkubiert. Abschließend wurden die Zellen in $0,2 \mathrm{ml}$ Aliquots in vorgekühlte $1,5 \mathrm{ml}$ Reaktionsgefäße aufgeteilt, in flüssigem Stickstoff schockgefroren und bis zur weiteren Verwendung bei $-80^{\circ} \mathrm{C}$ gelagert.

\subsubsection{Transformation von chemisch kompetenten $E$. coli- Zellen}

Bei $-80^{\circ} \mathrm{C}$ eingefrorene, kompetente E. coli Zellen wurden auf Eis aufgetaut. Je $100 \mu \mathrm{l}$ der Zellen wurden 1 bis $5 \mu$ DNA zugesetzt. Als Kontrolle diente jeweils ein Ansatz ohne DNA Zugabe. Beide Ansätze wurden zur DNA-Aufnahme für 30 min auf Eis inkubiert, um eine Anlagerung der DNA an die Bakterien zu ermöglichen. Anschließend wurden die Zellen für 1 min bei $42^{\circ} \mathrm{C}$ hitzegeschockt, um die DNA-Aufnahme zu initiieren und daraufhin zum Stoppen der Aufnahme wiederum auf Eis gestellt. Dem Ansatz wurden nun $800 \mu \mathrm{l}$ SOCMedium (SOB $+20 \mathrm{mM}$ Glukose) zugefügt, und es erfolgte eine Inkubation für $1 \mathrm{~h}$ bei $37^{\circ} \mathrm{C}$, zur Entwicklung der Ampicillin-Resistenz. Abschließend wurden die Kontrolle sowie verschiedene Mengen (5, 10, 20, $40 \mu \mathrm{l})$ der Proben auf Agarose-Ampicilin Platten ausgestrichen. Zur besseren Adhärenz der Zellen wurden die Agarose-Platten zunächst für 
15 min bei $37^{\circ} \mathrm{C}$ mit der Agar beschichteten Seite nach unten in den Brutschrank gestellt. Anschließend wurden die Platten umgedreht, so dass entstehendes Verdunstungswasser abtropfen konnte und über Nacht im Brutschrank inkubiert.

Am nächsten Tag wurden Einzelkolonien mit Hilfe einer Pipettenspitze gepickt und in $10 \mathrm{ml}$ Falconröhrchen (STET-Prep) bzw. 500 ml (Maxi-Prep) mit 3 ml bzw. 100 ml LB-Medium und $20 \mu \mathrm{l}$ bzw. $200 \mu \mathrm{l}$ Ampicilin überführt. Diese angeimpften Kulturen wurden auf einem Schüttler über Nacht bei $37^{\circ} \mathrm{C}$ und $150 \mathrm{rpm}$ im Dunkeln inkubiert.

\subsubsection{Isolierung von Plasmid-DNA aus E. coli}

\subsubsection{Isolierung von Plasmid-DNA aus $3 \mathrm{ml}$ Kulturen (STET Methode)}

Nach der Inkubation über Nacht (s. 2.3.8.4) wurden am folgenden Tag jeweils 1,5 ml der Kulturen bei $14000 \mathrm{rpm} 30$ Sekunden abzentrifugiert, der Überstand verworfen und die Bakterienpellets in $400 \mu$ STET-Puffer ( $8 \%$ Saccharose, 0,5 \% Triton X-100, 50 mM EDTA, pH 8,0, 10 mM Tris, pH 8.0) resuspendiert. Nach gründlichem Vortexen des Pellets wurden die Proben 55 Sekunden im kochenden Wasserbad aufgeschlossen und das hierdurch entstandene Zelldebris nach 30 minütiger Zentrifugation bei $1400 \mathrm{rpm}$ bei $4^{\circ} \mathrm{C}$ mit Hilfe eines sterilen Zahnstochers entfernt.

Die Plasmid-DNA wurde durch Zugabe von $50 \mu \mathrm{l}$ NaOAc $(3 \mathrm{M}, \mathrm{pH} 4,8)$ und $500 \mu \mathrm{l}$ Isopropanol gefällt und durch eine 10 minütige Zentrifugation bei $4^{\circ} \mathrm{C}$ abzentrifugiert. Das Pellet wurde mit $70 \%$-igem Ethanol gewaschen, getrocknet und in $50 \mu \mathrm{l}$ TE-Puffer und $1 \mu \mathrm{l}$ RNase A $(10 \mathrm{mg} / \mathrm{ml})$ aufgenommen. Die Plasmid-DNA wurde bei $-20^{\circ} \mathrm{C}$ aufbewahrt.

Diese Methode wurde vor allem für Kontrollansätze verwendet, welche der Analyse der Umklonierungen mittels Agarosegelelektophorese dienten. Bei positivem Resultat der Umklonierung erfolgte eine Isolierung der DNA-Fragmente aus dem Agarosegel (s. 2.3.12) sowie die im Folgenden beschriebene Maxi-Präparation. 


\subsubsection{Maxi-Präparation}

Zur Aufreinigung großer Mengen an Plasmid-DNA für stabile Transfektionen wurde das Maxi-Plasmid-Aufreinigungskit AX 500 der Firma MACHEREY-NAGEL (Düren, D) nach Angaben des Herstellers verwendet.

Hierfür wurden zunächst, wie bereits beschrieben, $100 \mathrm{ml} \mathrm{LB/Ampicillin-Medium} \mathrm{mit} \mathrm{einer}$ Einzelkolonie angeimpft und über Nacht bei $37^{\circ} \mathrm{C}$ geschüttelt $(150 \mathrm{rpm})$. Die Bakterienkultur wurde am nächsten Tag in zwei $50 \mathrm{ml}$ Falconröhrchen überführt und bei $4000 \mathrm{rpm}$ 10 Minuten bei $4^{\circ} \mathrm{C}$ zentrifugiert und der Überstand verworfen.

Das Bakterienpellet wurde mit $6 \mathrm{ml} \mathrm{S} 1$-Puffer $\left(4^{\circ} \mathrm{C}\right)$, welcher RNAsen enthält, resuspendiert und mit $12 \mathrm{ml} \mathrm{S2-Puffer} 5$ Minuten bei Raumtemperatur lysiert. Danach folgte die Zugabe von $12 \mathrm{ml}$ kaltem S3-Puffer, vorsichtiges Invertieren des Lysats sowie 5 Minuten Inkubation auf Eis. Das Lysat wurde dann durch einen mit Aqua destillata befeuchteten Faltenfilter in einen neues $50 \mathrm{ml}$ Falconröhrchen filtriert und auf die bereits mit $6 \mathrm{ml} \mathrm{N} 2$-Puffer äquilibrierte Säule gegeben. Anschließend wurde die Säule mit $32 \mathrm{ml}$ Waschpuffer N3 gewaschen und mit $15 \mathrm{ml}$ Eluationspuffer N5 eluiert. Das Eluat wurde nun mit $11 \mathrm{ml}$ Isopropanol versetzt und gut durchmischt. Nach einer Zentrifugation bei $15000 \mathrm{rpm}\left(4^{\circ} \mathrm{C}\right) 30 \mathrm{~min}$ wurde der Überstand vorsichtig abgegossen, das Pellet mit $50 \mu \mathrm{l}$ Ethanol gelöst und erneut 10 min bei $15000 \mathrm{rpm}$ zentrifugiert. Der Überstand wurde vorsichtig abgesaugt und das Pellet im Brutschrank getrocknet. Die DNA wurde in $400 \mu \mathrm{l}$ TE-Puffer gelöst und die DNA-Reinheit und -Konzentration mittels photometrischer Analyse ermittelt (s. 2.3.11).

\subsubsection{Reinigung von DNA durch Phenol-Chloroform-Extraktion}

Zur Aufreinigung großer Mengen DNA nach Restriktion oder erfolgter Maxi-Präparation wurde eine Phenolfällung vorgenommen. Dazu wurde die DNA-Lösung mit gleichem Volumen Phenol/Chloroform/Isoamylalkohol (Verhältnis: 25:24:1) versetzt, vermischt und für 30 Sekunden bei RT und $14000 \mathrm{rpm}$ zentrifugiert. Die DNA-haltige wäßrige obere Phase wurde daraufhin abgenommen, in ein neues steriles $1,5 \mathrm{ml}$ Reaktionsgefäß überführt, nochmals mit 1 Volumen Phenol/Chloroform/Isoamylalkohol versetzt, gevortext und wie beschrieben abzentrifugiert. Die Fällung der DNA erfolgte durch Zugabe von 1/10 Volumen $3 \mathrm{M}$ Natriumacetat $\mathrm{pH} \mathrm{4,8}$ und 2,5 Volumen eiskaltem Ethanol absolut. Nach mindestens 30 minütiger Lagerung bei $-20^{\circ} \mathrm{C}$ wurde die DNA sedimentiert (30 min, $14000 \mathrm{rpm}$ ), das 
Pellet mit $70 \%$-igem Ethanol gewaschen, getrocknet und schließlich in TE-Puffer aufgenommen. Die Ermittlung des DNA-Gehalts erfolgte mittels photometrischer Analyse und wird im Folgenden beschrieben.

\subsubsection{Konzentrations- und Reinheitsbestimmung von DNA}

Die Bestimmung der Konzentration und Reinheit gelöster DNA erfolgte über die Messung der optischen Dichte der DNA-Lösungen bei $260 \mathrm{~nm}$ und $280 \mathrm{~nm}$. Die Wellenlänge von $260 \mathrm{~nm}$ entspricht dem Absorptionsmaximum der Nukleotide AMP und UMP, wobei eine $\mathrm{OD}_{260}$ von 1 einer Konzentration von $50 \mu \mathrm{g} / \mu \mathrm{l}$ doppelsträngiger DNA entspricht. Der Quotient aus $\mathrm{OD}_{260}$ und $\mathrm{OD}_{280}$ ist ein $\mathrm{Maß}$ für die Reinheit der DNA-Lösung. Er sollte zwischen 1,8 und 2,0 liegen; ein geringerer Wert weist auf Verunreinigungen durch Proteine hin.

Standardmäßig wurden $2 \mu 1$ DNA Lösung mit $98 \mu$ Puffer verdünnt und die Konzentration der Lösung gegen einen Leerwert aus reinem Puffer im Spektralphotometer bestimmt.

\subsubsection{Agarose-Gelelektrophorese}

Die Agarose-Gelelektophorese ermöglicht die Auftrennung von DNA-Molekülen gemäß ihrer Molekülgröße (Fisher und Dingman 1971). Sowohl zur Analyse (nach erfolgter PlasmidAufreinigung durch die STET-Methode) als auch zur Aufreinigung von DNA-Fragmenten wurden horizontale, native Agarosegele verwendet, wobei sich die gewählte Agarosegelkonzentration aus der Größe der aufzutrennenden Fragmente ergibt. In der Regel wurden $1 \%$-ige Gele verwendet.

Der entsprechende Anteil an Agarose wurde in 1x TBE Puffer aufgekocht, mit $4 \mu 1 / 100 \mathrm{ml}$ Ethidiumbromidstammlösung versetzt und in die Gelkammer gegossen, wobei mittels eines Kunststoffkammes die Probentaschen ausgespart blieben. Nach Erkalten des Gels und der Herausnahme des Kammes wurden die Proben (mit 1/10 Volumen DNA-Ladepuffer (20 \% w/v Ficoll 400, 0,25 \% w/v Bromphenolblau, $100 \mathrm{mM}$ EDTA, $1 \% \mathrm{w} / \mathrm{v}$ SDS pH 8,0) gemischt) aufgetragen. Das Gel wurde in die Agarosegelelektrophoresekammer (gefüllt mit 1x TBE-Puffer) eingesetzt und die DNA-Proben bei etwa $120 \mathrm{~mA}$ elektrophoretisch aufgetrennt. Anschließend wurden die erhaltenen DNA-Banden mittels eines UVTransilluminators $(254 \mathrm{~nm})$ detektiert, dokumentiert und ausgewertet. 


\subsubsection{Isolierung von DNA-Fragmenten aus Agarosegelen}

Um DNA-Fragmente aus dem Agarosegel zu isolieren, wurde das QIAquick Gel Extraktionskit gemäß der Gebrauchsanweisung des Herstellers verwendet. Hierbei wurden zunächst die DNA-Fragmente aus dem Gel herausgeschnitten und gewogen. Anschließend wurden 3 Volumen des Puffers QX1 hinzugegeben und für 10 min bei $50^{\circ} \mathrm{C}$ inkubiert. Sobald sich das Gelfragment vollständig gelöst hatte, wurde das Gemisch auf die QIAquick-Säule gegeben und abzentrifugiert. Um die an die Säule gebundene DNA zu waschen, wurden 0,75 ml PEPuffer hinzugegeben und erneut zentrifugiert. Schließlich wurde die DNA mit 30 - $50 \mu$ EBPuffer eluiert.

\subsubsection{Molekulargewichtsmarker}

Um die Größe elektrophoretisch aufgetrennter DNA-Fragmente bestimmen zu können, wurden neben den $\mathrm{zu}$ untersuchenden Proben auch DNA-Längenstandards als Vergleichsstandard aufgetragen. Hierzu wurden jeweils 0,5 $\mu \mathrm{g}$ der DNA Ladder High Range (1500 bis 10000) bzw. DNA Ladder Mix (80 bis 10000bp) der Firma MBI Fermentas GmbH verwendet.

\subsubsection{Stabile Transfektion von Plasmid-DNA in RBL-2H3-Zellen}

Die Transfektion ermöglicht bei geeigneten Expressionsvektoren die Synthese von Fremdgenen in eukaryotischen Zellen. Bei der stabilen Transfektion wird die eingebrachte DNA in das Wirtsgenom integriert und an die Tochterzellen weitergegeben. Diese Methode hat den Vorteil, dass mit gleichbleibender Expression der Fremdproteine gut reproduzierbare Experimente durchgeführt werden können, beinhaltet aber einen langwierigen Selektionsprozess. 


\subsubsection{Elektroporation}

Bei der Elektroporation werden die Zellen kurzen elektrischen Impulsen hoher Spannung ausgesetzt, infolgedessen für kurze Zeit nanometergroße Poren in den Plasmamembranen der Zielzellen entstehen, wodurch die zu transfizierende DNA in die Zellen gelangen kann (Neumann et al., 1982). Dort integriert sie an zufälliger Stelle im Genom. Die Identifizierung und Isolierung der stabil transfizierten Zellen erfolgt durch Kotransfektion des Resistenzgens für Neomycin.

Zur Transfektion von RBL-2H3-Zellen wurde die zu transfizierende DNA zunächst linearisiert. Die Restriktion erfolgte idealerweise im Ampicillin-Gen des Vektors durch PvuI. Der Restriktion schloss sich jeweils eine Phenol-Fällung (s. 2.3.10) der DNA an.

Die etwa zu $80 \%$ konfluent gewachsenen RBL-2H3-Zellen wurden mit Trypsin/EDTA abgelöst, in 80/20-10-Medium aufgenommen und gezählt. Nach zweimaligem Waschen mit PBS wurden die Zellen auf eine Zellzahl von 4 × $10^{7}$ Zellen $/ \mathrm{ml}$ in PBS eingestellt und auf Eis gelagert.

Daraufhin wurden $20 \mu \mathrm{g}$ des linearisierten Expressionsvektors in eine auf Eis vorgekühlte Elektroporationsküvette gegeben und anschließend mit $250 \mu \mathrm{l}$ Zellsuspension für $10 \mathrm{~min}$ auf Eis inkubiert. Danach erfolgte die Elektroporation bei 260 Volt und $960 \mu \mathrm{F}$ bei RT. Die Zeitkonstante wurde notiert und die Zellen erneut für 10 min auf Eis inkubiert. Anschließend wurden die Zellen in $10 \mathrm{ml}$ vorgekühltes 80/20-10-Medium überführt und für $5 \mathrm{~min}$ bei $1000 \mathrm{rpm}$ bei RT abzentrifugiert. Das Zellpellet wurde in $1 \mathrm{ml}$ Medium resuspendiert, in 36 ml Medium überführt und auf 3 sterile 24-Loch-Zellkulturplatten verteilt, die vorher jeweils mit 0,5 ml Medium pro Napf befüllt wurden. Nach $24 \mathrm{~h}$ wurde das Medium abgesaugt und durch G418-haltiges $(600 \mu \mathrm{g} / \mathrm{ml})$ 80/20-10-Medium ersetzt. Nach weiteren 5 Tagen wurde das Medium erneuert, um Zelltrümmer zu entfernen. Nach weiteren 5 bis 10 Tagen konnten bereits Einzelzellklone isoliert werden.

\subsubsection{Identifizierung und Subklonierung von Transfektanten}

Pro stabiler Transfektion mittels Elektroporation wuchsen zwischen 10 und mehreren hundert Einzelkolonien heran. Einzeln liegende Klone wurden mit einer Pipette in einem Volumen von $20 \mu \mathrm{l}$ aspiriert und in eine 96-Loch-Zellkulturplatte überführt. Von dort aus wurden die Zellen nach 1 bis 3 Tagen auf zwei 24-Loch Näpfe aufgeteilt. Von einem der Näpfe wurde 
mittels FACS-Analyse (s. 2.2.10) die Rezeptorexpression überprüft. Von positiven Klonen wurde eine Subklonierung durchgeführt, um die Reinheit des Klons sicherzustellen. Dazu wurden die Zellen in drei Verdünnungen auf 260, 62 und 20 Zellen/ml eingestellt und in jeweils eine halbe 96-Loch-Zellkulturplatte getropft, so dass sich statistisch in jedem Napf 7,2, 2,4 bzw. 0,8 Zellen befanden. Nach etwa 10 Tagen Anzucht wurden nun erneut einzeln liegende Klone gepickt und im FACS analysiert. Falls nötig, schlossen sich erneute Subklonierungen an. Mindestens drei positive Klone pro Transfektion wurden angezogen und in funktionellen Tests verglichen, um klonale Artefakte zu vermeiden.

\subsection{Schließend- und beschreibend-statistische Auswertung}

Die erhaltenen Rohdaten der Experimente wurden mit Microsoft Excel 2000 aufbereitet und anschließend statistisch ausgewertet.

In den graphischen Darstellungen der vorliegenden Arbeit werden die Mittelwerte der Experimente und ihre Standardabweichung (SEM: Standard error of mean) widergegeben. Die statistische Signifikanz der Unterschiedlichkeit der Mittelwerte wurde mit Hilfe des Student's T-Test ermittelt, wobei die Mittelwerte zweier Experimente auf ihre Wahrscheinlichkeit eines gepaarten T-Tests mit zweiseitiger Verteilung untersucht wurden. Das Maß der statistischen Signifikanz wird durch den Faktor p angegeben. Alle Ergebnisse mit $\mathrm{p}<0,05$ wurden als statistisch signifikant eingestuft und sind mit einem Stern (*) markiert. 


\section{Ergebnisse}

\subsection{Herstellung des FPRL-2-Rezeptors}

Das zentrale Anliegen dieser Arbeit war, die Wirkungsweise der Defensine und ihrer Rezeptoren bei der Immunantwort zu analysieren und insbesondere potenzielle DefensinRezeptoren zu identifizieren.

Durch Voruntersuchungen in dem neu etablierten SCID Mausmodell der Arbeitsgruppe von Frau Prof. Dr. Soruri konnte bereits festgestellt werden, dass die humanen $\beta$-Defensine 2 und 3 potente Chemotaxine für Makrophagen und unreife DC ohne Beteiligung von CCR6 sind. Da Monocyten und ihre Abkömmlinge (Makrophagen sowie DC) den CCR6 nicht exprimieren (Greaves, 1997; Power, 1997), war es nicht überraschend, dass CCL20 (der einzig bekannte Chemokinligand des CCR6) weder Monocyten/Makrophagen noch aus Monocyten gewonnene DC im SCID Mausmodell rekrutieren konnte.

Neben den funktionellen Analysen der Defensine wurde zunächst anhand der aktuellen Erkenntnisse der Defensin-Forschung eine Eingrenzung der neben dem CCR6 in Frage kommenden bekannten Rezeptoren vorgenommen. Es stellte sich dabei heraus, dass vornehmlich der FPRL-2-Rezeptor die nötigen Charakteristika aufwies. FPRL-2 wird von Monocyten und Lymphocyten exprimiert, nicht aber von Granulocyten. Dies entspricht dem Expressionsmuster des für die $\beta$-Defensine beschriebenen Rezeptors (Yang et al., 1999). Zudem konnte das $\alpha$-Defensin HNP-1 die von fMLP (formyl-Met-Leu-Phe)-induzierte Migration von Monocyten supprimieren (Grutkoski et al., 2003), was darauf hinweisen könnte, dass beide Peptide über dieselben Rezeptoren aus der Familie der Formyl Peptid Rezeptoren (FPR) wirken.

In Folge dessen, wurde der FPRL-2-Rezeptor in den Expressionsvektor pEF/HisMycA umkloniert und anschließend stabil in RBL-2H3-Zellen transfiziert. Für die Herstellung der Transfektanten wurde die Elektroporationsmethode angewendet.

Aus den G418 resistenten Zellpopulationen wurden diejenigen Klone isoliert, kultiviert und nötigenfalls subkloniert, welche die stärkste Expression (d.h. höchste Anzahl Rezeptoren pro Zelle) des transfizierten Rezeptors aufwiesen. Als Nachweis der Expression der transfizierten Rezeptor-DNA diente die durchflusscytometrische Detektion der 3 HA-tags mit Hilfe des FITC-markierten HA-Antikörpers. Diese FACS-Analyse der Zellen wurde regelmäßig 
wiederholt, um eine mögliche Kontamination mit nicht exprimierenden Zellen bzw. klonale Artefakte frühzeitig zu erkennen.

Für die weiteren funktionellen Untersuchungen der Transfektanten wurden die drei Subklone gewählt, welche eine ähnlich starke, gleichmäßige Rezeptorexpression zeigten. In Abbildung 13 ist ein Histogramm der FACS-Analyse des für die funktionellen Untersuchungen eingesetzten Subklons 16/3 beispielhaft dargestellt.

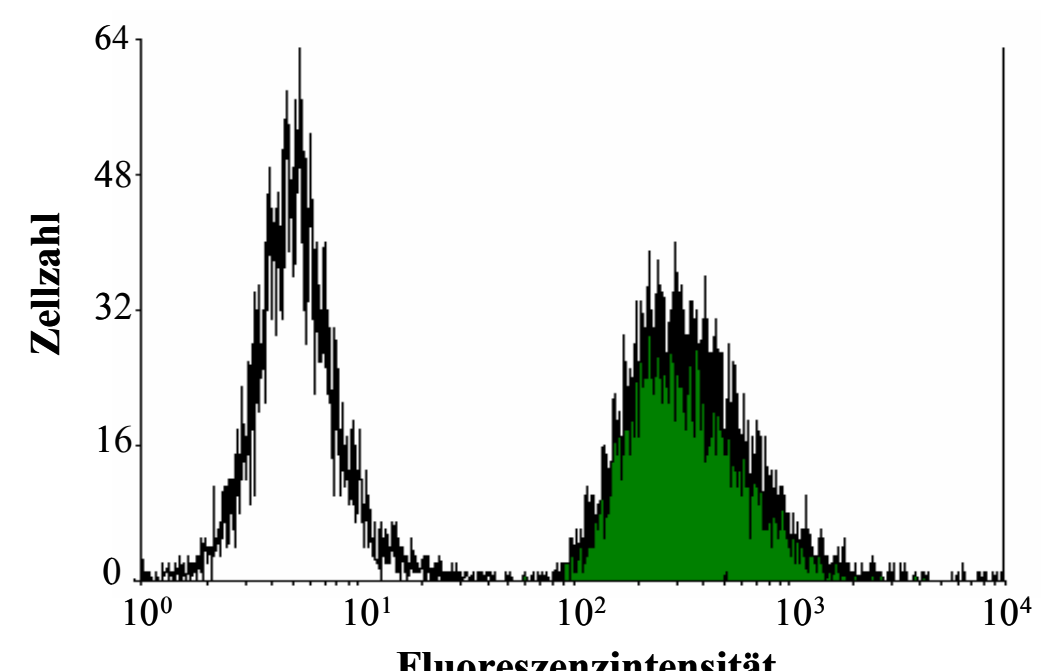

Abb. 13: Histogramm der FACS-Analyse der RBL-2H3-FPRL-2-Transfektante 16/3. Die Graphik zeigt einen overlay der Negativkontrolle (FITC/PE Isotypkontrolle; $1 \mu \mathrm{g} / 100 \mu \mathrm{l}$; weiß hinterlegt) sowie der anti-HAFITC-markierten, erfolgreich transfizierten Zellen $(1 \mu \mathrm{g} / 100 \mu \mathrm{l}$; grün hinterlegt). Dargestellt ist die Zellzahl in Abhängigkeit von der Fluoreszenzintensität, welche logarithmisch aufgetragen wurde.

\subsubsection{Funktionelle Analyse der RBL-2H3-FPRL-2-Transfektante}

Um die Funktionalität des transfizierten Rezeptors zu untersuchen, wurden zunächst in vitro Chemotaxis sowie intrazelluläre Calcium-Freisetzung in Bezug auf den in der Literatur angegebenen synthetischen Liganden des FPRL-2-Rezeptors WKYMVM (Bae et al., 2003) untersucht. Hierbei konnte weder bei den Chemotaxis Experimenten noch bei der fluoreszenzphotometrischen Calcium-Analyse ein Resultat erzielt werden. Selbst Ligandkonzentrationen zwischen 20 und $40 \mu \mathrm{M}$ konnten keine Migration bzw. Calciumfreisetzung stimulieren.

Dank neu veröffentlichter Literatur (Migeotte et al., 2005), welche darstellte, dass es sich bei WKYMVM nicht um einen effizienten Liganden des FPRL-2 handelt, und zudem ein neuer Ligand, F2L (Formyl-Peptid Rezeptor 2 Ligand), entdeckt wurde, konnten Zweifel an der erfolgreichen Transfektion widerlegt werden. Erneute Chemotaxis sowie Calcium-Messungen 
mit F2L zeigten positive Ergebnisse. Daraufhin konnten erste Untersuchungen der $\beta$-Defensin-FPRL-2-Interaktion mit F2L als Positivkontrolle durchgeführt werden.

Die folgende Graphik zeigt das Ergebnis der in vitro Chemotaxis der FPRL-2-Transfektante.

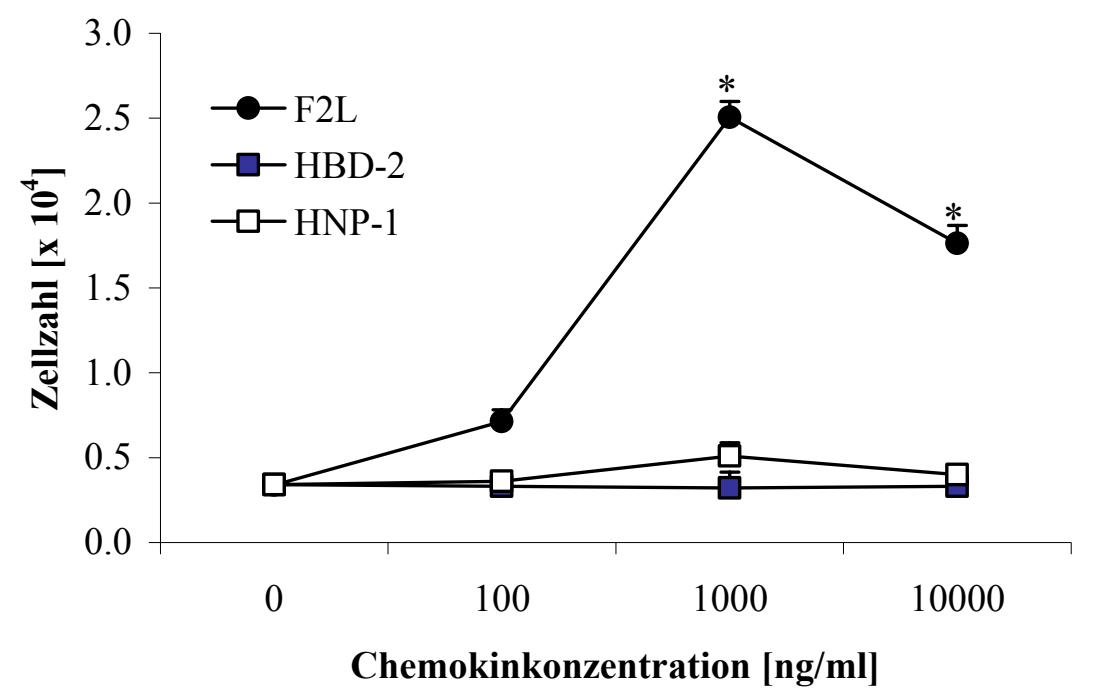

Abb. 14: Dosis-Wirkungskurven der in vitro Chemotaxis von RBL-2H3-FPRL-2-Transfektanten gegen den FPRL-2 Liganden F2L sowie die Defensine HBD-2 und HNP-1. Die Migrationszeit betrug 1,5 h und es wurden Einsätze mit einer Porengröße von $8 \mu \mathrm{m}$ verwendet. Dargestellt werden die Mittelwerte $(+$ SEM) von vier unabhängigen Experimenten. Signifikant zur Negativkontrolle $(0)$ unterschiedliche Werte $(p<0,05)$ sind mit * markiert.

Wie in Abbildung $14 \mathrm{zu}$ erkennen ist, zeigte sich für die Migrationsversuche gegen den FPRL-2 Liganden F2L eine typische dosisabhängige Chemotaxis. Bei allen G-Proteingekoppelten Rezeptoren (GPCR) steigt zunächst die Migration der Zellen bei zunehmender Chemokinkonzentration, sinkt aber bei weiter ansteigender Konzentration wieder bis auf den Nullwert zurück (Lefkowitz et al., 1998). Die abnehmende zelluläre Antwort eines GPCR auf die anhaltende oder wiederholte Stimulation mit einem Liganden wird auch als Desensibilisierung bezeichnet. Sie wird schon Sekunden nach der Ligand-Stimulation durch die Rezeptor-Phosphorylierung eingeleitet.

Das Maximum der Chemotaxis gegen F2L wurde bei einer Endkonzentration von $100 \mathrm{ng} / \mathrm{ml}$ erreicht. Statistisch signifikant im Vergleich zur Negativkontrolle waren die Messwerte bei 1000 sowie bei $10000 \mathrm{ng} / \mathrm{ml}$.

Es konnte hingegen keine Wanderung der transfizierten Zellen gegen die Defensine HBD-2 und HNP-1 detektiert werden. 
Des Weiteren wurde die Funktionalität des FPRL-2-Rezeptors mit Hilfe der deutlich sensibleren Methode der Messung der intrazellulären Calciumionenfreisetzung geprüft. Das Ergebnis dieses Experimentes ist in Abbildung 15 dargestellt.

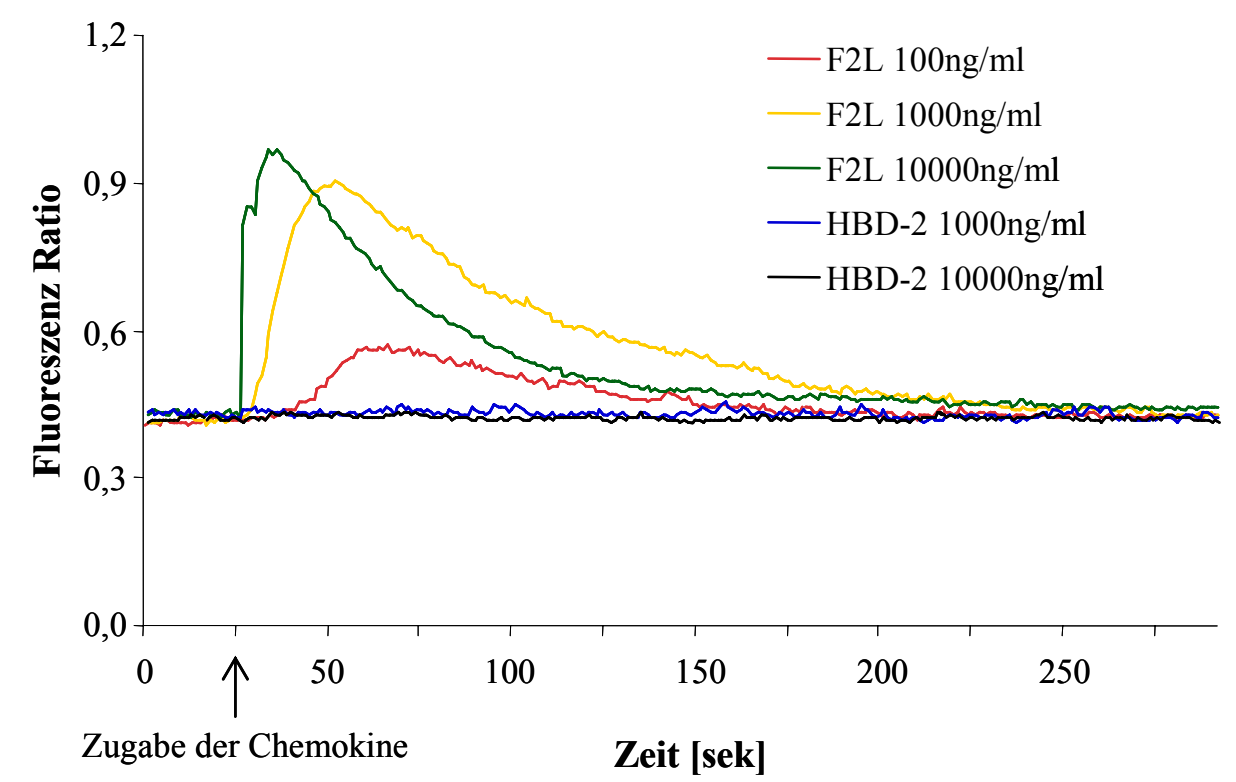

Abb. 15: Intrazelluläre Calciumfreisetzung in der RBL-2H3-FRPL-2-Transfektante nach Stimulation durch verschiedene Konzentrationen des bekannten Liganden F2L sowie durch das $\beta$-Defensin HBD-2. Als Fluoreszenz-Ratio wird das Verhältnis von blau-fluoreszierendem Indo1 zu dem violett-fluoreszierenden Indo1-Calcium-Komplex bezeichnet. Dargestellt ist beispielhaft eines von drei Experimenten.

Auch hier konnte das $\beta$-Defensin HBD-2 trotz hoher Endkonzentrationen keine Reaktion der Zellen bewirken. Dahingegen war F2L wiederum in der Lage, eine dosisabhängige Wirkung zu induzieren. Dabei wurde die intrazelluläre Calciumfreisetzung bei der höchsten F2L-Endkonzentration von $10000 \mathrm{ng} / \mathrm{ml}$ maximal stimuliert.

Da nun ausgeschlossen werden konnte, dass es sich bei dem FPRL-2-Rezeptor, um einen Rezeptor für Defensine handelt, stellte sich somit weiterhin die Frage, über welchen Rezeptor $\alpha$ - und $\beta$-Defensine ihre Wirkung erzielen. Daher wurde nun die Expression funktioneller $\alpha$ bzw. $\beta$-Defensin-Rezeptoren auf den verschiedenen Zelltypen des Immunsystems analysiert.

\subsection{Untersuchung der in vitro Migration von Granulocyten}

Zunächst wurden Granulocyten hinsichtlich ihres chemotaktischen Verhaltens gegenüber den Defensinen untersucht. Die Granulocyten wurden dafür durch Dichtegradientenzentrifugation aus Vollblut aufgereinigt und mittels FACS-Analyse auf ihre Reinheit untersucht. Die folgende Abbildung zeigt Histogramme der mittels Durchflusscytometrie erhaltenen Daten. 

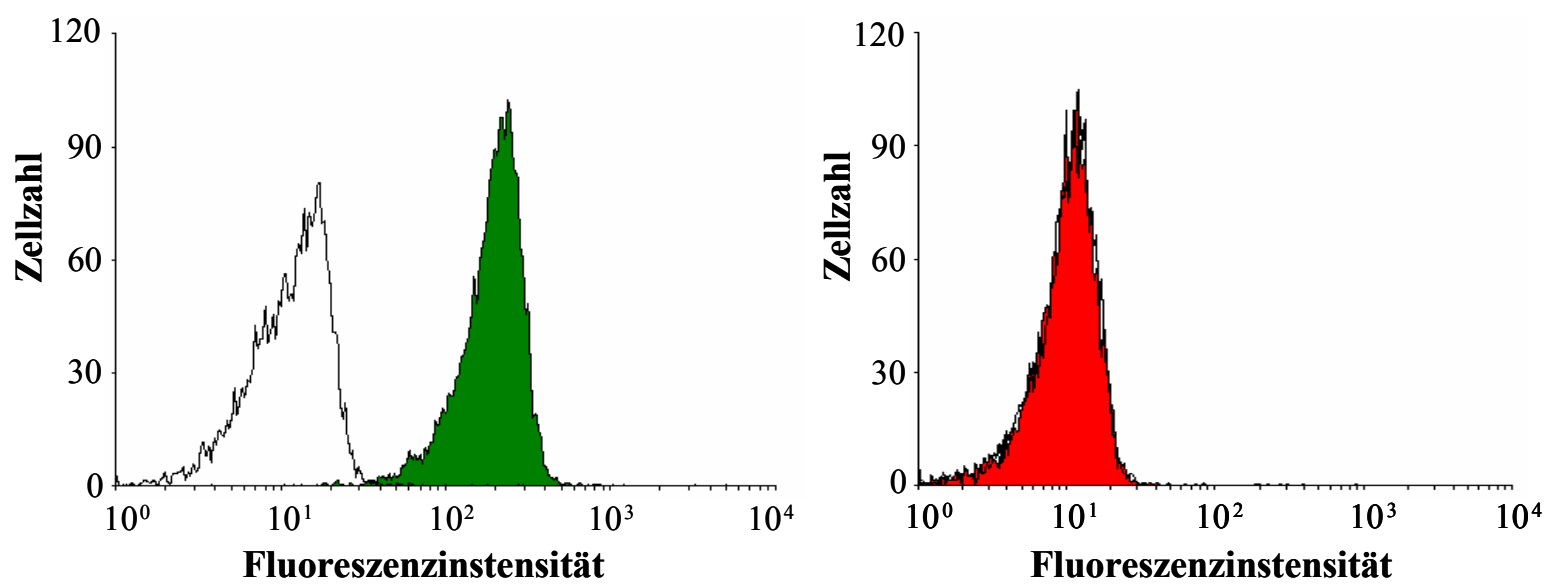

Abb. 16: Histogramme der FACS-Analyse der aus Vollblut angereicherten Granulocyten. Dargestellt ist jeweils die Zellzahl in Abhängigkeit von der Fluoreszenzintensität, welche logarithmisch aufgetragen wurde. Im linken Histogramm ist die Negativkontrolle (FITC/PE Isotypkontrolle; $1 \mu \mathrm{g} / 100 \mu \mathrm{l}$; weiß hinterlegt) sowie die Färbung des C5a-Rezeptors mit dem P12/1-FITC Antikörper $(1 \mu \mathrm{g} / 100 \mu \mathrm{l}$; grün hinterlegter peak) als overlay dargestellt. Zur Kontrolle diente die im rechten Histogramm gezeigte Färbung mit dem MHC-Klasse-IIAntikörper HLA-DR-PE (rot hinterlegter peak). Auch dies ist ein overlay von Negativkontrolle und Färbung. Die Kontrolle wird allerdings von der negativen PE-Färbung überdeckt.

Die für die folgenden in vitro Chemotaxis-Experimente (s. Abb. 17) verwendeten Zellsuspensionen enthielten $\geq 95 \%$ P12/1 positive sowie HLA-DR negative Granulocyten.

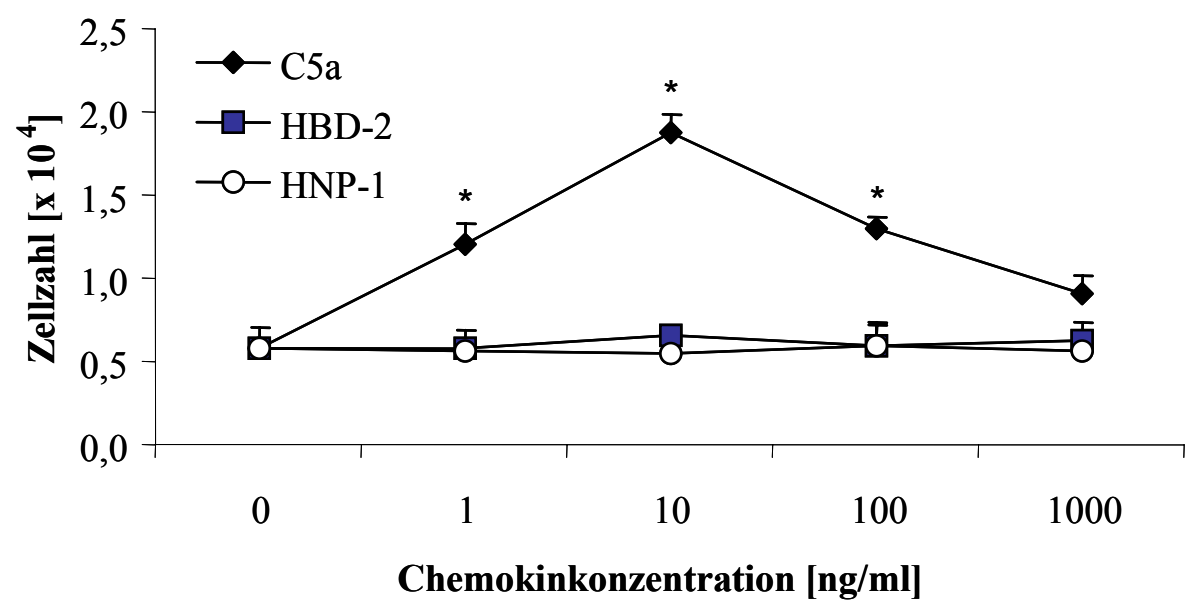

Abb. 17: Dosis-Wirkungs-Untersuchungen der Migration von Granulocyten gegen HBD-2, HNP-1 sowie C5a. Die Migrationsdauer betrug 1,5 h und es wurden Poren mit einem Durchmesser von $5 \mu \mathrm{m}$ verwendet. Es werden die Mittelwerte von 3 unabhängigen Experimenten mit der Standardabweichung der Mittelwerte (+SEM) gezeigt. Signifikanzen $(\mathrm{p}<0,05)$ sind mit * markiert.

Es konnte hierbei keine chemotaktische Reaktion der Granulocyten auf das HNP-1 und das HBD-2 festgestellt werden. Die Migration gegen das Anaphylatoxin C5a, welches als Positivkontrolle fungierte, zeigte hingegen die typische Dosis-Wirkungs-Abhängigkeit, wodurch die Funktionalität dieses Test bewiesen werden konnte (s. Abb. 17). 


\subsection{Untersuchung der in vitro Migration unbehandelter Monocyten}

Des Weiteren wurden frische, also unbehandelte Monocyten, welche direkt nach der Adhärenzzeit der Leukocytenapherese-Aufarbeitung geerntet wurden, für in vitro Chemotaxis Versuche gegen Defensine eingesetzt. Auch hier diente C5a als Positivkontrolle. In Abbildung 18 sind die Ergebnisse dieser Experimente graphisch dargestellt.

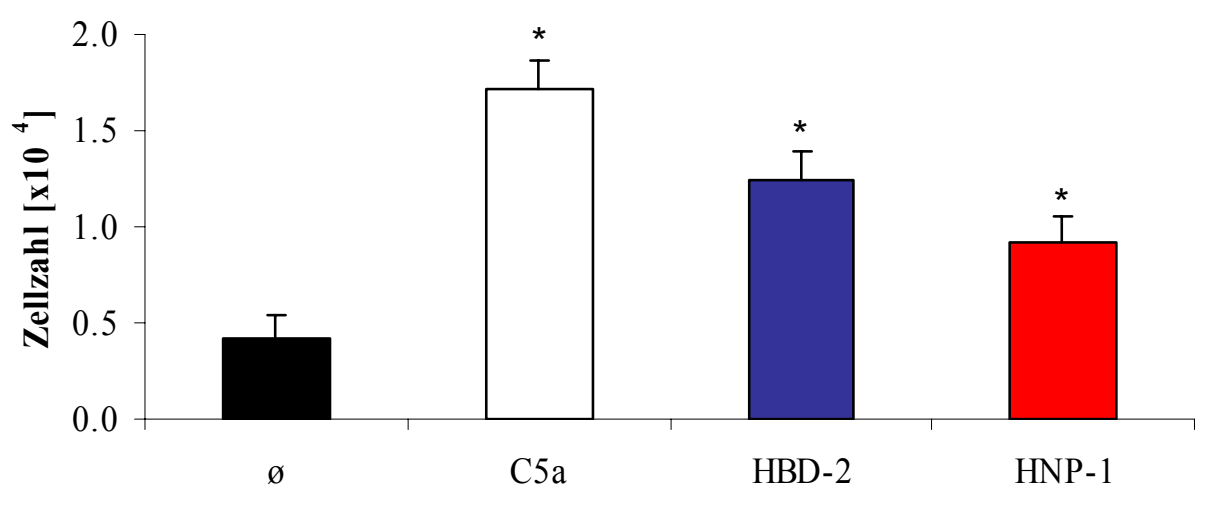

Chemokine

Abb. 18: In vitro Migration unbehandelter Monocyten gegen HBD-2, HNP-1 sowie C5a. Dargestellt sind Mittelwerte von 4 unabhängigen Experimenten (d.h. auch unterschiedliche Blutspender; +SEM). Für die 1,5stündige Wanderung der unbehandelten Monocyten gegen HBD-2 (1000 ng/ml), HNP-1 (1000 ng/ml), C5a $(100 \mathrm{ng} / \mathrm{ml})$ sowie gegen die Negativkontrolle ohne Chemokinzusatz $(\varnothing)$ wurde eine Porengröße von $8 \mu \mathrm{m}$ verwendet. Signifikanzen sind bei $\mathrm{p}<0,05 \mathrm{mit} *$ angegeben.

Die Abbildung verdeutlicht, dass bereits unbehandelte Monocyten in der Lage sind, sowohl gegen das $\alpha$-Defensin HNP-1, als auch gegen das $\beta$-Defensin HBD-2 mit Migration zu reagieren. Für das Anaphylatoxin konnte eine Vervierfachung der spontanen Wanderung der Zellen ohne Chemokineinsatz erreicht werden, während sich die Defensin-abhängige Migration gegen HBD-2 verdreifachte und gegen HNP-1 lediglich verdoppelte. Die eingesetzten optimalen Chemokinkonzentrationen ergaben sich aus zuvor durchgeführten diversen Vorversuchen, welche zwecks Übersicht hier nicht aufgeführt werden.

\subsection{Untersuchung der in vitro Migration humaner Makrophagen}

In Folge der positiven Ergebnisse für unbehandelte Monocyten, erfolgte die Untersuchung von aus Monocyten generierten Makrophagen. Diese wurden nach 2- bis 3-tägiger Kultivierung mit dem Cytokin GM-CSF (100 U/ml) und FACS-Analyse des 
Makrophagenmarkers CD14 sowie HLA-DR zur Bestätigung der Reinheit der Zellen ( $\geq 98 \%$ ) sowohl mittels in vitro als auch in vivo Chemotaxis untersucht.

Für die in vitro Chemotaxis wurden hierbei alle kommerziell erhältlichen $\alpha$ - und $\beta$-Defensine sowie der CCR6-Ligand CCL20 eingesetzt. Die Ergebnisse der $\beta$-Defensin-induzierten in vitro Chemotaxis sind in der Abbildung 19 dargestellt.

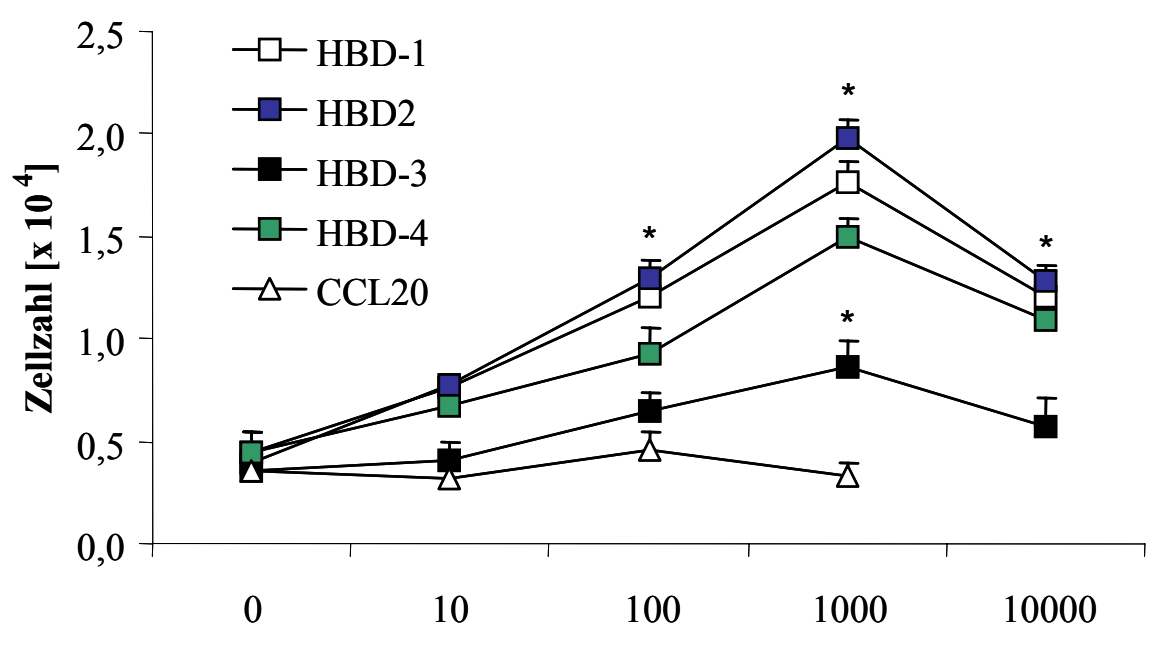

Chemokinkonzentration [ng/ml]

Abb. 19: Dosis-Wirkungs-Diagramm der in vitro Chemotaxis von humanen Makrophagen gegen $\beta$-Defensine. Dargestellt sind die Mittelwerte von 4 unabhängigen Experimenten (+SEM) bei einer Inkubationszeit von $1,5 \mathrm{~h}$ und einem Porendurchmesser von $8 \mu \mathrm{m}$. Zwecks Übersichtlichkeit wurden nicht alle Signifikanzen markiert (*). Für HBD-1, HBD-2 sowie HBD-4 waren alle Werte bei 100, 1000 und $10000 \mathrm{ng} / \mathrm{ml}$ signifikant $(\mathrm{p}<0,05)$.

Die Abbildung zeigt deutliche Unterschiede in der Chemotaxis-induzierenden Wirkung der $\beta$-Defensine auf die Makrophagen. Zwar weisen alle Mitglieder der $\beta$-Defensin-Familie einen maximalen Effekt bei $1000 \mathrm{ng} / \mathrm{ml}$ auf, die Stärke der Wirkung und somit die Anzahl der angelockten Zellen divergiert jedoch erheblich. Hat sich die migrierte Zellzahl bei $1000 \mathrm{ng} / \mathrm{ml}$ HBD-2 im Vergleich zur Negativkontrolle verfünffacht und bei HBD-4 vervierfacht, so ist bei dem $\beta$-Defensin HBD-3 lediglich eine Verdopplung bei optimaler Konzentration zu erkennen. Dahingegen ist bei Einsatz des CCR6-Liganden CCL20 keine Migration im Sinne der Chemotaxis detektierbar.

Im Folgenden sind die Ergebnisse der in vitro Chemotaxis von humanen Makrophagen gegenüber verschiedenen $\alpha$-Defensinen graphisch dargestellt. 


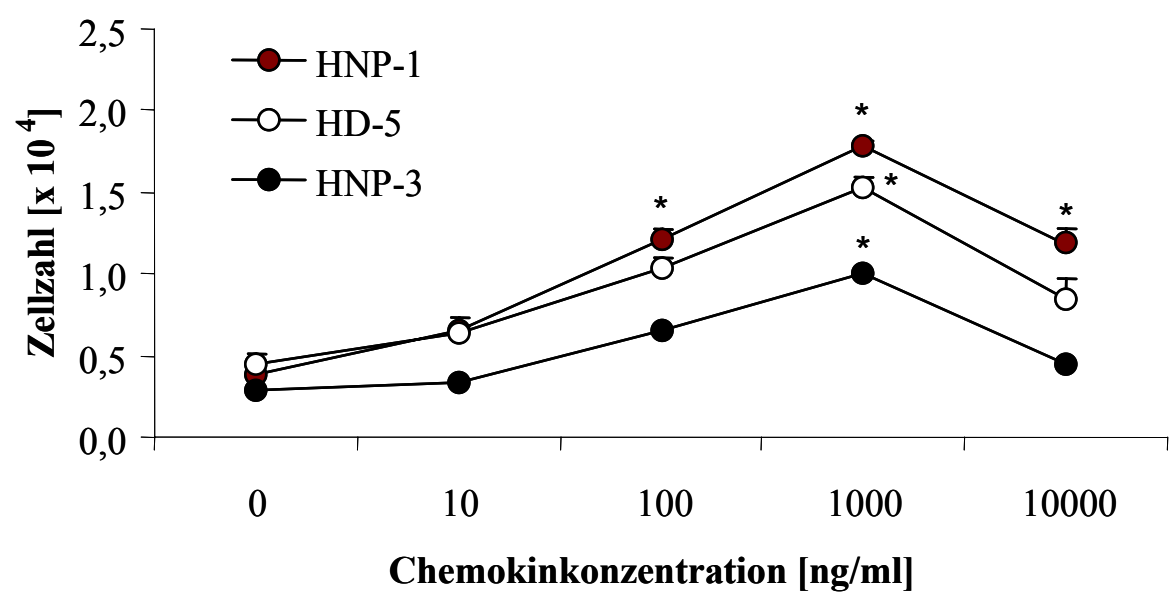

Abb. 20: In vitro Migration humaner Makrophagen gegen die $\alpha$-Defensine HNP-1, HNP-3 sowie HD-5. Die Migrationsdauer betrug 1,5 h. Es wurde eine Porengröße von $8 \mu \mathrm{m}$ verwendet. Dargestellt sind die Mittelwerte von 3 unabhängigen Experimenten (+SEM). Signifikanzen sind bei $\mathrm{p}<0,05$ mit * angegeben.

Bei der Untersuchung der humanen Makrophagen hinsichtlich ihrer Migrationsfähigkeit gegen die hier verwendeten $\alpha$-Defensine konnte eine konzentrationsabhängige Wirkung aller Defensine nachgewiesen werden. Auch hier lag die optimale Konzentration der Chemokine bei $1000 \mathrm{ng} / \mathrm{ml}$ und der typische glockenförmige Kurvenverlauf ist wiederum zu erkennen. Bei optimaler Konzentration verfünffachte sich die Migration der Makrophagen gegen HNP-1 im Vergleich zur Negativkontrolle. Das von den Paneth-Zellen synthetisierte HD-5 führte zu einer unwesentlich schwächeren Wanderung der Makrophagen, während die von HNP-3 ausgelöste Chemotaxis bei $1000 \mathrm{ng} / \mathrm{ml}$ dreimal so hoch ausfiel wie die spontane Wanderung ohne Chemokin.

\subsection{Untersuchung der in vivo Chemotaxis humaner Makrophagen}

Um die Aussagekraft der in vitro Versuche evaluieren zu können, wurde ein Teil der Experimente in vivo wiederholt. Da die Anzahl der verwendeten Versuchstiere auf ein Minimum limitiert werden sollte, wurden hier jedoch deutlich weniger Experimente durchgeführt. Somit zeigen die nachfolgenden Histogramme die Ergebnisse der Migration der humanen Makrophagen gegen verschiedene Chemokine bei gleichzeitiger Analyse der Blockierbarkeit durch das untersuchte sowie durch andere Chemokine. Hierfür wurden die Makrophagen zuvor mit $2 \mu \mathrm{g} / \mathrm{ml}$ des jeweiligen Chemokins für eine Stunde präinkubiert. 


\section{C5a}

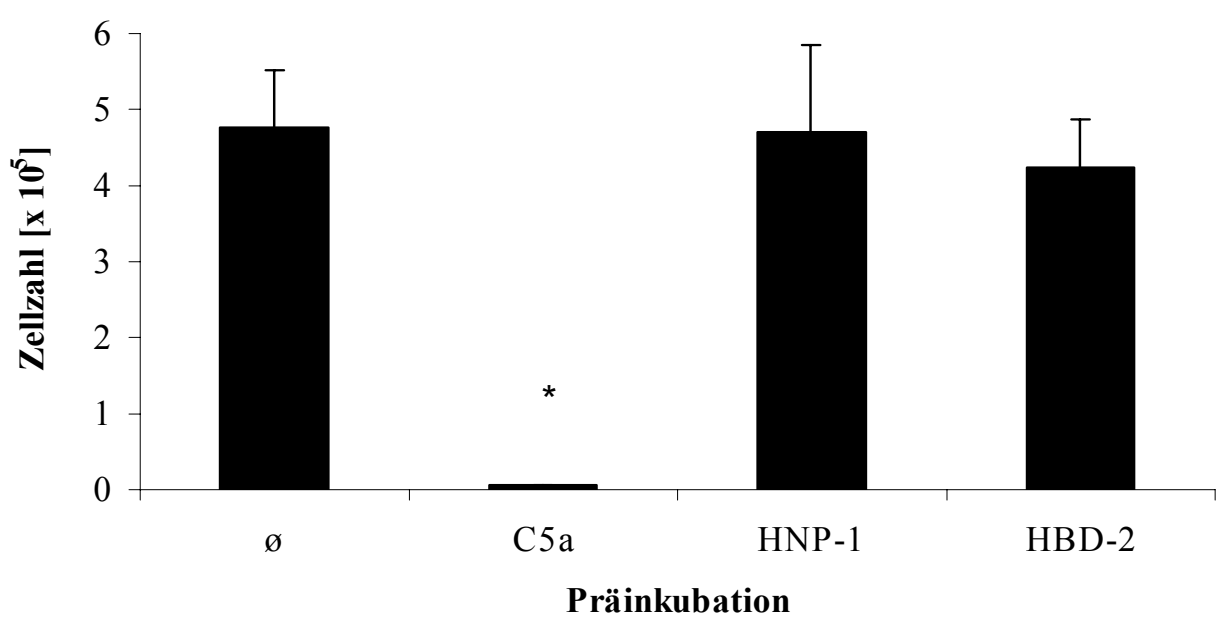

Abb. 21: Migration von humanen Makrophagen gegen C5a in vivo. Die vierstündige Migration erfolgte gegen $10 \mu \mathrm{g}$ C5a nach einer 30minütigen Präinkubation mit C5a, HNP-1 und HBD-2 (jeweils $2 \mu \mathrm{g} / \mathrm{ml}$ für $1 \mathrm{~h}$ bei $37^{\circ} \mathrm{C}$ ) oder ohne Präinkubation $(\varnothing)$. Dargestellt sind die Mittelwerte von 3 unabhängigen Experimenten (+SEM). Als signifikant gilt $\mathrm{p}<0,05(*)$.

Abbildung 21 zeigt den chemotaktischen Effekt des Anaphylatoxins C5a auf humane Makrophagen im in vivo System der SCID-Maus. Die durch C5a ausgelöste Chemotaxis lässt sich durch Präinkubation mit sich selbst bis auf ein Minimum reduzieren. Dahingegen zeigen die Defensine HNP-1 und HBD-2 keine inhibierende Wirkung auf die C5a vermittelte Migration.

Dieses Experiment diente als Beweis, dass das in vivo System reproduzierbare Ergebnisse lieferte und die von C5a induzierte Wanderung als gerichtete angesehen werden konnte, da mit Hilfe der Inhibition durch C5a selbst eine spezifische Wirkung nachgewiesen werden konnte.

Auch das $\beta$-Defensin HBD-2 konnte in vivo eine Migration der humanen Makrophagen induzieren. Zudem ließ sich die Wanderung durch Präinkubation mit sich selbst, aber auch mit dem $\beta$-Defensin HBD-3 vollständig inhibieren. Eine deutliche Reduktion der chemotaktischen Effekte des HBD-2 auf die humanen Makrophagen wurde ebenfalls durch das $\alpha$-Defensin HNP-1 erreicht, wenngleich dies nicht zu einer kompletten Blockade der Wanderung führte (s. Abb. 22). 
HBD-2

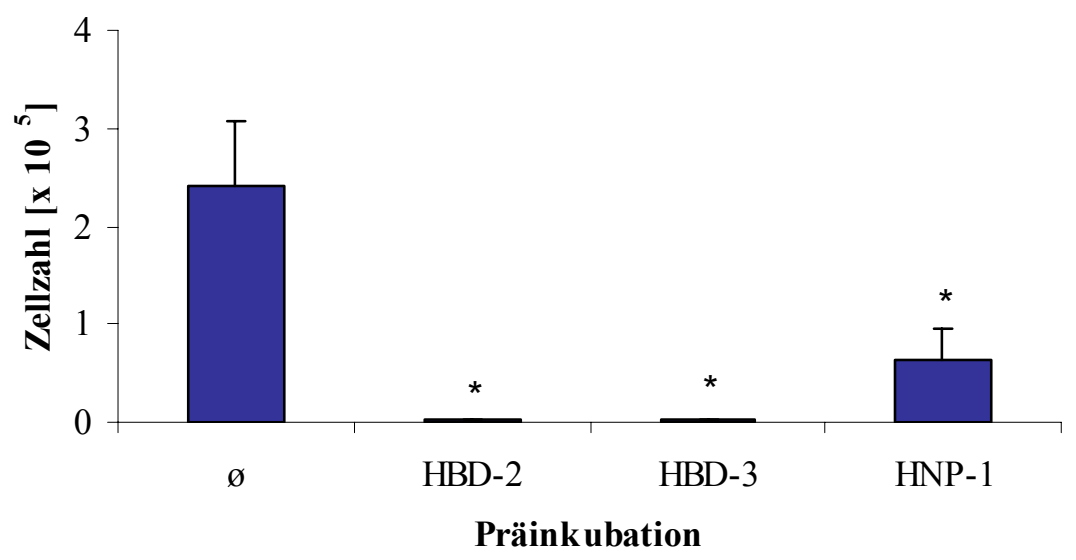

Abb. 21: In vivo Chemotaxis von humanen Makrophagen gegen HBD-2 (1000 $\mathbf{~ n g / m l ) . ~ D i e ~ M i g r a t i o n s z e i t ~}$ betrug $4 \mathrm{~h} .1 \times 10^{7}$ Zellen wurden jeweils $1 \mathrm{~h}$ mit $2 \mu \mathrm{g} / \mathrm{ml}$ Chemokin bzw. Chemotaxismedium $(\varnothing)$ präinkubiert. Die Graphik zeigt die Mittelwerte 3 unabhängiger Experimente (+SEM) sowie die signifikanten Unterschiede (* bei $\mathrm{p}<0,05)$.

Im Folgenden ist das Migrationsverhalten der humanen Makrophagen gegenüber dem $\alpha$-Defensin HNP-1 dargestellt.

\section{HNP-1}

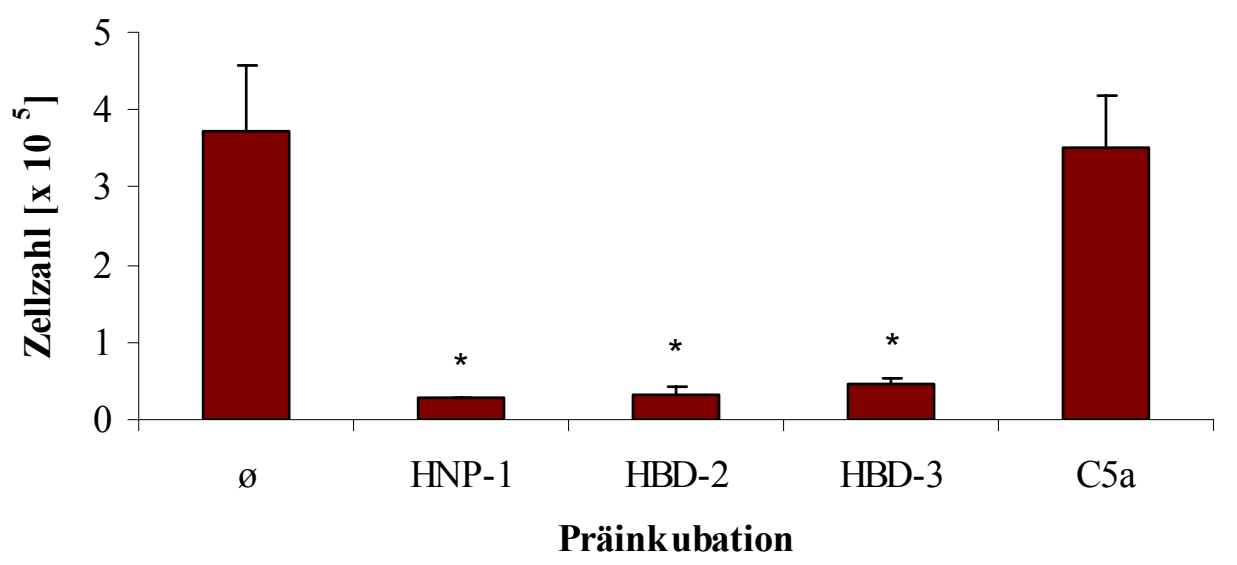

Abb. 23: Ergebnisse der in vivo Chemotaxis humaner Makrophagen gegen HNP-1. Die vierstündige Migration gegen 1000 ng/ml HNP-1 erfolgte nach Präinkubation der Zellen mit verschiedenen Chemokine ( $1 \mathrm{~h}$, $37^{\circ} \mathrm{C}$ mit $2 \mu \mathrm{g} / \mathrm{ml}$ Chemokin) bzw. ohne Präinkubation $(\varnothing)$. Dargestellt sind die Mittelwerte von 3 unabhängigen Experimente sowie deren Standardabweichungen ( $+\mathrm{SEM}) . \mathrm{p}<0,05$ wurde als signifikant $(*)$ bezeichnet.

Das $\alpha$-Defensin HNP-1 konnte eine gerichtete Migration der humanen Makrophagen in vivo stimulieren. Sowohl HNP-1 selbst als auch die $\beta$-Defensine HBD-2 und HBD-3 blockierten 
die Chemotaxis gegen HNP-1 deutlich. Im Gegensatz dazu zeigte die Präinkubation mit C5a keinerlei Effekt auf die gegen HNP-1 gerichtete Wanderung der Makrophagen (s. Abb. 23).

Da es sich bei HD-5 um das $\alpha$-Defensin handelt, welches die geringste AminosäuresequenzÄhnlichkeit mit allen anderen $\alpha$-Defensinen aufweist (lediglich ca. $50 \%$ Übereinstimmung in der AS Sequenz; Jones et al., 1992), wurde auch das Wanderungsverhalten der Makrophagen gegenüber diesem Chemokin untersucht (s. Abb. 24).

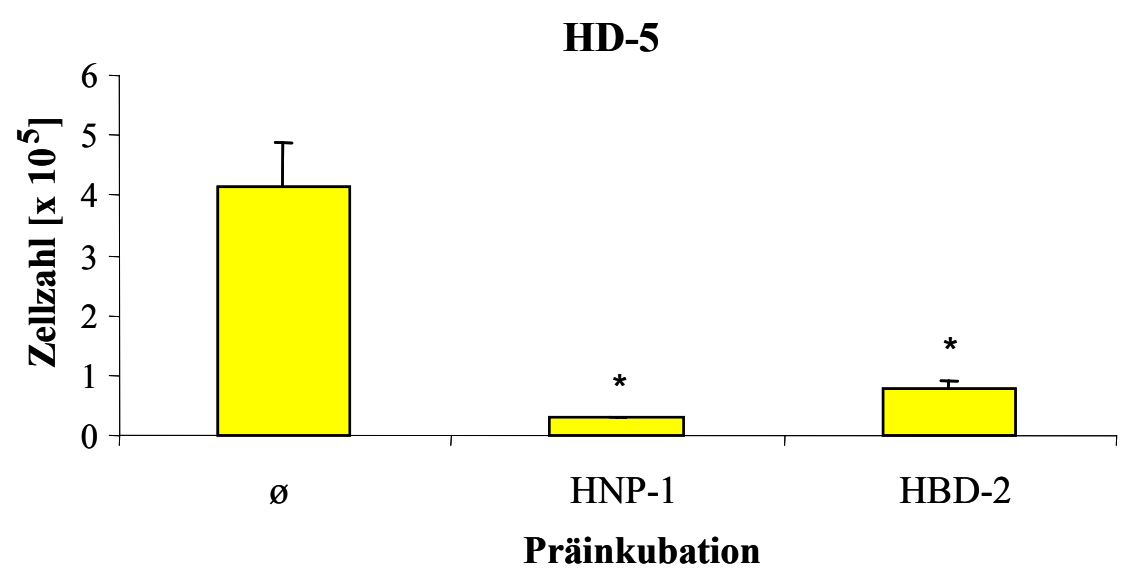

Abb. 24: HD-5-induzierte in vivo Migration von humanen Makrophagen. Die Zellen wurden vor der vierstündigen Migration gegen $1000 \mathrm{ng} / \mathrm{ml}$ HD-5 mit HNP-1 und HBD-2 (je $2 \mu \mathrm{g} / \mathrm{ml}, 1 \mathrm{~h}$ bei $37^{\circ} \mathrm{C}$ ) bzw. Medium ( $\varnothing)$ präinkubiert. Die Mittelwerte von 3 independenten Experimenten sowie deren Standardabweichungen werden dargestellt. Bei $\mathrm{p}<0,05 *$ Markierung.

HD-5 konnte eine gerichtete Migration der humanen Makrophagen in vivo auslösen. Diese Chemotaxis ließ sich durch HNP-1 stark und durch das $\beta$-Defensin HBD-2 schwächer inhibieren.

Diese Ergebnisse bestätigen somit die in vivo Relevanz der $\alpha$ - und $\beta$-Defensin-induzierten chemotaktischen Anlockung der Makrophagen und zeigt die Möglichkeit der gegenseitigen Überkreuz-Desensibilisierung beider Defensin-Familienmitglieder.

\subsection{Untersuchung der Migration humaner dendritischer Zellen}

Zur Generierung von dendritischen Zellen in vitro wurden die Cytokine Il-4 sowie GM-CSF verwendet. Bei einem Vergleich der Migration von dendritischen Zellen und Makrophagen wurde kürzlich entdeckt, dass das Il-4 einen inhibierenden Effekt auf die Anaphylatoxininduzierte Migration der Zellen ausübt (Soruri et al., 2003). Wie sich nun herausstellte, konnte die IL-4 Behandlung zudem die Migration von humanen, aus Monocyten generierten 
dendritischen Zellen gegen $\alpha$ - und $\beta$-Defensine sowohl in vitro als auch in vivo reduzieren. Abbildung 25 zeigt die Ergebnisse der in vitro Untersuchungen, während in Abbildung 26 die in vivo Daten graphisch darstellt.

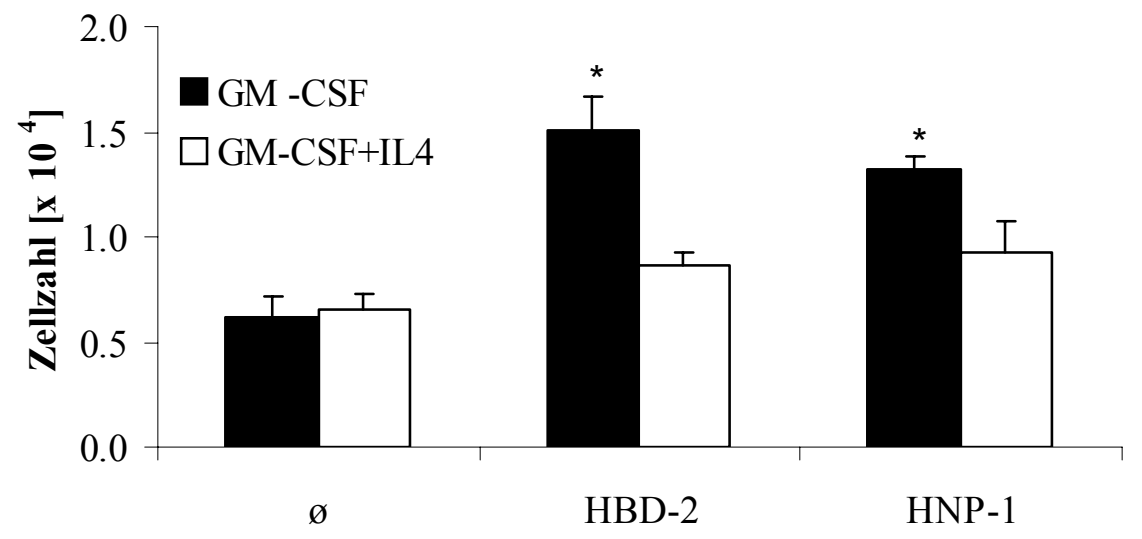

Chemokine

Abb. 25: Vergleich der in vitro Migration von DC (GM-CSF+IL-4) und Makrophagen (GM-CSF) gegen HBD-2 und HNP-1. Die Defensin-Konzentrationen betrugen jeweils $1000 \mathrm{ng} / \mathrm{ml}$. Die Negativkontrolle $(\varnothing)$ stellt die Migration gegen Medium ohne Chemokinzusatz dar. Die Inkubationszeit betrug $1,5 \mathrm{~h}$ bei $37^{\circ} \mathrm{C}$ und es wurde jeweils ein Porendurchmesser von $8 \mu \mathrm{m}$ verwendet. Dargestellt sind die Mittelwerte von 3 unabhängigen Experimenten sowie deren Standardabweichungen $(+$ SEM). Signifikant unterschiedliche Ergebnisse $(p<0,05)$ sind mit * markiert.

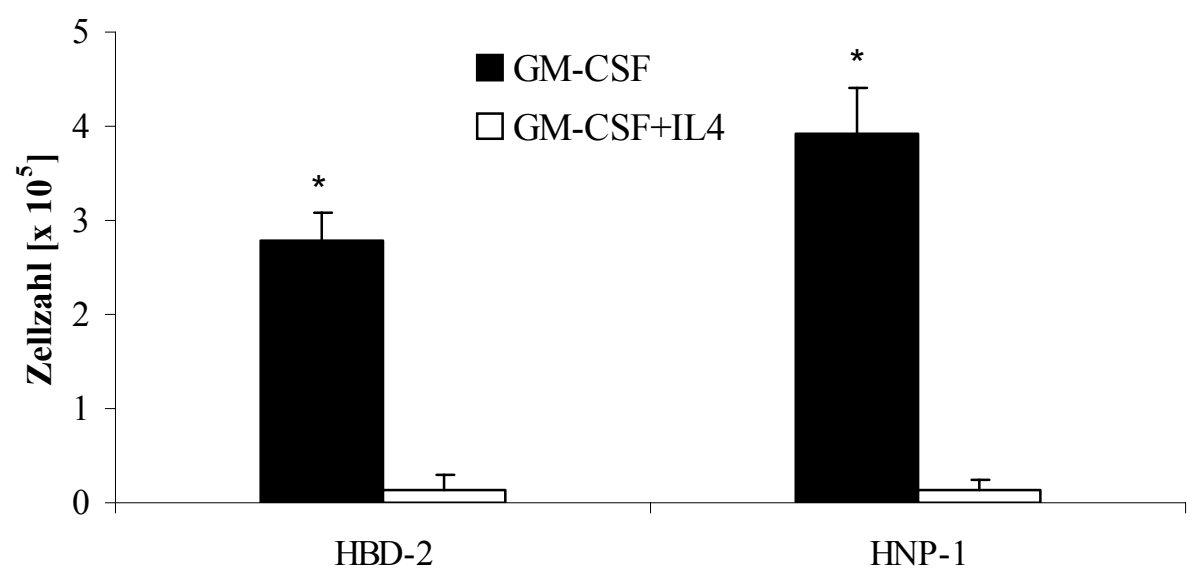

Chemokine

Abb. 26: Ergebnis der in vivo Chemotaxis mit GM-CSF und IL-4 kultivierter MoDC sowie GM-CSF stimulierter Makrophagen. Die Zellen wurden den SCID-Mäusen intravenös, die Chemokine $(10 \mu \mathrm{g})$ intraperitoneal appliziert und nach einer Inkubationszeit von $4 \mathrm{~h}$ mittels Peritoneallavage geerntete Zellen durch FACS-Analyse identifiziert (HLA-DR-PE + FITC-anti-CD14 Markierung der Makrophagen; HLA-DR-PE + FITC-anti-CD86 Markierung der DC). Dargestellt sind die Mittelwerte von 3 unabhängigen Experimenten und die Standardabweichung des Mittelwertes (+SEM). Als signifikant unterschiedlich (*) galten die Werte der Migration der GM-CSF zu den GM-CSF/IL-4 behandelten Zellen bei $\mathrm{p}<0,05$. 
Noch deutlicher als bei den in vitro Untersuchungen wurde die Migration der aus Monocyten gewonnenen DC in vivo durch die Kultivierung mit IL-4 stark reduziert. Die Anzahl der gewanderten DC sank etwa auf ein Zehntel der ermittelten Zellzahlen der Makrophagenwanderung.

\subsection{Untersuchung der Migration muriner DC sowie muriner Makrophagen}

Um weitere Bestätigung für die Hypothese $\mathrm{zu}$ finden, dass vor allem Makrophagen als primäre Zielzellen für Defensine fungieren, wurde die Migration muriner Makrophagen und dendritischer Zellen verglichen (s. Abb. 27). Die Makrophagen wurden aus murinen Knochenmarkszellen in Gegenwart von muM-CSF generiert. Für die Entwicklung der dendritischen Zellen aus dem Knochenmark erfolgte eine Kultivierung mit muGM-CSF.

A

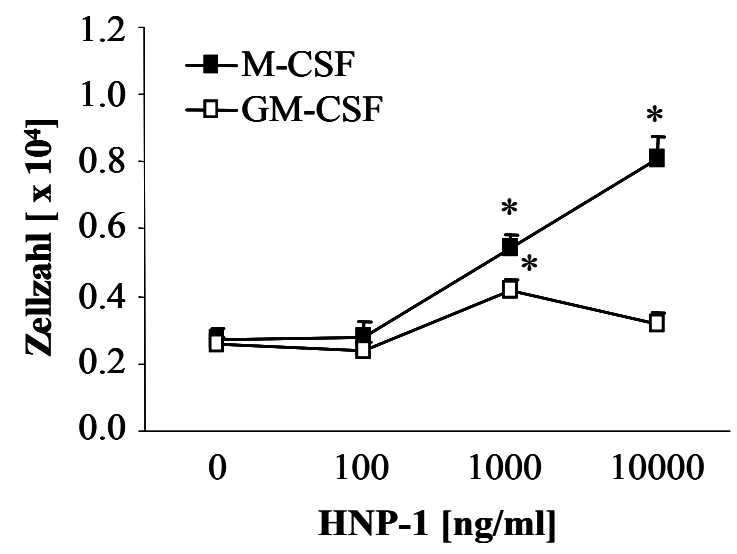

$\mathbf{C}$

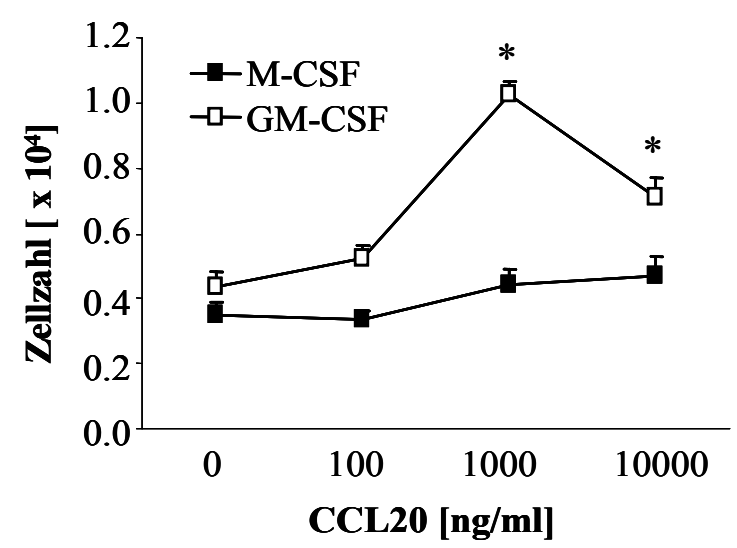

B

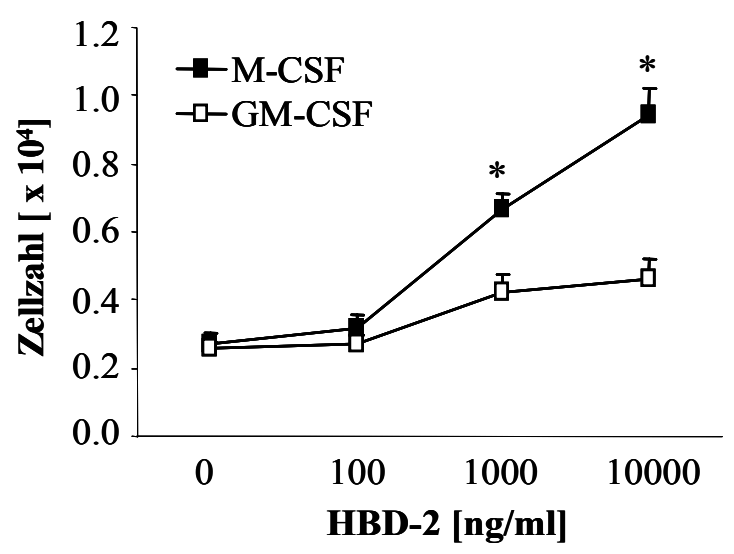

Abb. 27: Dosis-Wirkungskurven der in vitro Migration muriner Makrophagen (M-CSF) sowie muriner DC (GM-CSF) gegen die Defensine HNP-1 (A) und HBD-2 (B) sowie den CCR6-Liganden CCL20 (C). Es wurden Einsätze mit einem Porendurchmesser von $8 \mu \mathrm{m}$ verwendet und die Inkubationszeit betrug 1,5 h. Die Mittelwerte von drei unabhängigen Experimenten sowie deren Standardabweichungen (+SEM) und die im Vergleich zur Negativkontrolle (0) signifikanten Werte $(*$; bei $\mathrm{p}<0,05)$ sind dargestellt. 
Die Diagramme A und B der Abbildung 27 zeigen, dass sowohl das $\alpha$-Defensin HNP-1 als auch das $\beta$-Defensin HBD-2 präferenziell murine Makrophagen anlockten. Die maximal angelockte Zellzahl wurde jeweils bei einer Chemokinkonzentration von $10000 \mathrm{ng} / \mathrm{ml}$ ermittelt. Signifikant messbar war bei der Chemotaxis der dendritischen Zellen lediglich die Wanderung gegen 1000 ng/ml HNP-1. Im Gegensatz dazu induzierte CCL20 (s. Abb. 27/C) vornehmlich die Migration muriner dendritischer Zellen. CCL20 bewirkte eine eindeutig dosisabhängige Reaktion der dendritischen Zellen, was durch die glockenförmige Kurve deutlich wird. Das Optimum der CCL20-Konzentration lag bei 1000 ng/ml. Makrophagen wurden hingegen kaum messbar angelockt.

Im Folgenden sind die Ergebnisse der in vivo Chemotaxis der murinen dendritischen Zellen sowie Makrophagen graphisch dargestellt. Hierfür wurden die murinen Zellen vor der intravenösen Applikation in Balb/c Mäuse zur Ermöglichung der späteren Detektion mittels Durchflusscytometrie mit dem rot fluoreszierenden Farbstoff PKH-26 markiert.

A

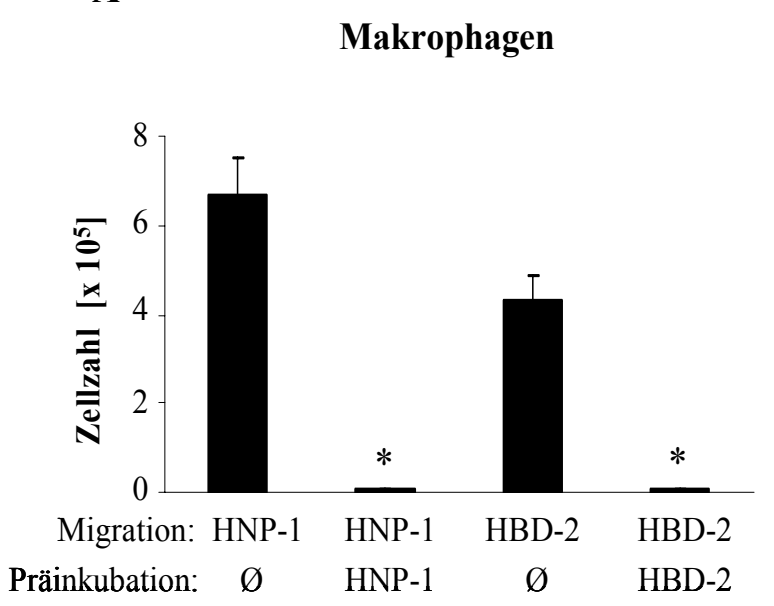

B

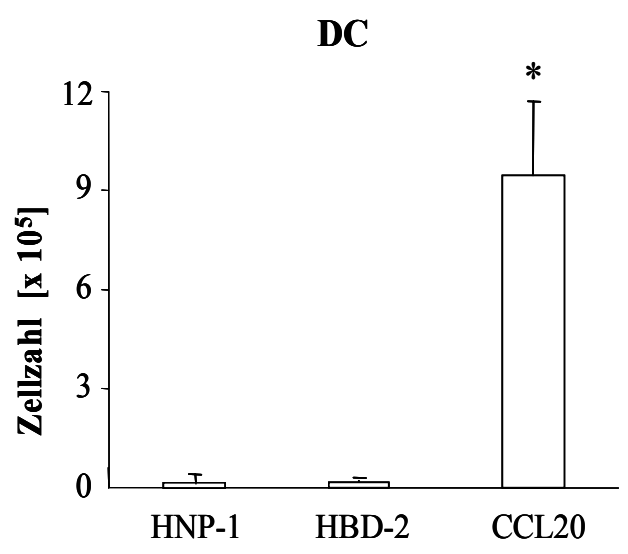

Abb. 28: Migration muriner Makrophagen (A) sowie muriner DC (B) in vivo. Die Migrationszeit betrug $15 \mathrm{~h}$. Es wurden $10 \mu \mathrm{g} \mathrm{HNP}-1$ und HBD-2 bei A sowie $20 \mu \mathrm{g}$ bei B intraperitoneal injiziert Die eingesetzte CCL20-Konzentration betrug $10 \mu \mathrm{g}$. Bei vorheriger Präinkubation (A) wurden $1 \times 10^{7}$ Zellen für $1 \mathrm{~h} \mathrm{mit} 2 \mu \mathrm{g} / \mathrm{ml}$ des jeweiligen Chemokins präinkubiert. Es werden die Mittelwerte von 3 unabhängigen Experimenten sowie deren Standardabweichungen (SEM) gezeigt. Als signifikant unterschiedlich zur Migration ohne vorherige Blockade wurden die Daten gewertet, bei denen der T-Test $p<0,05$ ergab $\left(^{*}\right)$.

Die Ergebnisse der in vivo Chemotaxis bestätigen die Aussage der in vitro Daten. Während die Defensine HNP-1 und HBD-2 eine spezifische Migration der murinen Makrophagen auslösten, welche sich durch Präinkubation desselben Defensins nahezu vollständig blockieren ließ, induzierten die Vertreter der beiden Defensin-Familien keinerlei Chemotaxis der murinen dendritischen Zellen. Das $\alpha$-Defensin HNP-1 konnte zudem eine größere Anzahl 
muriner Makrophagen anlocken als das $\beta$-Defensin HBD-2. CCL20 hingegen bewirkte eine starke gerichtete Migration der murinen dendritischen Zellen (s. Abb. 28/B).

Weiterhin wurde in diesem Zusammenhang die murine Makrophagen-Zelllinie J774A.1 untersucht. Die Resultate der in vitro Migrations-Versuche werden in der Abbildung 29 gezeigt.

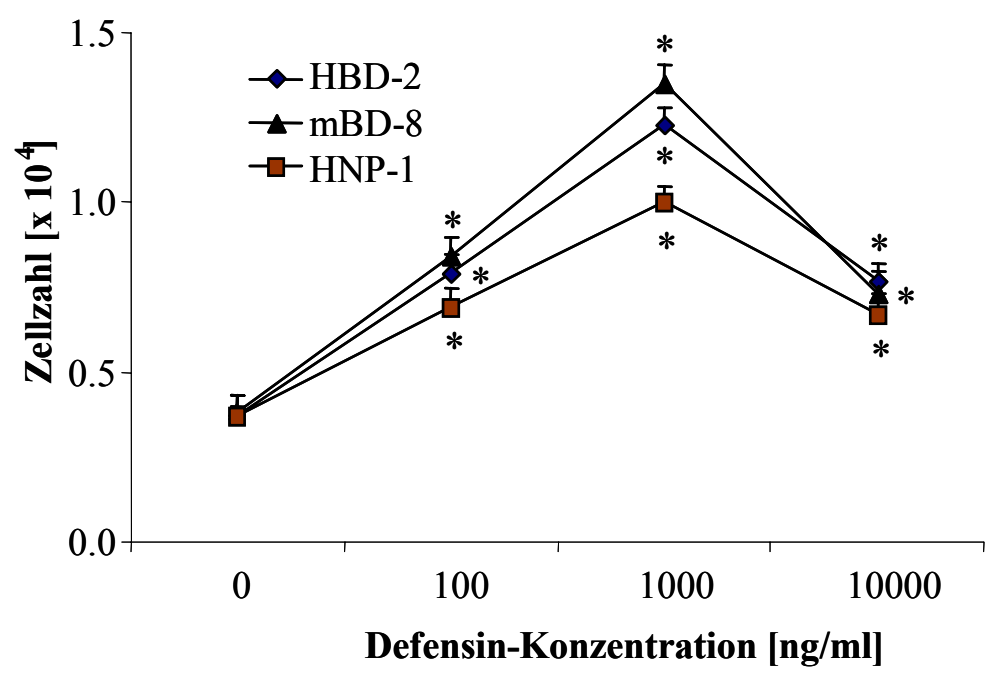

Abb. 29: Konzentrationsabhängige Wanderung der murinen Makrophagen Zelllinie J774A.1 in vitro. Der verwendete Porendurchmesser betrug $8 \mu \mathrm{m}$. Die Zellen wurden für 1,5 h im Brutschrank inkubiert. Dargestellt sind die Mittelwerte von 3 unabhängigen Experimente sowie die Standardabweichung (+SEM). Als signifikant unterschiedlich zur Negativkontrolle $(0)$ galt $\mathrm{p}<0,05$. Diese Werte sind mit * gekennzeichnet.

Auch die murine Makrophagen-Zelllinie J774A.1 ließ sich, wie Abbildung 29 zeigt, sowohl durch die humanen Defensine HNP-1 und HBD-2 als auch durch das murine Defensin mBD8 chemotaktisch anlocken. Wiederum ist eine deutliche Dosis-Wirkungsabhängigkeit mit einer maximalen Zellwanderung bei Defensin-Konzentrationen von $1000 \mathrm{ng} / \mathrm{ml}$ zu erkennen. Einen geringfügig größerer Effekt auf die Migrationsfähigkeit der J774A.1 Zellen als durch die humanen Defensine wurde durch das murine $\beta$-Defensin mBD-8 erzielt.

\subsection{Untersuchung der Migration humaner T-Lymphocyten}

Die $\beta$-Defensine HBD-1 bis -3 wurden in der Literatur bereits als selektive Chemokine für Gedächtnis-T-Zellen sowie unreife DC, welche über den CCR6-Rezeptor agieren, beschrieben (Biragyn et al., 2001; Yang et al., 1999; Wu et al., 2003; Conejo-Garcia et al., 2004). Dahingegen konnte für die $\alpha$-Defensine HNP-1 und HNP-2 eine spezifische Anlockung von naiven T-Lymphocyten und ebenfalls von unreifen dendritischen Zellen 
gezeigt werden (Yang et al., 2000). Aufgrund der zuvor in dieser Arbeit beschriebenen Ergebnisse hinsichtlich einer stärkeren Gewichtung der Defensin-induzierten Migration der Makrophagen, sowie ersten Zweifeln an der postulierten CCR6-Beteiligung der durch $\beta$-Defensine ausgelösten Chemotaxis, erfolgten weitere Untersuchungen an T-Lymphocyten.

Es wurden hierfür aus humanen PBMNL nach Dichtegradientenzentrifugation mittels magnetischer Zellsortierung (MACS) naive $\mathrm{CD}^{+}$- und $\mathrm{CD}^{+} / \mathrm{CD} 45 \mathrm{RA}^{+}$-T-Zellpopulationen sowie $\mathrm{CD}^{+}$- und $\mathrm{CD}^{+} / \mathrm{CD} 45 \mathrm{RO}^{+}$-Gedächtnis-T-Zellpopulationen selektiert.

\subsubsection{Untersuchung der Migration von $\mathrm{CD}^{+} / \mathrm{CD} 4 \mathrm{RO}^{+}$T-Lymphocyten}

Zunächst erfolgte die Analyse der Gedächtnis-T-Zellen, um die Ergebnisse der Literatur zu verifizieren.

Die folgenden Histogramme zeigen die Resultate der im Anschluss an die Aufreinigung durchgeführte FACS-Analyse der Gedächtnis-T-Zellen.

A

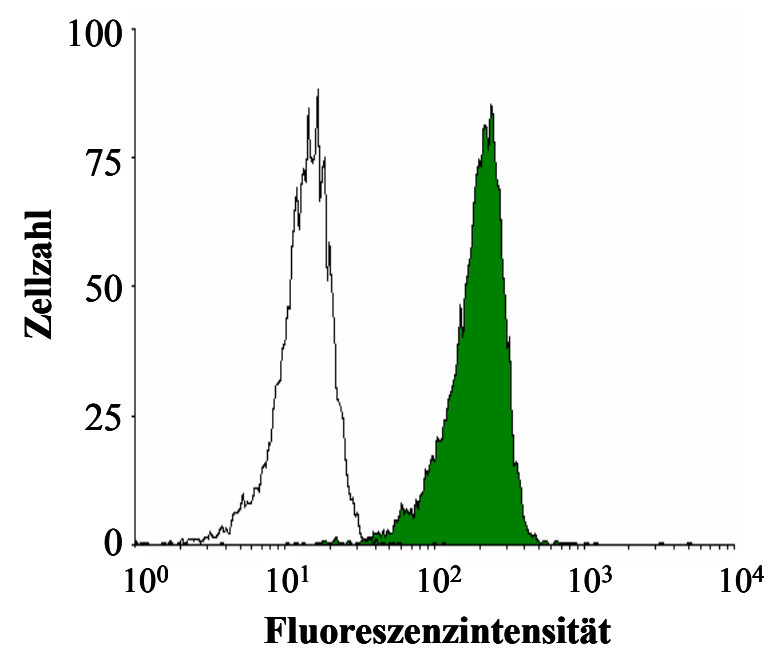

B

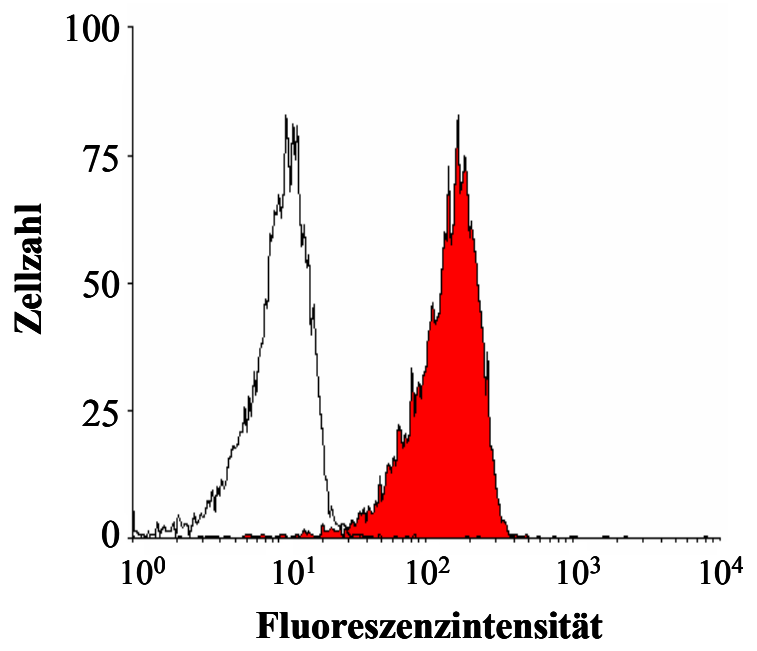

Abb. 30: Histogramme der FACS-Analyse mittels magnetischer Zellsortierung aufgereinigter GedächtnisT-Zellen. A zeigt die anti-CD45RO-FITC gefärbten Zellen (grün hinterlegt) sowie die Isotypkontrolle (FITC/PE; $1 \mu \mathrm{g} / 100 \mu \mathrm{l}$; weiß hinterlegt). In B ist das Ergebnis der Färbung mit anti-CD4-PE (1 $\mu \mathrm{g} / 100 \mu \mathrm{l}$; rot hinterlegt) sowie die entsprechende Isotypkontrolle (weiß hinterlegt) dargestellt. Gezeigt wird jeweils die Zellzahl in Abhängigkeit der Fluoreszenzintensität. Die mit Hilfe der Doppelfärbung anti-CD45RO-FITC/antiCD4-PE ermittelte Reinheit der T-Zellpopulation war immer größer als $95 \%$.

Die Resultate der in vitro Chemotaxis-Versuche mit den Gedächtnis-T-Lymphocyten zeigt die Abbildung 31. Dabei wurde sowohl die Wirkung von $\alpha$ - als auch von $\beta$-Defensinen im Vergleich zu CCL20 untersucht. 
A

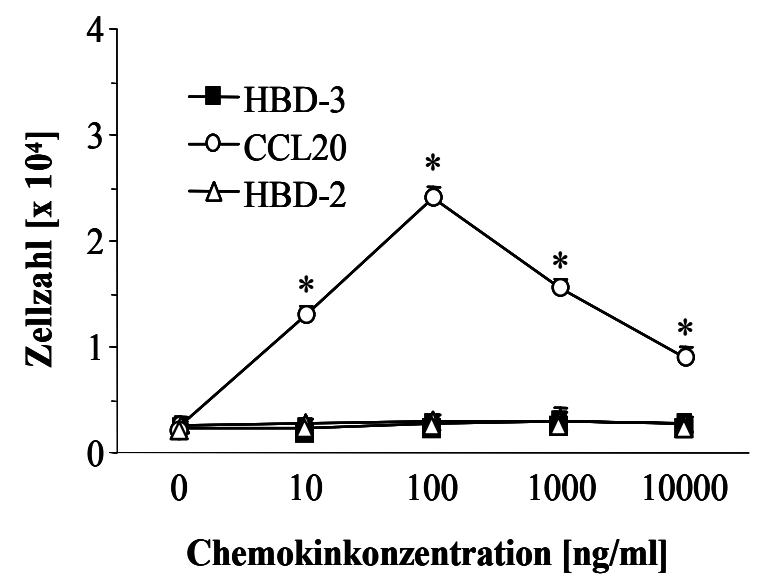

B

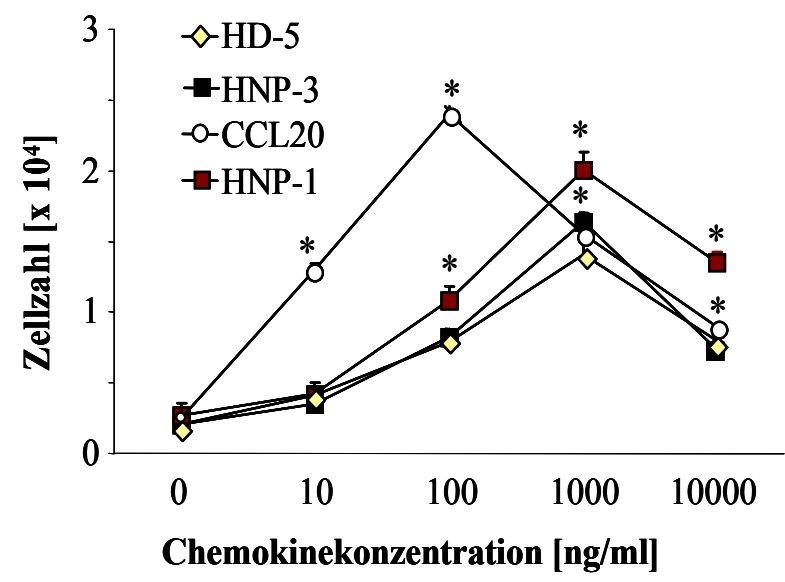

Abb. 30: Ergebnisse der konzentrationsabhängigen in vitro Migration von $\mathrm{CD4}^{+} / \mathrm{CD}^{45 \mathrm{RO}^{+}}$ T-Lymphocyten gegen die $\beta$-Defensine HBD-2 und HBD-3 (A) sowie gegen die $\alpha$-Defensine HNP-1, HNP-3 und HD-5 (B) im Vergleich zur CCL20-induzierten Wanderung. Die Migrationszeit betrug $4 \mathrm{~h}$ bei einer Porengröße von $5 \mu \mathrm{m}$. Dargestellt werden die Mittelwerte von 3 unabhängigen Ergebnissen sowie deren Standardabweichungen (+SEM). Bei $\mathrm{p}<0,05$ Markierung der Signifikanz durch *. Aus Gründen der besseren Übersicht, wurden in B bei 100 bis $1000 \mathrm{ng} / \mathrm{ml}$ nicht alle Werte mit Stern markiert, wenngleich alle signifikant unterschiedlich zu den Negativkontrollen (0) waren.

Während die $\beta$-Defensine HBD-2 und HBD-3 bei keiner der hier verwendeten Konzentrationen die Fähigkeit zur chemotaktischen Anlockung der Gedächtnis-T-Zellen aufweisen konnten (s. Abb. 30/A), induzierten alle getesteten $\alpha$-Defensine eine dosisabhängige Wanderung dieser T-Lymphocyten Subpopulation (s. Abb. 30/B). Dabei konnte ein maximaler Effekt jeweils bei einer Defensin-Konzentration von $1000 \mathrm{ng} / \mathrm{ml}$ erzielt werden. Die effektivste Anlockung der Gedächtnis T-Zellen erfolgte hingegen durch CCL20, wobei die größte Anzahl gewanderter Zellen bereits bei 100 ng/ml CCL20 zu detektieren war.

Da die Chemotaxis gegen CCL20 besonders stark ausfiel, während keinerlei Chemotaxis durch HBD-2 ausgelöst werden konnte, erfolgte eine weitere Untersuchung dieser Zusammenhänge durch einen in vitro Migrationsversuch gegen CCL20 mit und ohne Präinkubation durch sich selbst sowie durch $\alpha$ - und $\beta$-Defensine. Die Resultate dieser Experimente sind in der folgenden Abbildung graphisch dargestellt. 


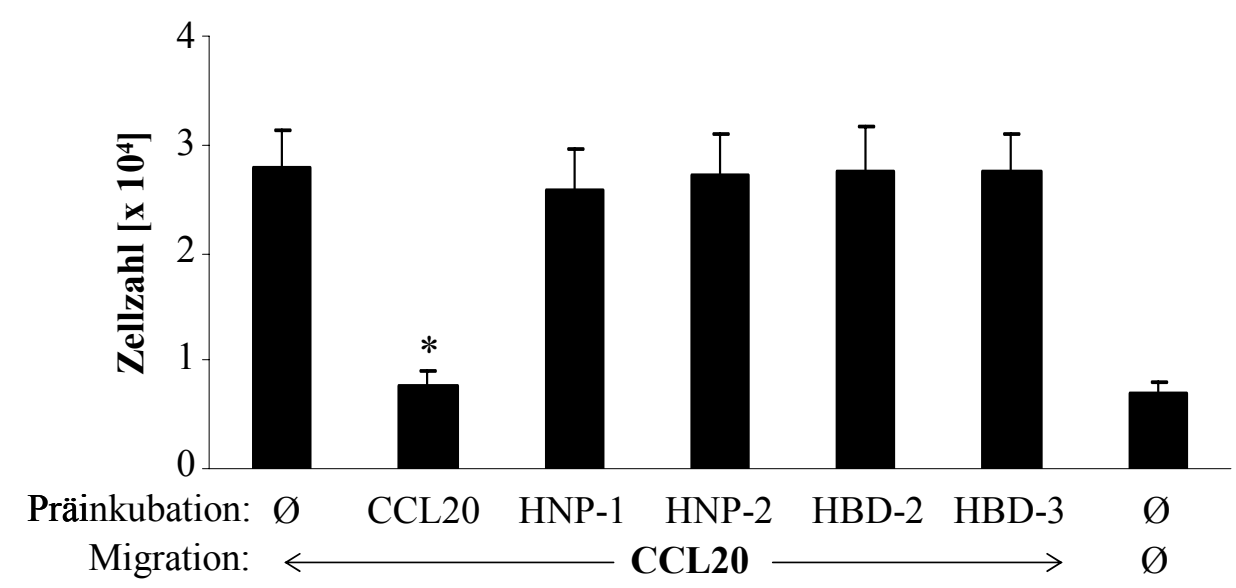

Abb. 32: In vitro Chemotaxis von $\mathrm{CD}^{+} / \mathrm{CD}$ 450 ${ }^{+}$-T-Lymphocyten gegen CCL20. Vor der Migration gegen $100 \mathrm{ng} / \mathrm{ml}$ CCL20 erfolgte eine Präinkubation mit $200 \mathrm{ng} / \mathrm{ml}$ CCL20, HNP-1, HNP-2, HBD-2 sowie HBD-3 bzw. mit Medium ohne Chemokinzusatz (Ø) für 30 min bei $37^{\circ} \mathrm{C}$. Die Inkubationszeit lag bei $4 \mathrm{~h}$ und es wurde ein Porendurchmesser von $5 \mu \mathrm{m}$ verwendet. Die Mittelwerte von 3 unabhängigen Ergebnissen sowie deren Standardabweichungen (+SEM) werden gezeigt. Bei $\mathrm{p}<0,05$ erfolgte eine Markierung der Signifikanz durch *.

Die Ergebnisse der Abbildung 32 zeigen eindrücklich, dass die Mitglieder beider DefensinFamilien keine Desensibilisierung der durch CCL20 induzierten Wanderung der Gedächtnis T-Zellen bewirken konnten. Die Migration der T-Lymphocyten gegen CCL20 ist allerdings als spezifisch zu bewerten, da sie von diesem Chemokin selber komplett (bis in den Bereich der Negativkontrolle (Ø)) inhibierbar ist.

\subsubsection{Untersuchung der Migration von $\mathrm{CD}^{+} / \mathrm{CD}^{2}$ RA ${ }^{+}$T-Lymphocyten}

Die Untersuchung der in vitro Chemotaxis naiver T-Zellen sollte zeigen, ob die $\alpha$-Defensine tatsächlich in der Lage sind, diese T-Lymphocyten-Subpopulation anzulocken. Zudem sollte die Rolle der $\beta$-Defensine in Bezug auf ihre Wirkung auf die naiven T-Zellen untersucht werden, da bereits die Ergebnisse der Gedächtnis T-Zell-Chemotaxis den in der Literatur beschriebenen Ergebnissen widersprachen. Die Ergebnisse der FACS-Analyse der aufgereinigten naiven T-Lymphocyten werden in der nächsten Abbildung dargestellt. 
A

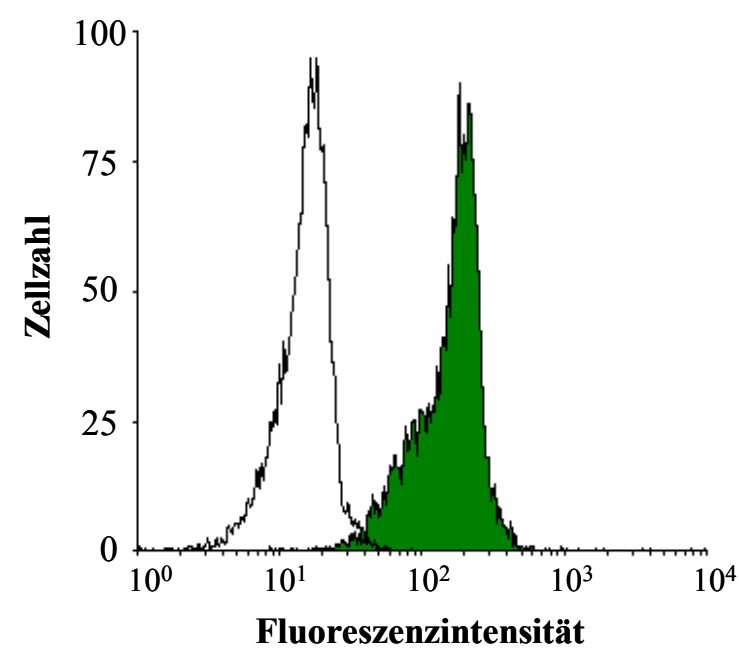

B

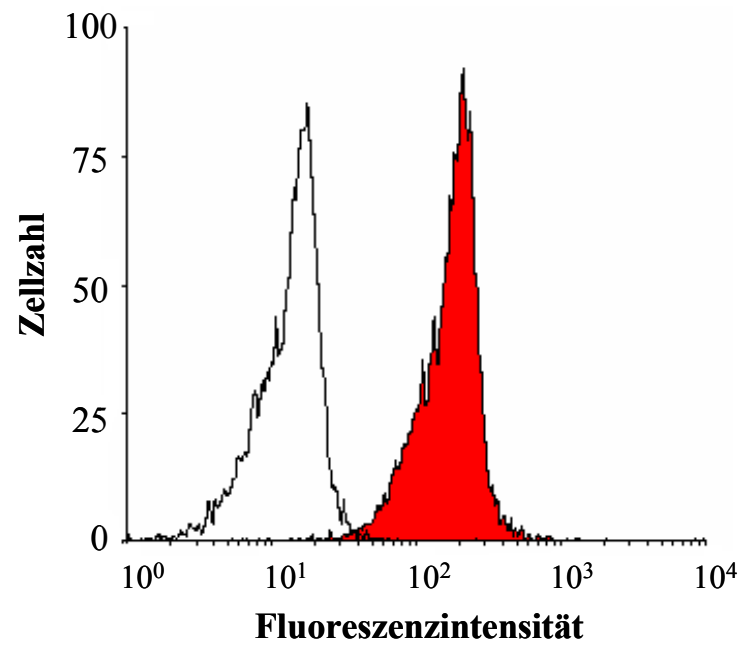

Abb. 33: Ergebnisse der FACS-Analyse mittels magnetischer Zellsortierung aufgereinigter naiver T-Zellen. Dargestellt ist jeweils die Zellzahl in Abhängigkeit von der Fluoreszenzintensivität. A zeigt die antiCD45RA-FITC gefärbten Zellen $(1 \mu \mathrm{g} / 100 \mu \mathrm{l}$; grün hinterlegt) sowie die Isotypkontrolle $(1 \mu \mathrm{g} / 100 \mu \mathrm{l}$; FITC/PE; weiß hinterlegt). In B ist das Ergebnis der Markierung mit anti-CD4-PE $(1 \mu \mathrm{g} / 100 \mu \mathrm{l}$; rot hinterlegt) sowie die entsprechende Isotypkontrolle $(1 \mu \mathrm{g} / 100 \mu \mathrm{l}$; weiß hinterlegt) abgebildet. Die mit Hilfe der Doppelfärbung anti-CD45RA-FITC/anti-CD4-PE ermittelte Reinheit der T-Zellpopulation war immer größer als $95 \%$.

Die nunmehr aufgereinigte Subpopulation der T-Lymphocyten wurde wiederum für eine in vitro Chemotaxis gegen das $\alpha$-Defensin HNP-1 sowie das $\beta$-Defensin HBD-2 verwendet. Als Positivkontrolle diente das Chemokin CCL19, welches im Vergleich zu CCL20 nur die naiven nicht aber die Gedächtnis T-Zellen anlockt. CCL19 bindet dabei an der Chemokinrezeptor CCR7. Die Ergebnisse dieser Experimente sind in Abbildung 34 dargestellt.

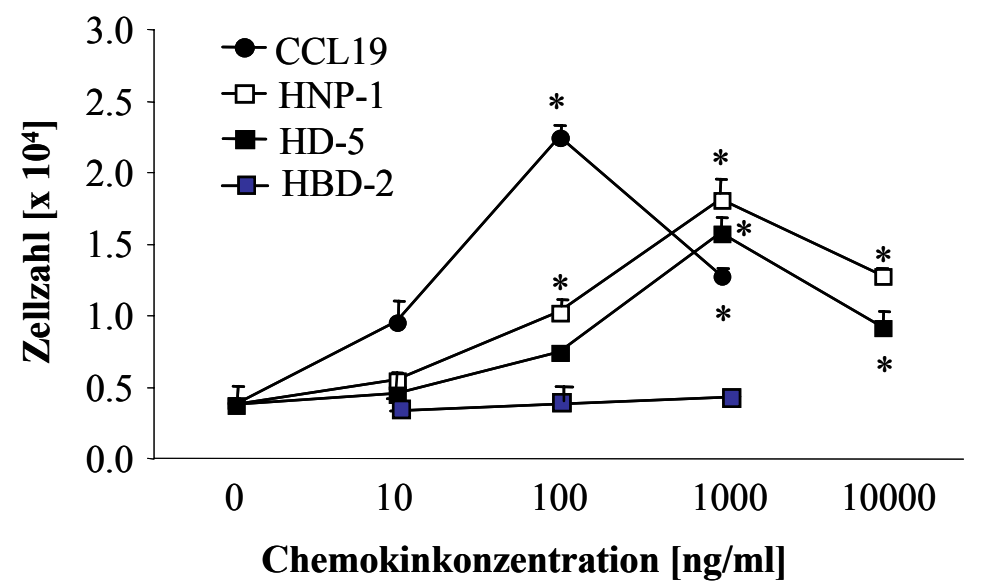

Abb. 34: Dosis-Wirkungsdiagramm der in vitro Chemotaxis von $\mathrm{CD4}^{+} / \mathrm{CD}^{2} \mathrm{RA}^{+}$-T-Lymphocyten gegen das $\beta$-Defensin HBD-2 und die $\alpha$-Defensine HNP-1 und HD-5 im Vergleich zur CCL20-induzierten Wanderung. Die Migrationsdauer betrug $4 \mathrm{~h}$. Es wurde ein Porendurchmesser von $5 \mu \mathrm{m}$ verwendet. Gezeigt werden die Mittelwerte 3 unabhängiger Ergebnisse sowie deren Standardabweichungen (+SEM). Bei $\mathrm{p}<0,05$ Markierung der Signifikanz durch*. 
Auch die naiven T-Zellen ließen sich nicht von dem $\beta$-Defensin HBD-2 anlocken. Die $\alpha$-Defensine HNP-1 sowie HD-5 konnten dagegen eine Migration der naiven T-Lymphocyten in einer dosisabhängigen Form induzieren. Hierbei zeigte HNP-1 eine etwas größere chemotaktische Stärke als HD-5, wobei eine maximale Chemotaxis bei $100 \mathrm{ng} / \mathrm{ml} \mathrm{zu}$ detektieren war. Das als Positivkontrolle eingesetzte CCL19 bewirkte eine maximale Chemotaxis bei $100 \mathrm{ng} / \mathrm{ml}$ und war somit deutlich effizienter als die $\alpha$-Defensine.

\subsection{Untersuchung der Migration muriner T-Lymphocyten}

Es wurde weiterhin das Migrationsverhalten muriner naiver sowie muriner GedächtnisT-Lymphocyten untersucht. Die aus der murinen Milz gewonnenen Lymphocyten wurden ebenfalls über das MACS-System aufgereinigt. Dabei wurden $\mathrm{CD}^{+} / \mathrm{CD} 2 \mathrm{~L}^{+}$naive T-Zellen sowie $\mathrm{CD}^{+} / \mathrm{CD} \mathrm{L}^{-}$Gedächtnis-T-Zellen angereichert. Die Reinheit der T-ZellSubpopulationen betrug immer mehr als $93 \%$.

A

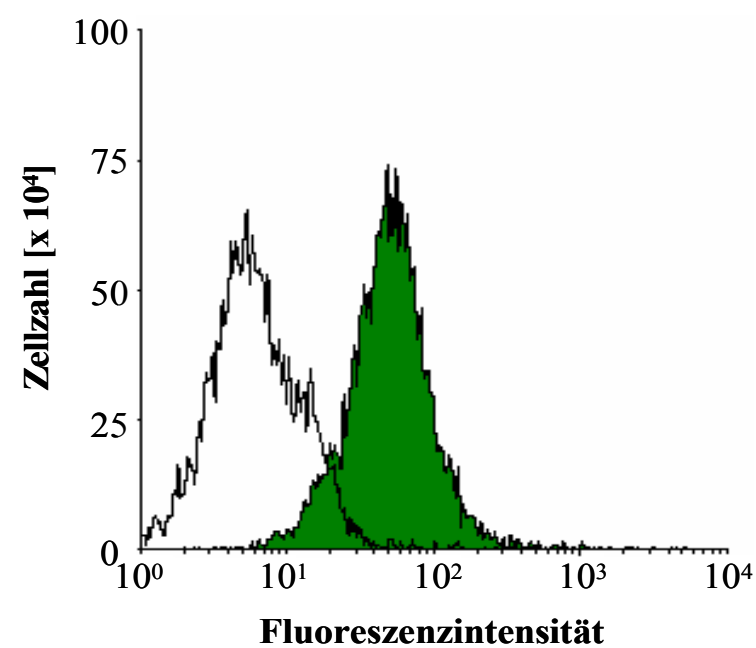

B

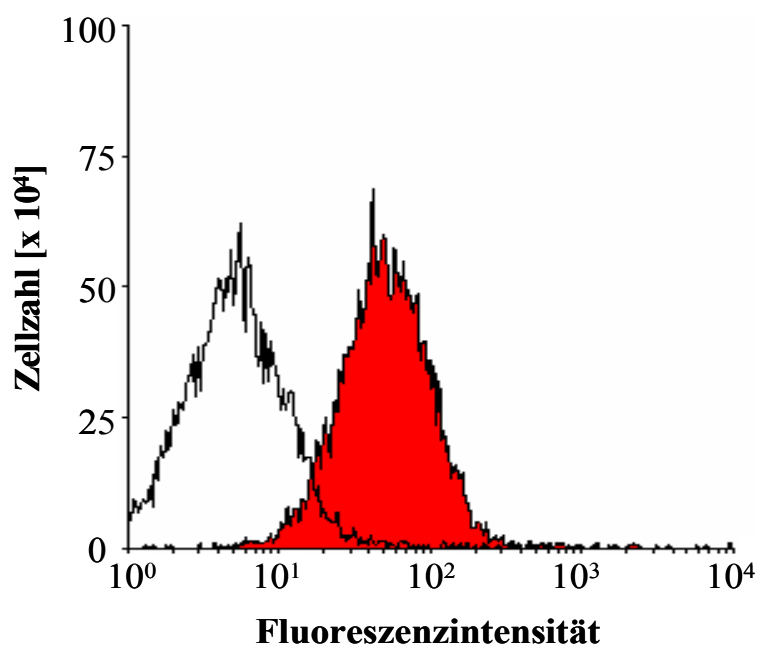

Abb. 35: Ergebnisse der FACS Messung muriner naiver T-Lymphocyten nach MACS-Aufreinigung. A zeigt die anti-CD62L-FITC-gefärbten Zellen (grün hinterlegt) sowie die Isotypkontrolle (FITC/PE; weiß hinterlegt). In $\mathrm{B}$ ist das Ergebnis der Zellmarkierung mit anti-muCD4-PE (rot hinterlegt) sowie die entsprechende Isotypkontrolle (weiß hinterlegt) abgebildet. Es wurden jeweils $1 \mu \mathrm{g}$ Antikörper pro $100 \mu \mathrm{l}$ FACS-Puffer verwendet. Die Gedächtnis T-Lymphocyten wurden in der gleichen Aufreinigung durch Negativselektion erhalten und waren CD4 positiv sowie CD62L negativ.

Für die in vitro Chemotaxis wurde das murine $\beta$-Defensin mBD8 verwendet, welches eine große Similarität der Tertiärstruktur bei nur 50 \%-iger Übereinstimmung der AS-Sequenz gegenüber dem humanen HBD-2 aufweist. Als Positivkontrolle diente CCL19 bei den naiven 
sowie CCL20 bei den Gedächtnis-T-Lymphocyten. Die Ergebnisse dieser Experimente werden im Folgenden graphisch dargestellt.

A

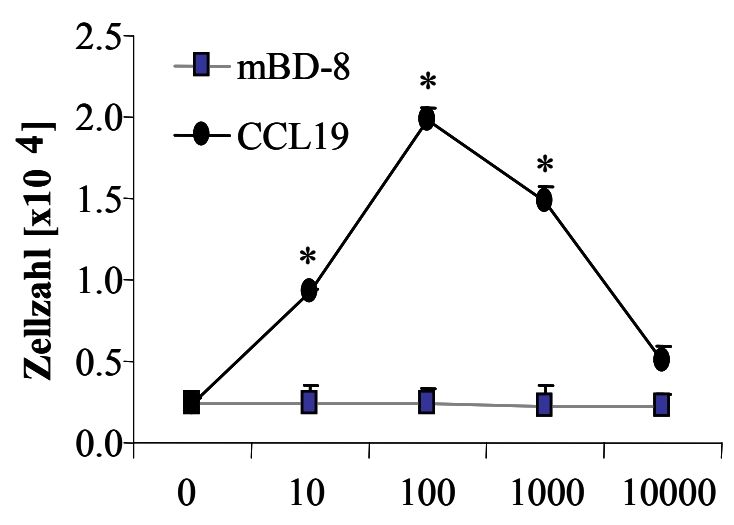

Chemokinkonzentration [ng/ml]
B

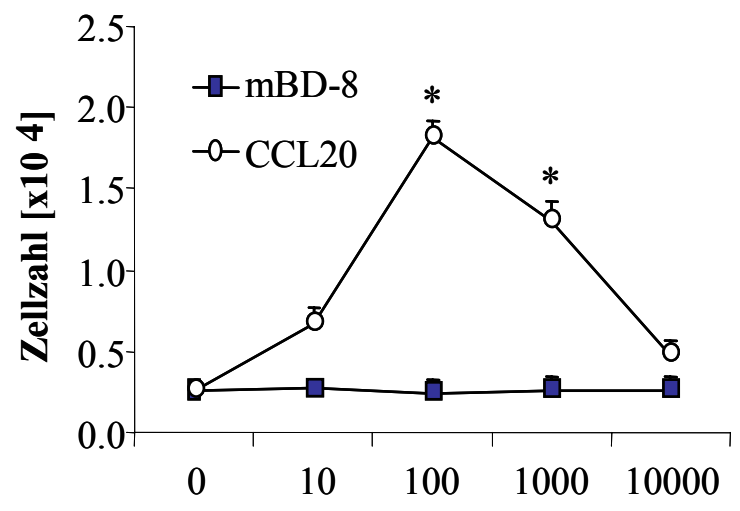

Chemokinkonzentration [ng/ml]

Abb. 36: Ergebnisse der konzentrationsabhängigen in vitro Migration von murinen naiven $\mathrm{CD}^{+} / \mathrm{CD}^{2} \mathrm{~L}^{+}$ T-Lymphocyten gegen das murine $\beta$-Defensin mBD-8 und gegen $\mathrm{CCL19}$ (A) sowie von $\mathrm{CD}^{+} / \mathrm{CD}^{-} \mathrm{L}^{-}$ murinen Gedächtnis-T-Lymphocyten gegen das murine $\beta$-Defensin mBD-8 und gegen CCL20 (B). Die Migrationszeit betrug $4 \mathrm{~h}$ bei einer Porengröße von $5 \mu \mathrm{m}$. Dargestellt werden die Mittelwerte von 3 unabhängigen Experimenten sowie deren Standardabweichungen (+SEM). Bei $\mathrm{p}<0,05$ wurden die Werte als signifikant unterschiedlich zur Negativkontrolle (0) mit * markiert.

Ähnlich wie die humanen T-Lymphocyten konnten auch die murinen T-Lymphocyten nicht durch das murine $\beta$-Defensin mBD8 rekrutiert werden. Im Gegensatz dazu konnte CCL19 wie erwartet eine starke konzentrationsabhängige chemotaktische Antwort der murinen naiven T-Zellen induzieren. Ebenso wanderten die murinen Gedächtnis-T-Zellen dosisabhängig gegen das Chemokin CCL20. Sowohl CCL19 als auch CCL20 waren dabei in der Lage die spontane Wanderung der Negativkontrolle (0) bei der optimalen Konzentration von 100 ng/ml um ein 6 bis 7 faches zu verstärken (s. Abb. 36/A und B).

Somit konnte bestätigt werden, dass die hier getesteten $\beta$-Defensine weder im humanen noch im murinen System eine Wirkung auf die T-Lymphocyten ausüben konnten.

\subsection{Untersuchung der Migration muriner Mastzellen}

Es wurde bereits gezeigt, dass HBD-2 bis -4 die in vitro Chemotaxis von peritonealen Mastzellen der Ratte induzieren konnten, während HBD-1 keinerlei Effekt auf diese Zellen zeigte (Niyonsaba et al., 2002; Chen et al., 2007). Über eine Migration von Mastzellen gegen die $\alpha$-Defensine wurde bisher nicht berichtet. 
Die in dieser Arbeit eingesetzten murinen Mastzellen wurden aus Knochenmarksvorläuferzellen durch Kultivierung mit murinem SCF sowie murinem IL-3 generiert.

Zunächst wurde die Migration der murinen Mastzellen mit und ohne Aktivierung durch Ionomycin als Antigen-unabhängiger Mechanismus untersucht. Die Ergebnisse der durchgeführten in vitro Chemotaxis-Experimente sind in der folgenden Abbildung dargestellt.

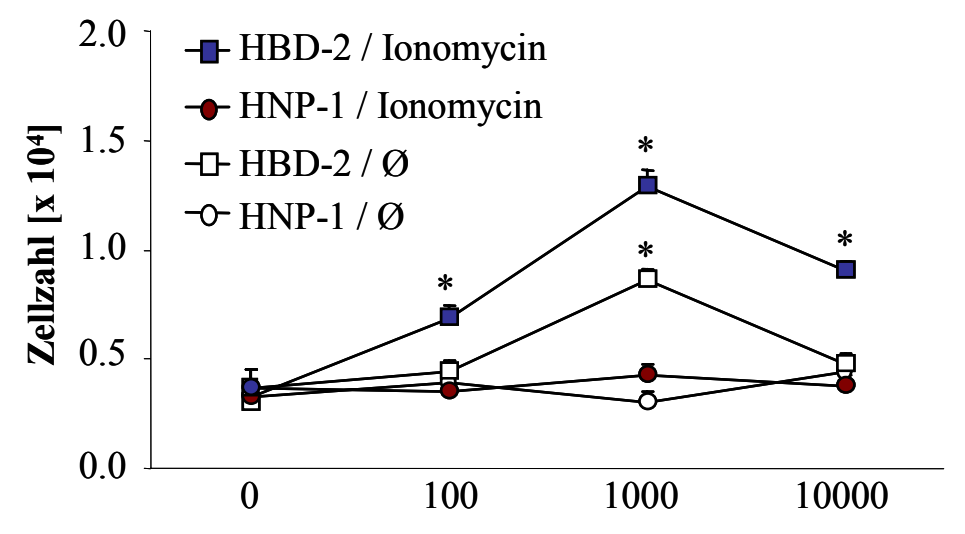

Chemokinkonzentration $[\mathrm{ng} / \mathrm{ml}]$

Abb. 37: Dosis-Wirkungs-Kurven der in vitro Chemotaxis muriner Mastzellen gegen HBD-2 und HNP-1 mit und ohne (Ø) Aktivierung durch Ionomycin. Hierfür wurden die Zellen zuvor $4 \mathrm{~h} \mathrm{mit} 750 \mathrm{ng} / \mathrm{ml}$ Ionomycin bzw. nur mit Medium $(\varnothing)$ präinkubiert. Der Porendurchmesser betrug $5 \mu \mathrm{m}$ und die Inkubationszeit 3 h. Gezeigt sind die Mittelwerte von 3 unabhängigen Experimenten sowie deren Standardabweichungen (+SEM). Waren die Werte im Vergleich zur Negativkontrolle $(0)$ signifikant unterschiedlich $(\mathrm{p}<0,05)$, wurden sie mit * gekennzeichnet.

Die in Abbildung 37 dargestellten Ergebnisse zeigen deutlich, dass das $\beta$-Defensin HBD-2 sowohl mit als auch ohne die Aktivierung durch Ionomycin eine dosisabhängige Migration der murinen Mastzellen induzieren konnte. Die Ionomycin-vermittelte Aktivierung der Mastzellen verstärkt dabei die Fähigkeit der Chemotaxis gegenüber diesem Defensin. Wiederum lag die maximale von HBD-2 ausgelöste Chemotaxis bei einer Konzentration von 1000 ng/ml. Das hier untersuchte $\alpha$-Defensin HNP-1 konnte weder mit noch ohne Präinkubation mit Ionomycin die murinen Mastzellen rekrutieren.

Um die verschiedenen $\beta$-Defensine hinsichtlich ihrer Fähigkeit, murine, durch Ionomycin aktivierte Mastzellen chemotaktisch anzulocken, vergleichen zu können, wurde weiterhin eine in vitro Chemotaxis mit HBD-1 bis -4 sowie mit dem Anaphylatoxin C5a als Positivkontrolle durchgeführt. 


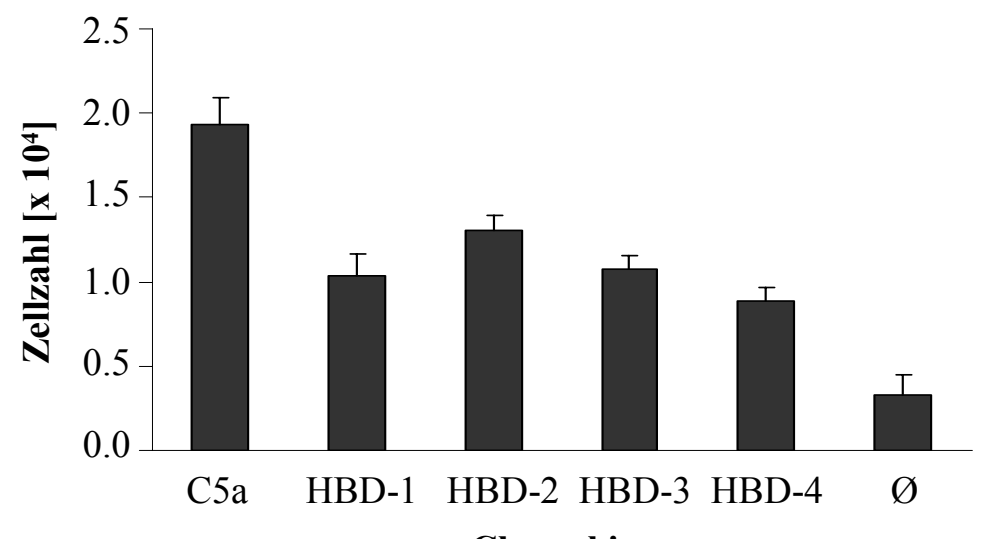

Abb. 38: In vitro Chemotaxis muriner Mastzellen nach Aktivierung durch Ionomycin (750 ng/ml, 4h) gegen die $\beta$-Defensine HBD-1 bis -4 sowie C5a. Die Mastzellen wurden vor der Migration für $4 \mathrm{~h}$ mit $750 \mathrm{ng} / \mathrm{ml}$ Ionomycin inkubiert. Als Negativkontrolle diente Medium ohne Chemokinzzusatz ( $\varnothing)$. Der Porendurchmesser betrug $5 \mu \mathrm{m}$ und die Inkubationszeit $3 \mathrm{~h}$. Die Mittelwerte von 3 unabhängigen Experimenten sowie die Standardabweichungen (+SEM) sind dargestellt.

Wie die vorhergehende Graphik zeigt, konnten alle vier $\beta$-Defensine die Ionomycinstimulierten murinen Mastzellen rekrutieren. Dabei war die von HBD-2 angelockte Zellzahl die höchste, während HBD-4 die Mastzellen weniger effektiv anlocken konnte als die anderen Mitglieder dieser Defensin-Familie. Im Vergleich zur von C5a induzierten Migration der Zellen erwiesen sich die $\beta$-Defensine als deutlich schwächere Chemokine.

Weiterhin wurde die Aktivierung muriner Mastzellen durch den Antigen-unabhängigen Mechanismus mittels Ionomycin-Präinkubation (4 h; $750 \mathrm{ng} / \mathrm{ml})$ und durch $\operatorname{IgE}(24 \mathrm{~h})$ und Antigen (Albumin-DNP; $4 \mathrm{~h}$ ) untersucht. Als Chemokin für diese vergleichenden in vitro Experimente diente das $\beta$-Defensin HBD-2. Die Resultate sind in Abbildung 39 festgehalten.

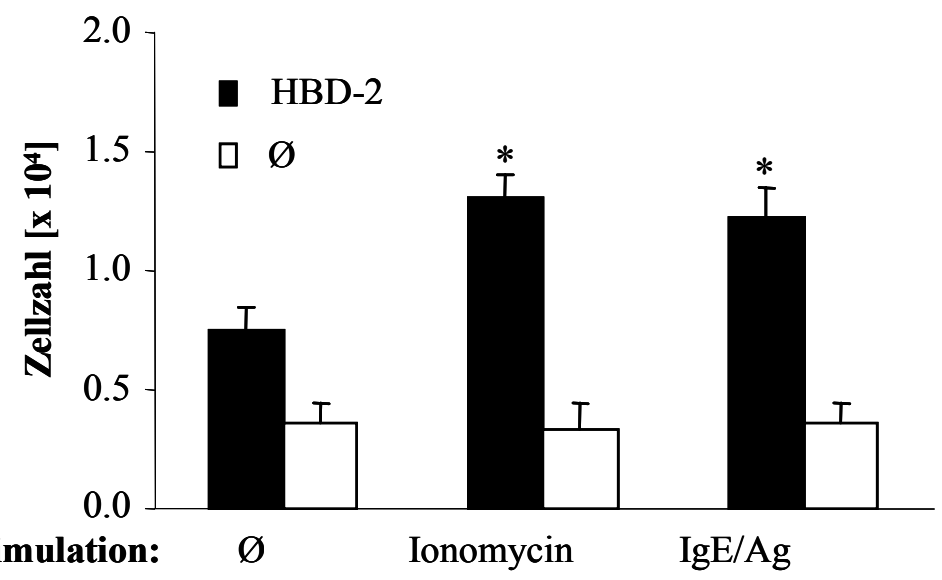

Abb. 39: Ergebnisse der in vitro Migration muriner Mastzellen gegen HBD-2. Die Zellen wurden vor der Migration gegen $1000 \mathrm{ng} / \mathrm{ml} \mathrm{HBD}-2$ mit Ionomycin $(750 \mathrm{ng} / \mathrm{ml} ; 4 \mathrm{~h})$ oder mit IgE anti-DNP $(2 \mu \mathrm{g} / \mathrm{ml} ; 24 \mathrm{~h})$ sowie Antigen (Albumin-DNP; $50 \mu \mathrm{g} / \mathrm{ml} ; 4 \mathrm{~h}$ ) präinkubiert. Als Negativkontrolle $(\varnothing)$ diente Medium ohne Chemokinzusatz. Die Porengröße betrug $5 \mu \mathrm{m}$. Dargestellt sind die Mittelwerte (+SEM) 3 unabhängiger Experimente. Bei $\mathrm{p}<0,05$ galten die Werte als signifikant unterschiedlich zur Negativkontrolle $(*)$. 
Sowohl Ionomycin als auch IgE und Antigen bewirkten eine Verstärkung der Migration muriner Mastzellen gegen HBD-2 im Vergleich zu unbehandelten Zellen. Die Unterschiede durch die beiden Aktivierungswege waren dabei nur minimal.

Zur Verifizierung der Ergebnisse wurden zudem in vivo Untersuchungen aktivierter muriner Mastzellen durchgeführt. Diese werden in der folgenden Abbildung dargestellt.

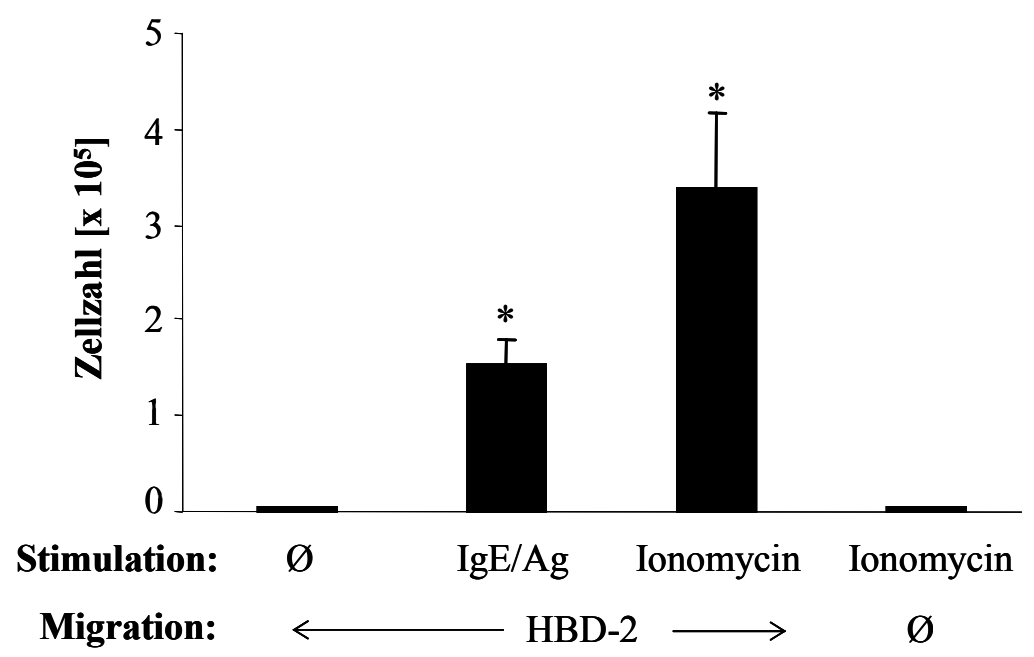

Abb. 40: In vivo Migration muriner Mastzellen gegen HBD-2. Die 15stündige Migration gegen $10 \mu \mathrm{g} / \mathrm{ml}$ HBD-2 erfolgte nach Kultivierung mit Ionomycin $(750 \mathrm{ng} / \mathrm{ml} ; 4 \mathrm{~h}) \mathrm{bzw}$. IgE anti-DNP (2 $\mu \mathrm{g} / \mathrm{ml} ; 24 \mathrm{~h})$ sowie Antigen (Albumin-DNP; $50 \mu \mathrm{g} / \mathrm{ml} ; 4 \mathrm{~h}$ ) im Anschluss. Die Zellen wurden zur späteren Detektion mit rotfluoreszierendem PKH26 markiert und 30 Minuten mit HBD-2 oder Puffer $(\varnothing)$ präinkubiert. Dann erfolgte die intravenöse Injektion der Zellen sowie die intraperitoneale Injektion des HBD-2 in Balb/c Mäuse. Als Negativkontrolle diente Puffer ohne Chemokinzusatz. Dargestellt sind die Mittelwerte 3 unabhängiger Experimente sowie die Standardabweichung (+SEM). Signifikanzen sind bei $\mathrm{p}<0,05$ mit * angegeben.

Die Untersuchung der in vivo Migration muriner Mastzellen gegen HBD-2 stellt die Unterschiede zwischen der $\beta$-Defensin-induzierten Mobilisierung von aktivierten und nicht aktivierten Mastzellen noch deutlicher heraus. Die PKH-26-markierten murinen Mastzellen wurden durch HBD-2 ausschließlich dann in das Peritoneum rekrutiert, wenn zuvor eine Stimulierung durch Ionomycin oder IgE und Antigen durchgeführt wurde. Dabei bewirkte die Behandlung der Zellen mit Ionomycin die Anlockung einer doppelt so großen Anzahl muriner Mastzellen als die Behandlung mit IgE und Antigen.

\subsection{Untersuchung der Migration der Mastzelllinie HMC-1}

Zur Analyse des Migrationsverhaltens im humanen System wurde die humane Mastzelllinie HMC-1 verwendet. Diese aus einer Mastzell-Leukämie generierten Zellen besitzen keinen funktionellen IgE Rezeptor, sind aber auf Grund zweier Punktmutationen im c-kit proto- 
Onkogen, welche dessen konstitutive Phosphorylierung bewirken, in einem Zustand der Daueraktivierung. Daher war es nicht nötig, die Zellen vor den Versuchen zu stimulieren.

Zunächst erfolgten in vitro Chemotaxis-Untersuchungen zum Vergleich des murinen und des humanen Systems. Dabei wurden verschiedene $\alpha$ - und $\beta$-Defensine auf ihre chemotaktische Wirkung untersucht. Die Ergebnisse sind in Abbildung 41 festgehalten.

A

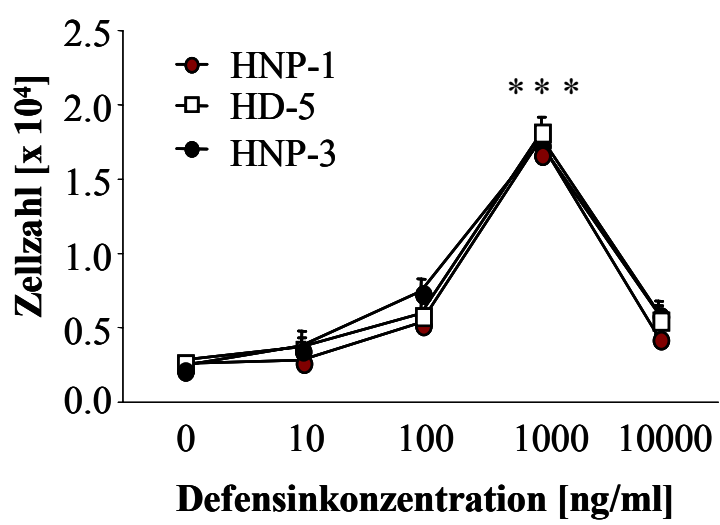

B

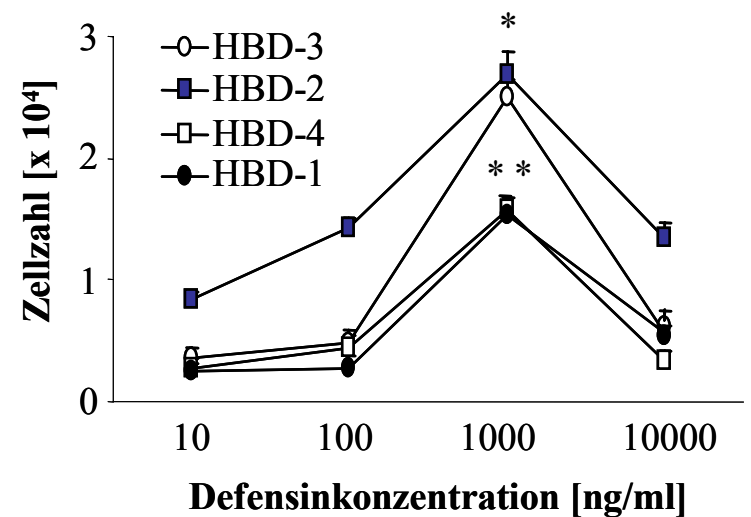

Abb. 41: Dosis-Wirkungs-Analysen der in vitro Chemotaxis der humanen Mastzellinie HMC-1 gegen die $\alpha$-Defensine HNP-1, HNP-3 und HD-5 (A) sowie gegen die $\beta$-Defensine HBD-1 bis HBD-4 (B). Der Porendurchmesser betrug $8 \mu \mathrm{m}$ und die Inkubationszeit $3 \mathrm{~h}$. Dargestellt sind die Mittelwerte von 3 unabhängigen Experimenten sowie deren Standardabweichungen (+SEM). Waren die Werte im Vergleich zur Negativkontrolle (0) signifikant unterschiedlich $(\mathrm{p}<0,05)$, wurden sie mit* gekennzeichnet.

Während das humane $\alpha$-Defensin HNP-1 keinerlei Wirkung auf die murinen Mastzellen hatte, konnte es die humanen HMC-1 Zellen konzentrationsabhängig rekrutieren. Auch HNP-3 und HD-5 zeigten einen ähnlich starken chemotaktischen Effekt auf die humane Mastzelllinie. Für alle drei verwendeten $\alpha$-Defensine lag die optimale Konzentration bei $1000 \mathrm{ng} / \mathrm{ml}$ (s. Abb. 41/A). Weiterhin konnten auch die Mitglieder der $\beta$-Defensine eine spezifische Migration der HMC-1 Zellen induzieren (s. Abb. 41/B). Hierbei stellte sich HBD-2 als das Defensin mit der größten chemotaktischen Wirksamkeit dar, wobei wiederum alle $\beta$-Defensine die höchste Zellanzahl bei einer Konzentration von 1000 ng/ml rekrutierten.

\subsection{Untersuchung der intrazellulären Calciumfreisetzung in HMC-1 Zellen}

Trotz der bereits unter 3.4, 3.5 sowie 3.6 gezeigten Fähigkeit der $\beta$-Defensine, Chemotaxis von humanen und murinen Makrophagen induzieren zu können, konnte keine intrazelluläre Calciumionenfreisetzung nach $\beta$-Defensin-Gabe in diesen Zelltypen detektiert werden. 
Im Gegensatz dazu antworteten die HMC-1 Zellen auf alle verwendeten $\beta$-Defensine mit einem deutlichen Calciumsignal. Dieses Signal ließ sich zudem von allen diesen $\beta$-DefensinMitgliedern komplett desensibilisieren. Die $\alpha$-Defensine HNP-1 und HD-5 konnten dagegen, trotz bereits dargestellter Effekte auf das Migrationsverhalten dieser Zellen, kein Calciumsignal in den humanen Mastzellen induzieren. Als Positivkontrolle diente C5a, welches einen starken Calciumeinfluss in die Zellen bewirkte, die Aktivität des HBD-2 aber nicht desensibilisieren konnte.

In der folgenden Graphik sind die Ergebnisse der intrazellulären Calciumfreisetzung durch die $\beta$-Defensine, die $\alpha$-Defensine und C5a sowie die Desensibilisierungsversuche dargestellt.

A

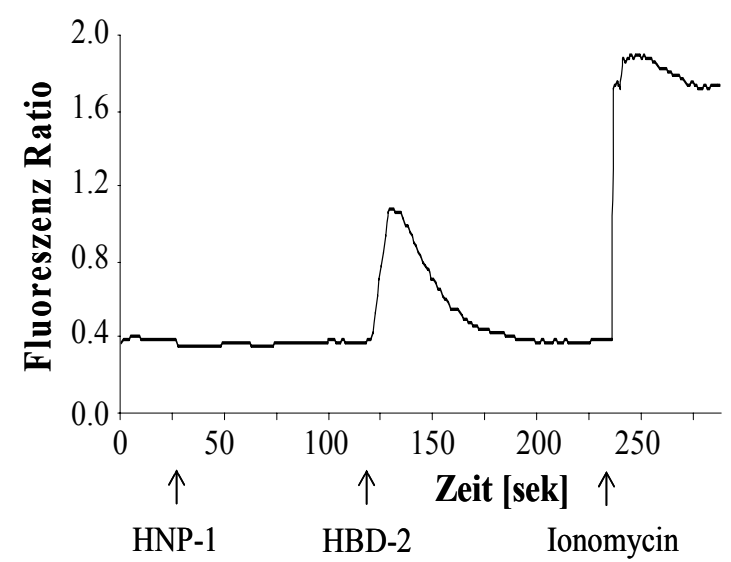

C

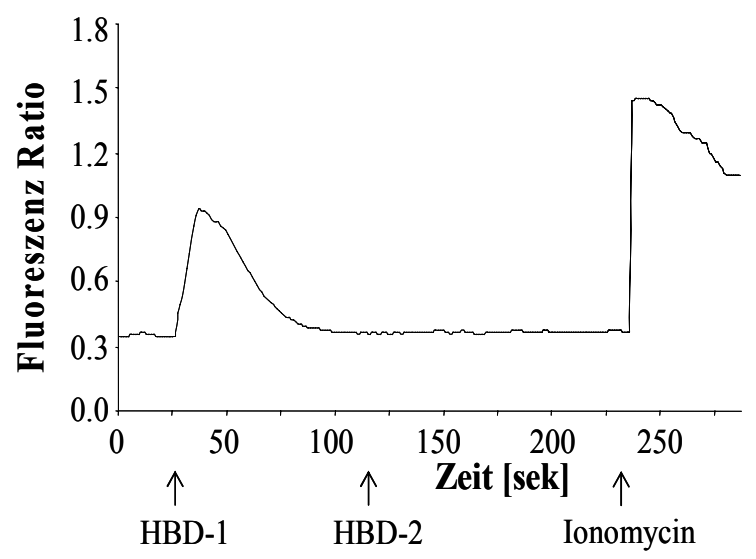

B

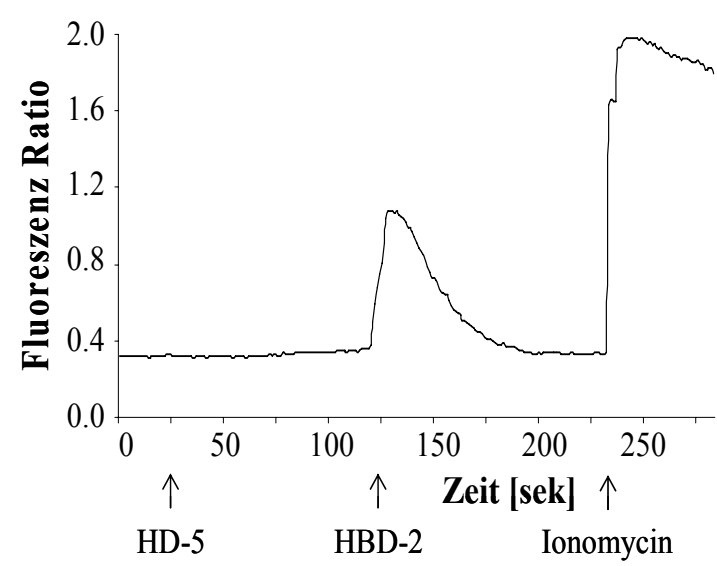

D

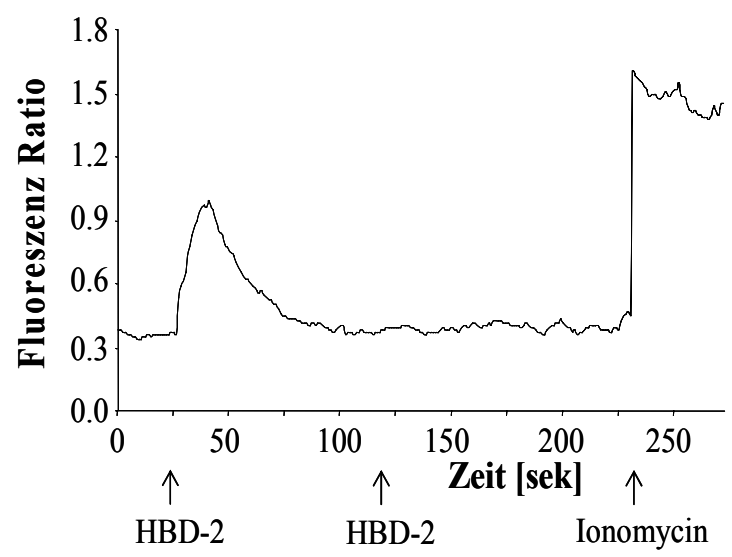


$\mathbf{E}$

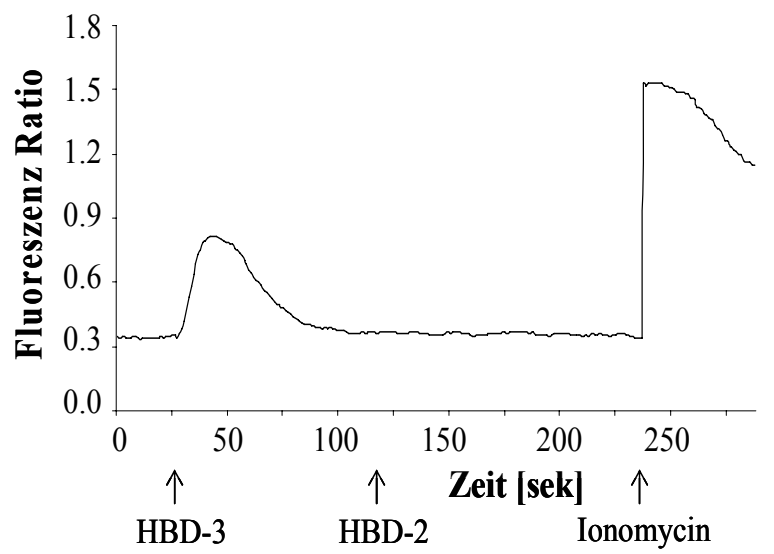

G

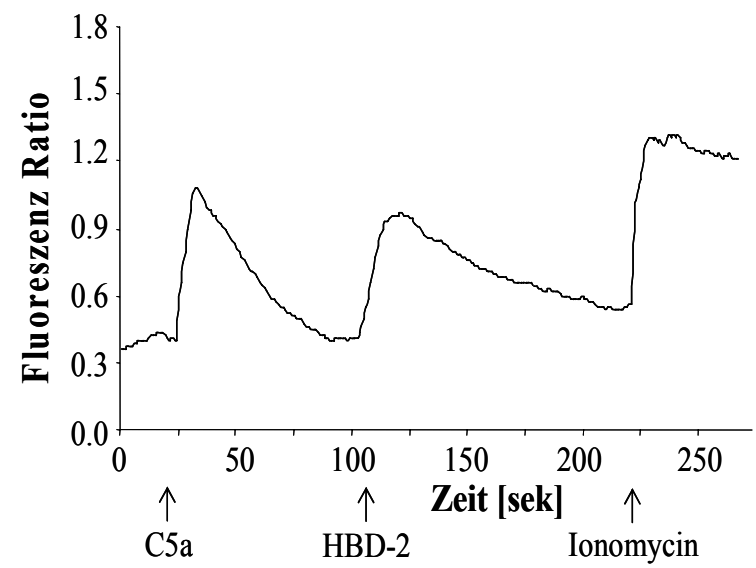

F

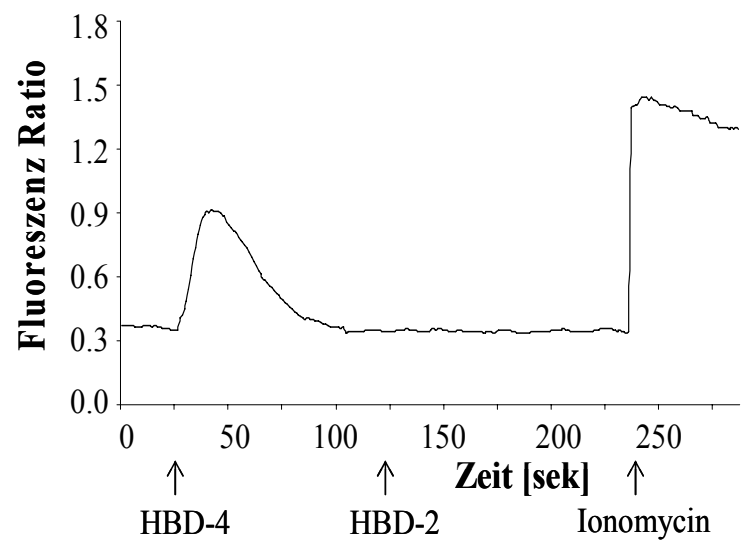

Abb. 42: Intrazelluläre Calciumfreisetzung in HMC-1 Zellen. Der Calciuminflux erfolgte nach Stimulation durch die $\alpha$-Defensine HNP-1 und HD-5 (A und B; je $10 \mu \mathrm{g} / \mathrm{ml}$ ) sowie durch die $\beta$-Defensine HBD-1 bis -4 (CF; je $10 \mu \mathrm{g} / \mathrm{ml})$ und durch C5a (G; $1 \mu \mathrm{g} / \mathrm{ml})$. Im Anschluss wurde direkt nach Abklang des Calciumsignals eine weitere Stimulation der Zellen mit HBD-2 als putativer Desensibilisierungsnachweis induziert. Das zum Ende der Messung zugegebene Ionomycin $(100 \mathrm{nM})$ diente der Öffnung der Calciumspeicher und somit als Positivkontrolle bzw. Relation. Als Fluoreszenz-Ratio wird das Verhältnis von blau-fluoreszierendem Indo1 zu dem violett-fluoreszierenden Indo1-Calcium-Komplex bezeichnet. Dargestellt ist je eines von drei Experimenten.

Neben den hier in Abbildung 42 dargestellten Experimenten wurden zudem Versuche zur Desensibilisierung der $\beta$-Defensine HBD-1, HBD-3 und HBD-4 durchgeführt. Auch diese konnten nach vorheriger Stimulation der Zellen mit den anderen $\beta$-Defensinen keine weiteren Calciumsignale induzieren. Weiterhin zeigten Vorversuche, dass sich eine Desensibilisierung ausschließlich direkt nach dem kompletten Abklingen des ersten Calciumsignals erzielen lässt. Erfolgte die zweite Stimulation 30 Sekunden nach der ersten Stimulation, so war bereits eine minimale Calciumantwort zu erkennen, erfolgte sie 1 bis 2 Minuten später, konnte ein reguläres Calciumsignal detektiert werden. Das Anaphylatoxin C5a konnte hingegen in keinem Fall eine Desensibilisierung der $\beta$-Defensin-induzierten Calciumfreisetzung bewirken. 


\subsection{Herstellung von RBL-2H3-CCR6-Transfektanten}

Auf Grund der erarbeiteten Ergebnisse, welche in Bezug auf die Rolle des CCR6-Rezeptors bei der HBD-2-induzierten Chemotaxis eindeutig den Ergebnissen der Literatur widersprachen, wurden eigene CCR6-Transfektanten hergestellt.

Hierfür wurde die CCR6-DNA in den Expressionsvektor pEF/HisMycA umkloniert und daraufhin stabil in RBL-2H3-Zellen mittels Elektroporation transfiziert.

Aus den heranwachsenden G418-resistenten Zellpopulationen wurden je nach Erfolg der Transfektion zwischen 20 und 100 Einzelzellklone isoliert und kultiviert. Subkloniert wurden diejenigen Transfektanten mit der stärksten Rezeptor-Expression. Als Nachweis der Expression der transfizierten Rezeptor-DNA diente die durchflusscytometrische Detektion des CCR6-Rezeptors mittels FITC-markiertem humanem CCR6-Antikörper. Zur Vermeidung eventueller Kontamination mit nicht exprimierenden Zellen bzw. um klonale Artefakte frühzeitig zu erkennen, wurde diese FACS-Analyse der Transfektanten regelmäßig wiederholt. Im Falle einer Kontamination hätten die Klone erneut subkloniert bzw. zuvor kryokonservierte Zellen verwendet werden müssen.

Für die funktionellen Analysen der CCR6-Transfektanten wurden drei Subklone gewählt, welche eine ähnlich starke, gleichmäßige Rezeptorexpression zeigten. In der folgenden Abbildung 43 ist ein Ergebnis der FACS-Untersuchung des für die funktionellen Untersuchungen eingesetzten Subklons 1/17 beispielhaft dargestellt.

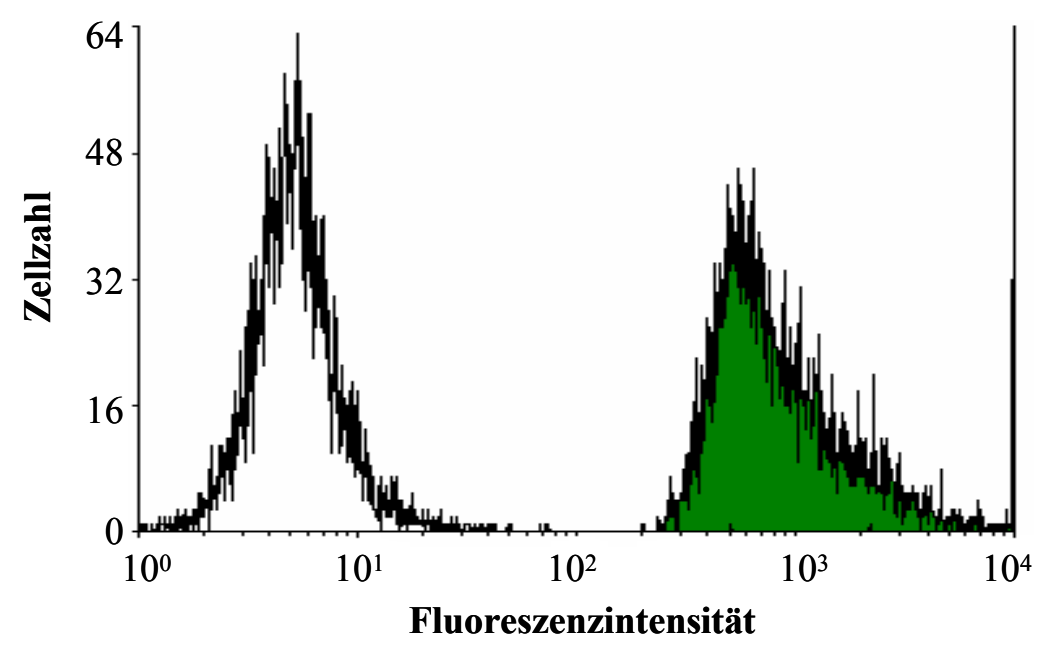

Abb. 43: FACS-Analyse des Subklons 1/17 der RBL-2H3-CCR6-Transfektante. Dargestellt ist die Zellzahl in Abhängigkeit der Fluoreszenzintensität als overlay der Isotypkontrolle $(1 \mu \mathrm{g} / 100 \mu \mathrm{l}$; weiß hinterlegter peak) sowie der anti-CCR6-FITC-markierten stabil transfizierten Zellen $(1 \mu \mathrm{g} / 100 \mu \mathrm{l}$; grün hinterlegter peak). Eine Färbung von 15 ist beispielhaft dargestellt. 


\subsubsection{Funktionelle Analyse der RBL-2H3-CCR6-Transfektante}

Nach dieser erfolgreichen Transfektion wurden die Zellen für in vitro ChemotaxisExperimente verwendet. Um ein zweifelsfreies Ergebnis $\mathrm{zu}$ erhalten, wurden drei verschiedene Subklone in diesem Assay getestet. Zunächst wurde somit die Migration der CCR6-Transfektanten gegen den Liganden CCL20 sowie gegen HBD-2 und HBD-3 als Vertreter der $\beta$-Defensine im direkten Vergleich untersucht. Die Ergebnisse sind in der folgenden Abbildung graphisch dargestellt.

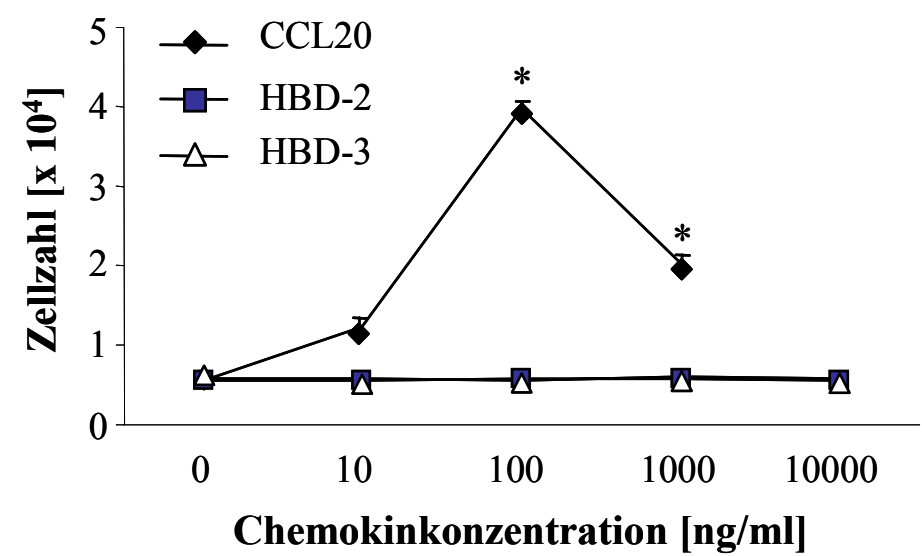

Abb. 44: Dosis-Wirkungs-Kurven der in vitro Chemotaxis von RBL-2H3-CCR6-Transfektanten gegen CCL20, HBD-2 und HBD-3. Die Migrationszeit betrug 1,5 h und es wurde eine Porengröße von $8 \mu \mathrm{m}$ eingesetzt. Dargestellt sind die Mittelwerte von 4 unabhängigen Experimenten sowie deren Standardabweichungen $(+\mathrm{SEM})$. Die mit * markierten Werte sind signifikant $(\mathrm{p}<0,05)$ von der Negativkontrolle (0) unterschiedlich.

Wie in Abbildung 44 ersichtlich, bestätigt das Resultat der in vitro Chemotaxis mit den RBL-2H3-Transfektanten die unterschiedlichen Migrationsergebnisse von dendritischen Zellen und Makrophagen als Antwort auf CCL20 und die $\beta$-Defensine, wenngleich diese im Gegensatz $\mathrm{zu}$ den bereits publizierten Ergebnissen stehen. So konnte bei deutlicher chemotaktischer Aktivität der CCR6-Transfektanten weder eine HBD-2- noch eine HBD-3induzierte Chemotaxis detektiert werden. Die Wanderung gegen den CCR6-Liganden CCL20 war zudem konzentrationsabhängig und die Kurve wies die typische Glockenform auf. Die maximale Zellzahl wurde bei einer CCL20-Konzentration von $100 \mathrm{ng} / \mathrm{ml}$ angelockt.

Bei weiteren in vitro Chemotaxis-Untersuchungen, konnte außerdem festgestellt werden, dass die Migration der RBL-2H3-CCR6-Zellen gegen CCL20 spezifisch war, da sie durch Präinkubation mit sich selbst, nicht aber mit HBD-2 oder HBD-3, nahezu vollständig inhibierbar war. Diese Ergebnisse sind im Folgenden dargestellt. 


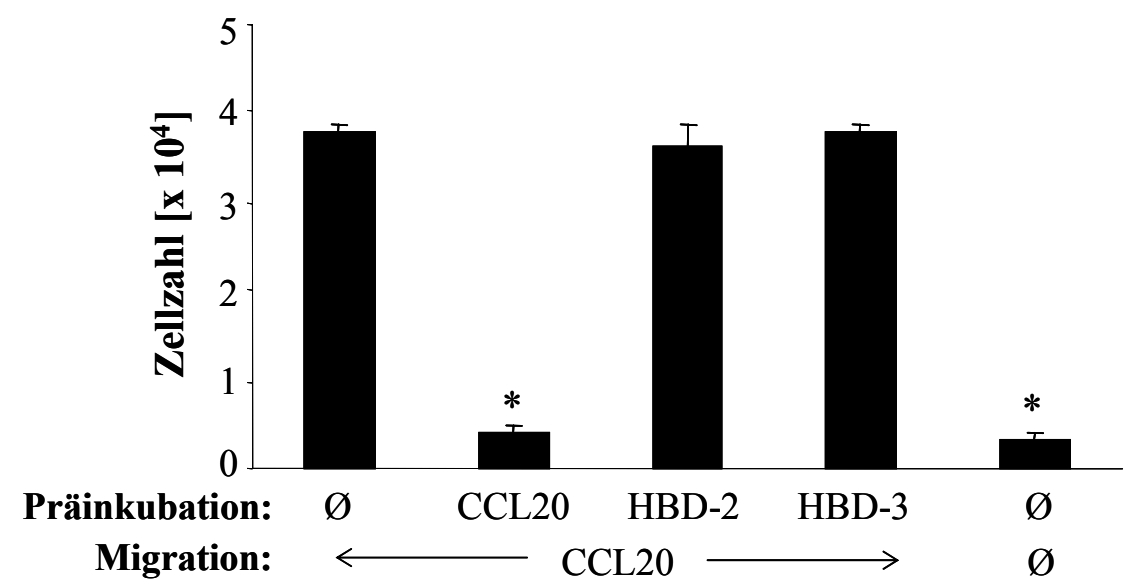

Abb. 45: Ergebnis der in vitro Migration der RBL-2H3-CCR6-Transfekanten gegen CCL20. Die 1,5stündige Migration gegen $100 \mathrm{ng} / \mathrm{ml}$ CCL20 erfolgte nach Präinkubation mit sich selbst sowie mit HBD-2 und HBD-3 (jeweils $200 \mathrm{ng} / \mathrm{ml}$ ) sowie mit Medium ohne Chemokinzusatz (Ø) für $30 \mathrm{~min}$ bei $37^{\circ} \mathrm{C}$. Gezeigt sind die Mittelwerte von 3 unabhängigen Experimenten mit dem Subklon 1/17 (+SEM). Bei p<0,05 wurden signifikant zur Positivkontrolle (Migration gegen CCL20 ohne Präinkubation) unterschiedliche Werte mit * gekennzeichnet.

Des Weiteren war HBD-2 nicht in der Lage eine intrazelluläre Calciumantwort zu induzieren, während CCL20 auch hier eine konzentrationsabhängige Calciumfreisetzung bewirkte, wie die folgende Abbildung zeigt.

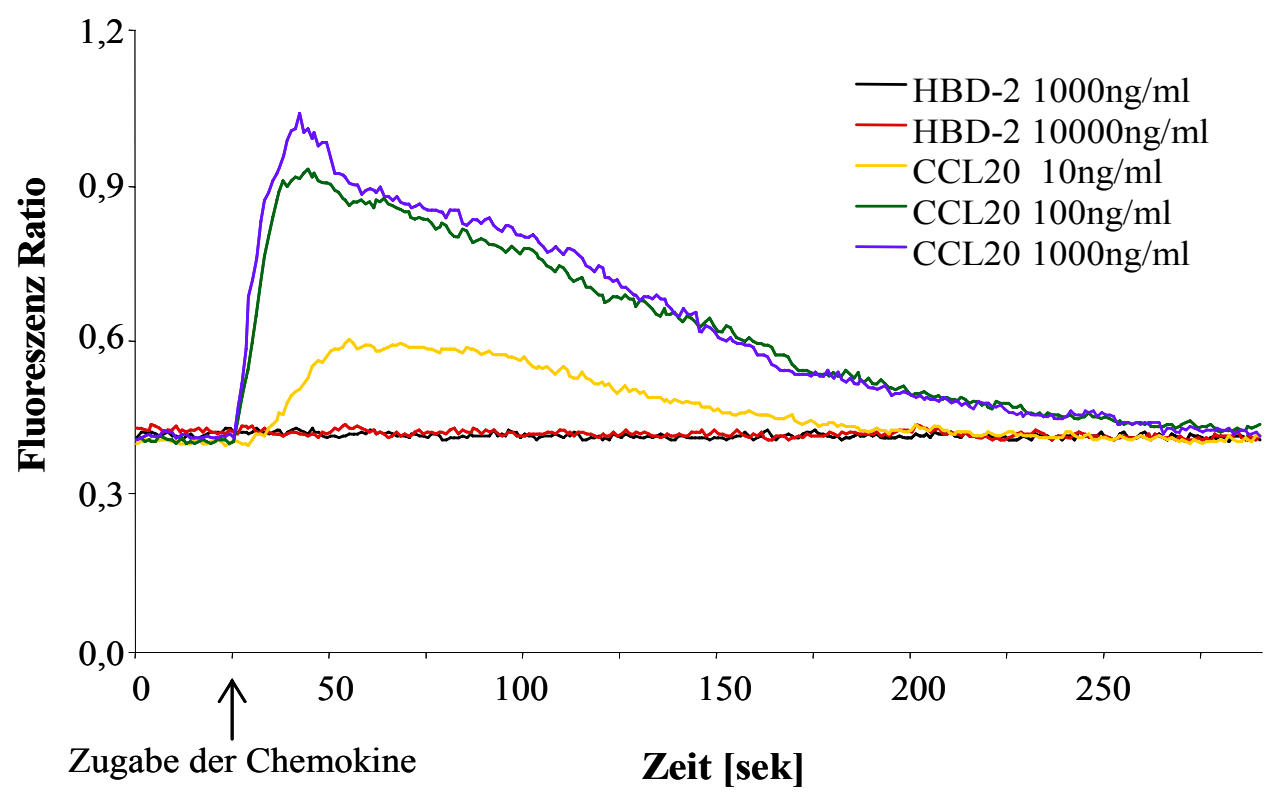

Abb. 46: Intrazelluläre Calciumfreisetzung in der RBL-2H3-CCR6-Transfektante nach Stimulation durch verschiedene Konzentrationen des Liganden CCL20 sowie durch das $\beta$-Defensin HBD-2. Als FluoreszenzRatio wird das Verhältnis von blau-fluoreszierendem Indo1 zu dem violett-fluoreszierenden Indo1-CalciumKomplex bezeichnet. Dargestellt ist beispielhaft eines von drei Experimenten. 
Weiterhin konnte die durch CCL20 induzierte intrazelluläre Calciumfreisetzung zwar durch erneute Stimulation der Zellen mit CCL20, nicht aber durch anschließende Stimulation mit HBD-2 desensibilisiert werden. Die Ergebnisse der Desensibilisierungsversuche sind in Abbildung 47 dargestellt.

A

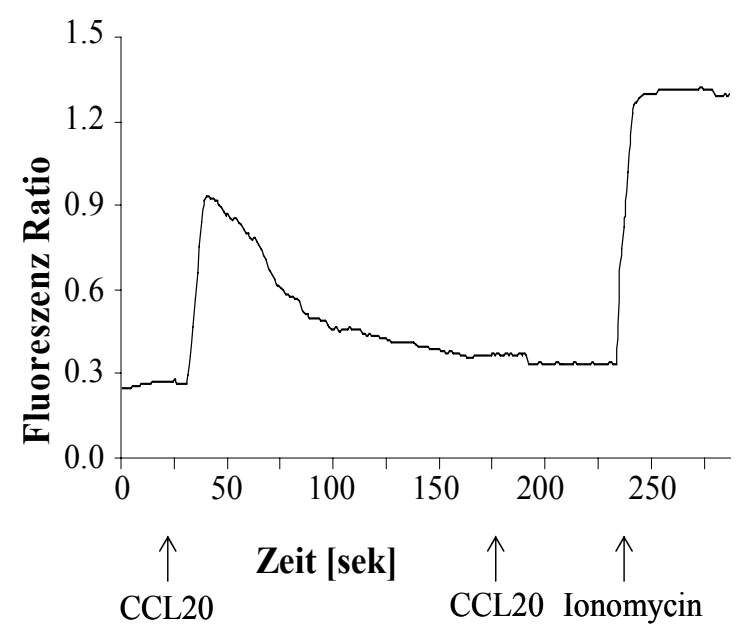

B

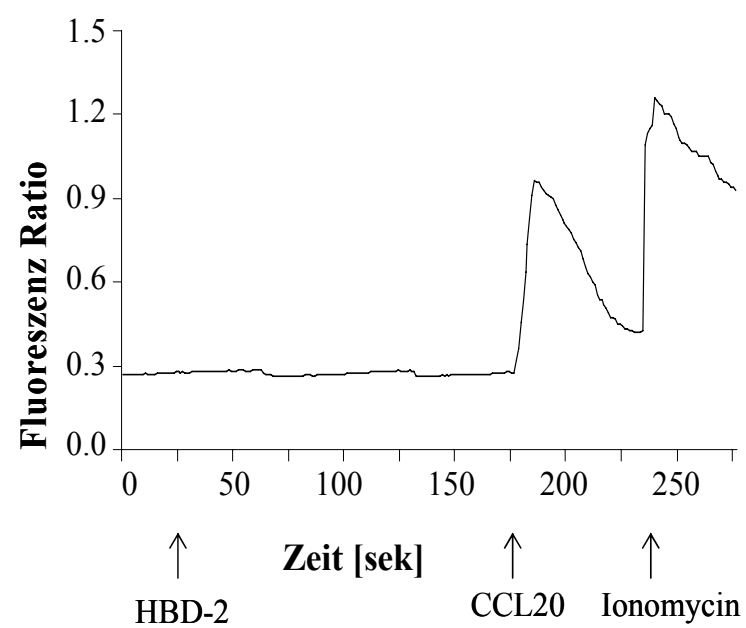

Abb. 47: Intrazelluläre Calciumfreisetzung in RBL-2H3-CCR6-Transfektanten nach Stimulation durch je CCL20 (A) und durch das $\beta$-Defensin HBD-2 (B). Im Anschluss erfolgte direkt nach Abklang des Calciumsignals eine weitere Stimulation der Zellen mit CCL20 selbst bzw. HBD-2 als putativer Desensibilisierungsnachweis. Stimuliert wurde mit jeweils $10 \mu \mathrm{g} / \mathrm{ml}$. Das zum Ende der Messung zugegebene Ionomycin $(100 \mathrm{nM})$ diente als Positivkontrolle, da es die Öffnung der Calciumspeicher bewirkt. Als Fluoreszenz-Ratio wird das Verhältnis von blau-fluoreszierendem Indo1 zu violett-fluoreszierenden Indo1Calcium-Komplex bezeichnet. Dargestellt ist je eines von drei Experimenten.

\subsection{Untersuchung der Defensin-induzierten Signaltransduktion}

\subsubsection{Untersuchung der Rolle der MAPK bei der Chemotaxis humaner Makrophagen}

Um die Rolle der MAP-Kinasen bei der von Defensinen induzierten Chemotaxis zu analysieren, wurde ein pharmakologischer Test durchgeführt. Dazu wurden zum Einen humane Makrophagen und zum Anderen murine Mastzellen verwendet. Als Chemokine dienten bei den humanen Makrophagen das $\alpha$-Defensin HNP-1, das $\beta$-Defensin HBD-2 sowie CCL3, welche als Kontrolle mitgeführt wurde. Die murinen Mastzellen wurden mit HBD-2 sowie C5a als Positivkontrolle angelockt. Da die $\alpha$-Defensine bereits im Vorfeld keine Chemotaxis bei diesen Zellen bewirken konnten, wurden sie hier nicht untersucht. Die verwendeten Zellen wurden jeweils vor der Migration für 30 Minuten mit den folgenden MAPK-Inhibitoren präinkubiert: PD098059 (ERK-Inhibitor), SP600125 (JNK-Inhibitor) und 
SB203580 (p38-Inhibitor). Im Folgenden sind zunächst die Ergebnisse der in vitro Chemotaxis der humanen Makrophagen abgebildet.

$\mathbf{A}$

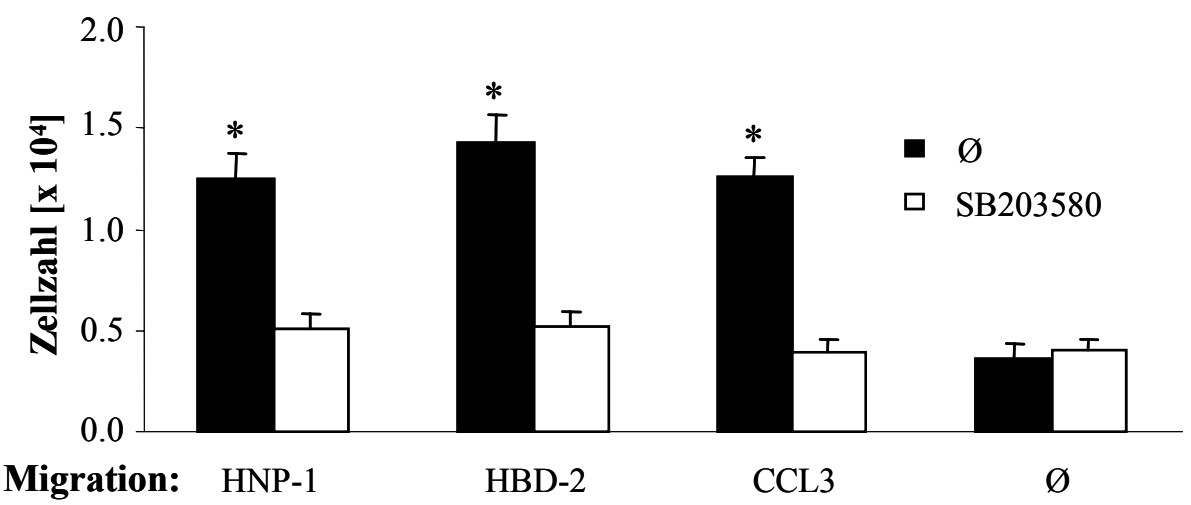

B

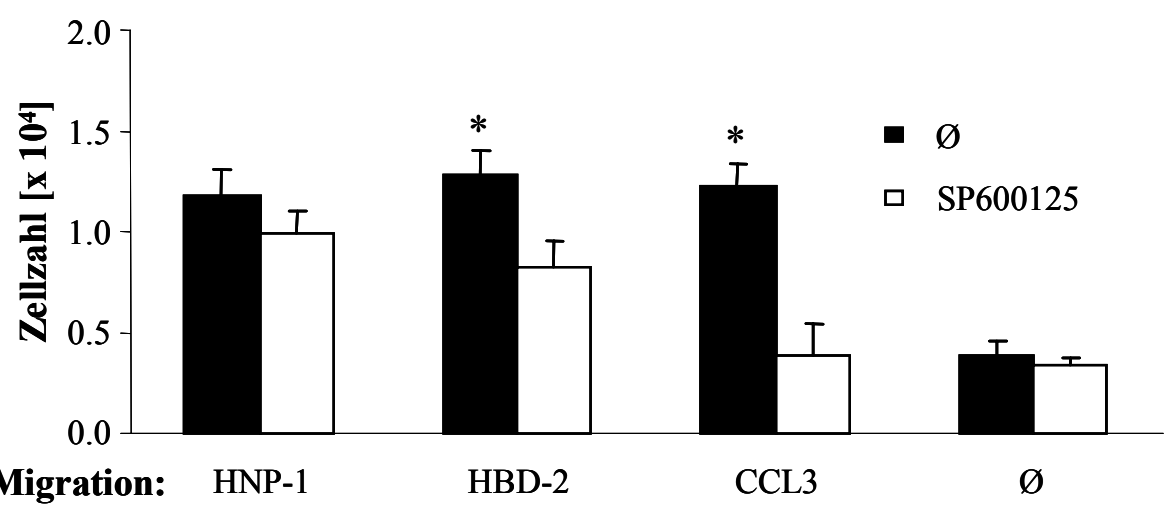

$\mathbf{C}$

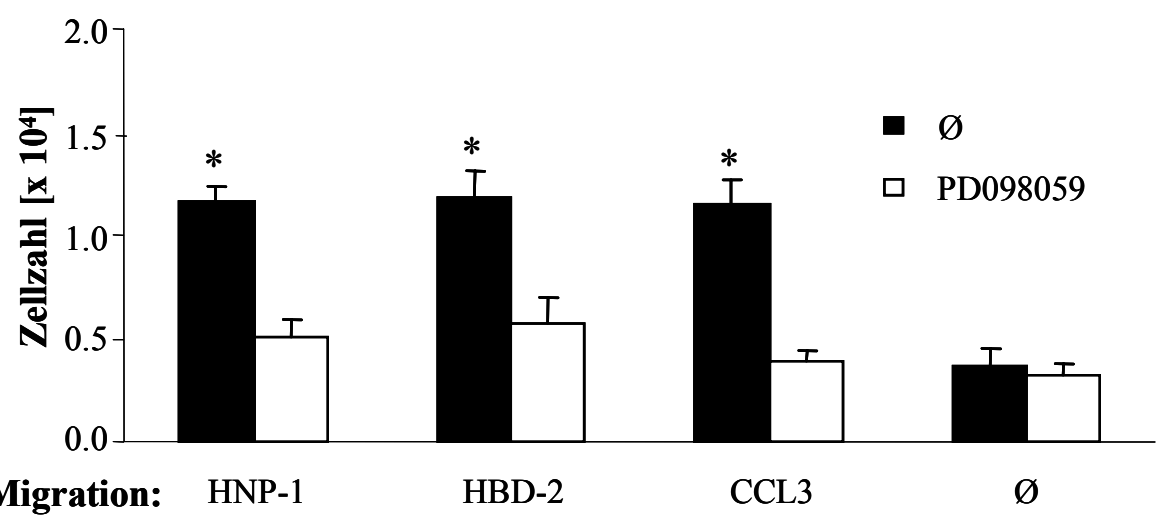

Abb. 48: Ergebnisse der in vitro Chemotaxis humaner Makrophagen mit und ohne Inhibition der MAPK. Die Wanderung erfolgte gegen je $1000 \mathrm{ng} / \mathrm{ml}$ HNP-1 und HBD-2, gegen $100 \mathrm{ng} / \mathrm{ml}$ CCL3 sowie gegen Medium ohne Chemokinzusatz $(\varnothing)$. Vor der 1,5 stündigen Migration ( $8 \mu \mathrm{m}$ Porendurchmesser) wurden die Zellen jeweils 30 Minuten bei $37^{\circ} \mathrm{C}$ mit je $20 \mu \mathrm{M}$ des p38 Inhibitors SB203580 (A), des JNK Inhibitors SP600125 (B) oder des ERK Inhibitors PD098059 (C) präinkubiert. Die mit* markierten Werte sind signifikant $(p<0,05)$ zu den mit MAPK-Inhibition erzielten Werten unterschiedlich. 
Wie in Abbildung $48 \mathrm{zu}$ erkennen ist, konnten alle MAPK-Inhibitoren die Migration gegen HNP-1, HBD-2 sowie CCL3 blockieren. Die p38- und die ERK-Inhibition bewirkten dabei die stärkste Verminderung der chemotaktischen Aktivität der humanen Makrophagen gegenüber den untersuchten Chemokinen.

Die Inhibition von JNK führte zu einer deutlich geringeren Reduktion der Migration gegen die Defensine HNP-1 und HBD-2; dabei ließ sich die Wanderung gegen HNP-1 am schlechtesten inhibieren. Die CCL3-induzierte Wanderung der Zellen wurde hingegen am effektivsten inhibiert.

\subsubsection{Untersuchung der Rolle der MAPK bei murinen Mastzellen}

Weiterhin wurde die Rolle der MAPK bei der HBD-2 induzierten in vitro Migration von murinen Mastzellen untersucht. Die aus Knochenmarkszellen aufgereinigten und mit muIL-3 und muSCF kultivierten Zellen wurden wie bereits zuvor für die humanen Makrophagen beschrieben vor der Chemotaxis mit den Inhibitoren präinkubiert, worauf eine Migration von 3 Stunden erfolgte. Bei der Analyse der Ergebnisse zeigte sich, dass die durch das $\beta$-Defensin HBD-2 ausgelöste Migration der murinen Mastzellen von allen MAPK-Inhibitoren deutlich reduziert werden konnte. Die Inhibition ist dabei ähnlich stark wie die der C5a-induzierten Chemotaxis. Den geringsten Effekt bewirkte der ERK-Inhibitor PD098059.

Die Ergebnisse dieser Untersuchung stellt die Abbildung 49 dar. 
A

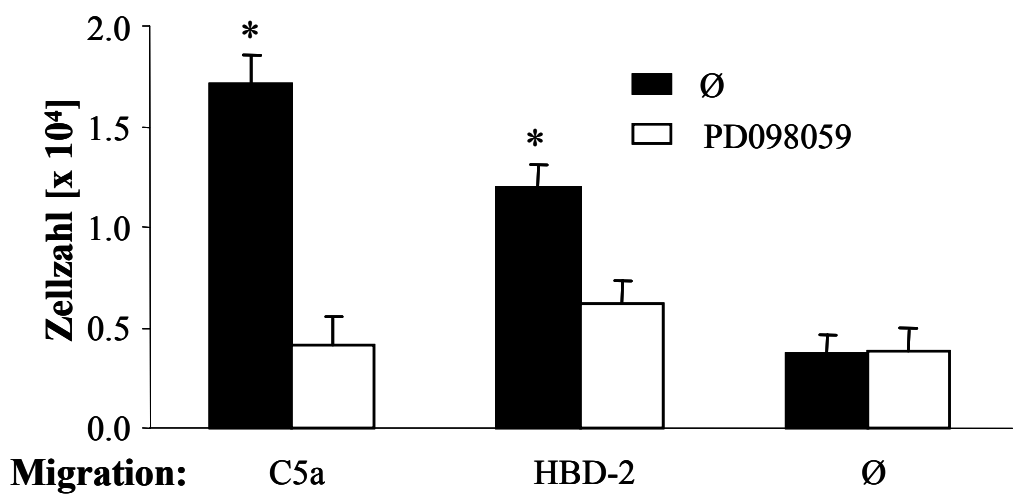

B
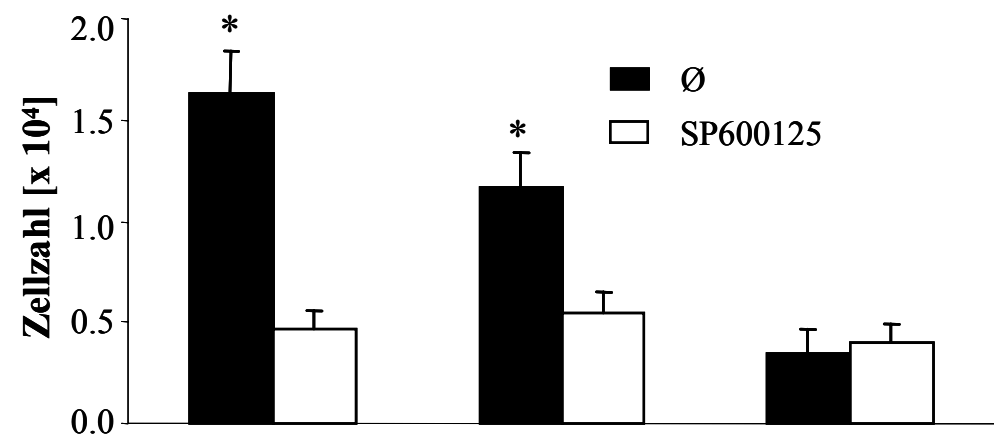

Migration:

C5a

HBD-2

$\varnothing$

C

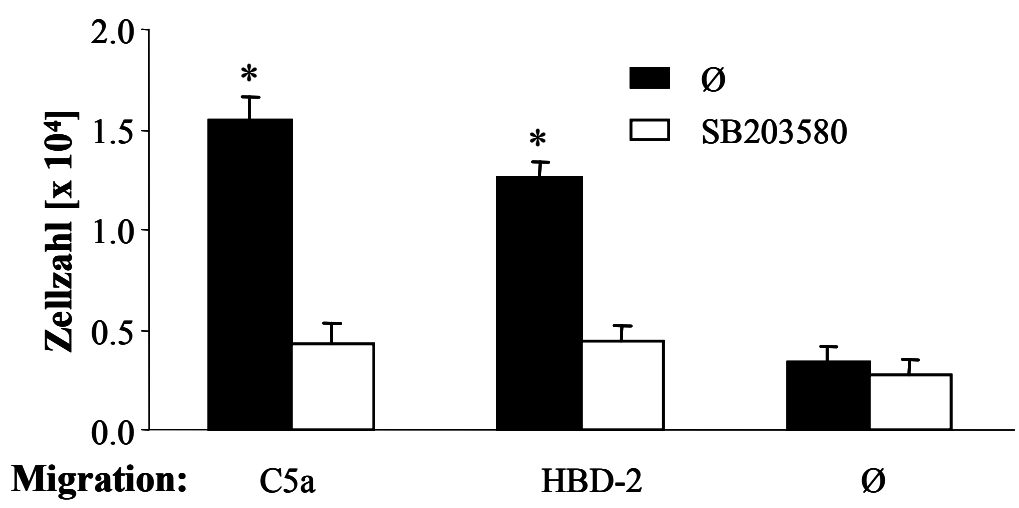

Abb. 49: In vitro Chemotaxis muriner Mastzellen nach MAPK-Inhibition. Die Wanderung erfolgte gegen $1000 \mathrm{ng} / \mathrm{ml} \mathrm{HBD}-2$, gegen $100 \mathrm{ng} / \mathrm{ml}$ C5a sowie gegen Medium ohne Chemokinzusatz $(\varnothing)$. Vor der 3 stündigen Migration $\left(5 \mu \mathrm{m}\right.$ Porendurchmesser) wurden die Zellen jeweils 30 Minuten bei $37^{\circ} \mathrm{C}$ mit je $20 \mu \mathrm{M}$ des ERKInhibitor PD098059 (A), des JNK-Inhibitor SP600125 (B) oder des p38-Inhibitor SB203580 (C) präinkubiert. Die mit * markierten Werte sind signifikant $(p<0,05)$ unterschiedlich zu den mit MAPK-Inhibitoren erzielten Werten. 


\subsubsection{Untersuchung der Rolle der $G_{\alpha i}$-Proteine}

Da bekannt ist, dass G-Protein-gekoppelte Rezeptoren mit den MAPK-Signalwegen durch die klassische G-Protein-stimulierte Synthese von second messengern verbunden sind (Lefkowitz et al., 2005), wurde untersucht, ob $\mathrm{G}_{\alpha \mathrm{i}}$-Proteine auch Teil des von Defensinen induzierten Signalweges in humanen Makrophagen sowie murinen Mastzellen sind. Hierfür wurden die Zellen vor der in vitro Chemotaxis gegen HNP-1 für vier Stunden mit ansteigenden Pertussis Toxin-Konzentrationen präinkubiert. Für die anschließende, vergleichende in vitro Chemotaxis gegen HNP-1, HBD-2 und C5a wurden die Zellen ausschließlich mit der sich als optimal herausgestellten Pertussis Toxin-Konzentration von $200 \mathrm{ng} / \mathrm{ml}$ inkubiert. Dieses aus dem Bakterium Bordetella pertussis stammende Toxin hemmt spezifisch die $\mathrm{G}_{\alpha \mathrm{i}}$-Proteine.

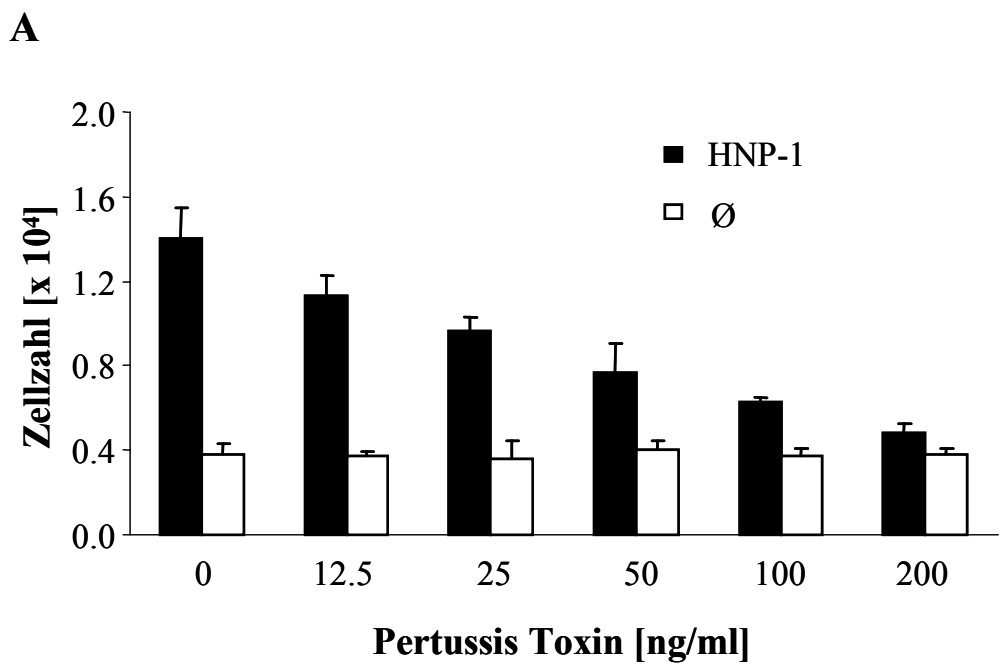

$\mathbf{B}$

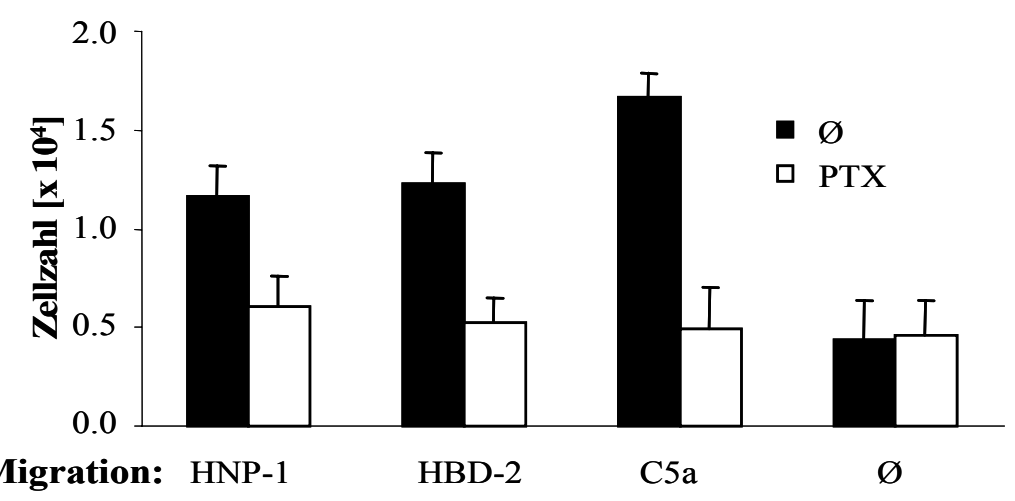

Abb. 50: Ergebnis der Migration humaner Makrophagen in vitro nach Inhibition von $G_{\alpha i}$-Proteinen durch Pertussis Toxin. Die Migrationsdauer betrug jeweils $1,5 \mathrm{~h}$. Es wurde eine Porengöße von $8 \mu \mathrm{m}$ verwendet. In (A) wurde eine Konzentrationsreihe des Pertussis Toxin bei Migration der Zellen gegen HNP-1 untersucht. (B) zeigt die Wirkung der optimalen, aber nicht letalen Pertussis Toxin Konzentration von $200 \mathrm{ng} / \mathrm{ml}$ im Vergleich zu unbehandelten Zellen $(\varnothing)$ bei der in vitro Chemotaxis gegen die Defensine HNP-1 und HBD-2 (je $1000 \mathrm{ng} / \mathrm{ml})$, gegen C5a (100 ng/ml) sowie gegen Medium ohne Chemokinzusatz $(\varnothing)$. Gezeigt sind jeweils die Mittelwerte von 3 unabhängigen Experimenten sowie die Standardabweichung (+SEM). 
Die Präinkubation mit unterschiedlichen Pertussis Toxin-Konzentrationen inhibierte die HNP-1-induzierte Migration der humanen Makrophagen in einer dosisabhängigen Weise (s. Abb. 50/A). Dabei wurde der 50-prozentige inhibitorische Effekt bei ca. $50 \mathrm{ng} / \mathrm{ml}$ Pertussis Toxin erzielt. Die stärkste Inhibition wurde bei einer Toxin-Konzentration von $200 \mathrm{ng} / \mathrm{ml}$ erreicht. Daher wurde diese Konzentration für die weitere Untersuchung verwendet. Hierbei zeigte sich, dass sich sowohl die Defensin- als auch die C5a-abhängige Chemotaxis durch das Pertussis Toxin deutlich reduzieren ließ. Die stärkste Reduktion konnte bei der Migration gegen C5a erzielt werden, während die HNP-1-stimulierte Migration deutlich schwächer inhibiert wurde (s. Abb. 50/B). Diese Ergebnisse deuten darauf hin, dass $\mathrm{G}_{\alpha i}$-Proteine an der Defensin-induzierten Signaltransduktion beteiligt sind.

\subsection{Untersuchungen zur Rolle der PKC bei der Rezeptor-Desensibilisierung}

Bei den bereits beschriebenen Blockade- und Desensibilisierungs-Experimenten waren alle $\alpha$-Defensine in der Lage die $\beta$-Defensin-induzierte Chemotaxis des jeweiligen Zelltyps zu einem gewissen Anteil zu inhibieren und vice versa. Einzig die durch Stimulation mittels $\beta$-Defensinen ausgelöste, intrazelluläre Calciumfreisetzung ließ sich durch Vorstimulation mit $\alpha$-Defensinen (welche selbst keinen Calciuminflux bewirken konnten) nicht desensibilisieren. Daher stellte sich die Frage, ob beide Defensin-Familienmitglieder ihre chemotaktische Wirkung über ein und denselben Rezeptor mit unterschiedlicher Affinität ausüben könnten.

\subsubsection{Untersuchung der homologen Rezeptor-Desensibilisierung}

Um der Antwort auf die Frage nach einem oder mehreren Rezeptoren ein Stück näher zu kommen, wurde sowohl innerhalb der Familien der $\alpha$ - und $\beta$-Defensine als auch zwischen den Familien eine funktionelle Desensibilisierung untersucht.

Wenngleich die Desensibilisierung homologer als auch heterologer Natur sein kann, so ist lediglich die letztere PKC-abhängig (Ali et al., 1999; Lefkowitz et al., 1998).

Zunächst wurde dafür die Migration der humanen Makrophagen untersucht. Tatsächlich konnte dabei gezeigt werden, dass der generelle PKC-Inhibitor GF109 die Desensibilisierung sowohl zwischen den $\alpha$-Defensinen als auch zwischen den $\beta$-Defensinen nicht blockieren konnte. Dieses Ergebnis deutet an, dass humane $\alpha$ - bzw. $\beta$-Defensine jeweils durch einen 
eigenen Rezeptor in Makrophagen agieren, was in einer PKC-unabhängigen homologen Rezeptor-Desensibilisierung resultiert.

A

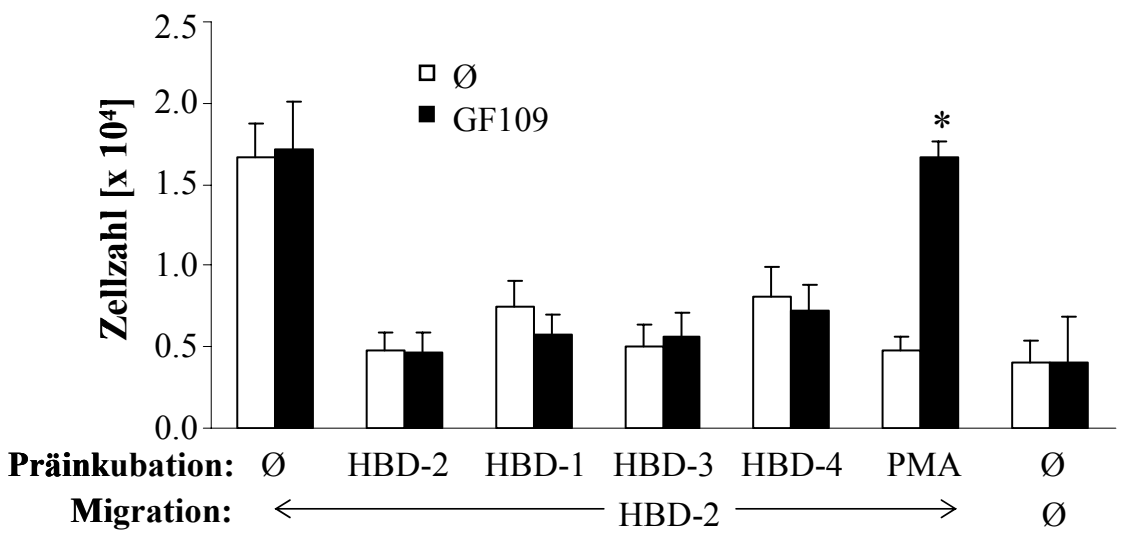

B

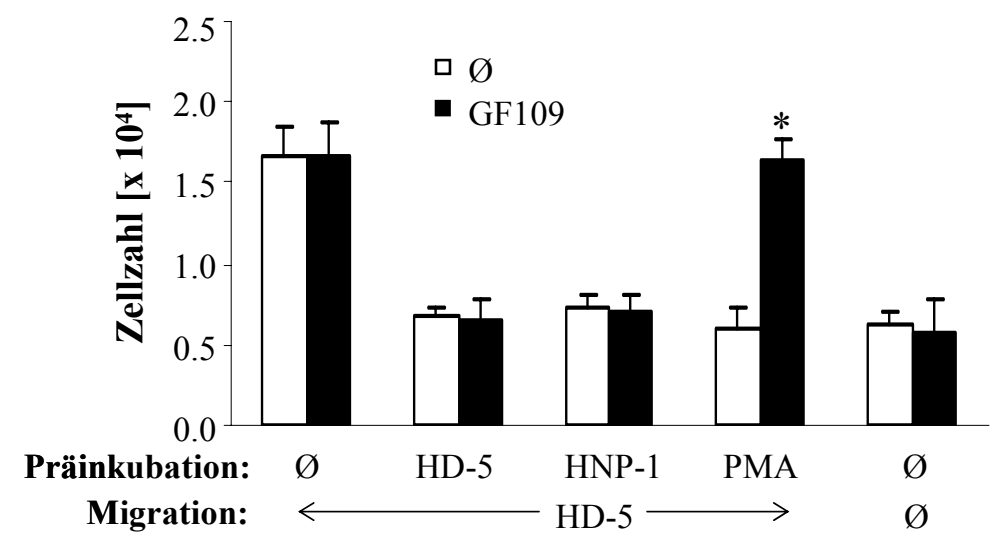

Abb. 51: In vitro Chemotaxis humaner Makrophagen mit und ohne Präinkubation des generellen PKCInihibitors GF109. Die 1,5stündige Migration (8 $\mu \mathrm{m}$ Porendurchmesser) erfolgte nach 30minütiger Präinkubation der Zellen mit $4 \mu \mathrm{M}$ GF109. Anschließend wurden die Zellen mit Defensinen (je $200 \mathrm{ng} / \mathrm{ml}$ ), PMA (PKC-Aktivator; $2 \mu \mathrm{M}$ ) oder Medium präinkubiert (jeweils 30 min bei $37^{\circ} \mathrm{C}$ ). Unter (A) ist die Migration gegen HBD-2 mit und ohne Desensibilisierung durch HBD-1 bis -4 dargestellt. In (B) wurde die Migration der Zellen gegen HD-5 mit und ohne Desensibilisierung durch sich selbst sowie HNP-1 untersucht. Gezeigt sind jeweils die Mittelwerte von 3 unabhängigen Experimenten (+SEM). Die mit Präinkubation von GF109 erhaltenen Werte, welche signifikant unterschiedlich $(\mathrm{p}<0,05)$ zur Negativkontrolle (ohne GF109, $\varnothing$ ) waren, wurden mit * markiert.

Der PKC-Aktivator PMA wurde in den Desensibilisierungs-Versuchen als Kontrolle eingesetzt. Durch die Aktivierung der PKC, also die PMA-induzierte heterologe Desensibilisierung, konnte die Migration der humanen Makrophagen gegen die untersuchten Defensine nahezu komplett inhibiert werden. Bei gleichzeitiger PKC-Inhibition durch GF109 
wurde dieser Effekt restlos aufgehoben. Dagegen konnte GF109 die homologe Desensibilisierung der Defensine nicht beeinflussen (s. Abb. 51).

\subsubsection{Untersuchung der heterologen Rezeptor-Desensibilisierung}

Des Weiteren sollte nun auch die heterologe Desensibilisierung der Defensin-Rezeptoren analysiert werden. Die Möglichkeit hierfür war bereits durch den erwähnten Effekt der Desensibilisierung der Defensin-induzierten Chemotaxis des PKC-Aktivators PMA gezeigt und wurde nun an Überkreuz-Blockaden von $\alpha$ - und $\beta$-Defensinen überprüft. Auf diese Weise sollte geklärt werden, ob ein gemeinsamer Defensin-Rezeptor existiert. Untersucht wurde diese Überkreuz-Blockade an humanen Makrophagen, humanen Gedächtnis-T-Zellen sowie der humanen Mastzelllinie HMC-1.

Die Resultate der Experimente zeigen bei beiden Zelltypen wiederum, dass PKC die heterologe Desensibilisierung durch PMA vermittelt. Dies galt als Positivkontrolle für die eigentlich zu untersuchende Überkreuz-Desensibilisierung der $\alpha$ - und $\beta$-Defensine. Bemerkenswerterweise konnte auch die Überkreuz-Blockade sowohl der HBD-2- als auch der HNP-1-induzierten Chemotaxis durch den PKC-Inhibitor GF109 aufgehoben werden. Im Gegensatz dazu bestätigte sich, dass die homologe Blockade der Defensine PKC-unabhängig und damit nicht aufhebbar war.

Die Ergebnisse der Desensibilisierungs-Experimente der humanen Makrophagen werden in der folgenden Abbildung dargestellt. 


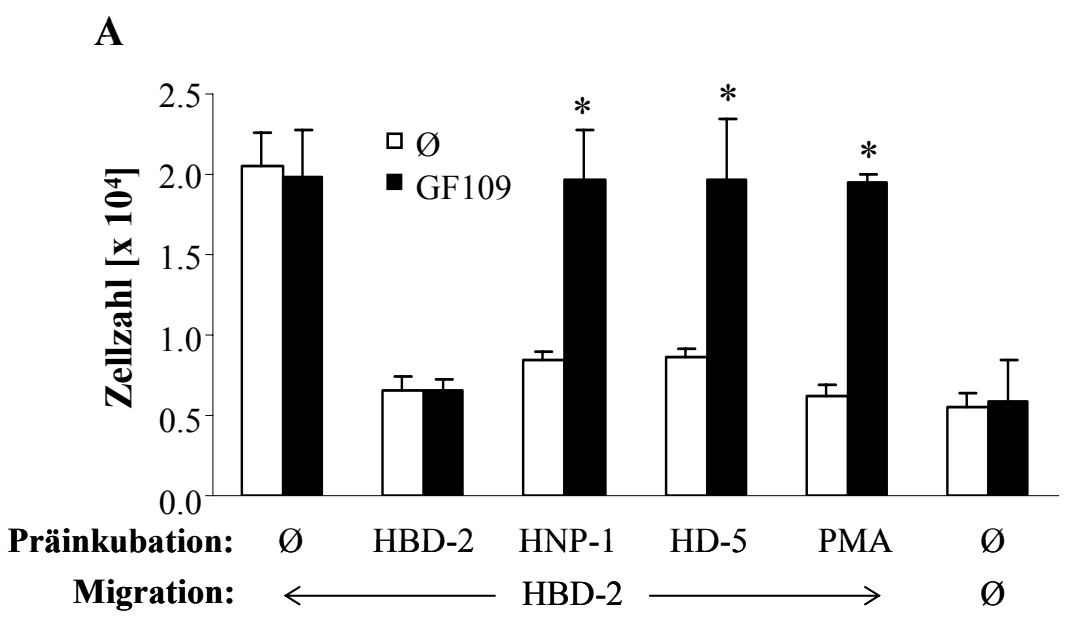

B

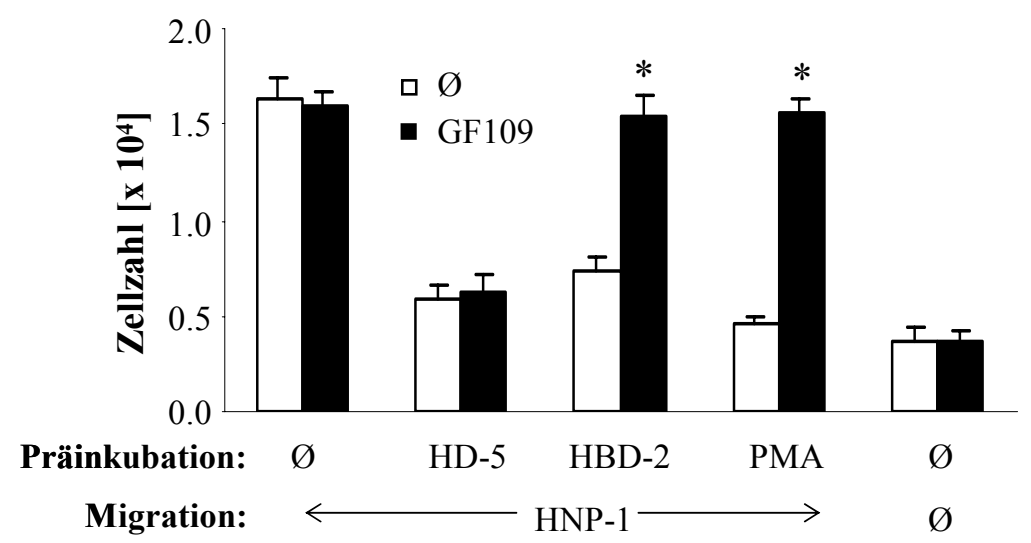

Abb. 52: Ergebnisse der heterologen Desensibilisierung der in vitro Chemotaxis von humanen Makrophagen gegen das $\beta$-Defensin HBD-2 (A) und gegen das $\alpha$-Defensin HNP-1 (B). Die Zellen wurden vor der Desensibilisierung mit den angegebenen Defensinen (je $200 \mathrm{ng} / \mathrm{ml}$ für $30 \mathrm{~min}$ bei $37^{\circ} \mathrm{C}$ ) mit dem generellen PKC-Inhibitor GF109 $(4 \mu \mathrm{M})$, mit dem PKC-Aktivator PMA $(200 \mu \mathrm{M})$ oder nur mit Medium $(\varnothing)$ präinkubiert. Danach erfolgte der 1,5 stündige Migrationsassay (ebenfalls bei $37^{\circ} \mathrm{C}$ und mit $8 \mu \mathrm{m}$ Porengröße) gegen jeweils $1000 \mathrm{ng} / \mathrm{ml}$ Defensin. Dargestellt sind die Mittelwerte dreier unabgängiger Experimente (+SEM). Bei $<<0,05$ galten die Werte mit GF109 als signifikant unterschiedlich zu den Kontrollwerten ohne GF109 ( $\varnothing)$ und wurden mit* gekennzeichnet.

In Analogie zu den humanen Makrophagen war der generelle PKC-Inhibitor GF109 nicht in der Lage die funktionelle Desensibilisierung zwischen den humanen $\alpha$-Defensinen zu blockieren. Es ist also möglich, dass HNP-1, HNP-3 und HD5 auch in T-Lymphocyten über einen gemeinsamen Rezeptor agieren, was $\mathrm{zu}$ einer PKC-unabhängigen homologen Rezeptor-Desensibilisierung führt. Der $\alpha$-Defensin-Rezeptor auf T-Zellen konnte zudem durch die Stimulierung der PKC mittels PMA heterolog desensibilisiert werden. Wie in Abbildung 52 und 53 gezeigt, ließ sich diese heterologe Desensibilisierung ebenso für HBD-2 nachweisen und konnte durch GF109 Präinkubation komplett aufgehoben werden. Obwohl 
HBD-2 also selbst keine Migration in T-Lymphocyten induzieren konnte, wurde die Wanderung der Zellen gegen HNP-1 durch HBD-2 blockiert (s. Abb. 53).

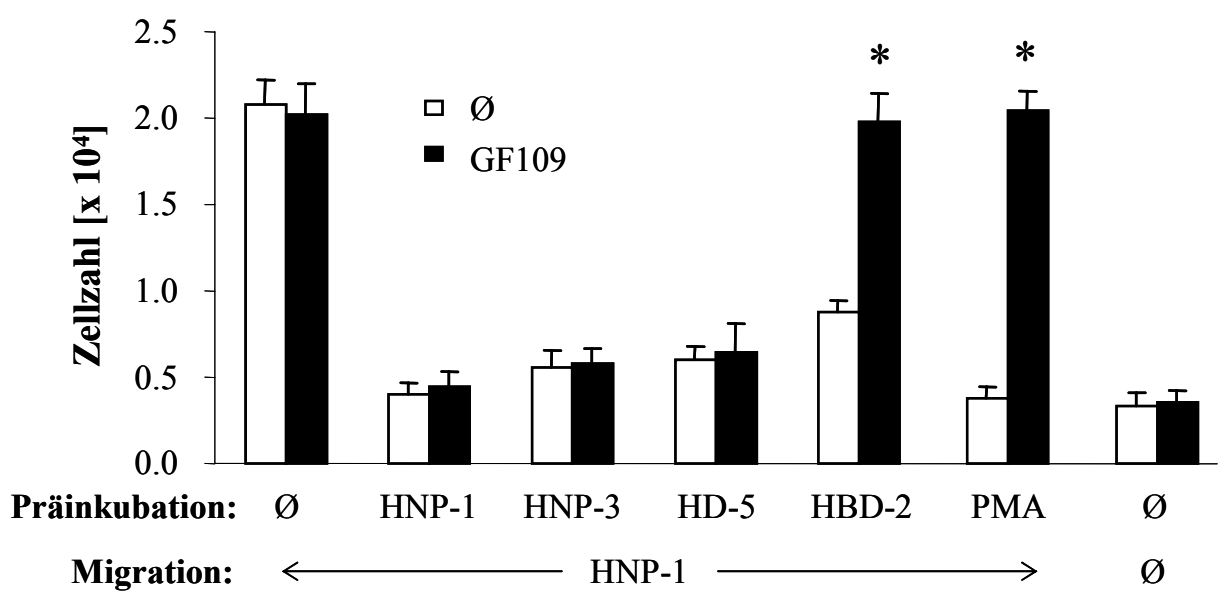

Abb. 53: Ergebnisse der in vitro Chemotaxis von humanen Gedächtnis T-Lymphocyten gegen das $\alpha$-Defensin HNP-1. Die Zellen wurden vor der Desensibilisierung mit den angegebenen Defensinen (je $200 \mathrm{ng} / \mathrm{ml}$ für $30 \mathrm{~min}$ bei $\left.37^{\circ} \mathrm{C}\right)$ mit dem PKC-Inhibitor GF109 $(4 \mu \mathrm{M})$, mit dem PKC-Aktivator PMA $(200 \mu \mathrm{M})$ oder nur mit Medium $(\varnothing)$ präinkubiert. Die Migration gegen $1000 \mathrm{ng} / \mathrm{ml} \mathrm{HNP}-1$ dauerte $4 \mathrm{~h}\left(37^{\circ} \mathrm{C} ; 5 \mu \mathrm{m}\right.$ Porendurchmesser). Dargestellt sind die Mittelwerte von 3 unabgängigen Versuchen (+SEM). Bei p<0,05 galten die Werte mit GF109 als signifikant unterschiedlich zu den Kontrollwerten ohne GF109 ( $\varnothing$ ) und wurden mit * gekennzeichnet.

Die Rolle der PKC bei der Rezeptor-Desensibilisierung wurde weiterhin durch die Präinkubation von HMC-1 Zellen mit dem PKC-Inhibitor Gö6976 untersucht, welcher ausschließlich Calcium-abhängige PKC-Isotypen inhibiert. Auf Grund der unterschiedlichen Fähigkeiten von $\alpha$ - und $\beta$-Defensinen, die intrazelluläre Calciumfreisetzung in HMC-1 Zellen $\mathrm{zu}$ stimulieren, konnte hierdurch möglicherweise eine Erklärung für dieses Beobachtung gefunden werden.

Die folgenden Diagramme zeigen die Ergebnisse dieser Untersuchung. 
A

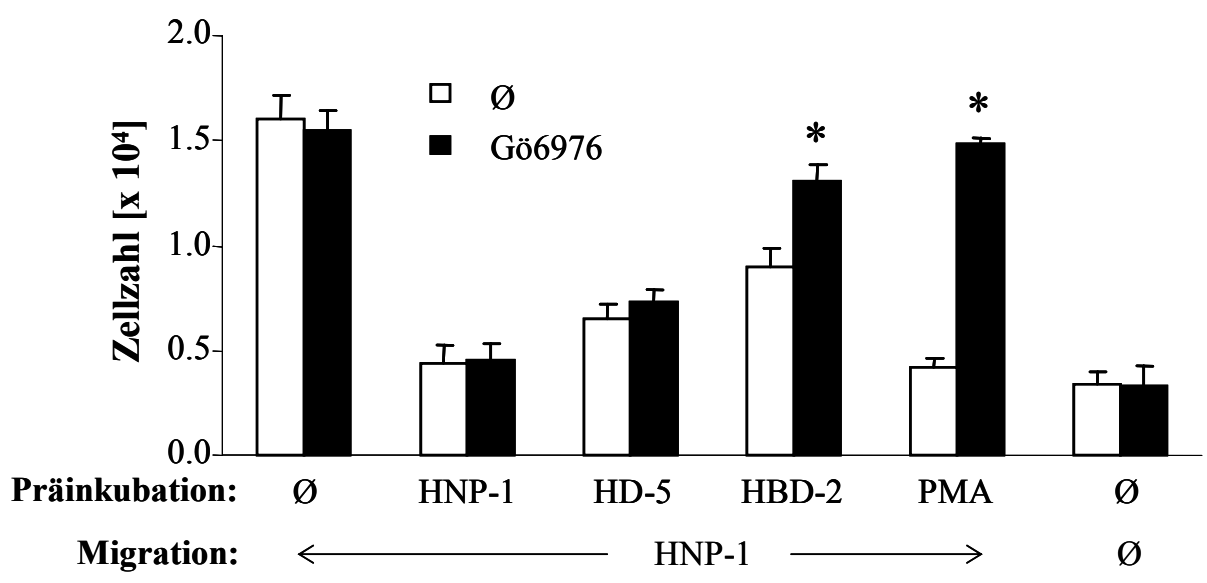

B

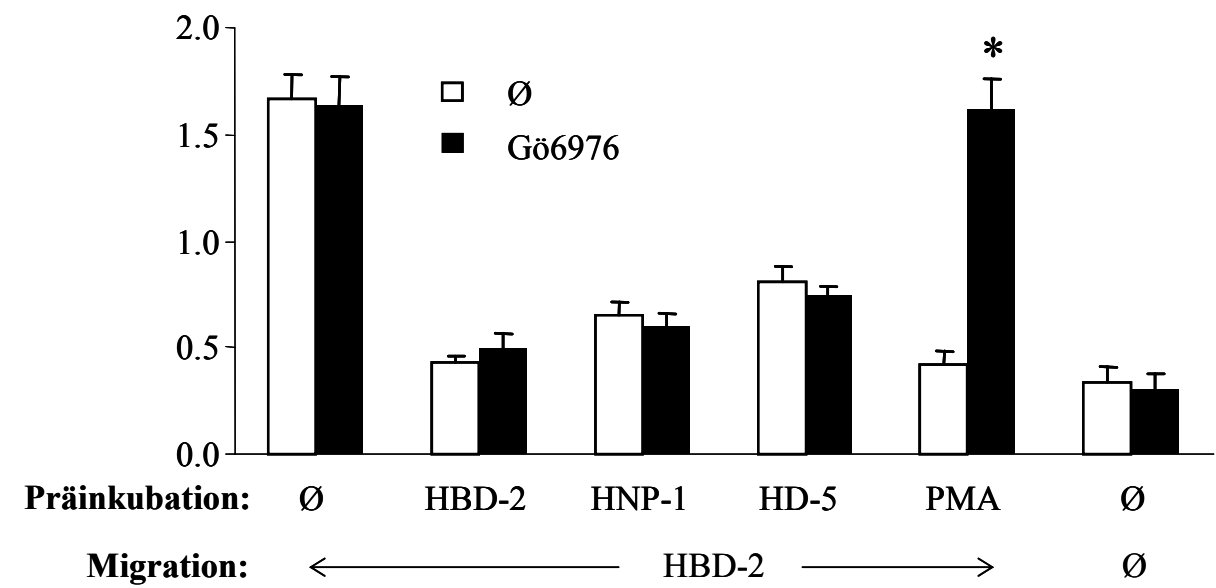

Abb. 54: Ergebnisse der Desensibilisierung der in vitro Chemotaxis von HMC-1 Zellen gegen das $\alpha$-Defensin HNP-1 (A) sowie gegen das $\beta$-Defensin HBD-2 (B). Die Zellen wurden vor der Desensibilisierung mit den angegebenen Defensinen (je $200 \mathrm{ng} / \mathrm{ml}$ für $30 \mathrm{~min}$ bei $37^{\circ} \mathrm{C}$ ) mit dem PKC-Inhibitor GF109 $(2 \mu \mathrm{M})$, mit dem PKC-Aktivator PMA $(200 \mu \mathrm{M})$ oder nur mit Medium $(\varnothing)$ präinkubiert. Danach erfolgte der 1,5stündige Migrationsassay gegen $1000 \mathrm{ng} / \mathrm{ml} \mathrm{HNP-1}$ bzw. HBD-2 (ebenfalls bei $37^{\circ} \mathrm{C}$ und mit $8 \mu \mathrm{m}$ Porengröße). Dargestellt sind die Mittelwerte von 3 unabgängigen Experimenten (+SEM). Bei $p<0,05$ galten die Werte mit Gö6976 als signifikant unterschiedlich zu den Kontrollwerten ohne Gö6976 ( $\varnothing)$ und wurden mit* markiert.

In Analogie zu den Ergebnissen, welche mit dem generellen PKC-Inhibitor GF109 erzielt werden konnten, konnte der Inhibitor Calcium-abhängigen PKC Gö6976 die funktionelle homologe Desensibilisierung zwischen $\alpha$ - bzw. $\beta$-Defensinen nicht aufheben (s. Abb. 53). Für die heterologe Desensibilisierung waren hingegen die Calcium-abhängigen PKC verantwortlich, da die Desensibilisierung durch den PKC-Aktivator PMA durch Präinkubation mit Gö6976 blockiert wurde. Dies galt ebenso für die Überkreuz-BlockadeExperimente durch HBD-2 bei Migration gegen HNP-1. Im Gegensatz dazu ließ sich der Desensibilisierungseffekt von HNP-1 und HD-5 auf die Wanderung gegen HBD-2 nicht durch Gö6976 aufheben. 
Daher scheint es möglich, dass zwar HBD-2, nicht aber HNP-1 und HD-5 durch Calciumabhängige PKC-Isotypen intrazelluläre Signale stimulieren, was wiederum mit dem Ergebnis übereinstimmen würde, dass HNP-1 und HD-5 nicht in der Lage sind, die intrazelluläre Calciumfreisetzung zu induzieren. 


\section{Diskussion}

Eine der Hauptfunktionen der Defensine ist die Zerstörung oder Inaktivierung von Mikroorganismen, was sie zu wichtigen Effektoren des angeborenen Immunsystems macht (Lehrer und Ganz, 2002; Selsted, 2005). Zudem konnte kürzlich der Beweis erbracht werden, dass die Defensine auch in die adaptive Immunität involviert sind, da sie in der Lage waren, immunkompetente Zellen zu den Orten der Infektion und Entzündung zu rekrutieren (Yang et al., 2002).

Ziel dieser Arbeit war es, die Zellen des Immunsystems zu identifizieren, welche von den Defensinen chemotaktisch angelockt werden, sowie der Frage nach dem oder den Rezeptor/en für die beiden Defensin-Familien nachzugehen.

Es stellte sich dabei zunächst heraus, dass der Versuch der Eingrenzung eines in Frage kommenden Rezeptors anhand der zu dieser Zeit publizierten Literatur kaum Chancen auf Erfolg hatte. So führte die funktionelle Analyse der FPRL-2-Transfektanten lediglich zu dem Ergebnis, dass weder der in der Literatur beschriebene Ligand WKYMVM (Bae et al., 2003) noch HBD-2 bzw. HNP-1 die stabil transfizierten RBL-2H3-Zellen chemotaktisch anlocken konnten. Dahingegen konnte die von F2L-induzierte konzentrationsabhängige Chemotaxis sowie intrazelluläre Calciumfreisetzung bestätigt werden (Migeotte et al., 2005).

\subsection{Wirkung der Defensine auf die Migration der Granulocyten}

Zunächst wurden mittels Dichtegradientenzentrifugation aus Vollblut aufgereinigte Granulocyten auf ihre Fähigkeit untersucht, gegen verschiedene Konzentrationen der Defensine HNP-1 und HBD-2 zu migrieren. Hierbei stellte sich in Übereinstimmung mit der Literatur heraus, dass weder HNP-1 noch HBD-2 eine in vitro Chemotaxis der Granulocyten induzieren konnten (Yang et al., 2000; Yang et al., 2002). Dahingegen zeigte sich wie in bisherigen Publikationen eine deutliche, dosisabhängige Migration der Zellen gegen den Komplementfaktor C5a (Fernandez et al., 1978; Morita et al., 1989). 


\subsection{Wirkung der Defensine auf die Migration unbehandelter humaner Monocyten}

Die frisch isolierten humanen Monocyten konnten in vitro sowohl durch das $\alpha$-Defensin HNP-1 als auch durch das $\beta$-Defensin HBD-2 mobilisiert werden. Die Migration der Monocyten gegen HNP-1 und HBD-2 konnte durch Kultivierung mit GM-CSF allerdings noch einmal verstärkt werden. So verdoppelte sich die Anzahl der migrierten Zellen bei 1000 ng/ml HNP-1 und HBD-2 bei den Makrophagen im Vergleich zu den unbehandelten Monocyten. Dies könnte in einer höheren Expression der jeweiligen Rezeptoren in Folge der Kultivierung begründet sein.

\subsection{Wirkung der Defensine auf die Migration humaner und muriner Makrophagen}

Die Untersuchungen der in vitro und in vivo Migration zeigten, dass die $\alpha$-Defensine HNP-1, HNP-3 sowie HD-5 humane, aus Monocyten generierte Makrophagen in einer dosisabhängigen Weise chemotaktisch anlocken konnten. In der Vergangenheit wurden bereits kontroverse Ergebnisse bezüglich der Fähigkeit der $\alpha$-Defensine, die Migration von Monocyten zu induzieren, publiziert. So wurde zum Einen gezeigt, dass HNP-1 und HNP-2 die Chemotaxis von Makrophagen vermitteln können (Territo et al., 1989), zum Anderen wurde ihnen diese Fähigkeit zu einem späteren Zeitpunkt von anderen Arbeitsgruppen abgesprochen (Chertov et al., 1996; Yang et al., 2000).

HNP-3 wiederum wurde ebenfalls als chemotaktisch inaktiv beschrieben (Chertov et al., 1996; Yang et al., 2000). Diese Erkenntnis scheint besonders überraschend, wird die Ähnlichkeit der Aminosäuresequenzen betrachtet: HNP-1 und HNP-3 unterscheiden sich lediglich in einer Aminosäure am N-Terminus (Lehrer und Ganz, 2002).

Im Gegensatz hierzu besitzt HD-5 nur eine moderate Sequenzsimilarität zu HNP-1 (Jones und Bevins, 1992) und wurde bisher für humane Makrophagen als chemotaktisch inaktiv beschrieben (Szyk et al., 2006). Die Ergebnisse der vorliegenden Arbeit zeigen hingegen, dass HD-5 in der Lage war, humane Makrophagen chemotaktisch anzulocken. Diesen Ergebnissen zu Folge ist zudem davon auszugehen, dass die Rekrutierung von humanen Makrophagen eine sowohl den neutrophilen als auch den intestinalen $\alpha$-Defensinen gemeinsame Funktion ist.

Die Diskrepanz zwischen den in dieser Arbeit dargestellten Daten und den anderen veröffentlichten Ergebnissen könnten von unterschiedlichen Defensin-Synthesearten bzw. 
-quellen herrühren. Während das hier eingesetzte, kommerziell erworbene synthetische HNP-3 eine Chemotaxis auslösen konnte, war das aus neutrophilen Zellen aufgereinigte HNP-3 chemotaktisch inaktiv (Brogden et al., 2003; Ma et al., 2006). Eine weitere mögliche Erklärung könnte auch die Verwendung von unterschiedlichen Methoden zur Analyse der in vitro Chemotaxis sein, da in den erwähnten Publikationen eine Mikro-Chemotaxiskammer eingesetzt wurde, während in dieser Arbeit das Transwell ${ }^{\circledR}$-System zum Einsatz kam. Weiterhin waren die hier verwendeten Makrophagen im Gegensatz zu den frisch-isolierten Monocyten ein bis vier Tage kultiviert worden, was eventuell zu einer höheren Anzahl exprimierter Defensin-Rezeptoren geführt haben könnte. Da allerdings auch diese unbehandelten Monocyten in dieser Arbeit untersucht wurden und diese Untersuchungen, wie bereits erwähnt, zu ähnlichen Resultaten führten, bleibt eine zufriedenstellende Erklärung der immens unterschiedlichen Ergebnisse äußerst schwierig.

Weiterhin konnte die $\alpha$-Defensin-induzierte Migration auch bei der murinen MakrophagenZelllinie J774A.1 sowie den in der Gegenwart von M-CSF aus Knochenmarksvorläuferzellen differenzierten murinen Makrophagen detektiert werden. Daher scheint die Mobilisierung von Makrophagen eine gemeinsame, evolutionär konservierte Fähigkeit der $\alpha$-Defensin-Familie zu repräsentieren.

Für die $\beta$-Defensine HBD-3 und -4 wurde ebenfalls in der Vergangenheit gezeigt, dass sie humane Monocyten chemotaktisch anlocken können (Conejo-Garcia et al., 2001a, b), wohingegen HBD-2 diese Funktion fehlt (Yang et al., 1999). Mit dieser Arbeit wird ein Beweis dafür erbracht, dass die Rekrutierung humaner Makrophagen eine funktionelle Fähigkeit aller vier getesteten humanen $\beta$-Defensine (HBD-1 bis -4 ) sowie des murinen $\beta$ Defensins mBD-8 ist. Zudem konnte, ähnlich wie für die $\alpha$-Defensine, eine $\beta$-Defensininduzierte Migration der murinen Makrophagen-Zelllinie J774A.1 und der murinen Makrophagen detektiert werden. Auch hier ist also die Induktion der chemotaktischen Wanderung von humanen Makrophagen wahrscheinlich eine evolutionär konservierte Funktion der $\beta$-Defensine.

Im Gegensatz zu den $\beta$-Defensinen konnte der CCR6-Ligand CCL20 keine Migration der humanen Makrophagen vermitteln, wodurch CCR6 als gemeinsamer Rezeptor für CCL20 und HBD-2 erstmals in Frage gestellt wurde.

Auf Grund der zu früheren Publikationen deutlich abweichenden Ergebnisse erscheint eine Erklärung hierfür diffizil. Auch die Möglichkeit, dass die kontroversen Ergebnisse daraus resultieren könnten, dass die untersuchten Makrophagen eventuell unbehandelte Monocyten 
waren, werden durch die HNP-1- und HBD-2-induzierte Migration der unbehandelten Monocyten in 3.3 widerlegt. Des Weiteren wurden die Makrophagen nach unterschiedlich langer Behandlung mit GM-CSF (1 bis 7 Tage) auf ihre Migrationsfähigkeit gegenüber den Defensinen untersucht, und auch hier konnte an jedem Tag der Kultivierung eine Migration induziert werden (Ergebnisse nicht dargestellt).

Wie im in vitro-System induzierten HNP-1 und HBD-2 auch in vivo eine Chemotaxis der humanen Makrophagen. Durch die zusätzlich durchgeführten Blockadeversuche konnte zudem gezeigt werden, dass es sich zum Einen um eine spezifische Wanderung der Zellen handelt, da diese durch Präinkubation mit demselben Chemokin blockiert werden konnte. Zudem konnte die Migration gegen HBD-2 durch Präinkubation mit HBD-3 aber auch mit dem $\alpha$-Defensin HNP-1 inhibiert werden, wenngleich zu einem geringeren Maße. Umgekehrt inhibierten auch HBD-2 und -3 die HNP-1-vermittelte Chemotaxis sowie HNP-1 und HBD-2 die HD-5-induzierte Chemotaxis in vivo. Da die Migration der humanen Makrophagen gegen C5a nicht durch die Defensine blockiert werden konnte, ist davon auszugehen, dass es sich bei der gegenseitigen Inhibition der Defensine untereinander um einen spezifischen Effekt handelt. Dies könnte entweder auf einen Rezeptor für beide Defensin-Familien hindeuten, wobei die unterschiedlich starke Inhibition sowie Migration aus unterschiedlichen Affinitäten der einzelnen Defensine diesem Rezeptor gegenüber resultieren könnten. Es wäre aber auch denkbar, dass es sich hierbei um heterologe Wechselwirkungen zweier oder mehrerer Rezeptoren handelt.

Durch die nahezu identischen Ergebnisse der in vitro und in vivo Untersuchungen werden des Weiteren die Relevanz und Aussagekraft der in vitro Resultate für die tatsächlichen Vorgänge in vivo verdeutlicht.

\subsection{Wirkung der Defensine auf die Migration der DC}

HNP-1 ist der Veröffentlichung von Yang und Mitarbeitern nach (Yang et al., 2000) in der Lage, DC chemotaktisch anzulocken. Den Resultaten der vorliegenden Arbeit zu Folge können allerdings sowohl die aus Monocyten generierten humanen als auch die aus Knochenmarksvorläuferzellen differenzierten, murinen DC in vitro nur marginal durch die $\alpha$-Defensine mobilisiert werden. Bei den in vivo Untersuchungen wurde keinerlei Migration detektiert werden. 
Weiterhin wurde publiziert, dass die dendritischen Zellen auf Gradienten der humanen und murinen $\beta$-Defensine 2 und 3 mit Migration reagieren. Diese Migration soll über den CCR6Rezeptor vermittelt werden (Yang et al., 1999; Biragyn et al., 2001). Bei der Analyse der hier vorliegenden Ergebnisse zeigt sich jedoch, dass auch die $\beta$-Defensine in vitro nur eine unerhebliche und in vivo keine Wanderung der DC induzieren konnten.

Aus diesen Ergebnissen kann der Schluss gezogen werden, dass es sich bei den DC in Bezug auf die chemotaktische Rekrutierung nicht um Zielzellen der $\alpha$ - und $\beta$-Defensine handelt.

In Übereinstimmung mit dieser Schlussfolgerung wurde IL-4, welches gemeinhin für die Generierung von humanen, aus Monocyten entwickelten DC verwendet wird, als Suppressor der $\alpha$ - und $\beta$-Defensin-induzierten Chemotaxis identifiziert. Dieses Ergebnis erinnert an den inhibitorischen Effekt von IL-4 auf die Anaphylatoxin-induzierte Migration der DC als Konsequenz der Herunterregulierung des entsprechenden Rezeptors (Soruri et al., 2003).

Zudem lockten HNP-1 und HBD-2 sowohl in vitro als auch in vivo ebenfalls präferenziell die aus murinen Knochenmarkszellen mittels muM-CSF generierten Makrophagen und nur in zu vernachlässigendem Maße die murinen muGM-CSF-behandelten DCs an. Im Gegensatz dazu konnte CCL20 in vitro und in vivo lediglich die Migration der DCs vermitteln. Ähnlich wie bei den humanen Makrophagen ließ sich die durch HNP-1 bzw. HBD-2 ausgelöste Chemotaxis muriner Makrophagen in vivo mit dem jeweiligen Defensin inhibieren, wodurch wiederum die Spezifität dieser gerichteten Migration bewiesen wurde.

Allerdings konnten Biragyn et al. (2002b) zeigen, dass das murine $\beta$-Defensin 2 eine Rolle bei der TLR4 (toll-like receptor 4)-abhängigen Aktivierung von murinen DC spielt. Im Gegensatz dazu konnte keinerlei modulatorischer Effekt der humanen $\beta$-Defensine auf die Reifung von humanen, aus Monocyten generierten DC gefunden werden (Bowdish et al., 2006), wodurch diese modulatorischen Funktionen der $\beta$-Defensine fraglich bleiben.

\subsection{Wirkung der Defensine auf die Migration humaner und muriner T-Lymphocyten}

Die Arbeitsgruppe um Chertov identifizierte HNP-1 und HNP-2 als chemotaktisch wirkende Peptide für $\mathrm{CD}^{+}$T-Zellen, während HNP-3, wie bereits für die Monocyten erwähnt, als inaktiv beschrieben wurde (Chertov et al., 1996). Später berichteten Yang et al. (2000), dass naive, nicht aber Gedächtnis-T-Lymphocyten auf HNP-1 mit Migration antworteten. In der vorliegenden Arbeit wurde hingegen gezeigt, dass die neutrophilen $\alpha$-Defensine HNP-1 und 
HNP-3 einen vergleichbaren chemotaktischen Effekt sowohl auf naive als auch auf Gedächtnis-T Lymphocyten in vitro haben.

Des Weiteren beweisen die ermittelten Daten, dass auch das HD-5 die Kapazität zur Rekrutierung von naiven und Gedächtnis T-Zellen besitzt. Dies steht im Gegensatz zu einer kürzlich erschienenen Veröffentlichung über die chemotaktische Inaktivität der $\alpha$-Defensine (Szyk et al., 2006). Eine interessante Spekulation wäre, dass die Rolle des HD-5 im adaptiven Immunsystem, insbesondere in der Pathogenese der entzündlichen Morbus CrohnErkrankungen des Ileums (Wehkamp et al., 2005 a, b), zum Teil aus der chemotaktischen Wirkung auf die Zellen des Immunsystems, einschließlich T-Lymphocyten und Makrophagen, resultiert, was deren antimikrobielle Aktivität unterstützen oder sogar verstärken könnte. Tatsächlich sind viele Peptide mit antimikrobieller Wirkung in vitro sensibel gegenüber physiologischen Salzkonzentrationen, was ihrer Aufgabe in der angeborenen Immunität entgegensteht (Ganz und Lehrer, 1998; Schröder, 1999). Der direkte antimikrobielle Effekt der Defensine in vivo erfolgt vermutlich eher in den phagocytären Vakuolen der Phagocyten sowie auf der Oberfläche der Haut oder von mukosalen Epithelien, wo geringere Ionenkonzentrationen herrschen (Ganz und Lehrer, 1998; Lehrer und Ganz, 1999). Daher könnte es möglich sein, dass die vorrangige Funktion der Defensine die Immunmodulation ist (Bowdish et al., 2005).

Die $\beta$-Defensine HBD-2 und HBD-3 waren hingegen nicht in der Lage die T-LymphocytenSubpopulationen in vitro zu rekrutieren. HBD-2 und -3 konnten weder die Chemotaxis der humanen T-Lymphocyten induzieren, noch die durch CCL20 über den von den GedächtnisT-Zellen exprimierten CCR6 ausgelöste Chemotaxis desensibilisieren, wenngleich publiziert wurde, dass HBD-2 humane Gedächtnis-T-Lymphocyten via CCR6 mobilisieren kann (Yang et al., 2000). Weiterhin vermittelte auch das murine $\beta$-Defensin mBD-8 in vitro keine Migration der murinen naiven sowie Gedächtnis-T-Lymphocyten. CCL20 und CCL19 induzierten dahingegen eine konzentrationsabhängige Migration der murinen sowie humanen Gedächtnis respektive naiven T-Lymphocyten.

Die T-Lymphocyten stellen also ein zusätzliches Ziel der $\alpha$-Defensine dar, was sie von den $\beta$-Defensinen deutlich unterscheidet und die modulatorischen Fähigkeiten dieser DefensinFamilie auf das adaptive Immunsystem ausdehnt.

In Frage gestellt werden kann auf Grund dieser der Literatur widersprechender Resultate weiterhin, ob es sich bei dem CCR6 tatsächlich um einen funktionellen Rezeptor der $\beta$-Defensine handelt. 


\subsection{Wirkung der Defensine auf die Migration humaner und muriner Mastzellen}

Die Mastzellen kommen über den ganzen Körper verteilt im interstitiellen Bindegewebe vor, am häufigsten jedoch in der Submucosa von Darm und Atemwegen und in der Lederhaut (Corium), in der Nähe von Gefäßen und Nerven. Die Mastzelle spielt eine wichtige Rolle bei der Allergie vom Typ1. Dies sind IgE-vermittelte Allergien wie Asthma, allergische Rhinitis oder systemische Anaphylaxie. Beim ersten Kontakt mit einem Allergen bleibt der Betroffene zunächst völlig symptomfrei, es wird jedoch die Bildung von spezifischen IgE-Antikörpern durch die Plasmazellen ausgelöst. Die massenhaft produzierten IgE-Antikörper setzen sich mit dem Fc-Teil (Fragment cristalyne) auf der Oberfläche von Mastzellen fest und sensibilisieren sie für die Reaktion auf das Allergen. Erst beim zweiten Kontakt mit dem Allergen kommt es zur allergischen Reaktion; wenn die Allergene an je zwei benachbarte IgE-Antikörper auf den Mastzellen binden, werden diese miteinander vernetzt. Dadurch werden die Mastzellen angeregt, ihre zahlreichen Granula durch Exocytose (Degranulation) $\mathrm{zu}$ entleeren und das darin enthaltene Histamin, ein Entzündungsmediator, freizusetzen (Janeway et al., 2002).

Es wurde beschrieben, dass peritoneale Mastzellen von Ratten auf humane neutrophile $\alpha$-Defensine mit der Sekretion von Histamin antworten (Befus et al., 1999). Der zugrunde liegende Mechanismus stellte sich, ähnlich dem anderer polykationische Moleküle wie Substanz P oder Polylysin, als Rezeptor-unabhängig heraus.

Für die vorliegende Arbeit wurden zunächst aus Knochenmarksvorläuferzellen mittels IL-3 und SCF differenzierte murine Mastzellen in vitro und in vivo auf ihre migratorischen Fähigkeiten gegenüber den Defensinen untersucht. Hierbei konnte gezeigt werden, dass die untersuchten humanen $\alpha$-Defensine in vitro keinen Effekt auf die murinen Mastzellen hatten. Zwar konnten die humanen $\alpha$-Defensine durch den dem humanen Rezeptor entsprechenden Rezeptor auf murinen Makrophagen agieren. Die murinen Mastzellen scheinen jedoch keinen entsprechenden Rezeptor für die humanen $\alpha$-Defensine zu exprimieren. In Übereinstimmung mit dieser Entdeckung steht, dass Mäuse die einzige bekannte Säugetierart sind, welche keine neutrophilen $\alpha$-Defensine besitzen (Raj und Dentino, 2002).

Dahingegen induzierten die $\beta$-Defensine HBD-1 bis -4 in vitro die Migration der murinen Mastzellen in konzentrationsabhängiger Weise. Dieser Befund bestätigt den bereits von der Gruppe um Niyonsaba festgestellten Chemotaxis-vermittelnden Effekt von HBD-2 bis HBD-4 auf die Mastzellen der Ratte (Niyonsaba et al., 2002). Bemerkenswert ist zudem die Zunahme der Stärke der chemotaktischen Antwort auf HBD-1 bis -4 nach Antigen- 
unabhängiger (durch Ionomycin), sowie nach Anitgen-spezifischer (durch IgE/Antigen) Stimulation der murinen Mastzellen. Dies gilt ebenso für die in vivo Chemotaxis der murinen Mastzellen gegen HBD-2, wobei das Ionomycin eine deutlich größere Steigerung der Chemotaxis bewirkte als IgE plus Antigen und nahezu keine Migration bei den unbehandelten Mastzellen zu detektieren war. Ähnlich wie bei der Kultivierung der DCs mit IL-4 könnten auch Ionomycin und IgE/Antigen eine stärkere Expression der jeweiligen Rezeptoren bewirkt haben. Somit weisen die Ergebnisse auf eine weitere potenzielle Aufgabe der $\beta$-Defensine in der Pathophysiologie allergischer Reaktionen hin (van Wetering et al., 1999; Levy et al., 2005; Beisswenger et al., 2006).

Des Weiteren wurde die humane Mastzelllinie HMC-1 verwendet, welche auf die untersuchten $\alpha$-Defensine HNP1- und -3 sowie HD-5 mit einer konzentrationsabhängigen Chemotaxis reagierte. Der chemotaktische Einfluss der $\alpha$-Defensine ist offensichtlich Rezeptor-vermittelt, da die induzierte Migration sowohl homolog durch die $\alpha$-Defensine als auch heterolog durch die $\beta$-Defensine desensibilisierbar war.

Die $\beta$-Defensine HBD-2 bis HBD-4 induzieren laut Literatur die Migration peritonealen Mastzellen von Ratten (Niyonsaba et al., 2002), während HBD-1 keinerlei Effekt auf diese Zellen hat (Chen et al., 2007). Im Gegensatz hierzu konnte in dieser Arbeit gezeigt werden, dass alle untersuchten $\beta$-Defensine einschließlich HBD-1 auf die Migration der untersuchten humanen Mastzelllinie HMC-1 eine dosisabhängige Wirkung haben.

\subsection{Wirkung der Defensine auf die intrazelluläre Calciumfreisetzung in HMC-1-Zellen}

Es konnte weiterhin gezeigt werden, dass die Stimulation der HMC-1 Zellen mit den $\beta$-Defensinen HBD-1 bis -4 eine intrazelluläre Calciumfreisetzung bewirkte. Dahingegen waren die $\alpha$-Defensine nicht in der Lage ein Calciumsignal in den HMC-1 Zellen zu induzieren. Zudem unterdrückten die $\beta$-Defensine untereinander ihre eigenen Calciumsignale durch Vorstimulation, während die Präinkubation der Zellen mit den $\alpha$-Defensinen HNP-1 sowie HD-5 keinerlei Wirkung auf die $\beta$-Defensin-induzierte Calciumfreisetzung hatte. Diese Ergebnisse deuten darauf hin, dass $\alpha$ - und $\beta$-Defensine zumindest auf den HMC-1 Zellen über mindestens zwei unterschiedliche Rezeptoren agieren. Zudem scheint die intrazelluläre Calciumfreisetzung in HMC-1 Zellen ein für die $\beta$-Defensine spezifischer Effekt zu sein. In 
anderen Zelltypen wurde bereits gezeigt, dass die Migration mit der Mobilisierung von intrazellulärem Calcium einhergehen kann (Lauffenburger und Horwitz, 1996). Des Weiteren haben Veränderungen der intrazellulären Calciumkonzentration einen direkten Effekt auf die Funktion von diversen Aktin-Binde-Proteinen, welche die Organisation des AktinNetzwerkes beeinflussen. Zudem sind viele Calcium-sensitive Kinasen (s. auch PKCInhibition) und Phosphatasen mit der Regulierung der Cytoskelett-Struktur assoziiert (Gaudry et al., 1992). Die $\beta$-Defensine scheinen zumindest auf den HMC-1 Zellen über Rezeptoren zu agieren, welche Calcium-abhängige Signalwege einleiten können.

Der scheinbare Widerspruch, dass die hier untersuchten $\alpha$-Defensine HNP-1 und -3 sowie HD-5 zwar eine dosisabhängige Chemotaxis induzieren konnten, ohne einen intrazellulären Calciumeinfluss stimulieren zu können, ist auch in der Literatur zu finden. Die Ergebnisse weisen auf eine deutliche Unabhängigkeit von Chemotaxis und Calciumfreisetzung hin. So konnte gezeigt werden, dass der intrazelluläre Calciumeinfluss weder notwendig noch suffizient für die chemotaktische Reaktion von Zellen auf verschiedenste chemotaktische Faktoren ist. So bewirkt MCP-2 zwar die Chemotaxis von Monocyten, kann aber keinen Anstieg der intrazellulären Calciumkonzentration bewirken (Sozzani et al., 1994). Im Gegensatz dazu ist Mip-1 $\alpha$ nicht in der Lage neutrophile Zellen zu mobilisieren, während dieses Chemokin eine deutliche Calciumantwort stimuliert (McColl et al., 1993).

\subsection{Wirkung der Defensine auf die Migration der RBL-2H3-CCR6-Transfektante}

Die Beobachtung, dass CCL20, der einzige bekannte Ligand des CCR6, murine DC in vitro und in vivo anlocken konnte, wohingegen die präferierten Zielzellen der $\beta$-Defensine (ähnlich wie die $\alpha$-Defensine) die Makrophagen waren, machte es erforderlich, die Interaktion zwischen CCR6 und den $\beta$-Defensinen genauer zu untersuchen. Daher wurde eine stabile Transfektion von RBL-2H3-Zellen mit CCR6-DNA durchgeführt. Diese basophile LeukämieZelllinie der Ratte wurde bereits erfolgreich mit diversen Rezeptoren, wie etwa dem C5aRezeptor (Monk et al., 1994) stabil transfiziert. Auch die CCR6-DNA konnte, wie anhand der FACS-Analyse zu erkennen ist, in die RBL-2H3-Zellen eingebracht werden und zeigt eine sehr homogen exprimierende Zellpopulation. Diese CCR6-exprimierenden Zellen zeigten keinerlei chemotaktische Reaktion auf die $\beta$-Defensine HBD-2 und HBD-3. Im Gegensatz dazu konnte CCL20 eine starke, dosisabhängige Migration der Transfektante induzieren. 
CCR6 gehört zu der großen Familie der G-Protein-gekoppelten Rezeptoren, die nach Stimulation durch den jeweiligen Liganden eine Desensibilisierung unterlaufen (Kohout und Lefkowitz, 2003). Im Unterschied zu bereits publizierten Ergebnissen mit HEK293-CCR6Transfektanten (Yang et al., 1999) konnte in dieser Arbeit kein Beweis für die Fähigkeit der $\beta$-Defensine HBD-2 und -3, den CCR6-Rezeptor zu desensibilisieren, gefunden werden.

Bei der Untersuchung der durch CCL20 sowie HBD-2 stimulierten intrazellulären Calciumfreisetzung zeigte sich wiederum, dass zwar CCL20 ein konzentrationsabhängiges Calciumsignal induzieren konnte, HBD-2 hingegen auch bei einer Endkonzentration von $10000 \mathrm{ng} / \mathrm{ml}$ nicht in der Lage war, eine Calciumfreisetzung zu bewirken.

Diese Resultate werden durch die zuvor beschriebenen Untersuchungen an den Gedächtnis T-Zellen, welche ebenfalls CCR6 endogen exprimieren (Liao et al., 1999) bestätigt. Zusammengenommen deuten die ermittelten Daten darauf hin, dass es sich bei dem CCR6Rezeptor nicht um einen funktionellen Rezeptor für $\beta$-Defensine handelt.

\subsection{Rolle der MAP-Kinasen bei der Defensin-inuzierten Migration}

Generell kann zunächst festgehalten werden, dass der Einsatz sowohl der MAPK-Inhibitoren als auch des Pertussis Toxins zu keinerlei letalen oder zelldeformierenden morphologischen Veränderungen der untersuchten Zellen geführt hat. Im Vergleich zur Kontrolle ohne Inhibitor wurden bei der Bestimmung der Anzahl vitaler Zellen mittels Trypanblau-Färbung keine Unterschiede festgestellt.

Die GPCR sind dafür bekannt, dass sie durch die klassische G-Protein-stimulierte Synthese von second messenger Molekülen mit MAPK-Signalwegen verbunden sind (Lefkowitz und Shenoy, 2005). Die Zellen der Mammalia enthalten drei Hauptklassen von MAPK: ERK, JNK und p38. Alle drei Kinasen wurden bereits als essenziell für die Zellmigration beschrieben (Huang et al., 2004). So zeigten auch Yen und Mitarbeiter (Yen et al., 1997), dass durch die MAP-Kinasen ERK und p38 die MCP-1-induzierte Chemotaxis von Monocyten vermittelt wird. Weiterhin wird berichtet, dass die Makrophagen-Zelllinie RAW264 durch Aktivierung von p38 sowie ERK gegen das Anaphylatoxin C5a migrieren kann (Don et al., 2007). Die Resultate dieser Arbeit bestätigen diese Erkenntnisse der Rolle der MAPK auch für die vom $\alpha$-Defensin HNP-1 induzierte Chemotaxis in vitro, wobei vorwiegend p38 und ERK für die von HNP-1-induzierte Migration der humanen Makrophagen benötigt wird. Bei der vom $\beta$-Defensin HBD-2 ausgelösten Zellmigration spielen ebenfalls alle drei genannten 
MAP-Kinasen eine bedeutende Rolle. Während allerdings vornehmlich ERK und p38 die Chemotaxis der Makrophagen vermitteln, sind für die Migration der murinen Mastzellen gegen HBD-2 ERK, p38 und JNK gleichermaßen essenziell. Von besonderem Interesse für diese Arbeit ist daher die Veröffentlichung von Chen, in der gezeigt wird, dass HBD-3 und -4 durch Aktivierung von p38 und ERK auch eine Degranulation der Mastzellen bewirken (Chen et al., 2007).

\subsection{Rolle der $G_{\alpha i}$-Proteine bei der Defensin-induzierten Migration}

Auf Grund der Sensibilität der HNP-1- sowie der HBD-2-vermittelten in vitro-Chemotaxis humaner Makrophagen gegenüber Pertussis Toxin ist davon auszugehen, dass sowohl der oder die $\alpha$-Defensin-Rezeptor/en als auch $\beta$-Defensin-Rezeptor/en in humanen Makrophagen an $\mathrm{G}_{\alpha \mathrm{i}}$-Proteine gekoppelt sind. Die Präinkubation der humanen Makrophagen mit unterschiedlichen Pertussis Toxin-Konzentrationen konnte die von HNP-1 induzierte Chemotaxis in einer dosisabhängigen Weise inhibieren. Dies bestätigen bereits publizierte Beobachtungen. So inhibierte Pertussis Toxin die durch HNP-1 ausgelöste Chemotaxis humaner naiver T-Lymphocyten (Yang et al., 2000) und zudem konnte Pertussis Toxin bei einer Konzentration von $200 \mathrm{ng} / \mathrm{ml}$ in den Mastzellen der Ratte die von HBD-2 induzierte Migration komplett blockieren (Niyonsaba et al., 2002). Des Weiteren wurde ebenfalls in Übereinstimmung mit diesen Ergebnissen gezeigt, dass die von HBD-2 aktivierte Signaltransduktion auf verschiedenen Immunzellen, wie etwa Makrophagen oder Mastzellen, über bisher nicht identifizierte G-Protein-gekoppelte Rezeptoren vermittelt wird (Chen et al., 2007; Yang et al., 2002).

Die $\alpha$-Untereinheit der G-Proteine ist für die Bindung und Hydrolysierung von GuaninNukleotiden verantwortlich und kann bei der Weiterleitung eines Signals von einem Rezeptor zur Dissoziation von dem heterotrimeren G-Protein stimuliert werden. Daraufhin leitet die an GTP-gebundene $\alpha$-Untereinheit das Signal beispielsweise an Adenylatcyclasen. Der Inhibitor Pertussis Toxin hat den Effekt, dass die $\alpha$-Untereinheiten $G_{\alpha i}$ und $G_{\alpha o}$ nicht von dem inaktiven heterotrimeren G-Protein dissoziieren können und führt somit zum Funktionsverlust des Proteins. Die Positionierung der G-Proteine als Integrationspunkt für Signale von vielen verschiedenen Rezeptoren sowie als potenzieller Verzweigungspunkt $\mathrm{zu}$ vielen Effektorsystemen macht dieses Protein zu einem geeigneten Ziel von Zell-Regulationen. 
Durch G-Proteine kann die Phospholipase C aktiviert werden (Omann et al., 1987). Auf diese Aktivierung folgen die Stimulierung des IP-3 und des DAG-Signalweges, welche schließlich zur Freisetzung von $\mathrm{Ca}^{2+}$ beziehungsweise zur PKC-Aktivierung führen. Letztendlich haben beide Signalwege eine Phosphorylierung von Cytoskelett-Komponenten wie etwa Aktin und Aktin-Binde-Proteinen zur Folge.

Bei der Erforschung des Signalweges, welcher von Chemokinen wie etwa fMLP (formylMet-Leu-Phe) aktiviert die Chemotaxis humaner Monocyten einleitet, wurde herausgefunden, dass diese Chemokine ihren Einfluss durch Bindung an spezifische G-Protein-gekoppelte Rezeptoren ausüben. Dabei scheinen besonders die $\mathrm{G}_{\alpha i}$-Proteine wie rho, rac und cdc42 sowie Serin/Threonin-Kinasen-Aktivierungen (u. a. MAPK-Aktivierungen) eine wichtige Rolle zu spielen. Diese Signaltransduktion konnte, ähnlich wie in dieser Arbeit für die Defensine gezeigt, durch die Präinkubation mit Pertussis Toxin blockiert und somit die gerichtete ZellMigration unterbunden werden (Fine et al., 2001).

Weiterhin ist das G-Protein ARF6 in den Vesikel-Verkehr sowie die Aktin-Umorganisation involviert. Es konnte außerdem gezeigt werden, dass das G-Protein den Verkehr von Zellmembranmaterial von recyclenden Endosomen zur Plasmamembran reguliert (Booth et al., 2001). Da die Zellmigration von der Um- und Anlagerung des Aktins abhängt, ist hiermit ein weiterer Angriffspunkt des G-Protein-Inhibitors Pertussis Toxin aufgezeigt, welcher die Chemotaxis-hemmende Wirkung des Toxins erklären könnte.

\subsection{Homologe und heterologe Desensibilisierung der Defensine}

Die unterschiedlichen Reaktionen von Lymphocyten und murinen Mastzellen gegenüber den $\alpha$ - und $\beta$-Defensinen lässt vermuten, dass die beiden Defensin-Familien über zwei verschiedene Rezeptoren wirken. Um weitere Bestätigung für diese Hypothese zu finden, wurde die Möglichkeit der homologen und heterologen Rezeptor-Desensibilisierung untersucht. Dabei wird die Ligand-induzierte Attenuation der Signalübertragung auf einen kontinuierlichen Stimulus als Desensibilisierung bezeichnet (Tardif et al., 1993). Es werden dabei zwei Mechanismen unterschieden, welche beide die Entkopplung der Rezeptoren zur Folge haben: die homologe und die heterologe Desensibilisierung (Hausdorff et al., 1990; Benovic et al., 1988). Bei der homologen Desensibilisierung handelt es sich um eine Agonistspezifische Desensibilisierung des Rezeptors. Diese Inaktivierbarkeit erfolgt durch eine schnelle, gezielte Phosphorylierung der Ligand-besetzten Rezeptoren durch eine cAMP- 
abhängige Protein Kinase (Hausdorff et al., 1989) oder eine $\mathrm{Ca}^{2+} /$ Phospholipid-abhängige Protein Kinase C (Raymond, 1991). Die Protein Kinasen agieren dabei entweder allein oder in Kombination mit hochspezifischen Rezeptorkinasen wie etwa GPCR-Kinasen (Lefkowitz, 1998), welche exklusiv die Agonist-aktivierten Rezeptoren erkennen. Weiterhin trägt vermutlich auch eine reversible Ligand-induzierte Internalisierung des Rezeptors zur homologen Desensibilisierung bei (Hüttenrauch et al., 2005; von Zastrow und Kolbika, 1992). Der regulatorische Mechanismus, welcher hinter dieser Rezeptor-Desensibilisierung steht, ist die Verhinderung negativer Effekte von verlängerter oder ständiger Aktivierung der G-Protein-gekoppelten Rezeptoren (Lefkowitz, 1998).

Die heterologe oder Überkreuz-Desensibilisierung, in die ebenfalls verschiedene GPCR involviert sind, wird gewöhnlich durch second-messenger-regulierte Kinasen wie PKC vermittelt und benötigt keine Besetzung des Rezeptors durch den Agonisten (Ali et al., 1999). Die Abnahme der Stimulierbarkeit des Rezeptors erfolgt hier auf Grund der Wirkung eines Liganden auf einen anderen Rezeptor. Dieser Rezeptor beziehungsweise die von ihm eingeleitete Signaltransduktion führt letztendlich zur Phosphorylierung an anderen Stellen des Rezeptors als bei der homologen Desensibilisierung durch GPCR-Kinasen (Hüttenrauch et al., 2005).

In der vorliegenden Arbeit konnte gezeigt werden, dass die homologe Desensibilisierung innerhalb der jeweiligen Defensin-Familie ohne Partizipation von PKC stattfindet, da weder GF109 noch Gö6976 die Migration der humanen Makrophagen, HMC-1 Zellen und der humanen Gedächtnis T-Lymphocyten gegen HNP-1, HD-5 oder HBD-2 inhibieren konnte. Dies deutet darauf hin, dass nur ein einzelner Rezeptor von allen Mitgliedern der entsprechenden Defensin-Familie aktiviert wird. Diese Resultate stimmen mit der Veröffentlichung überein, dass auch die chemotaktische Antwort von Monocyten auf fMLP MCP-1 sowie CCL3 unabhängig von der PKC-Aktivierung ist (Beisswenger et al., 2006; Fine et al., 2001).

Weiterhin waren die Rezeptoren der $\alpha$ - und $\beta$-Defensine Gegenstand der heterologen Desensibilisierung. Der PKC-Aktivator PMA konnte die Defensin-induzierte Chemotaxis der humanen Makrophagen, der HMC-1 Zellen sowie der $\mathrm{CD}^{+} / \mathrm{CD} 45 \mathrm{RO}^{+}$T-Lymphocyten blockieren. Ähnliches wurde bereits von der Gruppe um Fine beschrieben (Fine et al., 2001). So konnte gezeigt werden, dass die von fMLP, MCP-1 sowie CCL3 induzierte Migration humaner Monocyten durch Präinkubation mit PMA deutlich reduziert wird. Diese Inhibition ließ sich, ebenso wie in dieser Arbeit, bei zusätzlicher Präinkubation mit GF109 wieder 
aufheben und spricht somit dafür, dass die heterologe PKC-Aktivierung die Chemokininduzierte Chemotaxis blockieren kann.

Des Weiteren war die Fähigkeit der $\alpha$-Defensine, die chemotaktische Aktivität der $\beta$-Defensine (und umgekehrt) zu desensibilisieren, in allen untersuchten Zelltypen PKCabhängig, was auf eine heterologe Überkreuz-Desensibilisierung zwischen den verschiedenen Defensin-Rezeptoren hinweist. Erstaunlicherweise war auch das $\beta$-Defensin HBD-2 in der Lage, die HNP-1-vermittelte Chemotaxis der humanen Gedächtnis-T-Lymphocyten zu blockieren, wenngleich die $\beta$-Defensine selbst keine Chemotaxis der T-Lymphocyten vermitteln konnten. HBD-2 scheint zwar an einen Rezeptor auf den T-Zellen zu binden und darüber seine heterologe Desensibilisierung des $\alpha$-Defensin-Rezeptors zu bewirken, die Bindung an diesen Rezeptor bewirkt dabei allerdings keine Chemotaxis. $\mathrm{Zu}$ erklären wäre dieses Phänomen entweder mit einer zu geringen Rezeptordichte auf diesem Zelltyp, welche für eine Induktion der Migration nicht ausreichend ist. Es könnte sich hierbei aber auch um einen weiteren $\beta$-Defensin-Rezeptor handeln, welcher nicht in der Lage ist, eine Chemotaxis zu initiieren.

In Übereinstimmung mit den bereits gewonnenen Erkenntnissen sowie mit den Ergebnissen der intrazellulären Calciumfreisetzung in HMC-1 Zellen nach Defensin-Stimulation konnte mit Hilfe des PKC-Inhibitors Gö6976 weiterhin gezeigt werden, dass Calcium-abhängige PKC Isotypen für die heterologe, von HBD-2 induzierte Rezeptor-Desensibilisierung essenziell sind. Die heterologe Desensibilisierung des Rezeptor durch HNP-1 konnte hingegen nicht durch den Calcium-abhängigen PKC-Inhibitor Gö6976 aufgehoben werden sowie HNP-1 auch nicht in der Lage war, ein Calciumsignal in HMC-1 Zellen hervorzurufen. Die Ergebnisse dieser Desensibilisierungs-Untersuchungen sprechen somit wiederum für zwei unterschiedliche Rezeptoren für $\alpha$ - und $\beta$-Defensine.

In diesem Zusammenhang ist $\mathrm{zu}$ erwähnen, dass beschrieben wurde, dass Calciumunabhängige PKC Überkreuz-Desensibilisierung von Chemokinrezeptoren durch OpioidRezeptoren vermitteln (Zhang et al., 2003).

\subsection{Homogenität der Defensine trotz hoher Sequenzvariabilität}

Die neutrophilen und intestinalen $\alpha$-Defensin-Peptide weisen einen hohen Grad an Sequenzvariabilität sowie divergierende antimikrobielle Fähigkeiten, schon allein auf Grund ihrer unterschiedlichen Syntheseorte (neutrophile oder intestinale Zellen), auf (Ganz et al., 
2003; Lehrer et al., 2004). Die molekulare Basis der evolutionär konservierten Bindung von neutrophilen ebenso wie von intestinalen $\alpha$-Defensinen an einen gemeinsamen Rezeptor auf verschiedenen Zellen des Immunsystems könnte aus ihrer großen Ähnlichkeit bezüglich ihrer Tertiärstrukturen resultieren, welche durch die drei konservierten Disulfidbrücken stabilisiert werden (Szyk et al., 2006; Hill et al., 1991).

Die wichtigsten Ergebnisse der $\alpha$-Defensin-vermittelten Interaktionen mit den Zellen des Immunsystems sind in der folgenden Abbildung schematisch dargestellt.

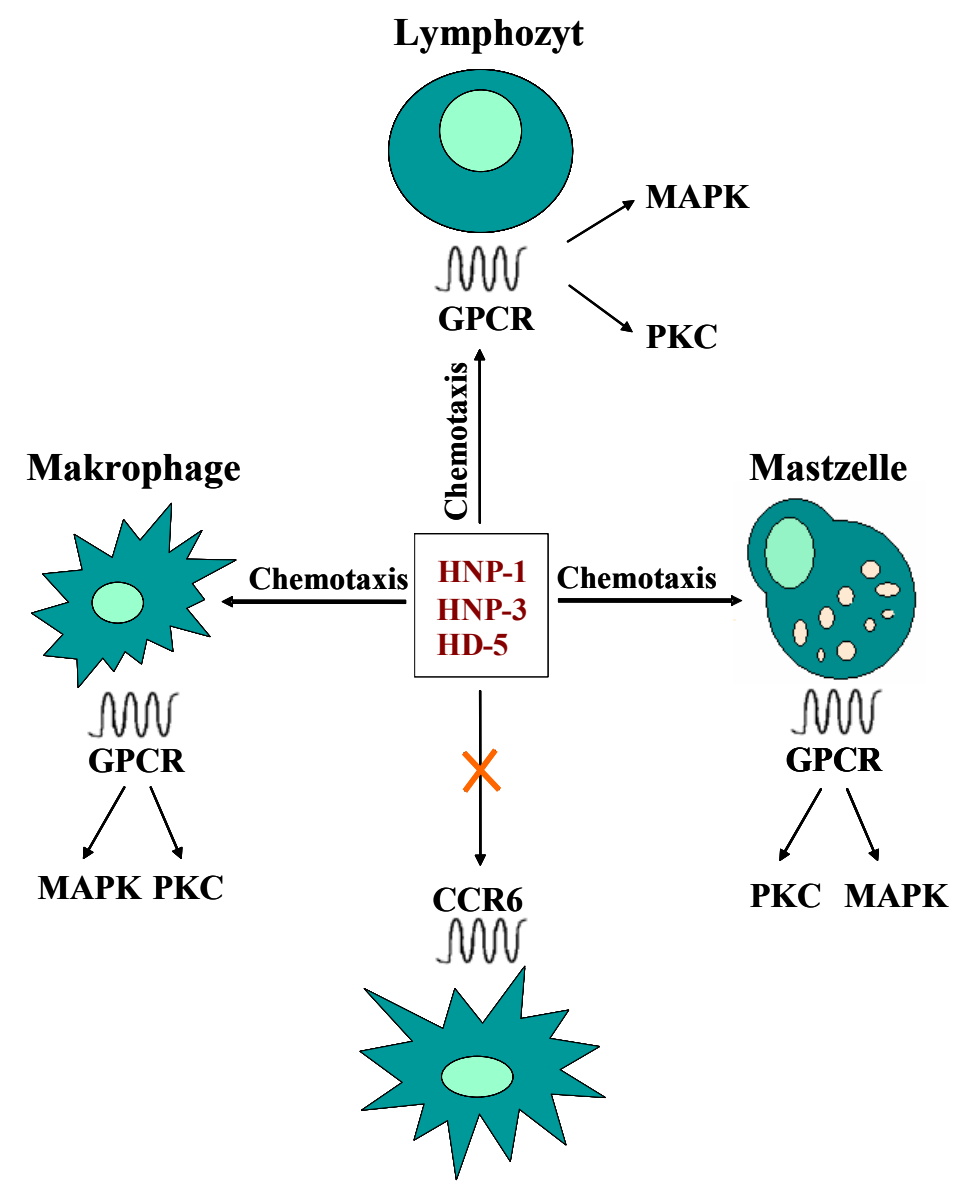

Dendritische Zelle

Abb. 55: Schematische Zusammenfassung der Ergebnisse der $\alpha$-Defensin-induzierten Interaktion mit den Zellen des Immunsystems. Untersucht wurden HNP-1, HNP-3 und HD-5. CCR6: CC Rezeptor 6; GPCR: G-Protein-gekoppelter Rezeptor; MAPK: Mitogen-aktivierte Phospho-Kinase; PKC: Protein Kinase C.

Auch die $\beta$-Defensin-Peptide besitzen eine große Sequenzvariabilität bei Erhalt der Lage und Bindung der sechs Cysteine. Wiederum scheint die Verknüpfung und die Lage der Disulfidbrücken für die funktionelle Struktur der Moleküle essenziell zu sein. Dennoch zeigte sich im Falle des $\beta$-Defensins HBD-3, dass die Disulfidbrücken zwar relevant für die 
induzierte Chemotaxis war, nicht aber für seine antimikrobielle Aktivität (Kluver et al., 2005; Wu et al., 2003). Des Weiteren konnte gezeigt werden, dass die lineare Form des HBD-3 seine Fähigkeit verloren hatte, Makrophagen chemotaktisch anzulocken. Somit scheint die Konservierung der drei Disulfidbrücken auch in $\beta$-Defensinen evolutionär essenziell für die Bindung an den gemeinsamen Rezeptor auf Zellen des Immunsystems zu sein. Die beeindruckende Ähnlichkeit der Tertiärstrukturen der verschiedenen $\beta$-Defensine scheint aus dieser Konservierung der Disulfidbrücken herzurühren.

In der folgenden Abbildung 56 werden auch die Resultate der Untersuchungen der $\beta$-Defensin-induzierten Chemotaxis sowie der von dieser Defensin-Familie stimulierten Signaltransduktionswege schematisch zusammengefasst.

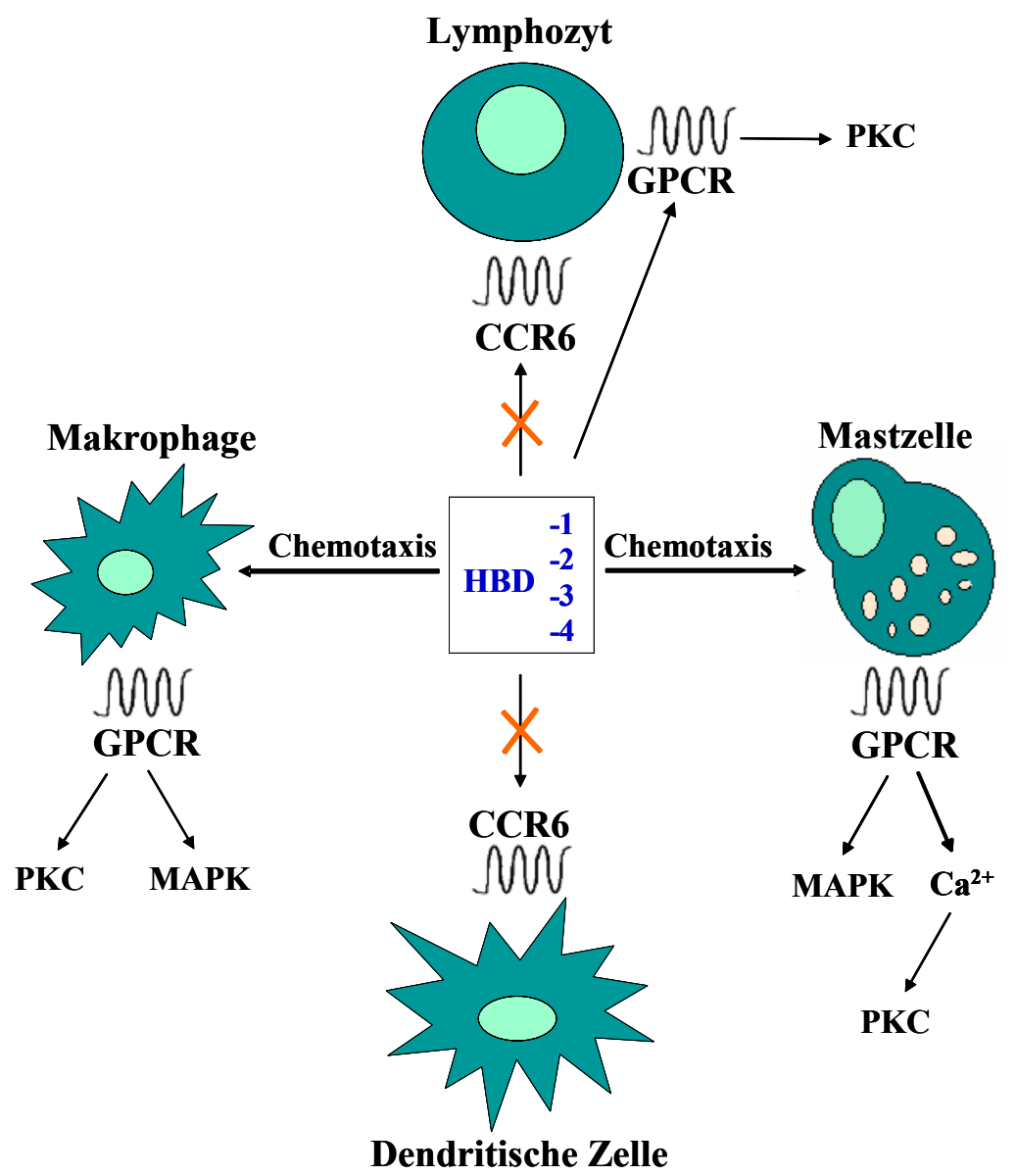

Abb. 56: Schematische Zusammenfassung der Ergebnisse der $\boldsymbol{\beta}$-Defensin-Analysen. Dargestellt sind die in dieser Arbeit ermittelten Funktionen der Defensine HBD-1 bis -4. CCR6: CC Rezeptor 6; GPCR: G-Proteingekoppelter Rezeptor; MAPK: Mitogen-aktivierte Phospho-Kinase; PKC: Protein Kinase C. 
Zusammenfassend kann somit festgehalten werden, dass sowohl humane $\alpha$-Defensine als auch humane $\beta$-Defensine durch ihre evolutionär konservierten Rezeptoren auf den Zielzellen Makrophagen, Mastzellen, sowie im Falle der $\alpha$-Defensine auch Lymphocyten, charakterisiert werden können (s. Abb. 54 und 55). Die Existenz eines gemeinsamen Rezeptors für alle Mitglieder der $\alpha$-Defensine als auch eines Rezeptors für alle $\beta$-Defensine auf den Zellen des Immunsystems stärkt die Annahme, dass die Modulation des Immunsystems eine prinzipielle Funktion des Defensin-Systems ist. Vor allem die Mobilisierung von Makrophagen sowie von humanen Mastzellen scheint die primäre Aufgabe der beiden Defensin-Familien zu sein, zumal die antimikrobielle Aktivität dieser und der meisten Peptide, welche der Verteidigung des Wirtes dienen, äußerst sensibel gegenüber physiologischen Salzkonzentrationen sind (Bowdish et al., 2006). Die Rolle der Defensine in der adaptiven Immunabwehr scheint von größerer Bedeutung zu sein, als bisher angenommen.

\subsection{Ausblick}

In dieser Arbeit konnten die von den Defensinen chemotaktisch angelockten Zellen des Immunsystems identifiziert sowie erste funktionelle Analysen der möglichen Defensin-Rezeptoren und der sich anschließenden Signalwege der beiden Defensin-Familien durchgeführt werden.

In der Zukunft könnten Bindungsstudien mit radioaktiv-markierten Defensinen die hier aufgestellte Theorie von jeweils einem Rezeptor pro Defensin-Familie endgültig beweisen. Des Weiteren müsste die Signaltransduktion in den beteiligten Zelltypen genauer beleuchtet werden, beispielsweise mittels verschiedener Phosphorylierungsnachweise durch WesternBlot-Verfahren. Die größte noch zu lösende Herausforderung bleibt allerdings die Identifizierung und die Charakterisierung der Rezeptoren für $\alpha$ - und $\beta$-Defensine auf den Zellen des Immunsystems. Es ist dringend nötig, die Rezeptoren der Defensine zu identifizieren und zu klonieren, um ein tiefer gehendes Verständnis für die Funktionsweise dieser Peptide im adaptiven Immunsystem zu erhalten.

Eine präzisere Definition der immunregulatorischen und effektorischen Funktionen der Defensine in vivo könnte mit Hilfe von knock-out Mäusen gefunden werden. Dennoch würde das Ausschalten von einem einzigen Defensin-Gen durch die funktionelle Überlappung der Defensine und Chemokine sowie der Defensin-Mitglieder selbst (Mäuse besitzen $17 \alpha$ - und 8 $\beta$-Defensine!) vermutlich nicht in einem eindeutigen Phänotyp resultieren (Ouellette und 
Selsted, 1996; Bauer et al., 2001). Bis jetzt wurde lediglich von einer Defensin-defizienten Maus berichtet (Wilson et al., 1999). Hierbei wurde das Gen, welches für Matrilysin kodiert, ausgeschaltet. Matrilysin wird für die Generierung von funktionellen murinen $\alpha$-Defensinen aus Paneth-Zellen benötigt. Verglichen mit den normalen Mäusen zeigten die Matrilysindefizienten Mäuse eine größere Empfänglichkeit für letale Infektionen durch oral verabreichte Salmonella typhimurium, was für die antimikrobielle Rolle der $\alpha$-Defensine im Darmtrakt spricht, sowie eine geringere Fähigkeit, exogene E. coli zu töten. Weitere Defekte bei der adaptiven antimikrobiellen Immunantwort wurden hierbei nicht bestimmt.

Weiterhin könnten Defensine in einer Zeit, in der viele Pathogene eine Resistenz gegen gängige Antibiotika entwickelt haben, auf Grund ihrer potenten antimikrobiellen Wirkung sowie ihrer kleinen Größe attraktive Kandidaten für die Entwicklung neuer klinisch einsetzbarer Antibiotika sein.

Zudem könnten ausgewählte Defensine oder auch Chemokine, basierend auf ihren immunregulatorischen Aufgaben, für die Entwicklung von Impfstoffen verwendet werden, da gezeigt werden konnte, dass sie das adaptive Immunsystem stärken können, wenn sie zusammen mit klinisch relevanten Antigenen verabreicht (Lillard, et al., 1999; Tani et al., 2000), bzw. wenn sie direkt mit Tumor-antigenen Epitopen fusioniert werden (Biragyn et al., 2001). So wurde bereits untersucht, ob $\beta$-Defensine in der Lage sind die adaptiven Immunantworten zu steigern (Biragyn et al., 2001). Hierbei wurden mBD-2 und mBD-3 mit B-Zell Lymphom Epitopen fusioniert und als DNA-Impfstoff an immunisierten Mäusen angewendet. Dabei zeigte sich, dass die Mäuse nicht nur potente humorale Immunantworten gegen sonst nicht-immunogene B-Zell Lymphom Antigene generierten, sondern zudem eine gegen den Tumor gerichtete Immunität entwickelten. Da die Induktion der Anti-TumorProtektion in diesem Modell auf der Entwicklung einer Tumor-spezifischen zellulären Immunität beruht (Biragyn, 1999 \& 2001), scheint es, dass die $\beta$-Defensine humorale als auch zelluläre adaptive Immunantworten fördern können. Die Defensine wären also möglicherweise interessante Anwärter als Modell-Moleküle für die Entwicklung neuer therapeutischer Agenzien, welche sowohl antimikrobielle als auch Immunsystemverstärkende Kapazitäten besäßen.

Zwar steht die Forschung bei der Untersuchung der Defensine noch weit am Anfang, die bereits entdeckten Funktionen dieser höchst konservierten und dennoch äußerst vielfältig wirkenden Peptide weisen jedoch auf eine tragende Rolle im angeborenen sowie adaptiven Immunsystem hin, welche einer gründlichen Analyse bedürfen. 


\section{Zusammenfassung}

Humane Defensine sind natürliche antibiotisch wirkende Peptide. Auf der Basis der Position und Verbindung ihrer sechs hoch konservierten Cystein-Reste werden diese Defensine in zwei Familien eingeteilt: $\alpha$ - und $\beta$-Defensine. Humane $\alpha$-Defensine werden vornehmlich von neutrophilen Zellen (HNP-1 bis -4) sowie von intestinalen Paneth-Zellen (HD5 und HD6) exprimiert. Wenngleich $\alpha$-Defensinen eine Funktion bei der Pathogenese von entzündlichen Darmerkrankungen nachgewiesen werden konnte, wird doch die Rolle bei der Modulation des zellulären Immunsystems bisher kaum verstanden. Humane $\beta$-Defensine werden ausschließlich in epithelialen Zellen (der Haut, des respiratorischen, des urogenitalen sowie des gastrointestinalen Traktes) konstitutiv oder als Reaktion auf Cytokine oder Mikroorganismen synthetisiert.

In dieser Arbeit konnte gezeigt werden, dass die $\alpha$-Defensine HNP-1, HNP-3, HD-5 sowie die $\beta$-Defensine HBD-1 bis -4 potente Chemotaxine für Makrophagen und Mastzellen, nicht aber für DC sind, wobei sie $\mathrm{G}_{\alpha \mathrm{i}}$-Proteine sowie die MAP-Kinasen p38, ERK und teilweise auch JNK für ihre Signaltransduktion nutzen. Zusätzlich können HNP-1, HNP-3 und HD-5 in ähnlichem Maße naive und Gedächtnis-T-Lymphocyten mobilisieren. Zudem induzieren die $\alpha$-Defensine die Migration von HMC-1 Zellen, sind aber im Gegensatz zu den $\beta$-Defensinen nicht in der Lage eine intrazelluläre Calciumfreisetzung hervorzurufen. Des Weiteren kann die von $\beta$-Defensinen vermittelte Migration muriner Mastzellen durch Präinkubation der Zellen mit IgE und entsprechendem Antigen oder mit Ionomycin deutlich gesteigert werden.

Ähnlich wie die humanen $\beta$-Defensine mobilisiert auch das murine $\beta$-Defensin mBD-8 murine Makrophagen, nicht aber murine T-Lymphocyten. In Übereinstimmung mit diesen Ergebnissen können die RBL-2H3-CCR6-Transfektanten nicht durch HBD-2 und -3 chemotaktisch angelockt werden.

Durch den Einsatz der PKC-Inhibitoren GF109 sowie Gö6976 konnte gezeigt werden, dass eine homologe, PKC-unabhängige funktionelle Desensibilisierung sowohl zwischen den $\alpha$ als auch zwischen den $\beta$-Defensinen auftritt, was für einen gemeinsamen Rezeptor für HNP-1, HNP-3 und HD-5 sowie für HBD-1 bis -4 auf den Zielzellen spricht. Die Untersuchung der heterologen Desensibilisierung durch den PKC-Aktivator PMA und die PKC-abhängige Überkreuz-Desensibilisierung der beiden Defensin-Familien zeigt, dass $\alpha$-Defensine die $\beta$-Defensin-induzierte Migration der untersuchten Makrophagen und HMC-1 
Zellen auf eine PKC-abhängige Weise desensibilisieren können und umgekehrt. Dies führt zu der Annahme, dass es für jede der beiden Defensin-Familien einen gemeinsamen Rezeptor gibt.

Somit zeigen die Ergebnisse dieser Arbeit, dass die chemotaktische Anlockung von Makrophagen, Mastzellen, sowie im Falle der $\alpha$-Defensine T-Lymphocyten, eine immunmodulatorische Funktion der Defensine repräsentiert. Diese Induktion der Chemotaxis der Zellen des Immunsystems ist trotz einer bedeutenden Sequenzvariabilität und unterschiedlicher antimikrobieller Aktivität in beiden Defensin-Familien evolutionär konserviert und kann durch die jeweils andere Defensin-Familie heterolog reguliert werden.

Die Involvierung des CCR6 in die $\beta$-Defensin-induzierte Migration von Immunzellen konnte nicht bestätigt werden. 


\section{Literaturverzeichnis}

Agerberth, B., Charo, J., Werr, J. Olsson, B., Idali, F., Lindbom, L., Kiessling, R.: „The human antimicrobial and chemotactic peptide LL-37 and $\alpha$-defensins are expressed by specific lymphocyte and monocyte populations.” Blood, 2000, 96: 3086-3093.

Agis, H., Füreder, W., Bankl, H. C., Kundi, M., Sperr, W. R., Willheim, M., Boltz-Nitulescu, G., Butterfield, J. H., Kishi, K., Lechner, K., Valent, P.: „Comparative immunophenotypic analysis of human mast cells, blood basophils and monocytes.” Immunology, 1996, 87: 535543.

Alberts, B., Johnson, A., Lewis, J., Raff, M., Roberts, K., Walter, P.: „Molekularbiologie der Zelle.“ 2004, Wiley-VCH Verlag GmbH \& Co. KgaA.

Ali, H., Richardson, R. M., Haribabu, B., Snyderman, R.: „Chemoattractant receptor crossdesensitization.” J. Biol. Chem., 1999, 274: 6027-6030.

Baggiolini, M.: „Chemokines and leukocyte traffic.“ Nature, 1998, 392: 565-568.

Bagley, K., Abdelwahab, S., Tuskan, R., Fouts, T., Lewis, G.: „Pertussis toxin and the adenylate cyclase toxin from Bordetella pertussis activate human monocyte-derived dendritic cells and dominantly inhibit cytokine production through a cAMP-dependent pathway". J. Leukoc. Biol., 2002, 72 (5): 962-9.

Bauer, F., Schweimer, K., Kluver, E., Conejo-Garcia, J.R., Forssmann, W.G., Rosch, P., Adermann, K. Sticht, H.: „Structure determination of human and murine $\beta$-defensins reveals structural conservation in the absence of significant sequence similarity." Protein Science, 2001, 10: 2470-2479.

Befus, A. D., Mowat, C., Gilchrist, M., Hu, J., Solomon, S., Bateman, A.: „Neutrophil defensins induce histamine secretion from mast cells: mechanisms of action." J. Immunol., 1999, 163: 947-953. 
Beisswenger, C., Kandler, K., Hess, C., Garn, H., Felgentreff, K., Wegmann, M., Renz, H.: „Allergic airway inflammation inhibits pulmonary antibacterial host defense.“ J. Immunol., 2006, 177: 1833-1837.

Benovic, J. L., Stniszewski, C., Mayor, F., Caron, M. G., Lefkowitz, R. J.: “beta-adrenergic receptor kinase. Activity of partial agonists for stimulation of adenylate cyclase correlates with ability to promote receptor phosphorylation." J. Biol. Chem., 1988, 263: 3893.3897.

Berridge, M. J.: „Inositol trisphosphate and diacylglycerol: two interacting second messengers." Annual rev. Biochem., 1987, 56:159-93.

Berridge, M. J., Irvine, R. F.: „Inositol trisphosphate, a novel second messenger in cellular signal transduction." Nature, 1984, 312: 315-321.

Biragyn, A., Belyakov, I. M., Chow, Y. H., Dimitrov, D. S., Berzofsky, J. A., Kwak, L. W.: „DNA vaccines encoding human immunodeficiency virus-1 glycoprotein 120 fusions with proinflammatory chemoattractants induce systemic and mucosal immune responses.“ Blood, 2002, 100: 1153-1159.

Biragyn, A., : „Genetic fusion of chemokines to a self tumor antigen induces protective, T-cell-dependent antitumor immunity." Nat. Biotechnol., 1999, 17: 253-258.

Biragyn, A., Surenhu, M., Yang, D., Ruffini, P. A., Haines, B. A., Klyushnenkova, E., Oppenheim, J. J., Kwak, L. W.: „Mediators of innate immunity that target immature, but not mature, dendritic cells induce antitumor immunity when genetically fused with nonimmunogenic tumor antigens.“ J. Immunol., 2001, 167: 6644-6653.

Bjerke, S., Gaudernack, G.: „Dendritic Cells and Monocytes as accessory Cells in T-Cell responses in Man. II. function as antigen-presenting Cells" Scandinavian J. Immunology, 1985, 21: 501-508.

Boniotto, M., Jordan, W. J., Eskdale, J., Tossi, A., Antcheva, N., Crovella, S., Connell, N. D., Gallagher, G.: „Human $\beta$-defensin 2 induces a vigorous cytokine response in peripheral blood mononuclear cells.“ Antimicrob. Agents Chemother., 2006, 50: 1433-1441. 
Booth, J. W., Trimble, W. S., Grinstein, S.: „Membrane dynamics in phagocytosis.“ Seminars Immunol., 2001, 13: 357-364.

Bowdish, D. M, Davidson, D. J., Hancock, R. E.: „A re-evaluation of the role of host defence peptides in mammalian immunity." Curr. Protein Pept. Sci., 2005, 6: 35-51.

Bowdish, D. M.., Davidson, D. J., Hancock, R. E.: „Immunomodulatory properties of defensins and cathelicidins. Curr. Top. Microbiol. Immunol., 2006, 306 27-66.

Brogden, K. A., Heidari, M., Sacco, R. E., Palmquist, D., Guthmiller, J. M., Johnson, G. K., Jia, H. P.: „Defensin-induced adaptive immunity in mice and its potential in preventing periodontal disease.” Oral Microbiol. Immunol., 2003, 18: 95-99.

Burns, D.: „Subunit structure and enzymatic activity of pertussis toxin". Microbiol. Sci., 1988, 5: 285-7.

Butterfield, J. H., Weiler, D., Dewald, G., Gleich, G. J.: „Establishment of an immature mast cell line from a patient with mast cell leukemia.” Leukocyte research, 1988, 124: 345-55.

Chaly, Y. V., Paleolog, E. M., Kolesnikova, T. S., Tikhonov, I. I., Petratchenko, E. V., Voitenok, N. N.: „Neutrophil alpha-defensin human neutrophil peptide modulates cytokine production in human monocytes and adhesion molecule expression in endothelial cells." Eur. Cytokine Netw.,2000, 11: 257-266.

Chen, C. I., Schaller-Bals, S. Paul, K. P., Wahn, U., Bals, R.: „Beta-defensins and LL-37 in bronchoalveolar lavage fluid of patients with cystic fibrosis.“ J. Cyst. Fibros., 2004, 3: 45-50.

Chen, X, Niyonsaba, F., Ushio, H., Hara, M., Yokoi, H., Matsumoto, K., Saito, H.: „Antimicrobial peptides human beta-defensin (hBD)-3 and hBD-4 activate mast cells and increase skin vascular permeability.” Eur J Immunol., 2007, 37: 434-44. 
Chertov, O., Michiel, D. F., Xu, L., Wang, J. M., Tani, K., Murphy, W. J., Longo, D. L., Taub, D. D., Oppenheim, J. J.: „Identification of defensin-1, defensin-2, and CAP37/azurocidin as T-cell chemoattractant proteins released from interleukin-8-stimulated neutrophils.” J. Biol. Chem., 1996, 271: 2935-2940.

Chung, W. O., Dale, B. A.: „Innate immune response of oral and foreskin keratinocytes: utilization of different signaling pathways by various bacterial species." Infect. Immunol., 2004, 72: 352-358.

Conejo-Garcia, J. R., Benencia, F., Courreges, M. C., Kang, E., Mohamed-Hadley, A., Buckanovich, R. J., Holtz, F.: „Tumor-infiltrating dendritic cell precursors recruited by a beta-defensin contribute to vasculogenesis under the influence of Vegf-A." Nat. Med., 2004, 10: $950-9588$.

Conejo-Garcia, J. R., Jaumann, F., Schulz, S., Krause, A., Rodriguez-Jimenez, J., Forssmann, U., Adermann, K.: „Identification of a novel, multifunctional beta-defensin (human beta-defensin 3) with specific antimicrobial activity.“ Cell Tissue Res., 2001a, 306: 257-264.

Conejo-Garcia, J. R., Krause, A., Schulz, S., Rodriguez-Jimenez, F. J., Klüver, E., Adermann, K., Forssmann, U.: „Human $\beta$-defensin 4: a novel inducible peptide with a specific salt-sensitive spectrum of antimicrobial activity.“ FASEB J., 2001b, 15: 1819-1821.

Diamond, G., Russell, J. P., Bevins, C. L.: „Inducible expression of an antibiotic peptide gene in lipopolysaccharide-challenged tracheal epithelial cells." Proc. Natl. Acad. Sci. USA., 1996, 93: 5156-5160.

Don, M. J., Liao, J. F., Lin, L. Y., Chiou, W. F.: „Cryptotanshinone inhibits chemotactic migration in macrophages through negative regulation of the PI3K signaling pathway." $B r . J$. Pharmacol., 2007, 151: 638-646.

Ericksen B., Wu, Z., Lu, W., Lehrer R. I.: „Antibacterial activity and specificity of the six human $\alpha$-defensins.” Antimicrob. Agents Chemother., 2005, 49: 269-275. 
Fernandez, H. N., Henson, P. M., Otani, A., Hugh, T. E.: "Chemotactic Response to Human C3a and C5a Anaphylatoxins." J. Immunology, 1978, 120: 109-115.

Fine, J. S, Byrnes, H. D., Zavodny, P. J., Hipkin, R. W.: „Evaluation of signal transduction pathways in chemoattractant-induced human monocyte chemotaxis." Inflammation, 2001, 25: 61-67.

Fisher, M. P., Dingman, C. W.: „Role of Molecular Conformation in Determining the Electrophoretic Properties of Polynucleotides in Agarose-Acrylamide Composite Gels" Biochemistry, 1971, 10: 1895.

Frye, M., Bargon, J., Dauletbaev, N., Weber, A., Wagner, T. O., Gropp, R.: „Expression of human alpha-defensin 5 (HD5) mRNA in nasal and bronchial epithelial cells." J. Clin. Pathol., 2000, 53: 770-773.

Furitsu, T., Tsujimura, T., Tono, T., Ikeda, H., Kitayama, H., Koshimizu, U., Sugahara, H., Butterfield, J. H., Ashman, L. K., Kanayama, Y.: „Identification of mutations in the coding sequence of the proto-oncogene c-kit in a human mast cell leukemia cell line causing ligandindependent activation of c-kit product.” J. Clin. Invest., 1993, 92: 1736-1744.

Gallo, R. I., Kim, K. J., Bernfield, M., Kozak, C. A., Zanetti, M., Merluzzi, L., Gennaro, R.: „Identification of CRAMP, a cathelin-related antimicrobial peptide expressed in the embryonic and adult mouse.“ J. Biol. Chem., 1997, 272: 13088-13093.

Gallo, R. L., Murakami, M., Ohtake, T., Zaiou, M.: „Biology and clinical relevance of naturally occurring antimicrobial peptides.” J. Allergy Clin. Immunol., 2002, 110: 823-831.

Ganz, T.: „Defensins: anti-microbial peptides of innate immunity.” Nat. Rev. Immunol., 2003, 3: 710-720.

Gaudry, M., Caon, A. C., Gilbert, C., Lille, S., Naccache, P. H.: "Evidence for involvement of tyrosine kinases in the locomotory responses of human neutrophils." J. Leukocyte Biol., 1992, 51: 103. 
Gekeler, V., Boer, R., Uberall, F., Ise, W., Schubert, C., Utz, I., Hofmann, J., Sanders, K. H., Schächtele, C., Klemm, K., Grunicke, H.: „Effects of the selective bisindolylmaleimide protein kinase C inhibitor GF 109203X on P-glycoprotein-mediated multidrug resistance.” Br. J. Cancer, 1996, 74(6) : 897-905.

Ghosh, D., Porter, E., Shen, B., Lee, S. K., Wilk, D., Drazba, J., Yadav, S. P., Crabb, J. W., Ganz, T., Bevins, C. L.: „Paneth cell trypsin is theprocessing enzyme or human defensin-5.” Nat. Immunol., 2002, 3:583-590.

Gierschik, P.: „ADP-ribosylation of signal transduction guanine nucleotide-binding proteins by Perussis Toxin.” Current Topics Microbiol. Immunol., 1992, 175: 69-96.

Grutkoski, P. S., D`Amico, R., Ayala, A., Simms, H. H.: “TNF- $\alpha$ stimulated PMN suppress migration and bactericidal activity of PMN in a paracrine manner." Crit. Care Med., 2002, 30: 591-597.

Gschwendt, M., Dieterich, S., Rennecke, J., Kittstein, W., Mueller, H. J., Johannes, F. J.: „Inhibition of protein kinase $\mathrm{C} \mathrm{mu}$ by various inhibitors. Differentiation from protein kinase c isoenzymes.” FEBS Lett., 1996, 392: 77-80.

Guo, C. J., Tan, N., Song, L., Douglas, S. D., Ho, W. Z.: „Alpha-defensins inhibit HIV infection of macrophages through upregulation of CC-chemokines." Aids, 2004, 18: 12171218.

Hamann, K., Grabbe, J., Welker, P., Haas, N., Algermissen, B., Czarnetzki, B. M.: „Phenotypic evaluation of cultured human mast and basophilic cells and of normal human skin mast cells.” Archives Dermatol. Res., 1994, 286: 380-385.

Harder, J., Bartels, J., Christophers, E., Schroder, J. M.: „A peptide antibiotic from human skin." Nature, 1997, 387: 861.

Harris, T. E., Persaud, S. J., Jones, P. M.: „Atypical isoforms of pKc and insulin secretion from pancreatic beta- cells: evidence using Go 6976 and Ro 31-8220 as Pkc inhibitors." BBRC, 1996, 227: 672. 
Harwig, S.S., Ganz, T., Lehrer, R.I.: „Neutrophil defensins: purification, characterization, and antimicrobial testing." Methods Enzymol., 1994, 236: 160-172.

Hausdorff, W. P., Bouvier, M., O`Dowd, B. F., Irons, G. P., Caron, M. G., Lefkowitz, R. J.: "Phosphorylation sites on two domains of the beta 2-adrenergic receptor are involved in distinct pathways of receptor desensitization.” J. Biol. Chem., 1989, 264: 12657-12665.

Hausdorff, W. P., Caron, M. G., Lefkowitz, R. J.: "Turning off the signal: desensitization of beta-adrenergic receptor function." FASEB, 1990, 4: 2881-2889.

Hers, I., Tavare, J. M., Denton, R. M.: „The protein kinase C inhibitors bisindolylmaleimide I (GF 109203x) and IX (Ro 31-8220) are potent inhibitors of glycogen synthase kinase-3 activity." FEBS Lett., 1999, 460: 433-436.

Hill, C. P., Yee, J., Selsted, M. E., Eisenberg, D.: „Crystal structure of defensin HNP-3, an amphiphilic dimer: mechanisms of membrane permeabilization." Science, 1991, 251: 14811485.

Hille, B.: „G protein-coupled mechanisms and nervous signaling.“ Neuron, 1992, 9: 187-195.

Huang, C., Jacobson, K., Schaller, M. D.: „MAP kinases and cell migration.” J. Cell Science, 2004, 117: 4619-4628.

Hüttenrauch, F., Pollok-Kopp, B., Oppermann, M.: „G protein-coupled Receptor Kinases promote phosphorylation and $\beta$-Arrestin-mediated internalization of CCR5 Homo- and Hetero-oligomers.” J. Biol. Chem., 2005, 280: 37503-37515.

Hultmark, D.: "Drosophila immunity: paths and patterns." Curr. Opinion Immunology, 2003, 15: 12-19.

Janeway, C. A., Travers, P., Walport, M., Shlomchik, M.: Immunologie, 2002, Spektrum Akademischer Verlag GmbH, Heidelberg. 
Jones, D. E., Bevins, C. L.: „Paneth cells of the human small intestine express an antimicrobial peptide gene." J. Biol. Chem., 1992, 267: 23216-2325.

Kaslow, H. R., Burns, D. L.: „Pertussis Toxin and target eukaryotic cells: binding, entry and activation." FASEB, 1992, 6: 2684-2690.

Keane, M. P., Strieter, R. M.: „Chemokine signaling in inflammation.“ Crit. Care Med., 2000, 28: pp N13-N26.

Kelly, P., Feakins, R., Domizio, P., Murphy, J., Bevins, C., Wilson, J., McPhail, G., Poulsom, R., Dhaliwal, W.: „Paneth cell granule depletion in the human small intestine under infective and nutritional stress.“ Clin. Exp. Immunol., 2004, 135: 303-309.

Kiss, Z., Phillips H., Anderson, W. H.: „The bisindolylmaleimide GF 109203X, a selective inhibitor of protein kinase $\mathrm{C}$, does not inhibit the potentiating effect of phorbol ester on ethanol-induced phospholipase C-mediated hydrolysis of phosphatidylethanolamine." Biochim. Biophys. Acta, 1995, 93: 1265.

Kleinschroth, J., Hartenstein, J., Rudolph, C., Schächtele, C.: „Non-glycosidic/nonaminoalkyl-substituted indolocarbazoles as inhibitors of protein kinase C." Bioorg. Med. Chem. Lett, 1993, 3: 1959.

Kluver, E., Schulz, A., Adermann, K., Forssmann, W. G.: „Chemical Synthesis of $\beta$-Defensins and LEAP-1 / Hepcidin.” J. Peptide Res., 2002, 59: 241-248.

Kluver, E., Schulz-Maronde, S., Scheid, S., Meyer, B., Forssmann, W. G., Adermann, K.: "Structure-activity relation of human beta-defensin 3: influence of disulfide bonds and cysteine substitution on antimicrobial activity and cytotoxicity." Biochemistry, 2005, 44: 9804-9816.

Kohout, T. A., Lefkowitz, R. J.: „Regulation of G protein-coupled receptor kinases and arrestins during receptor desensitization.” Mol. Pharmacol., 2003, 63: 9-18. 
Kost, C., Herzer, W., Li, P., Jackson, E.: „Pertussis toxin-sensitive G-proteins and regulation of blood pressure in the spontaneously hypertensive rat". Clin. Exp. Pharmacol. Physiol., 1999, 26: 449-55.

Lauffenburger, D. A., Horwitz, A. F.: „Cell migration: a physically integrated molecular process." Cell, 1996; 84: 359-369.

Lefkowitz, R. J.: „G protein-coupled receptors. III. New roles for receptor kinases and betaarrestins in receptor signaling and desensitization." J. Biol. Chem., 1998, 273: 1867718680.

Lefkowitz, R. J., Shenoy, K.: „Transduction of receptor signals by $\beta$-arrestins.” Science, 2005, 308: 512-517.

Lehrer, R. I.: „Primate defensins.“ Nat. Rev. Microbiol., 2004, 2: 727-738.

Lehrer, R. I., Ganz, T.: „Antimicrobial peptides in mammalian and insect host defence.” Curr. Opin. Immunol., 1999, 11: 23-27.

Lehrer, R. I., Ganz, T.: „Defensins of vertebrate animals.“ Curr. Opin. Immunol., 2002, 14: 96-102.

Levy, H., Raby, B. A., Lake, S., Tantisira, K. G., Kwiatkowski, D., Lazarus, R., Silverman, E. K.: „Association of defensin beta-1 gene polymorphisms with asthma.” J. Allergy Clin. Immunol., 2005, 115: 252-258.

Liao, F., Rabin, R. L., Smith, C. S., Sharma, G., Nutman, T. B., Farber, J. M.: „CCchemokine receptor 6 is expressed on diverse memory subsets of $T$ cells and determines responsiveness to macrophage inflammatory protein 3 alpha.” J. Immunol., 1999, 162: 186194.

Lillard, J. W., Boyaka, P. N., Chertov, O., Oppenheim, J. J., McGhee, J. R.: „Mechanisms for induction of acquired host immunity by neutrophil peptide defensins." Proc. Natl. Acad. Sci. USA,1999, 96: 651-656. 
Linzmeier, R. M., Ganz, T.: „Human defensin gene copy number polymorphisms: comprehensive analysis of independent variation in $\alpha$ - and $\beta$-defensin regions at 8p22-p23." Genomics, 2005, 86: 423-430.

Liu, A. Y.: "Human beta-defensin-2 production in keratinocytes is regulated by interleukin-1, bacteria, and the state if differentiation." J. Invest. Dermatol., 2002, 118: 275-281.

Liu, C., Hermann, T. E.: „Characterization of ionomycin as a calium ionophore.“ J. Biol. Chem., 1978, 17: 5892-5894.

Liu, L., Zhao, C., Heng, H. H. Q., Ganz, T.: „The human $\beta$-Defensin-1 and $\alpha$-Defensins are encoded by adjacent genes, two peptide families with differing disulfide topology share a common ancestry." Genomics, 1997, 43: 316-320.

Loetscher, P., Pellegrino, A., Gong, J.H., Mattioli, I., Loetscher, M., Bardi, G., Baggiolini, M., Clark-Lewis, I.: „The ligands of CXC chemokine receptor 3, I-TAC, Mig, and IP10, are natural antagonists for CCR3.” J. Biol. Chem., 2001, 276: 2986-2991.

Ma, X. T., Xu, B., An, L. L., Dong, C. Y., Lin, Y. M., Shi, Y., Wu, K. F.: „Vaccine with $\beta-$ defensin 2-transduced leukemic cells activates innate and adaptive immunity to elicit potent antileukemia responses." Cancer Res., 2006, 66: 1169-1176.

Martiny-Baron, G., Kazanietz, M. G, Mischak, H., Blumberg, P. M., Kochs, G., Hug, H., Marme, D., Schächtele, C.: „Selective inhibition of protein kinase C isozymes by the indolocarbazole Go 6976.” J. Biol. Chem., 1993, 268: 9194.

McColl, S. R., Hachicha, M., Levasseur, S.: "Uncoupling of early signal transduction events from effector function in human peripheral blood neutrophils in response to recombinant macrophage inflammatory proteins- $1 \alpha$ and $-1 \beta . "$ J Immunology, 1993, 150: 4550-4560.

Morgan, A. J., Jacob, R.: „Ionomycin enhances $\mathrm{Ca}^{2+}$ influx by stimulating store-regulated cation entry and not by a direct action at the plasma membrane." Biochem. J., 1994, 15, 300: 665-672. 
Morita, E., Schröder, J.-M., Christophers, E.: "Differential Sensitivities of Purified Human Eosinophils and Neutrophils to Defined Chemotaxins." Scandinavian J. Immunol, 1989, 29: 709-716.

Nagaoka, I., Hirota, S., Yomogida, S., Ohwada, A., Hirata, M.: „Synergistic actions of antibacterial neutrophil defensins and cathelicidins.“ Inflamm. Res., 2000, 49: 73-79.

Neumann, E., Schaefer-Ridder, M., Wang, Y., Hofschneider, P. H.: „Gene transfer into mouse lyoma cells by electroporation in high electric fields." EMBO, 1982, 1: 841-845.

Nilsson, G., Blom, T., Kusche-Gullberg. M., Kjellen, L., Butterfield, J. H., Sundström, C., Nilsson, K., Hellmann, L.: „Phenotypic Characterization of the Human Mast-Cell Line HMC-1.” Scandinavian J. Immunology, 1994, 39: 489-498.

Niyonsaba, F., Someya, A., Hirata, M., Ogawa, H., Nagaoka, I.: „Evaluation of the effects of peptide antibiotics human $\beta$-defensins-1/-2 and LL-37 on histamine release and prostaglandin $\mathrm{D}_{2}$ production from mast cells.” Eur. J. Immunol., 2001, 3:1066.

Niyonsaba, F., Iwabuchi, K., Matsuda, H., Ogawa, H., Nagaoka, I.: „Epithelial cell-derived human beta-defensin-2 acts a chemotaxin for mast cells through a pertussis toxin-sensitive and phospholipase C-dependent pathway.” Int. Immunol., 2002, 14: 421-426.

Omann, G. M.: „Signal Transduction and cytoskeletal activation in the neutrophil.“ Physiol. Reviews, 1987, 67: 285-322.

Ong, P. Y., Ohtake, T., Brandt, C., Strickland, I., Boguniewicz, M., Ganz, T., Gallo, R. L., Leung, D. Y.: „Endogenous antimicrobial peptides and skin infections in atopic dermatitis.“ New Engl. J. Med., 2002, 347: 1151-1160.

Ouellette, A. J., Selsted, M. E.: „Paneth cell defensins: endogenous peptide components of intestinal host defense." FASEB, 1996, 10: 1280-1289. 
Power, C. A., Church, D. J., Meyer, A., Alouani, S., Proudfoot, A. E. I., Clark-Lewis, I., Sozzani, S. ;Mantovani, A., Wells, T. N. C.: „Cloning and characterization of a spezific receptor for the novel CC chemokine MIP-3 alpha from lung dendritic cells.” J. Exp. Med., 1997, 186: 825.

Qatsha, K. O., Rudolph, C., Marme, D., Schächtele, C., May, W. S.: „Go 6976, a selective inhibitor of protein kinase $\mathrm{C}$, is a potent antagonist of human immunodeficiency virus 1 induction from latent/low- level-producing reservoir cells in vitro.” PNAS, 1993, 90: 4674.

Quayle, A. J., Porter, E. M., Nussbaum, A. A., Wang, Y. M., Brabec, C., Yip, K. P., Mok, S. C.: „Gene expression, immunolocalization, and secretion of human defensin-5 in human female reproductive tract.” Am. J. Pathol., 1998, 152: 1247-1258.

Raj, P. A., Dentino, A. R.:"Current status of defensins and their role in innate and adaptive immunity." FEMS Microbiol. Letters, 2002, 206: 9-18.

Raymond, J. R.: "Protein kinase C induces phosphorylation and desensitization of the human 5-HT1A receptor.” J. Biol. Chem., 1991, 266: 14747-14753.

Salzman, N. H., Ghosh, D., Huttner, K. M., Paterson, Y., Bevins, C. L.: „Protection against enteric salmonellosis in transgenic mice expressing a human intestinal defensin." Nature, 2003, 422: 522-526.

Scheffold, A., Kern, F.: „Recent Developments in Flow Cytometry.“ J. clinical Immunol., 2000, 20: 400-407.

Schneider, J. J., Unholzer, A., Schaller, M., Schäfer-Korting, M., Kortinge, H. C.: „Human defensins.“ J. Mol. Medicin, 2005, 83: 587-595.

Schröder, J.-M.: „Epithelial antimicrobial peptides: innate local host response elements.“ Celluar Mol. Life Science, 1999, 56: 32-46. 
Schutte, B. C., Mitros, J. P., Bartlett, J. A., Walters, J. D., Jia, H. P., Welsh, M. J., Casavant, T. L., McCray, P. B.: „Discovery of five conserved beta-defensin gene clusters using a computational search strategy.“ PNAS USA, 2002, 99: 2129-2133.

Selsted, M. E., Ouellette, A. J.: „Mammalian defensins in the antimicrobial immune response. Nature Immunol., 2005, 6: 551-557.

Selsted, M. E., Miller, S. I., Henschen, A. H., Ouellette, A. J.: „Enteric defensins: antibiotic peptide components of intestinal host defence.“ J. Cell Biol., 1992, 118: 929-936.

Semple, C. A., Gautier, P., Taylor, K., Dorin, J. R.: „The changing of the guard: Molecular diversity and rapid evolution of $\beta$-defensins.” Mol. Divers.; 2006. 10: 575-584.

Sorensen, O. E., Follin, P., Johnsen, A. H.,Calafat, J., Tjabringa, G. S., Hiemstra, P. S., Borregaard, M.: „Human cathelicidin, hCAP-18, is processed to the antimicrobial peptide LL-37 by exratcellular cleavage with proteinase 3.” Blood, 1997, 97: 3951-3959.

Soruri, A., Kiafard, Z., Dettmer, C., Riggert, J., Koh, J., Zwirner, J.: „IL-4 down-regulates anaphylatoxin receptors in monocytes and dendritic cells and impairs anaphylatoxin-induced migration in vivo.” J. Immunol., 2003, 170: 3306-3314.

Sozzani, S., Zhou, D., Locati, M.: "Receptors and transduction pathways for monocyte chemotactic protein-2 and monocyte chemotactic protein-3. Similarrties and differences with MCP-1.” J. Immunology, 1994, 152: 3615-3622.

Stolzenberg, E. D., Anderson, G. M., Ackermann, M. R., Whitlock, R. H., Zasloff, M.: „Epithelial antibiotic induced in states of disease.” Proc. Natl. Acad. Sci. USA, 1997, 94: 8686-8690.

Szyk, A., Wu, Z., Tucker, K., Yang, D., Lu, W., Lubkowski, J.: „Crystal structures of human alpha-defensins HNP4, HD5, and HD6.” Protein Science, 2006, 15: 2749-2760. 
Tang, Y. Q., Yuan, J., Osapay, G., Osapay, K. Tran, D., Miller, C, J., Ouellette, A. J., Selsted, M. E.: „A cyclic antimicrobial peptide produced in primate leukocytes by the ligation of two truncated $\alpha$-defensins." Science, 1999, 286: 498-502.

Tani, K., Murphy, W. J., Chertov, O., Salcedo, R., Koh, C. Y., Utsunomiya, I., Funakoshi, S., Asai, O., Herrmann, S. H., Wang, J. M., Kwak, L. W., Oppenheim, J. J.: „Defensins act as potent adjuvants that promote cellular and humoral immune responses in mice to a lymphoma idiotype and carrier antigens.“ Int. Immunol., 2000, 12: 691-700.

Tardif, M., Mery, L., Brouchon, L., Boulay, F.: “Agonist-dependent phosphorylation of Nformylpeptide and activation peptide from the fifth component of $\mathrm{C}(\mathrm{C} 5 \mathrm{a})$ chemoattractant receptors in differentiated HL60 cells.” J. Immunol., 1993, 150: 3534-3545.

Territo, M. C., Ganz, T., Selsted, M. E., Lehrer, R. I.: „Monocyte-chemotactic activity of defensins from human neutrophils.” J. Clin. Invest., 1989, 84: 2017-2020.

Toullec, D. Pianetti, P., Coste, H., Bellevergue, P., Grand-Perret, T., Ajakane, M., Baudet, V., Boissin, P., Boursier, E., Loriolle, F.: „The bisindolylmaleimide GF $109203 \mathrm{X}$ is a potent and selective inhibitor of protein kinase C.” J. Biol. Chem., 1991, 266: 15771.

Turner, J., Cho, Y., Dinh, N. N., Waring, A. J., Lehrer, R. I.: Activities of LL-37, a cathelinassociated antimicrobial peptide of human neutrophils." Antimicrob. Agents Chemother., 1998, 42: 2206-2214.

van Wetering, S., Sterk, P. J., Rabe, K. F., Hiemstra, P. S.: „Defensins: key players or bystanders in infection, injury, and repair in the lung?” J. Allergy Clin. Immunol., 1999, 104: 1131-1138.

von Zastrow, M., Kobilka, B. K.: „, Ligand-regulated internalization and recycling of human beta 2-adrenergic receptors between the plasma membrane and endosomes containing transferring receptors.” J. Biol. Chem., 1992, 267: 3530-3538.

Wehkamp, J., Fellermann, K., Stange, E. F.: „Human defensins in Crohn`s disease.” Chem. Immunol. Allergy, 2005a, 86: 42-54. 
Wehkamp, J., Salzman, N. H., Porter, E., Nuding, S., Weichenthal, M., Petras, R. E., Shen, B., Schaeffeler, E., Schwab, M., Linzmeier, R., Feathers, R. W., Chu, H., Lima, H., Fellermann, K., Ganz, T., Stange, E. F., Bevins, C. L.: „Reduced paneth cell $\alpha$-defensins in ileal Crohn`s disease.” Proc. Natl. Acad. USA ,2005b, 102: 18129-18134.

Wehkamp, J., Schmidt, K., Herrlinger, K. R., Baxmann, S. Behling, S., Wohlschlager, C., Feller, A. C., Stange, E. F., Fellermann, K.: „Defensin pattern in chronic gastritis: HBD-2 is differentially expressed with respect to Helicobacter pylori status.” J. Clin. Pathol., 2003, 56: 352-357.

Wenzel-Seifert, K., Schächtele, C., Seifert, R.: „N-protein kinase C isoenzymes may be involved in the regulation of various neutrophil functions." BBRC, 1994, 200: 1536.

Widmann, C., Gibson, S., Jarpe, M. B., Johnson, G. L.: „Mitogen-activated Protein Kinase: Conservation of a Three-Kinase Module from Yeast to Human." Physiological Reviews, 1999, 79: 143-180.

Wilson, C. L., Ouellette, A. J., Satchell, D. P., Ayabe, T., López-Boado, Y. S., Stratman, J. L., Hultgren, S. J., Matrisian, L. M., Parks, W. C.: „Regulation of intestinal $\alpha$-defensin activation by the metalloproteinase matrilysin in innate host defense." Science, 1999, 286: $113-117$.

Wu, Z., Hoover, D. M., Yang, D., Boulegue, C., Santamaria, F., Oppenheim, J. J., Lubkowski, J., Lu, W.: „Engineering disulfide bridges to dissect antimicrobial and chemotactic activities of human $\beta$-defensin 3.“ Proc. Natl. Acad. USA, 2003, 22: 8880-8885.

Yang, D., Biragyn, A., Kwak, L. W., Oppenheim, J. J.: „Mammalian defensins in immunity: more than just microbicidal.” Trends Immunol., 2002, 23: 291-296.

Yang, D., Chen, W., Chertov, O., Oppenheim, J. J.: „Human neutrophil defensins selectively chemoattract naive T and immature dendritic cells.” J. Leukoc. Biol., 2000, 68: 9-14. 
Yang, D., Chertov, O., Bykovskaia, S. N., Chen, Q., Buffo, M. J., Shogan, J., Anderson, M.: „Beta-defensins: linking innate and adaptive immunity through dendritic and T cell CCR6.” Science, 1999, 286: 525-528.

Yen, H. H., Zhang, Y. J., Penfold, S., Rollins, B. J.: "MCP-1 mediated chemotaxis requires activation of non-overlapping signal transduction pathways." J. Leokocyte Biol., 1997, 61: 529.

Zhang, N., Hodge, D., Rogers, T. J., Oppenheim, J. J.: „,Ca ${ }^{2+}$-independent protein kinase Cs mediate heterologous desensitization of leukocyte chemokine receptors by opioid receptors." J. Biol. Chem., 2003, 278: 12729-12736.

Zwirner, J., Werfel, T., Wilken, W. C., Theile, E., Gotze, O.: „Anaphylatoxin C3a but not $\mathrm{C} 3 \mathrm{a}$ (desArg) is a chemotaxin for the mouse macrophage cell line J774.” Eur. J. Immunol., 1998, 28: 1570-1577.

Zwirner, J., Gotze, O., Sieber, A., Kapp, A., Begemann, G., Zuberbier, T., Werfel, T.: „The human mast cell line HMC-1 binds and responds to C3a but not C3a(desArg)." Scand. J. Immunol., 1998, 47: 19-24. 


\section{Danksagung}

Bedanken möchte ich mich bei Frau Prof. Dr. Soruri sowie Herrn Prof. Dr. Zwirner für die freundliche Überlassung meines Doktorarbeitsthemas sowie für die stete Unterstützung und das Interesse am Fortgang meiner Arbeit.

Weiterhin gilt mein Dank Frau Prof. Dr. Hoyer-Fender für die freundliche externe Betreuung dieser Arbeit sowie Herrn Prof. Dr. Hardeland für die Übernahme des Koreferates.

Des Weiteren danke ich meiner Arbeitsgruppe für die Hilfe bei kleinen und großen Nöten. Dabei möchte ich vor allem Dr. Ziba Kiaffard und Claudia Dettmer-Richardt für die vielen hilfreichen Diskussionen über die Weiten der Immunologie sowie Olga Walter und Kerstin Eckelmann für die hervorragende technische und persönliche Unterstützung danken.

Ein großer Dank auch an Silvia Geuenich und Christine Paprotka für intensives Korrekturlesen dieser Arbeit und für regelmäßige Motivation. Weiterhin danke ich Birgit Meyer für eine schöne gemeinsame Promotionszeit in Göttingen sowie Brigitte Kania und Florian Bunke für die Aufmunterung und Unterstützung in dieser Zeit.

$\mathrm{Zu}$ guter Letzt gilt mein besonderer Dank meinen Eltern. 


\section{Lebenslauf}

Persönliche Daten:

Name: $\quad$ Grigat

Vorname: Jasmin

Geburtsort: Walsrode

Geburtsdatum: $\quad 12.06 .1979$

Staatsangehörigkeit: deutsch

Schulbildung:

08/1985-07/1989 Grundschule Walsrode

08/1989-07/1991 Orientierungsschule Walsrode

08/1991-07/1998 Gymnasium Walsrode

Abschluss: Allgemeine Hochschulreife

Studium:

10/1998-09/2000 Studium der Biologie an der Universität Hannover Abschluss: Vordiplom

10/2000-10/2003 Studium der Biologie an der Justus-Liebig Universität Giessen

Hauptfächer: Genetik, Tierphysiologie und Zellbiologie

Diplomarbeitsthema: „Untersuchungen zur Signaltransduktion an

Hämocyten von Manduca sexta bei Phagocytosevorgängen““

Abschluss: Diplom (Note: 1,1)

$07 / 2004$

Beginn der externen Dissertation in der Abteilung Immunologie der

Georg-August-Universität Göttingen

Thema der Dissertation: „Untersuchung Rezeptor-vermittelter

Interaktionen zwischen Defensinen und Zellen des Immunsystems.“ 
Wissenschaftliche Veröffentlichungen:

1. Grigat, Jasmin, Soruri, A., Forssmann, U., Riggert, J., Zwirner, J.: „Chemoattraction of Macrophages, T-Lymphocytes and Mast Cells is evolutionary conserved within the human $\alpha$ Defensin family.” Journal of Immunology, 2007, 179: 3958-3965.

2. Soruri, Afsaneh, Grigat, J., Forssmann, U., Riggert, J., Zwirner, J.: „ß-Defensins chemoattract Macrophages and Mast Cells but not Lymphocytes and Dendritic Cells: CCR6 not involved." European Journal of Immunology, 2007, 37: 2474-2486. 